\title{
A Novel Molecular Diagnostic Device Using Solid-Phase PCR on a Hotwire Optical Fibre Grating
}

\author{
By \\ Jason Koppert \\ A thesis submitted to the Faculty of Graduate Studies and Research \\ in partial fulfillment of the requirements for the degree of

\section{Masters of Applied Science \\ In Biomedical Engineering}

\author{
Ottawa-Carleton Institute for Biomedical Engineering \\ Department of Systems and Computer Engineering \\ Carleton University \\ Ottawa, Ontario, Canada \\ March 2016
}




\begin{abstract}
The usage of fibre optic technologies presents the possibility of high volume manufacturing at low costs when used with novel diagnostic assays. In this thesis, the technologies of hotwire fibre optic devices are combined with in-fibre Bragg gratings to produce a platform compatible with the developing field of Solid Phase PCR (SP-PCR). Here we demonstrate that the DNA coating of such devices can be performed with economical UV-cross-linking. In the process of validating the platform for SP-PCR usage we have also created a novel assay for monitoring real-time polymerase enzyme activity on solidsurface-attached DNA sequences. The device can function with SP-PCR in real-time through its usage of Total Internal Reflection Fluorescence (TIRF). Our device demonstrates the ability to spatially separate several reactions on a single fibre, representing a novel fibre application, and has the potential to reliably increase the speed and multiplexability of the SP-PCR reactions.
\end{abstract}




\section{Acknowledgements}

I would like to thank Dr. Hubert Jean-Ruel for his persistent enthusiasm and extreme flexibility in the process of designing and prototyping optical setups and new fibre optic device schematics. I would also like to thank Drs. William Willmore, Anatoli lanoul, Jacques Albert, and James Green for their significant contributions to the smooth functioning of this collaborative research. A thanks goes out to Devin O'Neill for his expertise and nanoparticle manufacturing and optimization. Additional thanks to Dr. Chris Harder for his assistance with industrial application and focus for this project.

This study was supported by the Natural Sciences and Engineering Research Council of Canada, Spartan Bioscience Inc., and MITACS. 


\section{Table of Contents}

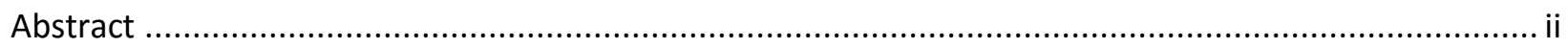

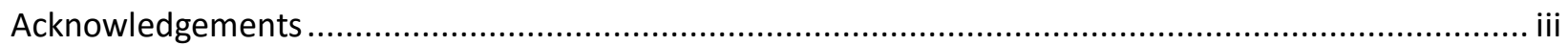

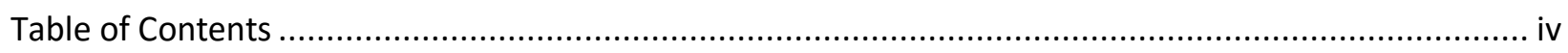

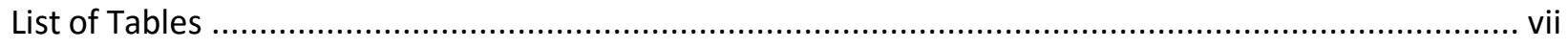

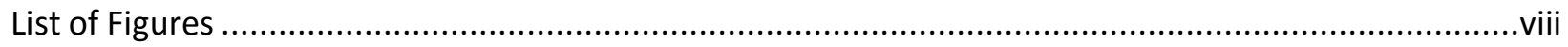

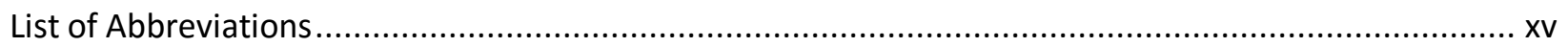

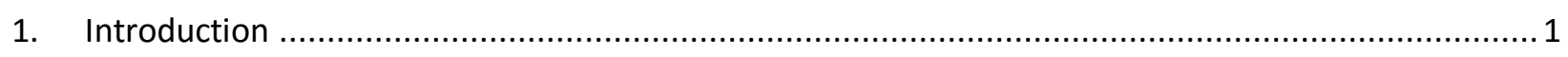

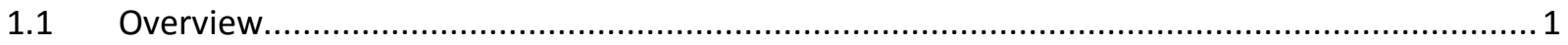

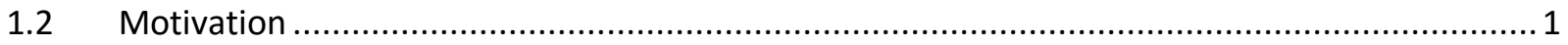

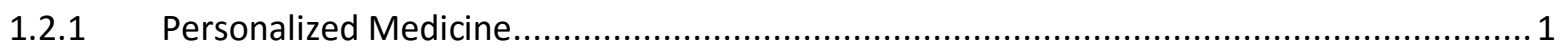

1.2.2 The Importance of Point-Of-Care Testing ..............................................................

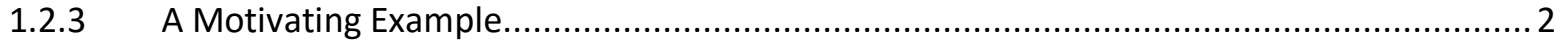

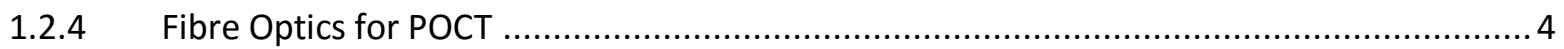

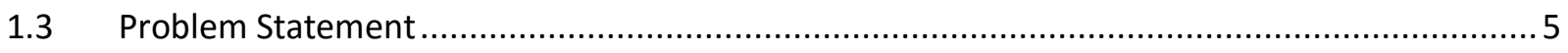

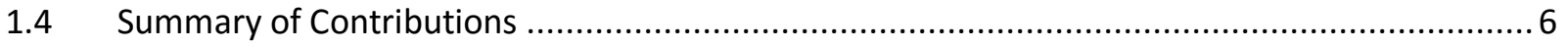

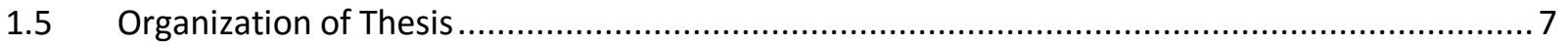

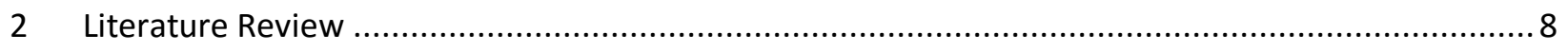

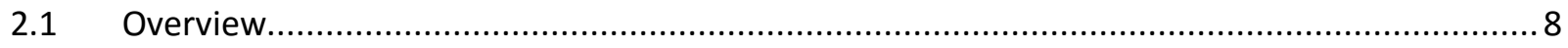

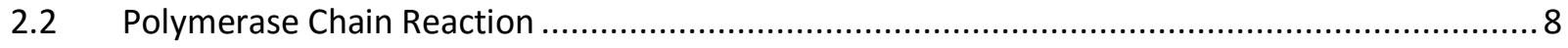

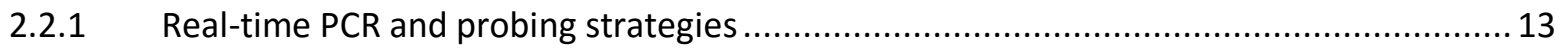

2.2.2 Melting Points of dsDNA for Species Identification .................................................. 19

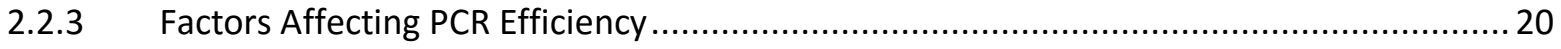

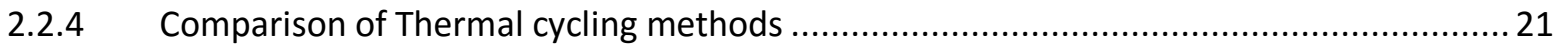

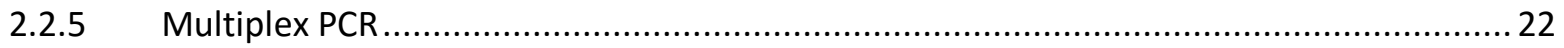

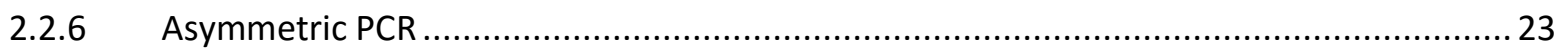

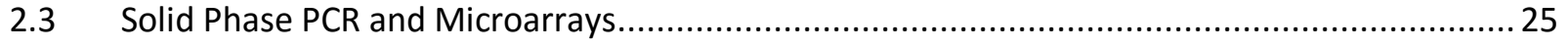

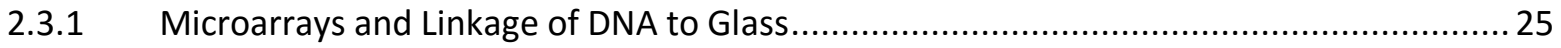

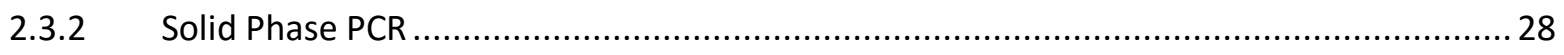

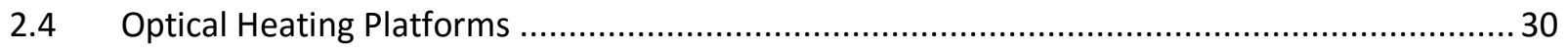

2.4.1 Fibre Bragg Gratings in Wind Anemometers ......................................................... 35

iv Page Jason Koppert MASc Thesis 
2.4.2 Optical Heating for Molecular Diagnostics .......................................................... 40

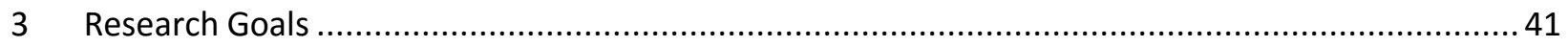

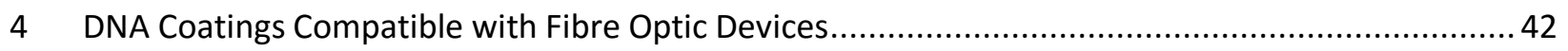

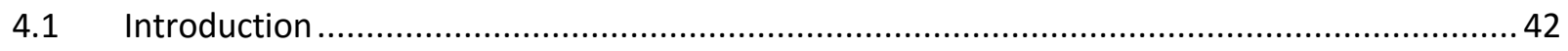

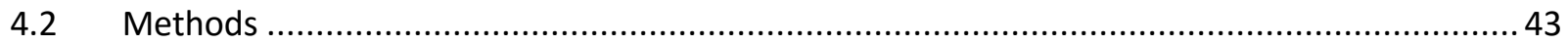

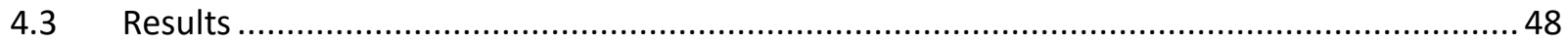

4.3.1 Coating Option I: Silane Poly-ethylene Glycol Coatings ............................................ 48

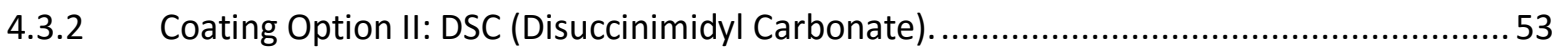

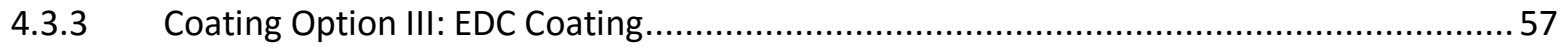

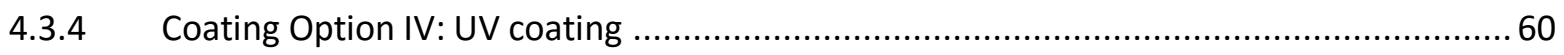

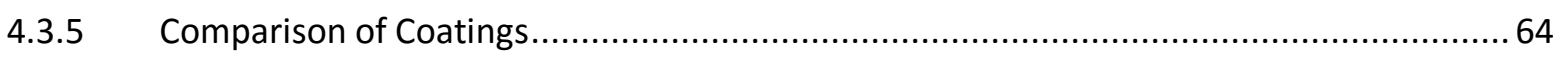

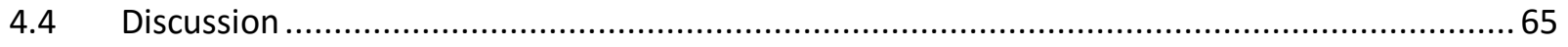

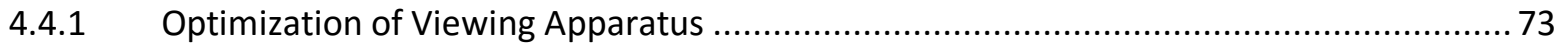

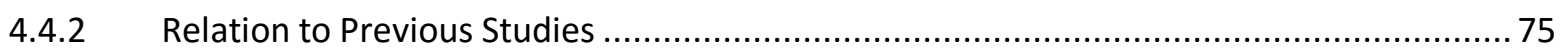

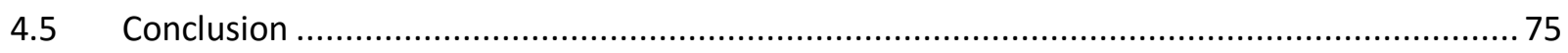

5 Assessing Surface Compatibility with SP-PCR through Real-time Monitoring .............................. 77

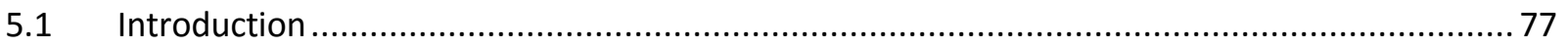

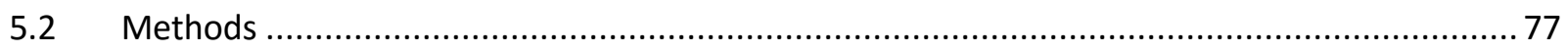

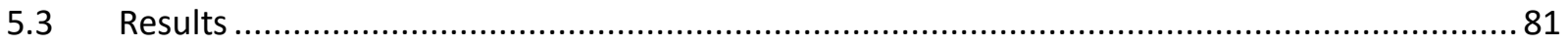

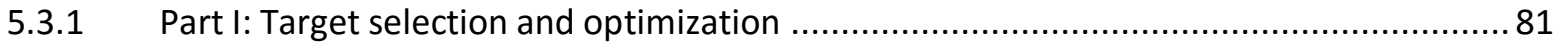

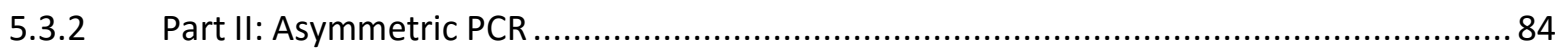

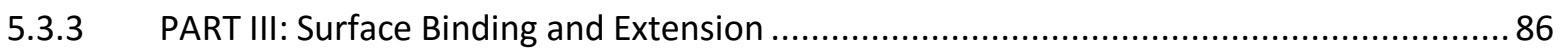

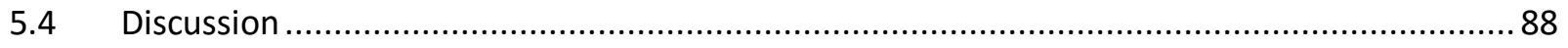

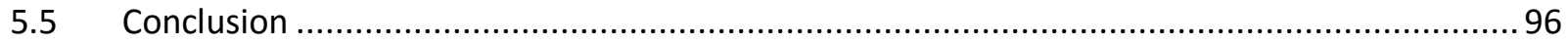

6 Application of optical fibre hotwire devices in molecular assays and SP-PCR ............................. 98

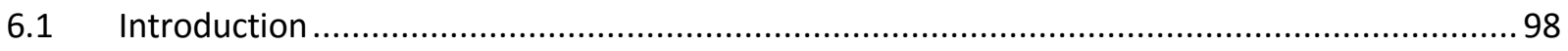

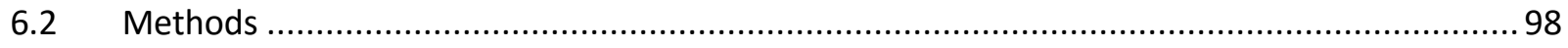

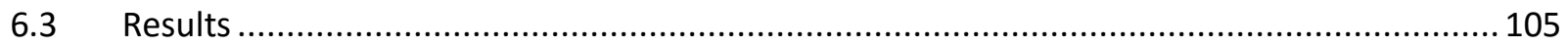

6.3.1 Part I: Fibre heating and excitation functionality with DNA coatings ........................... 105

6.3.2 Part II: Thermal Cycling and Solid Phase PCR with a Fibre Device .............................. 113

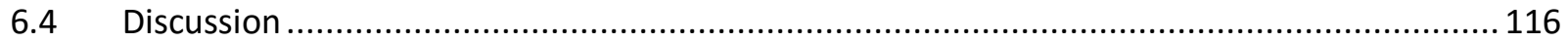

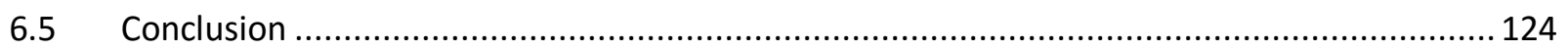

vlPage Jason Koppert MASc Thesis 
7 Thesis summary and Future Recommendations

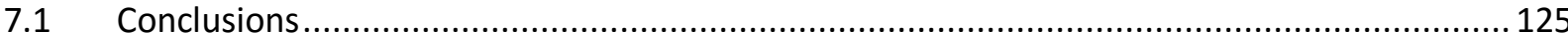

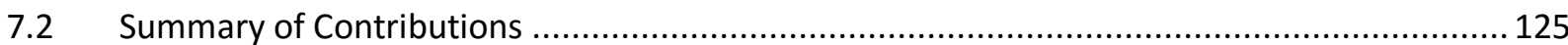

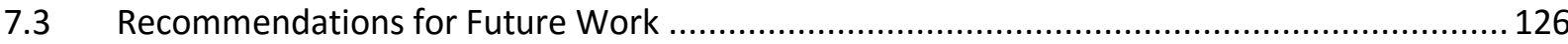

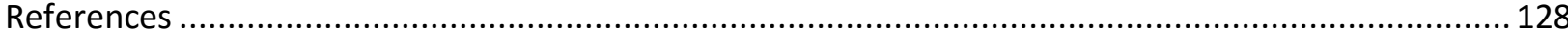

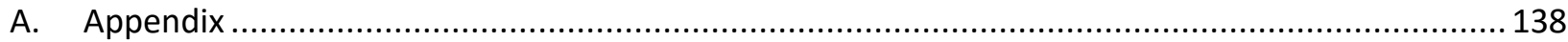

A.1 Methods: DNA Coatings Compatible with Fibre Optic Devices............................................. 138

A.2 Methods: Assessing Surface Compatibility with SP-PCR through Real-time ............................ 142

A.3 Methods: Application of optical fibre hotwire devices in molecular assays and SP-PCR ............. 144 


\section{List of Tables}

TABLE 2-1. LIST OF STATE-OF-THE-ART THERMAL CYCLING METHODOLOGIES AND THE CYCLING TIMES ASSOCIATED WITH THE EXAMPLE

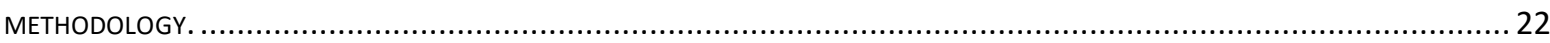

TABLE 6-1. COMPARISON OF TEMPERATURE MONITORING, HEATING METHOD, AND FLUORESCENCE EXCITATION APPROACHES FOR EACH OF

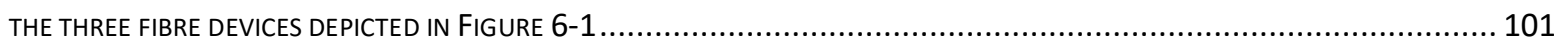




\section{List of Figures}

Figure 2-1. Key eVEnTS of the Polymerase Chain ReACtion. (A) REPRESENTS the INITIAL PHASE Of PCR With PRIMERS AND TEMPLATE IN A PCR REACTION SOLUTION. (B) HIGH TEMPERATURE DENATURATION CAUSES THE DISSOCIATION OF THE TEMPLATE. (C) RETURNING TO LOWER ANNEALING TEMPERATURES ALLOWS FOR THE PRIMERS TO ASSOCIATE WITH THEIR RESPECTIVE TEMPLATES. ONCE THE PRIMER HAS HYBRIDIZED TO ITS TEMPLATE THE POLYMERASE ENZYME CAN BIND TO THE COMPLEX. (D) EXTENSION OF THE DNA PRIMER OCCURS DURING A SLIGHTLY TEMPERATURE ELEVATED EXTENSION PHASE.

FIGURE 2-2. (A) EQUILIBRIUM PARADIGM OF PCR: THE THREE PHASES OF PCR ARE VIEWED AS OCCURRING AT A SINGLE TEMPERATURE WITH TIME ZERO INITIALIZED AT THE STAGE TEMPERATURE ARRIVAL. (B) KINETIC PARADIGM OF PCR: TEMPERATURE IS IN CONTINUOUSLY CHANGING STATE WITH THE REQUIRED TIME FOR EACH CYCLE REPRESENTED BY THE INTEGRATION OF THE REGIONS IN WHICH EACH PHASE CAN OCCUR. (CARL T. WITTWER, 2001). OBTAINED REPRINT PERMISSION FROM SPRINGER (LICENSE NO.: 3827810254910)

FiguRE 2-3. EXPONENTIAL NATURE OF PCR ONCE THE 3 PHASE REACTION IS REPEATED THROUGH THERMAL CYCLING. A TYPICAL PCR CAN CREATE TRILLIONS OF COPIES FROM A SINGLE STRAND OF DNA IN THIS MANNER BEFORE AMPLIFICATION PLATEAUS.

Figure 2-4. DePICTION OF THE BINDING MECHANISM OF SYBR GREEN INTERCALATING DNA DYE. THIS METHODOLOGY OF BINDING IS SIMILAR TO OTHER AVAILABLE INTERCALATING DYES SUCH AS SYTO-64 AND ETHIDIUM BROMIDE. INTERCALATING DYES ONLY FLUORESCE WHEN BOUND TO DOUBLE STRANDED DNA. FOR A COMPREHENSIVE LIST OF DYES SEE THE WORK OF GUDNASON ET AL. (H. GUDNASON, DUFVA, BANG, \& WOLFF, 2007). INTERCALATION DYE BINDING IS REVERSIBLE THROUGH MELTING OF THE DSDNA COMPLEX. IMAGE RE-PRINTED WITH PERMISSION FROM QIAGEN.

Figure 2-5. MoleCULAR BEACON DEPICTION IN CLOSED (TOP) AND TEMPLATE-BOUND (BOTTOM) FORMS. IN ITS CLOSED FORM THE FLUOROPHORE AND QUENCHER ARE IN CLOSE PROXIMITY THEREBY MINIMIZING THE EMITTED SIGNAL. THE BINDING OF THE LOOP REGION SEQUENCE TO ITS INTENDED TARGET COMPLEMENT OPENS THE STEM STRUCTURE AND ALLOWS FOR SEPARATION OF THE QUENCHER AND FLUOROPHORE FOR AN INCREASED SIGNAL. SUCH A SIGNAL IS REVERSIBLE THROUGH MELTING OF THE PROBE AND target complex. Adapted by permission from Macmillan Publishers Ltd: Nature Biotechnology(TyagI \& Kramer, 1996), COPYRIGHT (1996).

Figure 2-6. TAQMAN ${ }^{\text {TM }}$ PROBE DETECTION METHOdOLOGY. THE PROBE BINDS TO A TEMPLATE SEQUENCE IN A PCR REACTION WITHOUT HAVING A DETECTABLE SIGNAL. WHEN THE PRIMER IS BOUND TO THE SAME SEQUENCE AND THE POLYMERASE ENZYME EXTENDS THE PRIMER, THE POLYMERASE WILL EXCISE THE TAQMAN ${ }^{\text {TM }}$ PROBE BY DESTROYING THE PROBE SEQUENCE. THIS DESTRUCTION SEPARATES THE QUENCHER FROM THE FLUOROPHORE AND THEREBY IRREVERSIBLY GENERATES A SIGNAL. OBTAINED REPRINT PERMISSION FROM SPRINGER (LICENCE NO.: 3827811053171). (VOHR, 2016)

Figure 2-7. A tYPICAL REAL-TIME PCR SIGNAL OVER THE COURSE OF A 50 CYCLE REACTION. THE MONITORING IN THIS INSTANCE IS PERFORMED USING AN INTERCALATING DYE WITH IMAGING OCCURRING DURING THE EXTENSION PHASE OF THE PCR.

Figure 2-8. (A) MELTING PROFILE OF A SINGLE, HIGH CONCENTRATION, DSDNA SEQUENCE UTILIZING A DNA INTERCALATING DYE. SUCH A MELTING PROFILE POSSESSES A SHARP DROP IN FLUORESCENCE WHERE THE MID-POINT REPRESENTS THE STAGE AT WHICH HALF OF THE ORIGINAL DSDNA IS IN A MELTED OR SSDNA FORM. THIS POINT IS KNOWN AS THE MELTING TEMPERATURE OR TM. (B) DEPICTS THE NEGATIVE FIRST DERIVATIVE OF THE MELTING PROFILE HIGHLIGHTING THE TM REGION AS A DISTINCT PEAK. .. 21

FIgURE 2-9. DEPICTION OF THE MAJOR EQUILIBRIUM INTERACTIONS PRESENT IN PCR AMPLIFICATION AND DETECTION WITH A MOLECULAR BEACON $^{\text {TM }}$ PROBE. The INTERACTIONS ARE EXPLAINEd AS FOlLOWS: PATHWAYS (1) AND (2) COMPETE. The BINDING OF FREE FLOATING PRIMERS AND THE CORRESPONDING DNA TEMPLATE/COMPLEMENTARY STRAND IN THE PRESENCE OF POLYMERASE WILL PROCEED IRREVERSIBLY THROUGH (3) TO 'CONSUME' THE PRIMER. (4) AND (5): THE PROBE AND TEMPLATE COMPLEX COMPETES WITH THE DSDNA FORMATION AS WELL AS THE PROBE'S CLOSED FORMATION STRUCTURE..

Figure 2-10. AsymMetric SOlid PHASE PCR (SP-PCR) DEPICTED IN CRUCIAL STEPS AS THEY OCCUR IN THE POLYMERASE EXTENSION PROCESS. (A) SHOWS THE OVERPRODUCTION OF AN SSDNA STRAND IN SOLUTION THROUGH ASYMMETRIC PCR, REPRESENTED HERE BY THE GREEN STRAND. (B) THE OVERPRODUCED TEMPLATE DNA THEN BINDS WITH THE SURFACE LINKED DNA PRIMER AND EXTENSION OCCURS THROUGH THE POLYMERASE ENZYME, SHOWN AS A RED BALL. THERE IS SOME BACKGROUND SIGNAL WHEN AN
viii | P a g e
Jason Koppert MASc Thesis 
INTERCALATING DYE IS USED DUE TO THE DSDNA PRESENT IN THE PRIMER/TEMPLATE HYBRIDIZATION REGION. (C) THE POST EXTENSION PRODUCT IS STILL BOUND TO THE GLASS SURFACE BUT NOW PRODUCES A LARGE FLUORESCENT SIGNAL WHEN BOUND TO THE COMPLEMENTARY STRAND. ALL THREE STAGES DEPICTED HERE CAN OCCUR SIMULTANEOUSLY WHEN ASYMMETRIC PCR IS USED IN THE PRESENCE OF A DNA COATED SURFACE.

FIGURE 2-11. DEPICTION OF FIBRE OPTIC CARRYING OF LIGHT. LIGHT THAT ENTERS THE CORE OF THE FIBRE AT AN ACCEPTABLE ANGLE, AN ANGLE THAT PERMITS REFLECTION VERSUS TRANSMISSION, IS RETAINED IN THE CORE FOR CONTINUED PROPAGATION DUE TO THE TOTAL INTERNAL REFLECTION OF LIGHT AT THE BOUNDARY OF THE FIBRE CORE AND THE FIBRE CLADDING. THIS TOTAL INTERNAL REFLECTION IS PERMITTED DUE TO THE HIGHER INDEX OF REFRACTION OF THE CORE COMPARED TO THE INDEX OF REFRACTION OF THE CLADDING. (C) GRINGER 2008.

Figure 2-12. Optical Fibre FUNCTION WITH A BRAgg GRATING WRITTEN IN THE FIBRE CORE. (A) AN FBG WRITTEN IN A FIBRE OPTIC CORE. REFRACTIVE INDICES ARE $N_{3}>N_{2}>N_{1}>N_{0}$, WHILE $\wedge$ REFLECTS THE PERIODICITY OF THE GRATING ITSELF. (B) REFRACTIVE INDEX IN THE CORE OF THE OPTICAL FIBRE SPIKES IN THE GRATING REGION PERIODS. (C) SPECTRAL RESPONSE WHEN MONITORING A GRATING IN TRANSMISSION MODE. SIMILAR SPECTRAL RESPONSES CAN BE GENERATED USING A REFLECTION SETUP PROVIDED BY A MIRROR DOWNSTREAM OF THE GRATING AS DEPICTED IN THE WORK OF LEPINAY ET AL. (LEPINAY, STAFF, IANOUL, \& ALBERT, 2014).FBG (C) SAKURAMBO. (CC BY-SA 3.0)

Figure 2-13. Fibre Bragg Grating (FBG) DeVICES that haVe beEn uSED IN FIBRE OPTIC CORES. (A) RePRESENTATION OF A STANDARD FBG. (B) CHIRPED FBG USED FOR LARGE BAND SPECTRAL REFLECTION. SUCH A GRATING CAN ALSO REPLACE A MIRROR AND

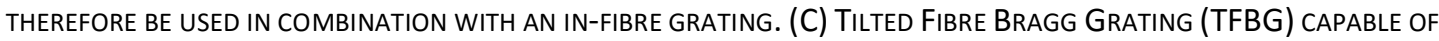
COUPLING LIGHT OF A DESIRED WAVELENGTH OUT OF THE FIBRE CORE. FBG3.GIF (C) GRAHAMWILD. (CC BY-SA 3.0).....

FIGURE 2-14. TFBG SURFACE INTERACTION PROBING MECHANISM. LIGHT IS DIVERTED FROM THE FIBRE CORE THROUGH INTERACTION WITH THE TILTED GRATING. THIS LIGHT CAN INTERACT WITH THE SURFACE OF THE OPTICAL FIBRE. REPRINTED WITH PERMISSION from (SheVChenko et Al., 2011). Copyright (2011) American Chemical Society.

Figure 2-15. Fibre Wind ANeMOMEter deVice apparatus using a fibre FBG With a No Core Fibre (NCF) SEGMENT. The NCF SEGMENT ALLOWS FOR THE PARTIAL COUPLING OF IR LIGHT TO THE CLADDING OF THE FIBRE FOR INTERACTION WITH THE SILVER FILM TO ALLOW HEATING OF THE SILVER FILM REGION. THIS CONFIGURATION CONTINUES TO PERMIT LIGHT REFLECTED BY THE GRATING TO Return to the detector. The examples of Anemometers in Figure 2-16, Figure 2-17, and Figure 2-18 ARE ALL USED IN THIS WIND TUNNEL AND LASER/INTERROGATOR SETUP DEPICTED HERE (WANG ET AL., 2013) (C) 2011 IEEE.

FIGURE 2-16. FIBRE WIND ANEMOMETER DEVICE BASED ON A TWISTED ENLARGED BITAPER SPLICING. THE BITAPER SPLICING PRODUCES A BULGE LIGHT REGION IN THE FIBRE CORE THAT PERMITS PARTIAL COUPLING OF LIGHT TOWARDS THE SILVER FILM COATED REGION FOR HEATING. REPRINTED FROM (X. WANG ET AL., 2014) WITH PERMISSION FROM ELSEVIER.

FIGURE 2-17. OfFSET COUPLING MECHANISM FOR FIBRE BASED HEATING IN A WIND ANEMOMETER DEVICE. THE OFFSET COUPLING PERMITS PARTIAL LOSS OF IR LIGHT FROM THE FIBRE CORE THAT CAN THEN INTERACT WITH THE SILVER FILM TO PRODUCE HEATING (XINYONG DONG ET AL., 2012). (C) 2012 IEEE.

FIGURE 2-18. LIGHT ABSORBING FIBRE DEVICE CONFIGURATION FOR A WIND ANEMOMETER. THIS DEVICE CONFIGURATION DOES NOT REQUIRE A METALLIC SURFACE COATING BUT DOES REQUIRE A SEGMENT OF DOPED OPTICAL HEATING FIBRE (OHF) TO BE INSERTED BETWEEN SEGMENTS OF NON-DOPED FIBRE TO LOCALIZE HEATING TO THE OHF REGION (GAO ET AL., 2011)......

FIGURE 2-19. BASIC MEASUREMENT PRINCIPLE OF A FIBRE OPTIC WIND ANEMOMETER DEVICE. IR LIGHT IS PUMPED AT A RELATIVELY HIGH POWER TO PRODUCE HEAT IN THE FBG REGION. THIS PRODUCES THE PEAK FOUND AT O WHEN AIRFLOW IS ABSENT. THIS PEAK IS THE SOURCE REFLECTION RETURNED BY THE GRATING WRITTEN IN THE FIBRE CORE. THIS PEAK GENERATION IS SHOWN IN FIGURE 2-12. AS AIRFLOW INCREASES IN SPEED OVER THE SURFACE OF THE HEATED FBG REGION, COOLING OF THE REGION WILL BLUE-SHIFT THE SPECTRAL PEAK. THIS BLUE-SHIFTING ALLOWS FOR A SPECTRAL PEAK CONVERSION INTO A WIND-SPEED DETERMINATION. ANY OF THE PRESENTED WIND ANEMOMETER DEVICES WILL OPERATE IN THIS MANNER. REPRINTED FROM (X. WANG ET AL., 2014) WITH PERMISSION FROM ELSEVIER.

FIGURE 4-1. SIMPLISTIC MICROSCOPY APPARATUS ILLUSTRATING THE SETUP USED TO EXAMINE FIBRE OPTIC COATINGS DURING THE INITIAL PHASE OF THE PROJECT. THE SAMPLE SLIDE (1) WOULD BE USED TO MOUNT COATED FIBRE FRAGMENTS (2). A GLYCEROL BASED

ix Page Jason Koppert MASc Thesis 
MEDIUM (3) WOULD THEN BE PLACED ON TOP OF THE FIBRES AND COVERED WITH A GLASS COVERSLIP (4). THIS SLIDE WOULD THEN BE PLACED ONTO THE MICROSCOPE STAGE FOR VIEWING. MODIFIED FROM MLLYNK 2012 (CC BY-SA 3.0).

FIGURE 4-2. FIBRE IMAGING ANALYSIS SETUP USED FOR DIRECT IN-SOLUTION IMAGING OF COATED FIBRES. THIS IN SOLUTION IMAGING REPRESENTED ENHANCED HANDLING OF FIBRES WITH COMPARABLE IMAGE QUALITY TO FLUORESCENCE MICROSCOPY. THE CAPILLARY TUBE IS USED TO HOLD LIQUID AROUND A COATED OPTICAL FIBRE WITH THE POTENTIAL FOR REAL TIME MONITORING. .46

Figure 4-3. Chemical structure depiction of the Si-PEG-FitC molecule. (A) Glass Surface Reactive entity. (B) LinKage SPACER CONSISTING OF END FUNCTIONALIZED POLYETHYLENE GLYCOL (PEG). (C) FLUORESCENT ENTITY REPRESENTED HERE BY FLUORESCEIN ISOTHYIOCYANATE.

Figure 4-4. Positive CONTROL Oligomer AS USED WITH SEVERAL COATING METHODOLOGIES FOR THE PURPOSE OF DIRECT VISUAL CONFIRMATION OF COATING SUCCESS. THE OLIGOMER HAS THE DIRECTIONALITY AS AN SP-PCR PRIMER WOULD BE REQUIRED..... 47

FiguRE 4-5. DEPICTION OF INDIRECT COATING SUCCESS DETECTION. A FLUORESCENTLY LABELLED ANTIPARALLEL DNA OLIGOMER IS BROUGHT INTO HYBRIDIZATION WITH THE SURFACE BOUND OLIGOMER. THIS FLUORESCENTLY LABELLED OLIGOMER CAN BE REMOVED AFTER CHECKING SURFACE COATINGS FOR SUCCESS. THE REMOVAL OF THE PROBE COULD BE PERFORMED THERMALLY OR CHEMICALLY THROUGH THE INTRODUCTION OF A BASIC SOLUTION. 47

FIGURE 4-6. INHERENT CONTROL MECHANISM USED TO ESTABLISH AN ADJACENT POSITIVE AND NEGATIVE CONTROL IN FLUORESCENCE MICROSCOPY. THIS ALLOWS FOR A MORE DISTINCT FRAME OF REFERENCE AND HELPS TO CONTROL THE AMOUNT OF VARIANCE SEEN IN FLUORESCENCE IMAGING. EFFECTIVELY, A SMALLER AREA WAS FUNCTIONALIZED WITH DNA RELATIVE TO THE AREA EXPOSED DURING THE HYBRIDIZATION OF A FLUORESCENT PROBE COMPLEMENT.

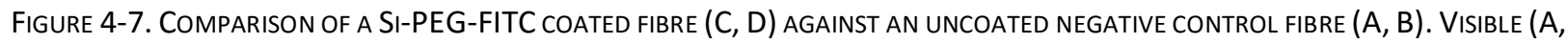
C) AND FLUORESCENCE $(B, D)$ IMAGES ARE DISPLAYED FOR EACH FIBRE DEMONSTRATING THE APPARENT FLUORESCENCE OF THE SIPEG-FITC COATED FIBRE RELATIVE TO BOTH A NEGATIVE CONTROL AND A VISIBLE IMAGE OF THE SAME FLUORESCENT FIBRE. NOTE THAT THERE ARE AUTO CONTRAST SETTINGS WITH THE MICROSCOPE SOFTWARE THAT CAUSE THE IMAGES TO APPEAR SIMILAR DESPITE LARGE PIXEL DENSITY DIFFERENCES. 51

FIGURE 4-8. BARE, GLASS, TFBG FIBRE COATED WITH SI-PEG-FITC AND PROBED BY A PRELIMINARY BASIC OPTICAL SETUP CONTAINING A FIBRE COUPLED LASER ARGON-ION LASER, A BAND PASS FILTER AND DEVELOPMENT BOARD CAMERA.

FiguRE 4-9. (A) SMF-28 FIBRE PARTIALLY COATED WITH SI-PEG-FITC AS EXAMINED UNDER VISIBLE MICROSCOPY. (B) BOUNDARY BETWEEN COATED AND UNCOATED REGIONS ON THE SAME FIBRE LOCATION WHEN VIEWED UNDER FLUORESCENCE MICROSCOPY. THIS BOUNDARY REGION, INDICATED BY THE WHITE ARROW, IS CREATED AS AN ARTEFACT OF THE DIPPING PROCESS WHERE FIBRES ARE VERTICALLY SUBMERGED INTO A SOLUTION OF THE SI-PEG-FITC MOLECULE. THE BOUNDARY EFFECT MARKS THE MENISCUS OF THE SI-PEG-FITC COATING SOLUTION.

FIgURE 4-10. FluORESCENCE OF FIBRES COATED WITH Si-PEG-FITC SOLUTION. VARIOUS Si-PEG-FITC CONCENTRATIONS WERE UTILIZED AND APPEAR TO DEMONSTRATE AN INCREASE IN FLUORESCENCE WITH INCREASING CONCENTRATIONS. THIS FLUORESCENT INCREASE APPEARS TO OVERCOME THE BACKGROUND FLUORESCENCE AROUND THE $100 \mu \mathrm{M}$ LEVEL. THE BACKGROUND SIGNAL IS REPRESENTED BY THE RED LINE. THE CONCENTRATION INCREASE AFFECT APPEARS TO PLATEAU AROUND $1000 \mu \mathrm{M}$ AND THEREFORE $750 \mu \mathrm{M}$ WAS CHOSEN AS THE OPTIMAL RETURN OF FLUORESCENCE FOR REAGENT COST. ERROR BARS IN THIS FIGURE REPRESENT STANDARD DEVIATION OF THE POPULATION OF FIBRES EXAMINED BY FLUORESCENCE MICROSCOPY.

FIGURE 4-11. DNA IMMOBILIZATION WITH DSC CHEMISTRY ON THE SURFACE OF A GLASS SUBSTRATE (A), THE AMINOSILANE COMPOUND, APTMS, REACTS WITH THE HYDROXYL GROUPS, LEAVING AN AMINE TERMINATED SURFACE (B); THE HOMOBIFUNCTIONAL DSC BINDS TO THE AMINE GROUPS, TERMINATING THE SURFACE WITH N-HYDROXY SUCCINIMIDE (NHS) (C); FINALLY, AN OLIGONUCLEOTIDE WITH 5'-AMINE MODIFICATION IS COVALENTLY BOUND TO THE SURFACE (D). IN THIS CASE, THE OLIGONUCLEOTIDE ALSO POSSESSED A TERMINAL FLUORESCENCE MODIFICATION. THE IMAGES ASSOCIATED WITH EACH STEP PERTAIN TO NEGATIVE CONTROLS FOR STEPS A-C WHILE THE SUCCESSFUL ATTACHMENT IS SHOWN IN STEP D. THIS FLUORESCENT DNA ATTACHMENT IS DEPICTED IN FIGURE 4-4.. .55

Figure 4-12. FluoresCENCE OF FIBRES COATED WITH THE DSC METHOdOLOGY. VARIOUS AMINE FUNCTIONALIZED DNA OLIGOMER CONCENTRATIONS WERE UTILIZED AND APPEAR TO DEMONSTRATE AN INCREASE IN FLUORESCENCE WITH INCREASING

xlPage Jason Koppert MASc Thesis 
CONCENTRATIONS. LITERATURE SEARCHES SUGGEST THE USAGE OF OLIGOMER AROUND $1 \mu \mathrm{M}$ BUT IT APPEARS THAT $10 \mu \mathrm{M}$ IS NEEDED TO HAVE SUFFICIENT SIGNAL ABOVE THE BACKGROUND SIGNAL.

FIGURE 4-13. FLUORESCENT MICROSCOPY IMAGING OF THE HYBRIDIZATION AND SUBSEQUENT REMOVAL THROUGH A MELTING APPLICATION OF THE OLIGOMER COATED FIBRE. THE HYBRIDIZED SURFACE COATING REGION HAS A CLEAR TERMINATION BOUNDARY VISIBLE ON THE FIBRE SURFACE. THIS BOUNDARY IS CREATED AS A RESULT OF THE COATING CONTROL MECHANISM DEPICTED IN FIGURE 4-6.

FIGURE 4-14. DEPICTION OF NEGATIVE AND POSITIVE CONTROLS FOR THE COVALENT ATTACHMENT OF DNA TO GLASS FIBRE SURFACES WITH THE EDC CROSS-LINKING METHODOLOGY. THE IMAGES TAKEN WITHOUT EDC IN THE COATING PROCESS REPRESENT AN UNDESIRABLE RESULT.

FiguRE 4-15. HYBRIDIZATION AND ATTEMPTED REMOVAL UTILIZING COATINGS FUNCTIONALIZED WITH EDC. MICROSCOPY IMAGE PROCESSING AUTO ADJUSTS SOME FLUORESCENCE TO APPEAR DARKER IN REGIONS OF LOWER FLUORESCENCE. THEREFORE, PIXEL DENSITY ANALYSIS WAS PERFORMED AS SEEN IN FIGURE 4-16. SIGNIFICANT FLUORESCENCE BACKGROUND REMAINS ON THE FIBRE SURFACE AFTER PROBE REMOVAL AND IN THE NEGATIVE CONTROL SAMPLES.

FiguRE 4-16. DENSITOMETRY MEASUREMENTS WITH THE EDC HYBRIDIZATION AND NEGATIVE CONTROL SAMPLES. THE HYBRIDIZATION ASSAY CAN BE SEEN TO WORK WITH THE DENSITOMETRY DELTA THAT OCCURS UPON REMOVAL OF A SURFACE HYBRIDIZED PROBE. THIS HYBRIDIZATION WORKS WHEN THE COVALENT LINKER, EDC, IS NOT PRESENT THEREBY INDICATING THAT A PORTION OF THE SUCCESSFUL SIGNAL, WHEN EDC IS USED, MAY BE NON-SPECIFIC. ERROR IN THESE MEASUREMENTS IS REPRESENTATIVE OF A LARGE POPULATION OF EDC COATED FIBRES.

FIGURE 4-17. (A) GLASS TFBG FIBRE COATED WITH THE UV CROSS-LINKING METHOD. THE CENTRAL WHITE LINE VISIBLE IN ALL OF THE IMAGES IS A PHOTOLUMINESCENT EFFECT OF A TFBG. (B) HYBRIDIZATION OF FLUORESCENT PROBE ON THE SURFACE OF A FIBRE COATED WITH DNA OLIGOMER THROUGH A UV COATING EXPOSURE. CLEAR NON-UNIFORMITY IS VISIBLE IN THE HYBRIDIZATION STEP OF THE PROCEDURE. (C) THERMALLY INDUCED REMOVAL OF THE FLUORESCENT PROBE FROM THE FIBRE SURFACE. (D, E) DEPICTION OF PROBE HYBRIDIZED, DNA SPOTTING RESOLUTION OF THE DNA OLIGOMERS COATED ONTO A GLASS FIBRE USING THE UV COATING METHOdOLOGY. AREAS BETWEEN THE FLUORESCENT SPOTS DO NOT HAVE DNA OLIGOMER ON THE SURFACE AND THEREBY ARE UNABLE TO BIND THE FLUORESCENT PROBE WHEN THE FIBRE IS EXPOSED TO A FLUORESCENT PROBE SOLUTION. (F, G) CORRESPOND TO (D), (E) RESPECTIVELY AND REPRESENT THE MELTING EFFECT WHEN THE FLUORESCENT PROBE IS REMOVED THROUGH A HEAT TREATMENT. THE EXCITATION SOURCE IN ALL IMAGES IS A 488NM LASER.

FIGURE 4-18. THE DENSITOMETRY MEASUREMENTS DEPICT A POPULATION OF FIBRES HYBRIDIZED WITH A FLUORESCENT COMPLEMENT PROBE AFTER COATING WITH DNA. THE DIFFERENCE IN ERROR IN THE MEASUREMENTS ACROSS THE DIFFERENT COATING TYPES IS DUE TO DIFFERENT IMAGE CAPTURE METHODOLOGIES BEING USED TO EVALUATE EACH. ALL THE DEPICTED MEASUREMENTS ARE NORMALIZED. .

FIGURE 5-1. DEPICTION OF ALL UTILIZED PROBING STRATEGIES FOR EXAMINATION OF ABCB1 DNA COATING FUNCTIONALITY AND PCR COMPATIBILITY. (A) HYBRIDIZATION OF FLUORESCENT PROBE TO THE SURFACE BOUND DNA OLIGOMER. (B) BINDING OF A HYBRIDIZATION PROBE TO THE SURFACE OF THE ULTRAMER SEQUENCE WHICH IS IN TURN BOUND TO THE SURFACE CONNECTED oligomer. (C) A similar strategy to (B) With the usage of a Molecular Beacon probe. Such a probe CAN LOWER BACKGROUND IN SOLUTION WHEN NOT BOUND TO THE ULTRAMER SEQUENCE. (D) SURFACE BOUND REVERSE PRIMER IN ITS EXTENDED FORMAT. THIS EXTENSION OCCURS DURING BINDING OF THE ULTRAMER AND EXPOSURE TO A POLYMERASE AS IN PCR. DETECTION OF DSDNA IS OBSERVED WITH AN INTERCALATING DYE. (E) REVERSE PRIMER AND ITS EXTENSION UPON REMOVAL OF THE DYE AND TEMPLATE STRAND AS SEEN IN (D) A FORWARD PRIMER PROBE BINDS TO THE EXTENDED REGION OF THE NEWLY CREATED SURFACE BOUND OLIGOMER SECTION. NOTE THAT FOR ALL THE FLUOROPHORES DEPICTED HERE THE DEFAULT COLOR IS GREEN ALTHOUGH FLUOROPHORES OF ANY COLOR CAN BE INTERCHANGED.

Figure 5-2. REAL-TIME PCR RUN PROFILE WITH THE ABCB1 GENE TARGET RUN FROM A BUCCAL SWAB SAMPLE. THIS PCR WAS RUN With MoleCUlar BeACONS ${ }^{\text {TM }}$ DESIGNed by SPARTAN BIOSCIENCE TO PROVIDE A SIGNAL SPECIFIC FOR THE CORRECT TARGET. THE POST PCR PRODUCTS, SHOWN IN TRIPLICATE ON THE ELECTROPHORESIS GEL INSET, ARE OF THE SAME LENGTH (132 BASE PAIRS) WITHOUT SECONDARY PRODUCTS. 
Figure 5-3. Melt curve of the ABCB1 PCR product With both Molecule Beacons and post Run addition of SYBR GReEN InTERCALATING DYE. THE Negative CONTROL DOES NOT CONTAIN SYBR GREEN. THE MELTING PEAK, AT APPROXIMATELY 84 DEGREES CELSIUS, IS THAT ASSOCIATED WITH THE SPECIFIC GENE PRODUCT.

Figure 5-4. (A) Concentration optimization of the 10 CYCle PCR REACtion through Starting template VARIANCE. (B) AlL OF THE AMPLIFICATIONS PRODUCED IDENTICAL MELT PEAKS AS SEEN ON THE RIGHT. HOWEVER, SATURATION IS REACHED BEFORE THE FIRST CYCLE IS COMPLETED WITH A 50 NM STARTING TEMPLATE CONCENTRATION. NORMALIZATION TO THE INITIAL DATA POINT WAS PERFORMED ON DATA IN THE PCR RUN PROFILES OF (A) TO EXAMINE CHANGE IN REACTION SIGNAL. .84

FIGURE 5-5. ASYMMETRIC PCR DEPICTION DURING RUN PROFILE AND MELTING CURVES. (A)THE NORMALIZED RUN PROFILES ON THE LEFT BETWEEN 1:1 AND 1:16 DEPICT VERY SIMILAR PCR PLATEAUING WHICH WOULD INDICATE THAT THE EFFICIENCY OF PCR HAS NOT CHANGED SIGNIFICANTLY. (B) MELTING CURVES DEPICT THAT THESE CORRESPONDING PLATEAUS HAVE SIGNIFICANTLY DECREASED DOUBLE STRANDED DNA PRESENCE. THE INITIAL PCR PRIMER RATIO IS PROPORTIONAL TO THE DSDNA THAT GENERATES A FLUORESCENT SIGNAL.

Figure 5-6. Molecular BeACONS ${ }^{\mathrm{TM}}$ WITH ASYMMETRIC PCR ReVERSE: FORWARd PRIMER RATIOS. The CONTINUED AMPLIFICATION BEYOND THE PLATEAU REGIONS OF THE SYBR GREEN BASED DETECTION METHOD INDICATES THAT THE PRODUCTION OF SINGLE STRANDED AMPLICON CONTINUES IN AN ASYMMETRICAL MANNER.

FIGURE 5-7. BINDING OF ULTRAMER TEMPLATE TO THE SURFACE OF THE SPOTS COATED ON A GLASS FIBRE. ULTRAMER BINDING IS MADE fluorescent through usage of the Ultramer Probe as depicted in Figure 5-1B. (A) Binding of the Ultramer HYBRIDIZATION PROBE AT A TYPICAL PCR ANNEALING TEMPERATURE. (B) REMOVAL OF THE COMPLEX THROUGH A HEAT TREATMENT. EXCITATION WAS PERFORMED EXTERNALLY WITH AN ARGON-ION LASER.

FiguRE 5-8. PolymerASE EXTENSION DETECTION IN REAL-TIME ON THE SURFACE OF A DNA PRIMER COATED GLASS FIBRE. THE POLYMERASE INJECTION POINT IS MARKED BY THE STAR AROUND 1100 SECONDS. THE FLUORESCENCE SIGNAL IS GENERATED THROUGH THE BINDING OF SYBR GREEN TO THE NEWLY CREATED DOUBLE STRANDED DNA ON THE SURFACE OF THE FIBRE. THE INSET IMAGES DEPICT THE PROGRESSION OF THE SURFACE EXTENSION OF TEMPLATE. LEFT INSET: 0-1000 SECONDS. RIGHT INSET: 1500 SECONDS. EXTENSION OF TEMPLATES IN SOLUTION IS NOT POSSIBLE DUE TO THE LACK OF A PRIMER FOR THE TEMPLATE...... 88

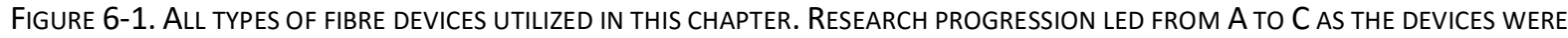
ADAPTED TO SP-PCR. (A) TFBG WRITTEN IN AN SMF 28 FIBRE. THE HEATING MECHANISM OCCURS AT THE FIBRE SURFACE AND UTILIZES AN ABSORPTIVE NANOPARTICLE COATING. A GOLD MIRROR ENSURES THE REFLECTION OF TEMPERATURE SIGNAL AND A SECOND PASSAGE OF IR WAVELENGTHS THROUGH THE TFBG. (B) BULGE-BASED HEATING DEVICE. THE BULGE COUPLES LIGHT FROM THE MMF FIBRE INTO THE CLADDING OF THE SMF 28 FIBRE WHERE LIGHT CAN INTERACT WITH THE NANOPARTICLE (NP) COATING FOR HEATING. AN FBG IS USED FOR TEMPERATURE INQUIRY. (C) LIGHT ABSORBING FIBRE DEVICE. THIS DEVICE IS CREATED BY SPLICING A SEGMENT OF PROPRIETARY CORATIV ${ }^{\text {TM }}$ LIGHT ABSORBING FIBRE ALONG WITH SMF-28 FIBRE (CORNING). HEATING OCCURS IN THE CORE OF THE DEVICE WHERE AN FBG ALLOWS FOR TEMPERATURE MONITORING. DNA SPOTS EXIST AS GREEN SPOTS ON THE SURFACE OF THE FIBRES IN ALL THESE DEVICE DEPICTIONS. THE SOURCE OF THE IR AND VISIBLE LIGHT NEEDED FOR PCR ARE INDICATED BY ARROWS. 102

Figure 6-2. Prototype Hotwire-Fibre Rapid Thermal Cycling DeVICE SETUP. Light SOURCES INCLUde AN IR BROAdBAND SOURCE (BBS), AN IR PUMP, AND A VISIBLE LIGHT SOURCE. THE VISIBLE LIGHT IS COUPLED INTO A FIBRE OPTIC CONNECTION AFTER PASSING THROUGH A SHUTTER CONTROL. VISIBLE LIGHT, BBS, AND IR LIGHT FOR HEATING ARE ALL COUPLED INTO THE FIBRE DEVICE SIMULTANEOUSLY. THE DEVICE CONSISTS OF ONE OF THE SCHEMATICS OUTLINED IN FIGURE 6-1. SUCH A DEVICE IS CONTAINED IN A CAPILLARY VESSEL FOR INTRODUCTION OF LIQUIDS SUCH AS HYBRIDIZATION AND PCR SOLUTIONS. ALL DEVICES ARE USED IN REFLECTION MODE THEREFORE RETURNING AN OPTICAL SIGNAL BASED ON BRAGG GRATING INTERACTION, BACK THROUGH THE

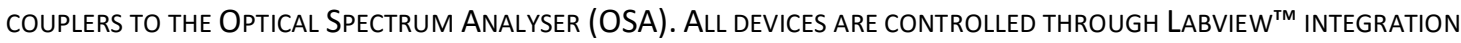

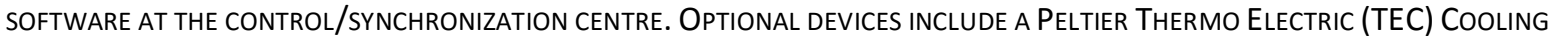
MOdULE AND A FAN FOR ASSISTED HEATING AND COOLING OF FIBRE DEVICES. DiAGRAM IS COURTESY OF HUBERT JEAN-RUEL. .. 103

FIgURE 6-3. (A): THE FINAL, FUNCTIONAL, FIBRE HOTWIRE DEVICE. REFER TO FIGURE 6-1 FOR THE COMPONENT LABELLING AND FIBRE CORE SIZE BREAK DOWN. (B): THREe LIGHT SOURCES, IR, BBS, AND VIS LIGHT, ENTER THE FIBRE SIMULTANEOUSLY. The FUNCTIONALITIES OF THE IR LIGHT AND VIS LIGHT ARE SEPARATED IN ‘C' AND ‘D’ BUT OCCUR SIMULTANEOUSLY. (C): IR AND BBS

xii I Page Jason Koppert MASc Thesis 
LIGHT PASS THROUGH THE MMF SEGMENT WITH MINIMAL LOSS OF POWER. BBS LIGHT REFLECTED BY THE GRATING AND IS USED TO PROBE THE TEMPERATURE OF THE LIGHT ABSORBING Fibre DEVICE. (E): IR LIGHT THEN INTERACTS WITH THE LIGHT ABSORBING FIBRE AND IS REFLECTED BY THE CHIRPED FBG TO ALLOW A SECOND PASS OF LIGHT THROUGH THE LIGHT ABSORBING FIBRE. (D): VIS LIGHT EXPERIENCES RELATIVELY MORE LOSS OF LIGHT TO THE FIBRE CLADDING THAN THE IR LIGHT. (F): VIS LIGHT PROPAGATING THROUGH THE FIBRE CLADDING CREATES AN EVANESCENT WAVE THAT TRAVELS PARALLEL TO THE SURFACE OF THE FIBRE. THIS EVANESCENT WAVE ALLOWS FOR EXCITATION OF THE DNA SPOTS. FLUORESCENCE CREATED AT THESE SPOT LOCATIONS IS THEN CAPTURED AT A PERPENDICULAR LOCATION TO THE FIBRE DEVICE.

FIGURE 6-4. COMPOSITE IMAGE OF DIFFERENT DNA SPOTS ON A NANOPARTICLE COATED TFBG FIBRE. THE FIBRE FUNCTIONALITY SCHEMATIC CAN BE SEEN IN FIgURE 6-1A. The DNA SPOTS ARE HYBRIDIZED TO A FLUORESCENT PROBE. SPOTS A-D ARE UNIQUE ENTITIES REPRESENTATIVE OF POTENTIAL MULTIPLEXING ABILITY ON THE SURFACE OF A FIBRE. THE SOLID BORDER BOX ENCLOSES THE AREA OF THE SPOT USED FOR ANALYSIS WITH THE DOTTED ENCLOSURE REPRESENTING THE REGION USED FOR BACKGROUND MEASUREMENTS.

Figure 6-5. (A) NORMALIZED FLUORESCENCE INTENSITY VERSUS TFBG TEMPERATURE FOR FIGURE 6-4 SPOT C. THE AVERAGE INTENSITY WITHIN THE AREA REPRESENTED BY THE SOLID WHITE RECTANGLE IS NORMALIZED TO THE AVERAGE INTENSITY WITHIN THE AREA REPRESENTED BY THE DOTTED WHITE RECTANGLE (CORRESPONDING TO THE SOLUTION ADJACENT TO SPOT C). THE LATTER IS ALSO SUBTRACTED FROM THE FORMER TO PROVIDE A MORE ACCURATE BASELINE. THE DATA PRESENTED WERE NOT SMOOTHED. (B) CORRESPONDING MELT CURVE FOR SPOT C. A BOXCAR SMOOTHING WAS APPLIED.

Figure 6-6. INTERFERENCE CAUSED BY TFBG LUMINESCENCE EFFECT. THE EFFECT IS PRONOUNCED WITH 488 NM EXCITATION LIGHT AND VARIES IN INTENSITY BETWEEN FIBRE DEVICES. FOR THIS REASON, MEASUREMENTS ARE DIFFICULT TO TAKE WITH INTERNAL EXCITATION WITH A TFBG DEVICE. THIS COLLECTION OF IMAGES CORRESPONDS TO BARE GLASS FIBRES POSSESSING NO FUNCTIONAL COATINGS FOR HEATING. SUCH COATINGS SCATTER LIGHT EMITTED FROM THE FIBRE CORE AND THEREBY EXACERBATE THIS LUMINESCENCE PROBLEM. 109

FIGURE 6-7. COMPARISON OF A TFBG FIBRE WITH HYBRIDIZATION PROBE BINDING WITH BOTH INTERNAL EXCITATION (A) AND EXTERNAL EXCITATION (B). THE INTERNAL EXCITATION DOES NOT APPEAR TO FUNCTION WELL IN THIS INSTANCE ALTHOUGH THERE ARE SOME VISIBLE PERTURBATIONS WHERE SPOTS ARE PRESENT IN THE EXTERNAL EXCITATION IMAGE. THE RED SPOTS ARE AN EFFECT OF UTILIZATION OF TEXAS RED DYE IN PLACE OF FLUORESCEIN ON THE PROBE USED IN THE HYBRIDIZATION ASSAY. TEXAS RED DYE WAS USED DUE TO ITS EXCITATION LINE BEING AT 590 NM. THIS LASER LINE PRODUCES LESS LUMINESCENCE IN THE TFBG CORE COMPARED TO 488 NM EXCITATION.

FIGURE 6-8. SIMPLISTIC DEPICTION OF A COMMON PROBLEM WITH FIBRES AND EXTERNAL EXCITATION OF FLUORESCENT SPOTS. THE EXCITATION OF THE FLUORESCENCE IS PERFORMED THROUGH A LASER DIODE. EXCITATION HAS AN EFFECTIVE BEAM REGION THAT IS DEPICTED BY THE BLUE OVOID SHAPE. OUTSIDE OF THIS REGION FLUOROPHORES WILL HAVE MINIMAL FLUORESCENCE. THIS BEAM SHAPE IS AN EFFECT OF THE CYLINDRICAL GLASS CAPILLARY AND LASER BEAM SHAPE. BECAUSE OF THIS REGIONAL EFFECT, MOVEMENT OF THE FIBRE CAN CAUSE FLUORESCENT SPOTS TO VARY IN INTENSITY ESPECIALLY DURING THERMAL APPLICATIONS....

FiguRE 6-9. MMF-SMF BULGE DEVICE WITH INTERNAL EXCITATION (A) AND EXTERNAL EXCITATION (B) METHOdOLOGIES. THIS REPRESENTS THE IDENTICAL HYBRIDIZATION ASSAY CONDITIONS AS SEEN IN FIGURE 6-7.

FIGURE 6-10. COMPARISON OF SIGNAL TO NOISE RATIOS FOR EXTERNAL VERSUS INTERNAL EXCITATION METHODOLOGY. A SIGNIFICANT CAVEAT HERE PERTAINS TO THE QUALITY OF THE EXTERNAL EXCITATION READINGS. IN THIS EXPERIMENT, EXTERNAL EXCITATION WAS MAXIMIZED THROUGH PROPER ALIGNMENT. THIS ALIGNMENT IS FREQUENTLY SUB-OPTIMAL DURING REAL-TIME IMAGE ACQUISITION.

FIGURE 6-11. GREEN INTENSITY (FLUORESCENCE INTENSITY) AS A FUNCTION OF TIME, WITH 1 SEC EXPOSURE, AS THE IR POWER IS CYCLED BETWEEN 0 AND $700 \mathrm{MW}$. A SMALLER PORTION OF THE TFBG (APPROXIMATELY 0.5 MM LENGTH) IS CONSIDERED FOR IMPROVED CONTRAST AND THE CORE LUMINESCENCE WAS EXCLUDED. THE FLUORESCENCE MEASUREMENTS WERE COLLECTED VIA EXTERNAL

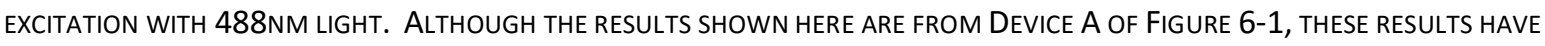
BEEN REPRODUCED WITH ALL THREE OF THE FIBRE DEVICES SHOWN IN THIS FIGURE 6-1. THE DUPLICATED RESULTS OF THE SEQUENTIALLY DEVELOPED DEVICES ARE NOT SHOWN. 
Figure 6-12. (A) FLUORESCENCE IMAGE ACQUIRED AT EACH CYCLE. THE IMAGE INTENSITY WAS MULTIPLIED BY 5 IN EACH CASE TO IMPROVE VISUALIZATION. ONLY A SUB-REGION OF THE IMAGE IS SHOWN HERE AND CONSIDERED FOR THIS ANALYSIS. (B) CORRESPONDING FLUORESCENT INTENSITY COUNT FOR THE FIBRE SPOT (BLUE) AND FOR THE BACKGROUND SOLUTION (RED). THE INSET SHOWS THE DIFFERENCE IN INTENSITY BETWEEN THE SPOT AND THE BACKGROUND.

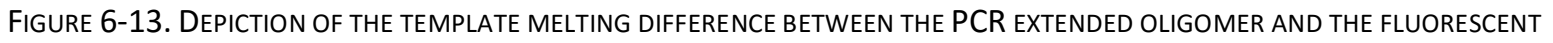
HYBRIDIZATION PROBE. THE OBSERVED DELTA IS APPROXIMATELY THAT OF THE EXPECTED THEORETICAL DIFFERENTIAL BETWEEN THE PROBE AND THE PRODUCED TEMPLATE. 


\section{List of Abbreviations}

\begin{tabular}{|c|c|}
\hline Abbreviation & Definition \\
\hline $\mathrm{ABCB} 1$ & A gene for ATP binding Cassette sub-family B \\
\hline APTMS & Amino-propyl trimethoxy silane \\
\hline BBS & Broad-Band light Source \\
\hline CYP2C19 & Cytochrome P450 2C19 \\
\hline DMSO & Dimethyl Sulfoxide \\
\hline DNA & Deoxyribonucleic acid \\
\hline DSC & Disuccinimidyl Carbonate \\
\hline dNTP & Deoxyribose Nucleotide Triphosphate \\
\hline dsDNA & Double Stranded DNA \\
\hline EDC & 1-Ethyl-3-[3-methylaminopropyl]carbodiimide hydrochloride. \\
\hline FAM & 6-carboxy fluorescein \\
\hline FBG & Fibre Bragg Grating \\
\hline FITC & Fluorescein Isothiocyanate \\
\hline IR & Infrared \\
\hline $\operatorname{LAF(D)}$ & Light Absorbing Fibre (Device) \\
\hline LATE PCR & Linear After The Exponential PCR \\
\hline MMF & Multi Mode Fibre \\
\hline $\mathrm{OHF}$ & Optical Heating Fibre \\
\hline $\mathrm{PCl}$ & Percutaneous Coronary Intervention \\
\hline PCR & Polymerase Chain Reaction \\
\hline PEG & Poly Ethylene Glycol \\
\hline POCT & Point-of-Care Testing \\
\hline SI-PEG-FITC & Silane-PEG-FITC molecular entity \\
\hline SMF & Single Mode Fibre \\
\hline SP-PCR & Solid-Phase PCR \\
\hline SPR & Surface Plasmon Resonance \\
\hline ssDNA & Single Stranded DNA \\
\hline TEC & Thermo Electric Cooler \\
\hline
\end{tabular}




\begin{tabular}{|l|l|}
\hline TFBG & Tilted Fibre Bragg Grating \\
\hline TIRF & Total Internal Reflection Fluorescence \\
\hline UV & Ultraviolet \\
\hline WGS & Whole Genome Sequencing \\
\hline
\end{tabular}




\section{Introduction}

\subsection{Overview}

This chapter acts as an introduction to the content of this thesis and will summarize the motivation, problem addressed and contributions from this thesis. Concepts needed to understand the motivation behind this thesis project will be addressed from a general perspective. Additionally, a clinical example is provided to illustrate how such medical devices are relevant to research in biomedical engineering.

\subsection{Motivation}

\subsubsection{Personalized Medicine}

Although there are many topics of research in the realm of healthcare, personalization of healthcare has been a central component to the approaches of many physicians and caretakers. Through new software, medical devices, and surgical techniques, many advances have been made towards patient outcome improvement. More recently a focus has been placed on the personalization of pharmaceuticals through usage of a patients' genetic information. This area of study, known as pharmacogenomics, has recently been highlighted as a major opportunity for the development of new medical devices by organizations such as the United States Food and Drug Administration (FDA) (Frueh \& Gurwitz, 2004). Through the personalization of medicine, Adverse Drug Reactions (ADRs) and the associated hospitalizations and fatalities could be minimized (Frueh \& Gurwitz, 2004). Severe ADRs currently account for nearly 7\% of all hospitalizations in the United States (Z.-Y. Wang et al., 2015). Personalization of pharmaceuticals may have the greatest effect on reducing adverse reactions to drugs. Additionally, personalization of medicine could lead to increased drug availability: by excluding those patients who are genetically predisposed to reactions, many more drugs could pass through clinical trials if they were associated with specific gene requirements.

1IPage Jason Koppert MASc Thesis 


\subsubsection{The Importance of Point-Of-Care Testing}

A common problem with healthcare and the application of medical diagnostics is the delay between realization that a diagnosis is required and the availability of results. In clinical settings, the difference between Point-of-Care Testing (POCT) results and lab-centric results can be between life and death. However, even in situations of lower priority, care can be greatly improved using POCT. Results pertaining to bacterial infections, such as a potential throat infections or sexually transmitted infections, allow for proper prescription of medication and can minimize unnecessary antibiotic usage while also ensuring patients do not require a follow-up appointment to be informed of their diagnosis (Roosevelt, Kulkarni, \& Shulman, 2001).

POCT offers the opportunity not only to eliminate shipping, handling, and storage concerns but also presents the possibility of shorter run times. Run time variations make little difference in a conventional laboratory setting; whether an assay takes 1 hour or 30 minutes requires the same worker-hours to perform and therefore there is little pressure to make the assay quicker. POCT clearly benefits from reduced result turnaround time. Additionally, POCT devices are important due to their lower resource requirement. They do not require conventional laboratory personnel and can be run in environments that are not laboratory regulated. This can lead to lower healthcare costs and more testing accessibility.

\subsubsection{A Motivating Example}

Myocardial infarction, also known as heart attack, is not a planned phenomenon. The average patient may not even know that they were at risk for such an event. This usually leads to an emergency treatment known as a Percutaneous Coronary Intervention (PCI). Such a procedure involves the introduction of a stent into a region of the heart to re-open an area of poor circulation in order to relieve the symptoms of atherosclerosis. Once a $\mathrm{PCl}$ has been completed in the operating room, the patient is exposed to a new range of risks beyond the initial acute coronary syndrome. They are now at 
risk of an adverse cardiac event based primarily on the type of antiplatelet medication they were given to assist with the recovery of the $\mathrm{PCl}$.

Antiplatelet medication assists with the body's response to a stent in terms of scar tissue formation. From a simplified perspective, an increased dose of antiplatelet medication will increase the probability of internal bleeding thereby introducing a new round of complications. However, too low of a dosage of antiplatelet medication leads to increased chance of scarring in the area of the stent. This increases the potential of stent thrombosis as well as an increased risk of a major adverse cardiovascular event (Roberts et al., 2012).

After a $\mathrm{PCl}$, a patient is faced with the choice of several drugs. The most economical option is Clopidogrel with alternative options of Ticagrelor and Prasugrel. The latter two drugs are known to cause significantly increased internal bleeding complications as well as being significantly more expensive (Nellåker, Wållgren, \& Karlsson, 2007; Wallentin et al., 2010; Wiviott SD, Braunwald E, McCabe CH, Montalescot G, Ruzyllo W, Neumann FJ, Ardissino D, De Servi S, Murphy SA, Riesmeyer J, \& Gibson CM, 2007). It may seem then that the obvious choice for prescribing would be Clopidogrel. However, approximately $25 \%$ of persons with Caucasian and African ancestries and up to $50 \%$ of those with Asian ancestries possess a gene that causes the inability to activate Clopidogrel from its ingested form into its active form (Fricke-Galindo et al., 2015). Therefore, the effective dosage of two individuals given the same ingested quantity can be a life or death difference. A patient's genome is therefore directly linked to their platelet response and ultimately their response to a $\mathrm{PCl}$. This relationship is an example of 'pharmacogenomics' and belongs to a prime example of how personalized medicine can save lives. Most patients have not had a genetic test prior to such an event, and traditional methods to determine a patient's genotype are expensive, complex, and can take anywhere from 1 to 2 weeks including shipping and sample handling. This motivates the need for rapid POCT technologies.

3IPage Jason Koppert MASc Thesis 
Spartan Bioscience Inc., the industrial sponsor of the research included in this thesis project, has developed a point-of-care test for the testing of the genotypes associated with the processing of the Clopidogrel (Roberts et al., 2012). Specifically, the test examines the CYP2C19 enzyme involved in the activation of the Clopidogrel drug, to determine which genotype the patient possesses. The test involves the collection of a buccal swab (inner cheek), and the immediate running of the test in a shoebox-sized instrument. In additional to being one of the only instances of an FDA-approved, non-invasive POCT collection method, their test allows the collection of crucial genetic information in less than one hour. This timeline is important due to the emergency situation involved with a myocardial infarction.

The reason for continued development of POCT with regards to pharmacogenomics is due to the complexity of the testing. The CYP2C19 test is fairly simplistic with regards to the number of genomic targets since the majority of individuals have only 1 of 3 potential mutations that could affect their drug metabolism ability. There exist many more examples of personalized medicine with regards to pharmacogenomics that involve many more targets (Zanger \& Schwab, 2013). Many of these tests are outside of the capabilities of Spartan Bioscience's current system and therefore require novel POCT technologies.

\subsubsection{Fibre Optics for POCT}

In an effort to contribute to the advancement of POCT, Spartan Bioscience Inc. and Carleton University formed a partnership to create a novel molecular diagnostic device. The goal of both the academic and the industry partners is to apply recent advances in fibre optic technologies to the rapidly expanding market of DNA diagnostics. Ottawa-based research has included many inventions in fibre optic development, including the invention of the Fibre Bragg Grating (FBG) in 1978, and Carleton University retains significant fibre optic expertise such as those of Dr. Jacques Albert. Dr. Albert has performed significant research with the inventors of several fibre technologies and continues to work at Carleton University (K. O. Hill, Malo, Bilodeau, Johnson, \& Albert, 1993; Kenneth O. Hill \& Meltz, 1997). 
Spartan Bioscience Inc. has recognized the need for faster, highly multiplex, Point-of-Care PCR devices. Such devices ideally would minimize moving parts, use small volumes to allow high heating and cooling rates, and be amenable to manufacture in high volumes.

By using fibres as a dual purpose entity to both heat and monitor the temperature of a PCR reaction, miniaturization of such reactions would be precise, fast, and accurate. Furthermore, due largely to major advances in manufacturing developed by the telecom sector, fibre optic component development and manufacturing are highly optimized. Therefore, fibre-based PCR devices would be sufficiently economical for deployment in doctor's offices and pharmacies, not only in centralized laboratories.

\subsection{Problem Statement}

Many POCT applications require amplification of genomic samples to achieve measurable quantities.

This is normally done using PCR and new efforts to perform PCR have been implemented on solid surfaces. Based on the current state-of-the-art in the field of molecular diagnostics and biomedical engineering, it appears that using fibre optic technologies for heating may be compatible with the recently developing molecular diagnostic technique of Solid-Phase PCR. However, existing hotwire optical fibre devices have not yet been used for any molecular diagnostics applications. Neither has Solid Phase PCR been used in a multiplexable real-time environment. These technologies underpin much of the thesis and are discussed in detail in Chapter 2.

The combination of SP-PCR and hotwire optical fibres presents the potential for a low-cost, portable, high speed, POCT-compatible, and patentable genetic testing device. Because of this, we seek to combine the fibre optic technology advantages of cost, novelty, and size, with the existing chip-based multiplex ability of using SP-PCR to develop a proof-of-concept molecular diagnostic device. This thesis will develop and conduct experiments to develop and test the viability of such a proof-of-concept device.

5IPage Jason Koppert MASc Thesis 


\subsection{Summary of Contributions}

The critical biomedical engineering contribution of this thesis is the creation of a hotwire fibre optic device that is capable of performing SP-PCR. The device is able to provide adequate heating for a capillary reaction vessel for the purpose of performing PCR while simultaneously monitoring reaction temperature. It also demonstrates key features that are valuable for an industry commercialization project. These features include economy of production and multiplexability. Additionally, contained in this thesis are several key innovations: (1) Two DNA coating methodologies have been successfully adapted for use with optical glass fibres. (2) Solid Phase DNA polymerase activity has been monitored in real time with fluorescence imaging for the first time. (3) Total Internal Reflection Fluorescence (TIRF) has been developed for the first time with fibre-based DNA assays. (4) The first demonstrated use of real-time fluorescence measurements for the monitoring of SP-PCR.

The work presented in this thesis is brought together through the combined efforts of Spartan Bioscience Inc. and select laboratory groups at Carleton University. The collaboration was formed in an effort to design a fibre-optic based DNA diagnostic device for the purpose of genetic testing.

The collaboration involves the Biochemistry expertise of the lanoul and Willmore labs, the physical optics expertise of the Albert lab, and the molecular diagnostics and market knowledge of Spartan Bioscience Inc. A plethora of disciplines are thereby represented throughout this collaboration. The incorporation of all these fields is necessary for biomedical engineering projects in today's high tech medical device market.

My role in this collaboration includes: (1) leading the development of optical-fibre-compatible DNA coatings, (2) manufacturing of hotwire optical fibre devices, (3) compatibility testing of all proposed devices, and (4) molecular diagnostic assay development. Of the work presented in this document, all 
experimental data was collected and analysed by myself for the purpose of directing this collaborative effort.

\subsection{Organization of Thesis}

The remainder of this thesis contains six chapters. Chapter 2 will introduce the reader to the biological and biochemical information pertaining to PCR. The compatibility with hotwire fibre optic sensors with SP-PCR will then be discussed. Once this background information has been presented, Chapter 3 will summarize the goals of this thesis. Chapter 4 will present novel innovations, produced by this thesis work, to existing DNA coating methodologies that allow for economical coating of fibre optic surfaces. Chapter 5 will illustrate the adaptation of a molecular diagnostic assay for use in SP-PCR and ultimately describe the novel usage of fibre optic surfaces for real-time polymerase activity monitoring. Chapter 6 will present the culmination of the previous innovations with the functionalities of hotwire fibre optic surfaces, in combination with internal excitation of these same surfaces. This chapter presents evidence that indicates the successful development of a proof-of-concept device that addresses the initial problem statement. The seventh and final chapter will summarize the findings of this thesis, discuss the relevance of this technology to current market demands, and propose future development and applications for this successful proof-of-concept medical device. 


\section{Literature Review}

\subsection{Overview}

This chapter presents the necessary background information for this thesis in three main sections. The first section describes PCR and SP-PCR. The second section addresses the requirements of SP-PCR and relevance of microarray devices. The third section addresses hotwire optical fibre devices. Each section will begin with an overview of the basic information required to understand the chapter content. The sections will then describe the state-of-the-art in that area. This organization is necessary in order to understand the connection between the three sections as they pertain to the problem statement of the thesis.

\subsection{Polymerase Chain Reaction}

The polymerase chain reaction, also known as PCR, was invented in 1983 by Kary Mullis. This reaction lead to his winning of the Nobel Prize in 1993, a mere 10 years later. The value of the reaction was realized soon after its invention due to its ability to create copies of DNA for cloning, sequencing and diagnostics. It gave the scientific community the ability to take a single copy of a DNA sequence and amplify it to create many billions of copies in a relatively short time frame (S. A. Bustin, 2009). Today, PCR continues to be useful to tens of thousands of scientists around the world. It has taken a crucial role in the development of tests for diagnosis of diseases, genetic disorders, and pathogen detection to name only a few applications.

PCR is rather simplistic from a design standpoint. As depicted in Figure 2-1, it requires a DNA template, primers complementary to that template, a polymerase enzyme, and a reaction buffer containing dNTPs (deoxyribose Nucleotide Triphosphates), the building blocks of DNA. By combining all of these components and heating them to melt the double stranded DNA template structure, primers 
bind to the DNA template and are then extended by the polymerase enzyme at their $3^{\prime}$ end. This extension of the original template would continue beyond the desired region of amplification indefinitely if allowed to continue. To permit amplification to restart on the newly created strands, thermal cycling is begun. This process is illustrated in Figure 2-1. Standard PCR consists of a three phase thermal cycling reaction as depicted in Figure 2-2A. The first phase is a high temperature separation of the DNA template strand, known as the denaturation step. The second lower temperature phase allows for the annealing of DNA primers to the recently denatured DNA template, known as the annealing step. Concentrations of the primers are high in order to make the priming interaction more favourable than the template interaction with its antiparallel compliment. The temperature is then raised to the extension temperature, during what is known as the extension step. At this temperature the polymerase enzyme extends the primer. This three phase thermal cycle is then typically repeated for $40-50$ cycles. It is also possible to combine the annealing and extension phases to form a two-phase PCR in place of the conventional three-phase PCR.

Each of the three phases of PCR requires a period of time to be completed. There are two approaches to satisfying these time requirements as outlined by Carl Wittwer (S. A. Bustin, 2009). The first is the equilibrium approach. In this approach, time zero begins when the desired temperatures of each step are reached. This approach is not entirely realistic and nearly all PCR devices have some form of thermal lag, on the order of several seconds, between thermistor readings and PCR solution temperatures (Sanford \& Wittwer, 2013). Additionally, the kinetics of the primer and template binding as well as the polymerase can be nearly instantaneous ( $<1$ second). Combining thermal lag and fast kinetics means that each step may begin significantly before time zero and end during the transition to the next phase. Wittwer has proposed a new paradigm of PCR which is the kinetic paradigm as seen in Figure 2-2B (S. A. Bustin, 2009). This paradigm accounts for the lag and the true kinetic start and end points of each phase of PCR. By considering the integral of the effective area of temperature and time 9lPage Jason Koppert MASc Thesis 
for each of these phases, along with thermal ramp and cooling rates, PCR reactions can be more precisely controlled and thereby made to become significantly faster. Rate optimizations have even decreased the entire run times of PCR from hours to merely minutes (Farrar \& Wittwer, 2015). 


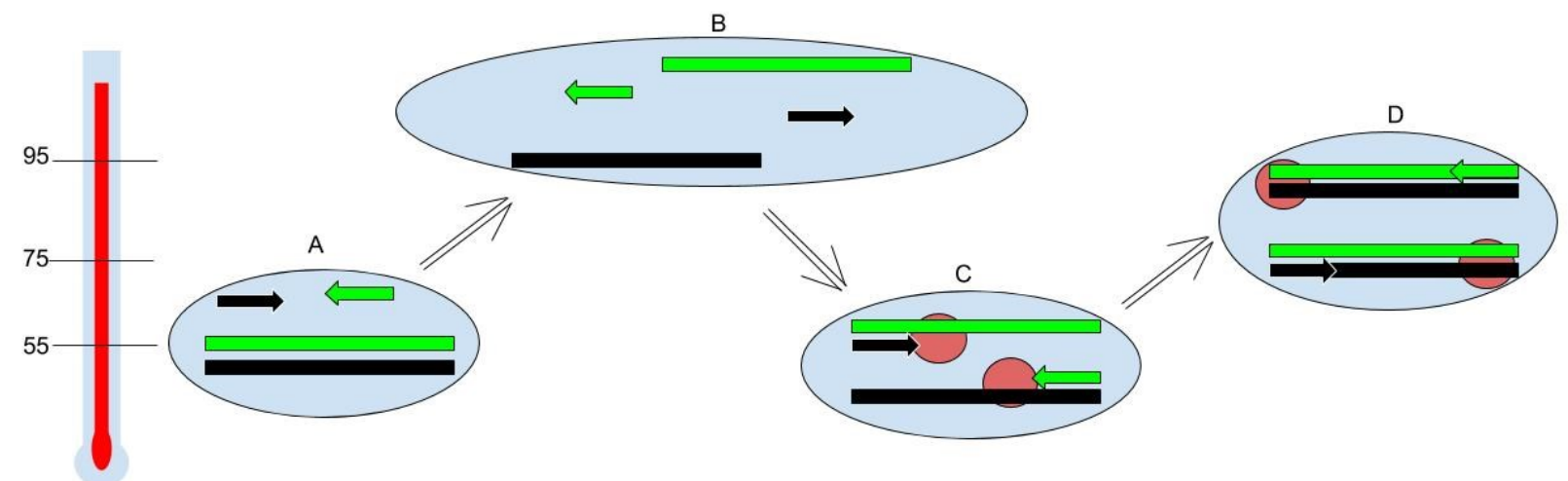

Figure 2-1. Key events of the Polymerase chain reaction. (A) represents the initial phase of PCR with primers and template in a PCR reaction solution. (B) High temperature denaturation causes the dissociation of the template. (C) Returning to lower annealing temperatures allows for the primers to associate with their respective templates. Once the primer has hybridized to its template the polymerase enzyme can bind to the complex. (D) Extension of the DNA primer occurs during a slightly temperature elevated extension phase. 


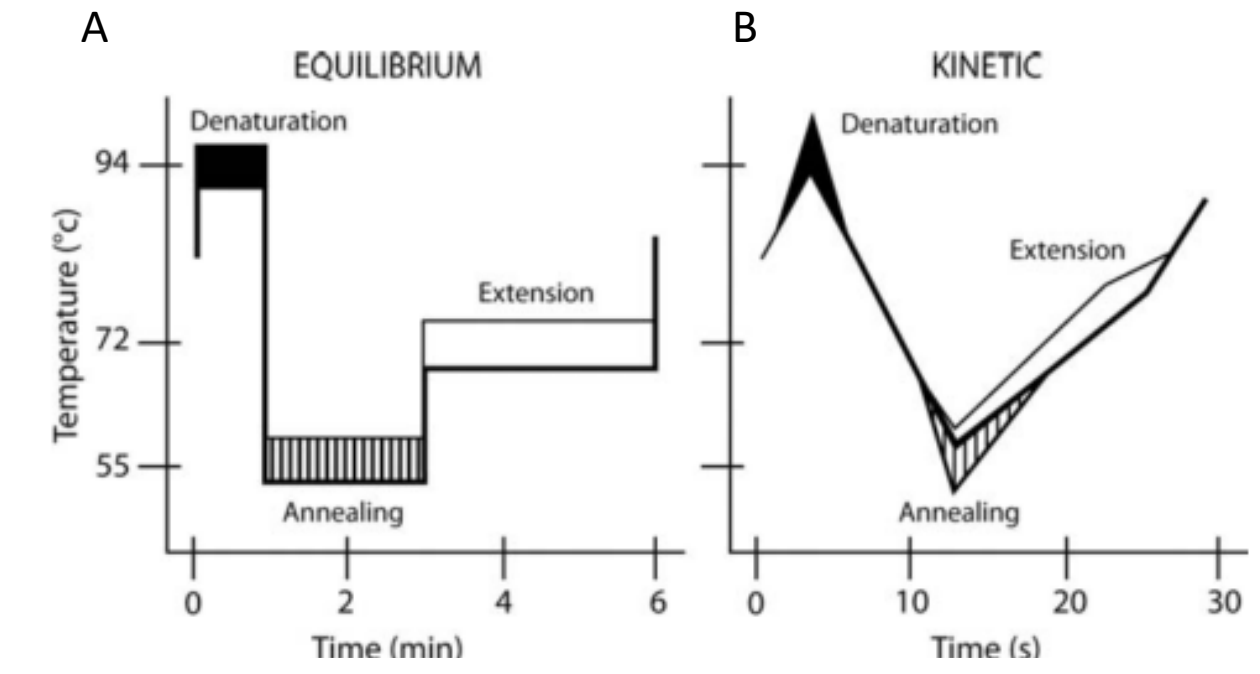

B KINETIC

Figure 2-2. (A) Equilibrium paradigm of PCR: The three phases of PCR are viewed as occurring at a single temperature with time zero initialized at the stage temperature arrival. (B) Kinetic paradigm of PCR: Temperature is in continuously changing state with the required time for each cycle represented by the integration of the regions in which each phase can occur. (Carl T. Wittwer, 2001). Obtained reprint permission from Springer (license no.: 3827810254910) 


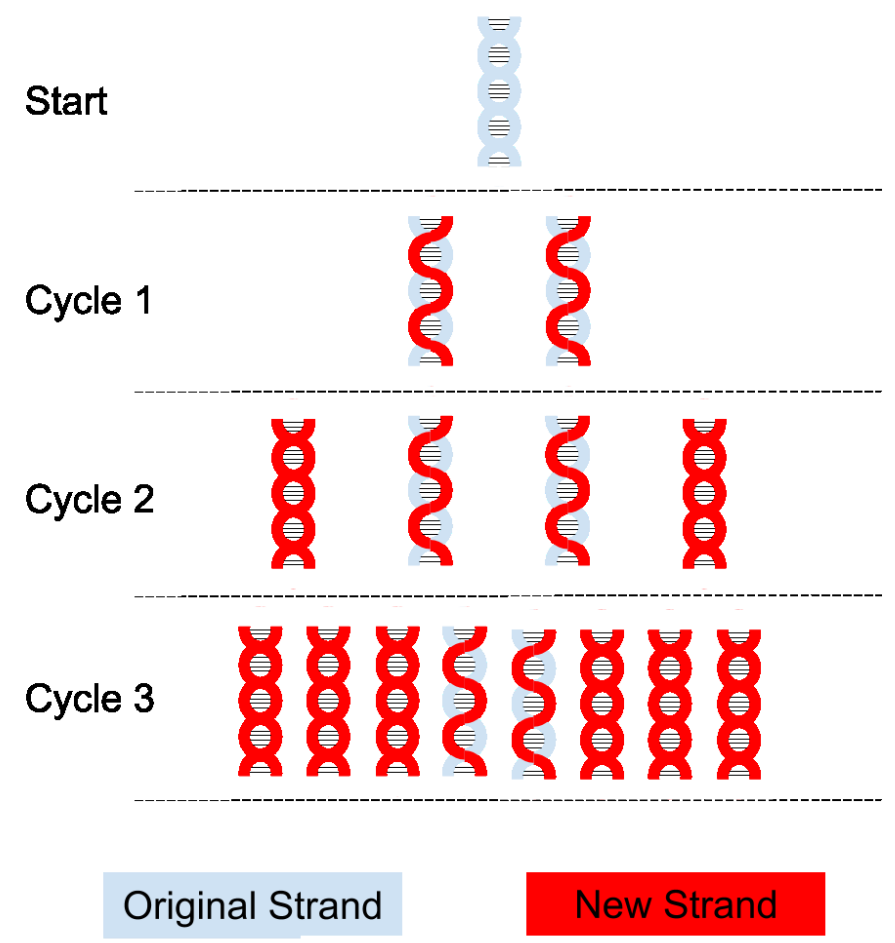

Figure 2-3. Exponential nature of PCR once the 3 phase reaction is repeated through thermal cycling. A typical PCR can create trillions of copies from a single strand of DNA in this manner before amplification plateaus.

\subsubsection{Real-time PCR and probing strategies}

PCR, as seen in Figure 2-3, will produce a large amount of product from a small amount of template after 50 cycles of the reaction have passed. This can be useful if large amounts of DNA are desired, such as in cloning applications, but little information is gathered about the process of producing the DNA product. This is where real-time PCR comes in. First invented by Russell Higuchi in 1993, realtime PCR involves the usage of a fluorescent probe that reflects the amount of DNA being created by the polymerase during the extension phase of the reaction (Higuchi, Fockler, Dollinger, \& Watson, 1993). By 
selectively monitoring for double stranded DNA products, Higuchi was able to realize the amount of DNA being created at each point in a reaction. There are many different mechanisms for monitoring PCR in real-time but three major strategies represent those most commonly found in laboratory settings.

The first methodology of DNA detection for real-time PCR is the usage of intercalating dyes as seen in Figure 2-4. The first application of real-time PCR utilized this mechanism through ethidium bromide (Higuchi et al., 1993). Such dyes create a signal when exposed to dsDNA but no signal in the presence of ssDNA. Since PCR creates new dsDNA based on an existing DNA template, more binding sites for intercalating dye are made available. This allows for imaging in the extension phase of the PCR reaction to correlate with an increase in fluorescence, based on the amount of fluorescing dye and therefore the amount of amplicon produced.

Molecular Beacon ${ }^{\mathrm{TM}}$ probes present a second method for detection of PCR. They possess three possible states of existence, two of which are depicted in Figure 2-5 (Tyagi \& Kramer, 1996). The first state is the unbound and closed beacon state. This state occurs in the absence of the target sequence and at lower temperatures. When in the presence of the correct target sequence, the probe will bind its loop region to the template and force the separation of the quencher and fluorophore thereby allowing for the creation of a fluorescence signal. This process is reversible if the template strand becomes unavailable through binding to another segment of DNA. The third state of existence is represented by an open state where fluorescence occurs due to temperature or chemical-induced melting of the stem region. This can be done in the presence or absence of a target sequence (Tyagi \& Kramer, 1996). Designing of Molecular Beacon ${ }^{\mathrm{TM}}$ sequences is important due to the competition of the template and loop hybridization and the hybridization of the stem structure.

A third methodology for detection of PCR in real-time is depicted in Figure 2-6 and involves the usage of Taqman ${ }^{\mathrm{TM}}$ probes. This methodology was initially introduced in 1991 but was originally used in 
a post-PCR fashion without analysis of signal in real-time (Holland, Abramson, Watson, \& Gelfand, 1991). This methodology irreversibly destroys probes during the PCR extension phase as the polymerase enzyme removes the probe from the template strand. This destruction creates a fluorescence signal but causes each probe to only serve functionality during the monitoring of PCR (C T Wittwer, Herrmann, Gundry, \& Elenitoba-Johnson, 2001). As DNA amplification proceeds, continued probe binding to newly created DNA strands allows for more probe destruction and therefore an increase in fluorescent signal.

Regardless of the methodology utilized for probing the reaction in real-time, the signal profile of the intercalating dyes, Molecular Beacons ${ }^{\mathrm{TM}}$ and Taqman $^{\mathrm{TM}}$ probes will all resemble that of Figure 2-7. This graph demonstrates the exponential nature of PCR. Although PCR is occurring exponentially from the beginning, the signal does not overcome the background until the 25-30 cycle range. The cycle at which the background signal is overcome is known as the 'quantification cycle' or Cq (S. A. Bustin et al., 2009). This Cq value represents the efficiency of PCR as well as the initial starting template concentration (Montgomery \& Wittwer, 2014). The Cq value is important in the optimization of PCR. Lower Cq values indicate more efficient PCR when identical starting template concentrations are used (S. A. Bustin et al., 2009). The plateau region of the 40 cycle mark and beyond demonstrates the saturation of the PCR solution and the effective end point for amplification. 


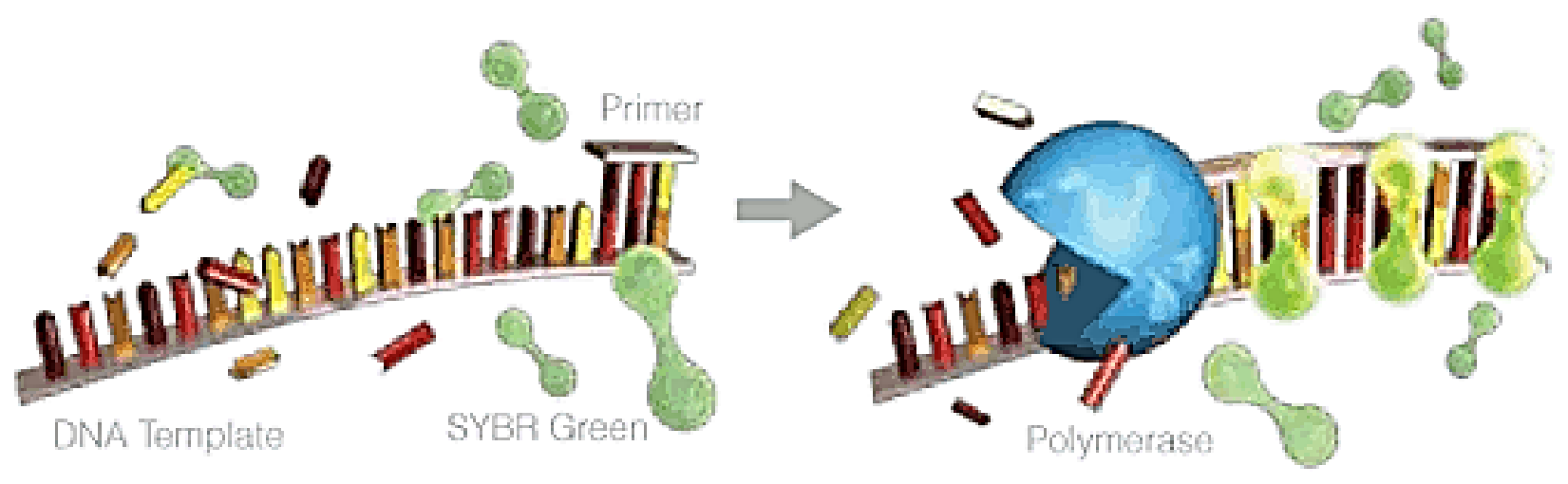

Figure 2-4. Depiction of the binding mechanism of SYBR Green intercalating DNA dye. This methodology of binding is similar to other available intercalating dyes such as SYTO-64 and ethidium bromide. Intercalating dyes only fluoresce when bound to double stranded DNA. For a comprehensive list of dyes see the work of Gudnason et al. (H. Gudnason, Dufva, Bang, \& Wolff, 2007). Intercalation dye binding is reversible through melting of the dsDNA complex. Image re-printed with permission from QIAGEN. 


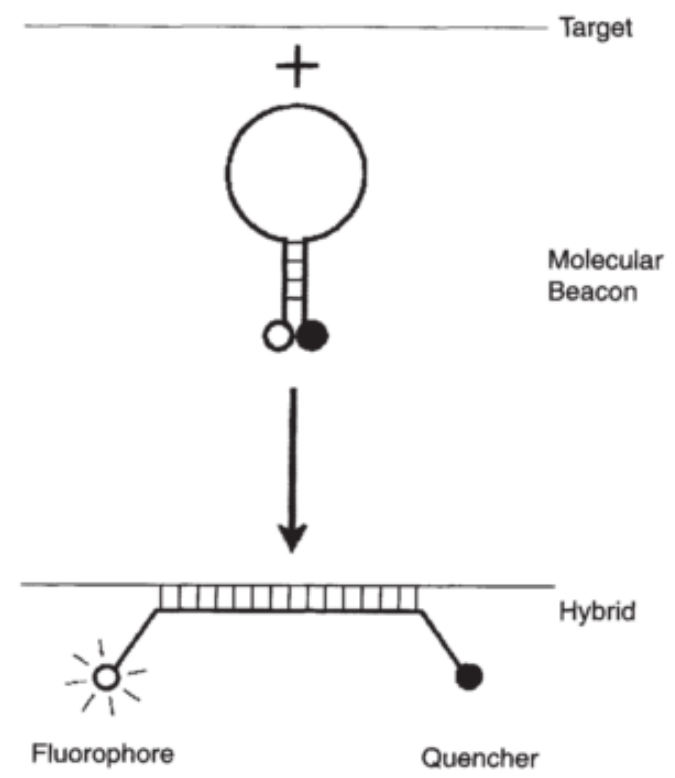

Figure 2-5. Molecular Beacon depiction in closed (top) and template-bound (bottom) forms. In its closed form the fluorophore and quencher are in close proximity thereby minimizing the emitted signal. The binding of the loop region sequence to its intended target complement opens the stem structure and allows for separation of the quencher and fluorophore for an increased signal. Such a signal is reversible through melting of the probe and target complex. Adapted by permission from Macmillan Publishers Ltd: Nature Biotechnology(Tyagi \& Kramer, 1996), Copyright (1996). 


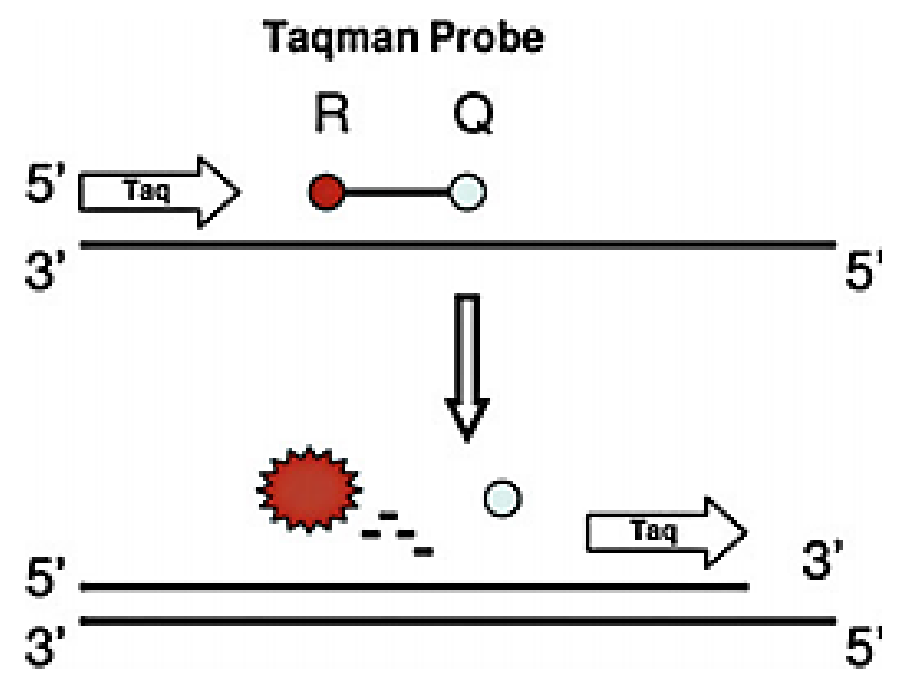

Figure 2-6. Taqman ${ }^{\mathrm{TM}}$ probe detection methodology. The probe binds to a template sequence in a PCR reaction without having a detectable signal. When the primer is bound to the same sequence and the polymerase enzyme extends the primer, the polymerase will excise the Taqman $^{\mathrm{TM}}$ probe by destroying the probe sequence. This destruction separates the quencher from the fluorophore and thereby irreversibly generates a signal. Obtained reprint permission from Springer (licence no.: 3827811053171). (Vohr, 2016) 


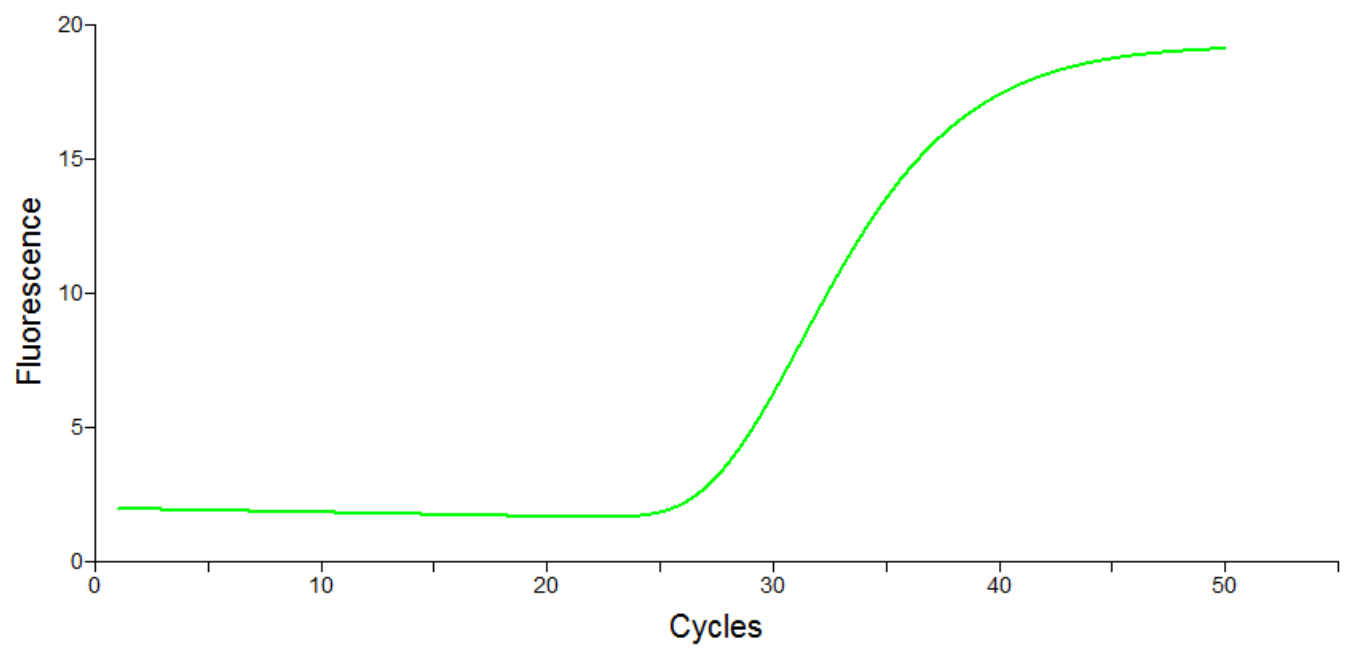

Figure 2-7. A typical real-time PCR signal over the course of a 50 cycle reaction. The monitoring in this instance is performed using an intercalating dye with imaging occurring during the extension phase of the PCR.

\subsubsection{Melting Points of dsDNA for Species Identification}

dsDNA sequences all melt into ssDNA when heated to a high enough temperature to overcome the hydrogen bonding between the strands. This melting phenomenon can be estimated based on the sequence composition but varies based on environmental conditions such as salt concentrations and presence of high Guanine and Cytosine base composition (Owczarzy, Moreira, You, Behlke, \& Walder, 2008). Although intercalating dyes are not specific for a particular region of DNA, they possess an important feature that can help differentiate between different sequences of DNA, the ability to provide melting temperature profiles for sequence analysis (Gudnason, Dufva, Bang, \& Wolff, 2007). This feature is illustrated in Figure 2-8. This figure illustrates the low temperature presence of dsDNA producing a fluorescent signal with an intercalating dye. As the temperature is increased, the dsDNA structure melts quickly when thermal energy overcomes the hydrogen bonding between the DNA strands. This creates a large drop in fluorescence close to a sequence's melting temperature as seen in Figure 2-8A around 85 
degrees Celsius. A negative first derivative of the melting profile produces the melting peak as depicted in Figure 2-8B. This melting peak can be used to specifically identify a DNA sequence in a post-PCR context if resolution of the melting if sufficiently high. High Resolution Melt (HRM) curves can be obtained that can allow for diagnostic differentiation between sequences based on signal base pair mutations in a DNA sequence (Dwight, Palais, \& Wittwer, 2011). This HRM analysis requires significant precision on thermal instrumentation meaning that standard melting curve apparatuses may not be capable of such analysis.

\subsubsection{Factors Affecting PCR Efficiency}

Real-time PCR analysis has shown that there are numerous factors that affect assay performance. These parameters include vessel material composition, salt, primer, and polymerase concentrations (Elenitoba-Johnson, David, Crews, \& Wittwer, 2008; Montgomery \& Wittwer, 2014). If optimal PCR specificity or speed cannot be obtained by varying these parameters there are many additives that can be considered when potentially nefarious conditions are encountered. These include addition of BSA, PEG, or Tween-20 to minimize interactions with glass or other surfaces (Christensen et al., 2007; Michel, Pasche, Textor, \& Castner, 2005). Concentration of real-time probes can also affect PCR efficiency (H. Gudnason et al., 2007). Additives such as DMSO and glycerol can minimize sequence specific problems (Montgomery \& Wittwer, 2014). This is by no means a comprehensive list of PCR reagent optimization and thousands of PCR reaction combinations exist in the literature. 

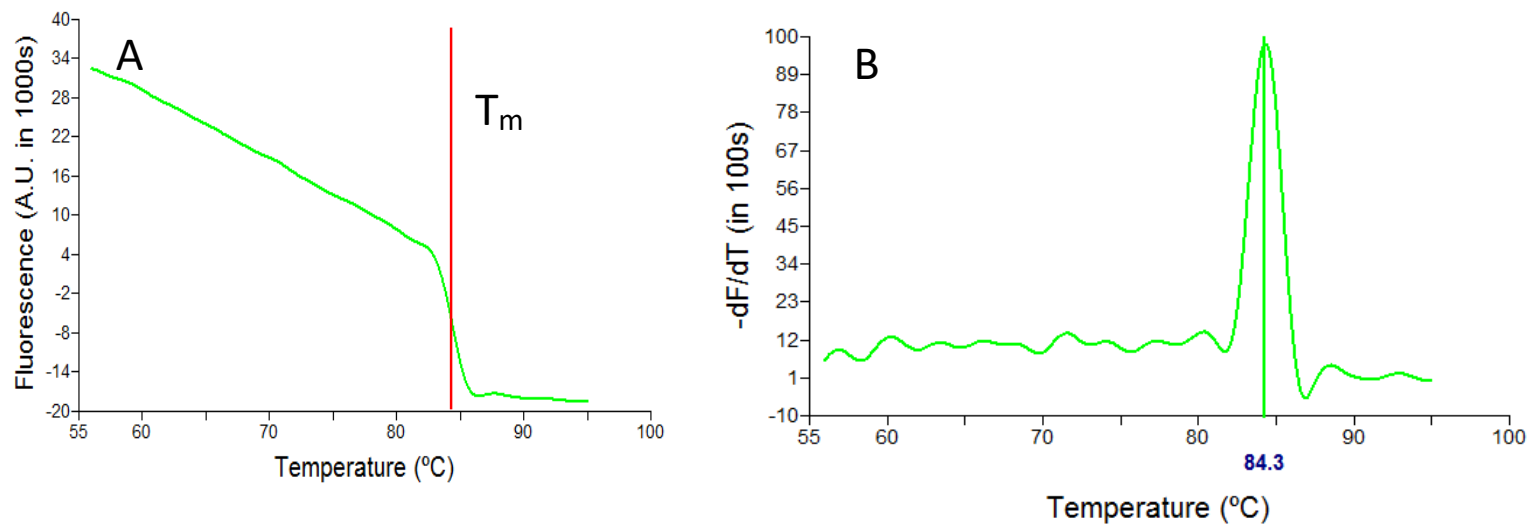

Figure 2-8. (A) Melting profile of a single, high concentration, dsDNA sequence utilizing a DNA intercalating dye. Such a melting profile possesses a sharp drop in fluorescence where the mid-point represents the stage at which half of the original dsDNA is in a melted or ssDNA form. This point is known as the melting temperature or $T_{m}$. (B) Depicts the negative first derivative of the melting profile highlighting the Tm region as a distinct peak.

\subsubsection{Comparison of Thermal cycling methods}

Through better understanding of reaction parameters and tailoring to the requirements of fast kinetics, fast PCR has been performed using many different, improved, thermal cycling devices and sensing techniques. Such devices include many different approaches to heating. An example is photonic based devices which have used gold layers for plasmonic heating (Son et al., 2015). Table 2-1 provides a non-comprehensive list of devices and strategies used for PCR. From a simplistic view point, the basic requirements for real-time PCR include the ability to heat and cool a reaction vessel and the ability to collect a signal reflective of polymerase activity. 
Table 2-1. List of state-of-the-art thermal cycling methodologies and the cycling times associated with the example methodology.

\begin{tabular}{|l|c|l|}
\hline Method & Cycling Time (s) & References \\
\hline Rapid-cycle PCR & $20-60$ & $\begin{array}{l}\text { (Roper, Easley, \& Landers, 2005; Zhang, Xu, } \\
\text { Ma, \& Zheng, 2006) }\end{array}$ \\
\hline Infrared heating & $16-37$ & $\begin{array}{l}\text { (Oda et al., 1998; Roper, Easley, Legendre, } \\
\text { Humphrey, \& Landers, 2007) }\end{array}$ \\
\hline Metal coated capillaries & 40 & (Friedman \& Meldrum, 1998) \\
\hline Closed loop convective PCR & $24-42$ & $\begin{array}{l}\text { (Agrawal, Hassan, \& Ugaz, 2007; Wheeler et } \\
\text { al., 2004) }\end{array}$ \\
\hline Spartan DX-12 & 30 & Data not shown \\
\hline Direct electrolytic heating & 21 & (Heap, Herrmann, \& Wittwer, 2000) \\
\hline Thin film resistive heating & 8.5 & (Belgrader et al., 1998) \\
\hline Ferrofluid loop & 9 & (Y Sun, Kwok, \& Nguyen, 2007) \\
\hline Continuous flow systems & 5.2 & (Hashimoto et al., 2004) \\
\hline LED photonic PCR & 10 & (Son et al., 2015) \\
\hline SPR detection PCR & Depends on & (Pollet, Janssen, Knez, \& Lammertyn, 2011) \\
\hline
\end{tabular}

\subsubsection{Multiplex PCR}

In the basic case described above, only a single DNA target strand is amplified when using specifically selected forward and reverse primers. However, PCR is not limited to only a single target production. Multiplexing can be performed in a single reaction where multiple pairs of primers are used simultaneously (C T Wittwer et al., 2001), each pair targeting a different sequence region. Multiplexing of reactions usually involves the usage of multiple probes that are specific for each separate target (Exner, 2012). Probe signals are typically differentiated through utilization of different types of fluorophores. Equipment limitations generally mean that 3-5 targets can be simultaneously probed in real-time PCR reactions when multiplexing is used (Exner, 2012). 
Multiplex reactions are generally not as simple as throwing all desired target primers into a reaction mixture. The conditions of the different target amplifications need to be characterized as a range of functionality. Once a set of conditions is established that falls in the functional range of all the desired targets, then the reactions can be combined for further optimization. The multiplexed reactions may experience overlapping of primer regions, interference due to non-specific binding of primers, or combinations of primers producing an undesirable product (Elnifro, Ashshi, Cooper, \& Klapper, 2000). To prevent this, sequences of primers must be selected that minimize the potential for unwanted interactions.

An additional challenge of multiplex PCR is mismatched efficiencies of amplification. While all targets may amplify well in single-plex reactions, a target with a slightly higher efficiency may sequester all the resources needed by the other targets present in a multiplex reaction (Elnifro et al., 2000).

Although there are increased challenges in combining different target regions into a single reaction, multiplexing allows for increased diagnostic functionality from a single sample. It also allows for the incorporation of control targets into a reaction thereby permitting calibration of diagnostic results that may not be possible through multiple single target reactions (C T Wittwer et al., 2001). Lowered reagent costs and sample requirements also make multiplexing of PCR an ideal goal when attempting to use such reactions in a POCT setting.

\subsubsection{Asymmetric PCR}

PCR is conventionally performed with nearly equivalent concentrations of forward and reverse primers for amplification of the target region. This allows for the production of equivalent amounts of ssDNA sequences that can form dsDNA. When attempting to detect a mutation or confirm a specific sequence of DNA, target probes are frequently utilized (Sanchez, Pierce, Rice, \& Wangh, 2004). These probes include previously discussed Molecular Beacons ${ }^{\mathrm{TM}}$ and Taqman $^{\mathrm{TM}}$ probes. A problem with
23 I P a g e
Jason Koppert MASc Thesis 
specificity and sensitivity of these probes is their need to compete with the dsDNA complex that is formed when PCR is done symmetrically. This competition, as seen in Figure 2-9, can be minimized through the usage of unequal quantities of the initial DNA primers (Gyllensten \& Erlich, 1988). In the depiction of Figure 2-9, the green ssDNA template is the target of the molecular beacon. If concentrations of the black ssDNA strands are too high then the binding of the Molecular Beacon ${ }^{\mathrm{TM}}$ and the green template will be blocked by annealing of the green and black templates. To prevent this, the green DNA primer can be introduced to the reaction in excess of the black primer. This causes the green and black strand target molecules to be in a ratio that resembles that of the primer concentrations. By increasing the amount of green template through increased green primer concentration, the Molecular Beacon $^{\mathrm{TM}}$ has an increased chance to bind to the green target template and thereby produce a signal.

Usage of forward and reverse primer ratios that are not 1:1 can cause different PCR kinetics and have the potential to lower the efficiency of PCR if improperly designed (Sanchez et al., 2004). When optimized, asymmetric PCR can have the same amplification efficiency as regular PCR. The benefits of using asymmetric PCR also extend beyond using Molecular Beacons ${ }^{\mathrm{TM}}$ or Taqman $^{\mathrm{TM}}$ probes. The overproduced strand can be used in sequencing or could itself be used for probing purposes and may also have the ability to participate in other molecular interactions (Khan, Poetter, \& Park, 2008). 


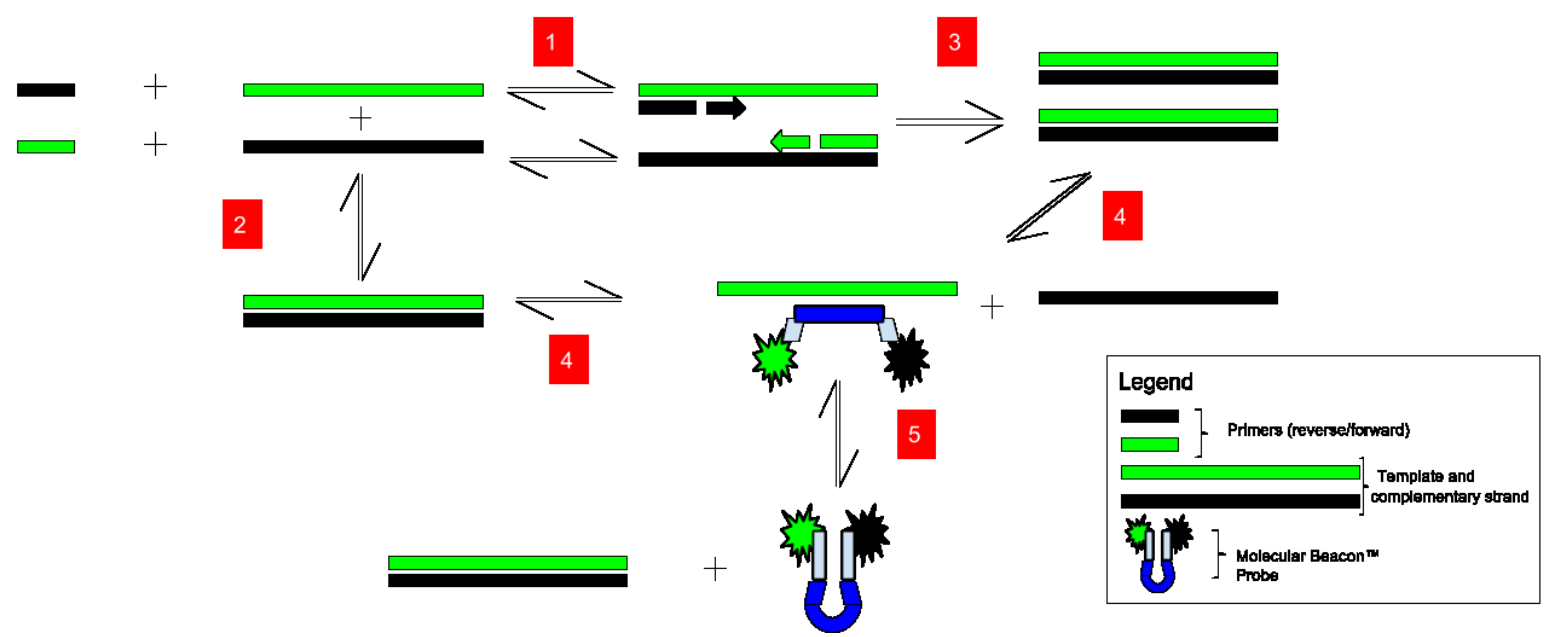

Figure 2-9. Depiction of the major equilibrium interactions present in PCR amplification and detection with a Molecular Beacon ${ }^{\mathrm{TM}}$ probe. The interactions are explained as follows: Pathways (1) and (2) compete. The binding of free floating primers and the corresponding DNA template/complementary strand in the presence of polymerase will proceed irreversibly through (3) to 'consume' the primer. (4) and (5): the probe and template complex competes with the dsDNA formation as well as the probe's closed formation structure.

\subsection{Solid Phase PCR and Microarrays}

Beyond the usage of real-time PCR and multiplexing, a more recent application of PCR pertains to its use with amplification of surface-bound DNA molecules (Adessi et al., 2000). This application of PCR is known as Solid Phase PCR (SP-PCR) and has been shown to be useful for the purpose of SNP detection as well as detection of the presence of a virus (Guo, Guilfoyle, Thiel, Wang, \& Smith, 1994; Yi Sun et al., 2011). This technology adapts its main features from the field of DNA microarray devices.

\subsubsection{Microarrays and Linkage of DNA to Glass}

Microarrays are devices that allow for concurrent detection of numerous DNA targets by spatially separating target-specific probes on a planar surface through printing of the surface with a 
complementary DNA strand. These microarrays can be used for SNP detection and are frequently used for analysis of whole genomes (Heise \& Bier, 2006). The caveat being that microarrays represent a postanalysis step where introduction of purified DNA samples or PCR-produced samples are introduced to a DNA spotted surface. This can be a time consuming and sensitive process, requiring numerous controls.

The DNA probes on microarray surfaces are most frequently printed onto a functional planar surface with a high resolution printer (Heise \& Bier, 2006). Printing of DNA probes onto a planar surface does not itself attach DNA to a surface for usage in a microarray capacity. Generally, a chemical interaction of some form is required to ensure that DNA remains on the microarray surface for target detections. Since microarray procedures frequently involve long incubation periods and multiple rinsing applications, the DNA linkage to the planar surface needs to be rather resilient (Zammatteo et al., 2000). Due to this requirement, there have been many strategies developed for DNA linkage to surfaces such as glass and a variety of polymers.

The majority of strategies for linkage of DNA to a surface can be broken down into several categories. The first category includes the usage of adsorptive interactions (Heise \& Bier, 2006). These interactions can be electrostatic or hydrogen bonding interactions between DNA and a charged or hydrogen bonding capable surface (Heise \& Bier, 2006). These methods of functionalization are frequently criticised for their inability to survive thermal applications or high salt exposures. To increase the stability of the interaction numerous covalent attachment methodologies exist.

For the purpose of an example, consider the application of covalent linkages to glass surfaces. Covalent methodologies with glass generally involve the attachment of organic functional groups through the use of organosilane molecules (Hoffmann, Hin, Stetten, Zengerle, \& Roth, 2012a). This allows for a myriad of organic-chemistry-based, cross-linkage approaches to be performed on the surface (Heise \& Bier, 2006). Such organic cross-linkers create an activated surface that can be 26IPage Jason Koppert MASc Thesis 
introduced to a functionalized DNA oligomer or, alternatively, cross-linkers can be introduced alongside DNA oligomers (von Nickisch-Rosenegk et al., 2005; Xia et al., 2006a). In organic cross-linking methodologies, DNA oligomers generally require end functionalization to participate with activated surfaces. Strategies have been developed that allow for single organic cross-linking processes to be adapted to multiple surface types (Hoffmann et al., 2012a).

A final category of linkage methodologies includes the usage of photochemical cross-linking. These methods include UV curing of DNA onto functionalized surfaces (Dufva, Petronis, Jensen, Krag, \& Christensen, 2004). The mechanism of cross-linking DNA to the surface is unknown but high energy UV is thought to induce bonding between amines in the structure of DNA with hydroxyl groups on the surface of glass (Dufva, Petersen, Stoltenborg, Birgens, \& Christensen, 2006). Such cross-linking can be done between non-functionalized DNA and an amine coated glass surface (Dufva et al., 2004). Alternatively, the cross-linking can be done on a non-treated glass surface when a poly Cytosine/poly-Thymidine tail is introduced on the end of a DNA sequence (Dufva et al., 2006). This method of DNA surface coupling offers the potential for an inexpensive alternative to complex organic chemistry-based cross linking methods.

One of the important realizations of microarray technology is the beneficial incorporation of a spacer between a surface-bound DNA fragment and the surface itself. If the DNA is mounted directly to the surface without a spacer molecule, hybridization of the surface bound DNA is less effective compared to hybridization with a spacer molecule (Guo et al., 1994). Steric hindrance has been proposed as the reason for lowered hybridization when surface linked DNA is too close to a surface (Guo et al., 1994; Halperin, Buhot, \& Zhulina, 2006). 


\subsubsection{Solid Phase PCR}

Solid phase PCR is an incorporation of all of the primarily important aspects of PCR and microarrays as previously discussed. The introduction of PCR with a tethered DNA oligomer differentiates SP-PCR from solution PCR. By performing PCR with primers on a glass surface, signals can be localized on such a surface and can be used to improve signal qualities compared to conventional PCR and microarray testing. In contrast, conventional PCR and microarray-based surface detection are performed in a separate two-step process which can take a significant amount of time while also involving sample transfer (Hoffmann et al., 2012a). The SP-PCR process is illustrated in Figure 2-10. SPPCR requires a few specific differences pertaining to the DNA oligomer coatings of surfaces. Primarily, SP-PCR requires DNA oligomers to be bound to surfaces by the $5^{\prime}$ end of the DNA strand (Adessi et al., 2000). This allows for extension to occur at the $3^{\prime}$ end of the oligomer. A second requirement of the DNA oligomer coating is that it must possess sufficient resilience to thermal cycling treatments. Covalent bonding or UV cross-linking are the only methods that would survive the repetitive cycling between high and low temperatures during PCR (Hoffmann et al., 2012a). Although improved over adsorptive coupling, covalent linkages can be damaged through thermal cycling if the connection to the surface is compromised (Hoffmann et al., 2012a). The most resilient methodology of coating surfaces with DNA for PCR appears to be that of UV cross-linking combined with the poly Cytosine/poly-Thymidine tail on a DNA oligomer (Haukur Gudnason, Dufva, Duong Bang, \& Wolff, 2008). The weak point of most covalent linkages appears to the be aminosilane bond and its sensitivity to surface delamination (Haukur Gudnason et al., 2008).

The molecular spacing requirement for hybridization of microarrays becomes doubly important in the application of SP-PCR. With enzymatic activity occurring near the surface, steric hindrance of the polymerase enzyme itself can prevent the polymerase from operating on surface bound DNA oligomers (Carmon et al., 2002).

28IPage Jason Koppert MASc Thesis 


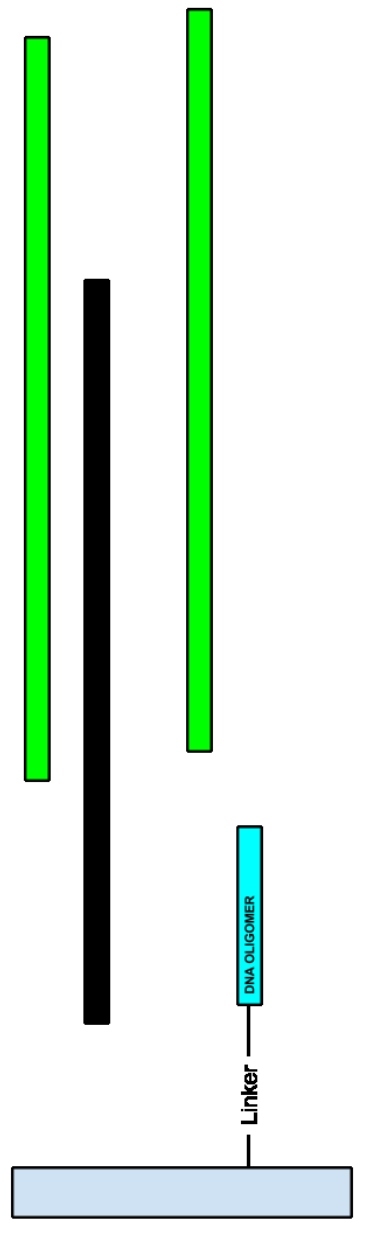

A

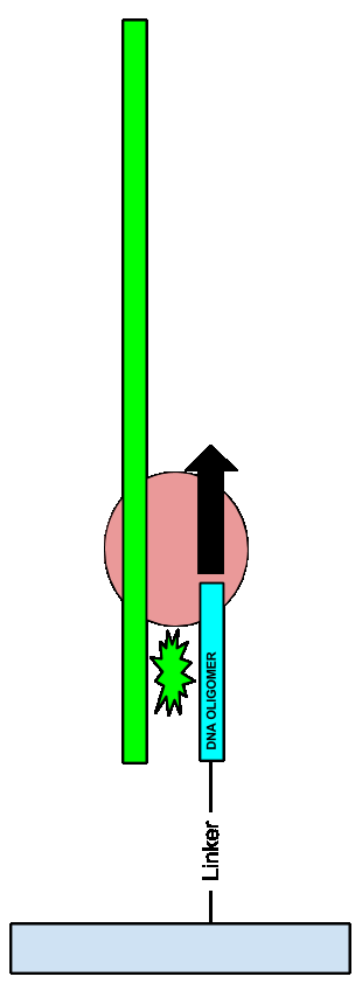

B

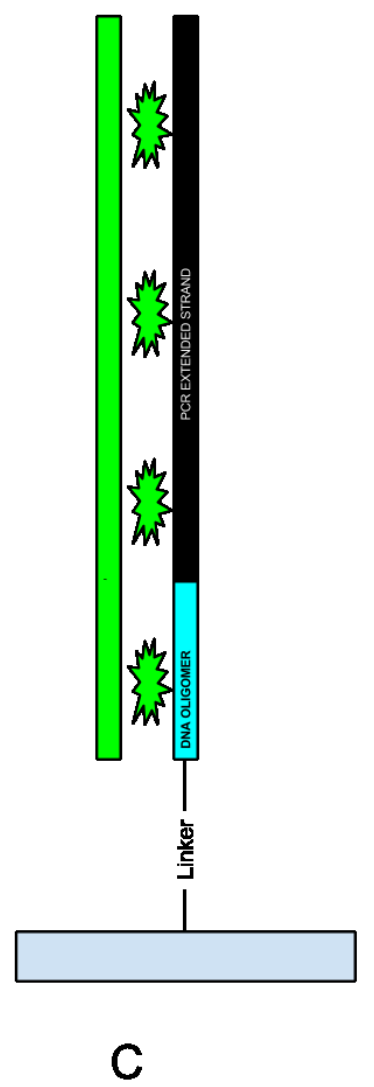

Figure 2-10. Asymmetric Solid Phase PCR (SP-PCR) depicted in crucial steps as they occur in the polymerase extension process. (A) Shows the overproduction of an ssDNA strand in solution through asymmetric PCR, represented here by the green strand. (B) The overproduced template DNA then binds with the surface linked DNA primer and extension occurs through the polymerase enzyme, shown as a red ball. There is some background signal when an intercalating dye is used due to the dsDNA present in the primer/template hybridization region. (C) The post extension product is still bound to the glass surface but now produces a large fluorescent signal when bound to the complementary strand. All three stages depicted here can occur simultaneously when asymmetric PCR is used in the presence of a DNA coated surface. 
SP-PCR has been shown to operate optimally when used in combination with solution PCR (Hoffmann et al., 2012a). Specifically, the use of asymmetric PCR and a single immobilized primer strand allows for the overproduced template strand of asymmetric PCR to more easily bind to its surface bound primer complement (Khan et al., 2008). This allows for extension of the surface-bound primers to occur with minimal interference from the solution PCR. The newly created surface-bound DNA can then be probed through strategies such as fluorophore incorporation or post-PCR probe hybridization (Hoffmann et al., 2012a; Yi Sun et al., 2011).

To date, it appears that real-time SP-PCR has only been performed with fibre optic based systems that utilize a surface plasmon resonance (SPR) effect as opposed to a fluorophore detection system (Pollet et al., 2011). Little work has been done that combines SP-PCR and microarrays (Damin, Galbiati, Ferrari, \& Chiari, 2016).

\subsection{Optical Heating Platforms}

In the search for novel, faster and more economical ways of doing PCR, the use of fibre optic components represents a possible methodology that could allow for the combination of the required assay components such as heating, surface functionalization for multiplexing, and quick thermal cycling for POCT applications. Years of intensive telecom-driven development has led to fibre optic devices being economical and high quality light transmitting devices (Shevchenko et al., 2011). The core technology on which these devices are based is depicted in Figure 2-11. Generally, fibre optics are used for long distance, high quality, low loss, and high speed transmission of light. However, fibre optic devices have also been developed that manipulate light inside of the fibre in ways that allow for probing of molecular phenomenon in the area surrounding a fibre (Albert, Lepinay, Caucheteur, \& DeRosa, 2013). Pertaining specifically to PCR, the most recent development with fibre optic sensors involves the usage of fibres in combination with SPR and SP-PCR (Pollet et al., 2011). In this research, a highly 
sensitive fibre optic device was used to monitor SP-PCR in real-time. To date, this appears to be the only monitoring of SP-PCR in real-time, thereby representing the state-of-the-art in this area.

While using fibres for detection of PCR may represent an interesting approach to monitoring PCR signals without fluorophores, the real promise of fibre optic technology could be in its ability to produce heat using Fibre Bragg Gratings (FBG). FBGs are created in the core of an optical fibre by introducing refractive index perturbations into the core region. These perturbations interact with light, as seen Figure 2-12 by blocking the passage of specific wavelengths of light. The wavelengths of light that interact with the gratings are a function of the gratings periodicity (Jacques Albert, Shao, \& Caucheteur, 2013). The wavelengths reflected are also a function of temperature. As temperature increases, a red shift occurs in the reflected spectra from an FBG while a temperature decrease would produce a blue shift in the spectral peak (Jacques Albert, Lepinay, et al., 2013). Fibre Bragg gratings come in many different configurations for many different applications. Some of these configurations are illustrated in Figure 2-15 to Figure 2-18.

Figure 2-13 represents a standard FBG. Such FBGs have been used for numerous applications including strain, acoustic, and temperature sensing devices (Albert, Shao, et al., 2013). When chirping is introduced in these FBG configurations, as in Figure 2-13B, the spectrum of light reflected towards the source can be increased to resemble an in-fibre mirroring device. Figure 2-13C depicts a tilted variant of an FBG. This tilted FBG (TFBG) allows for redirection of light from the core of the optical fibre to the cladding. This allows for the monitoring of the signal interference based on evanescent field interactions with the solution around the TFBG surface or on molecules attached directly to the surface. Such an interaction schematic is depicted in Figure 2-14.

31 Page Jason Koppert MASc Thesis 


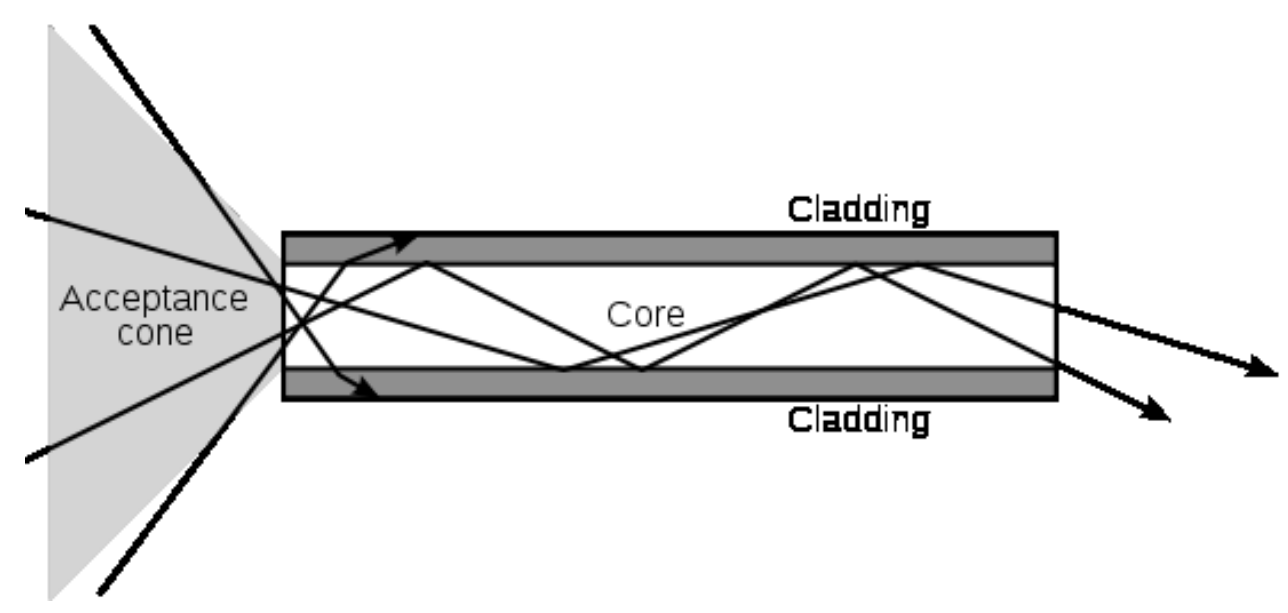

Figure 2-11. Depiction of fibre optic carrying of light. Light that enters the core of the fibre at an acceptable angle, an angle that permits reflection versus transmission, is retained in the core for continued propagation due to the total internal reflection of light at the boundary of the fibre core and the fibre cladding. This total internal reflection is permitted due to the higher index of refraction of the core compared to the index of refraction of the cladding. (c) Gringer 2008. 

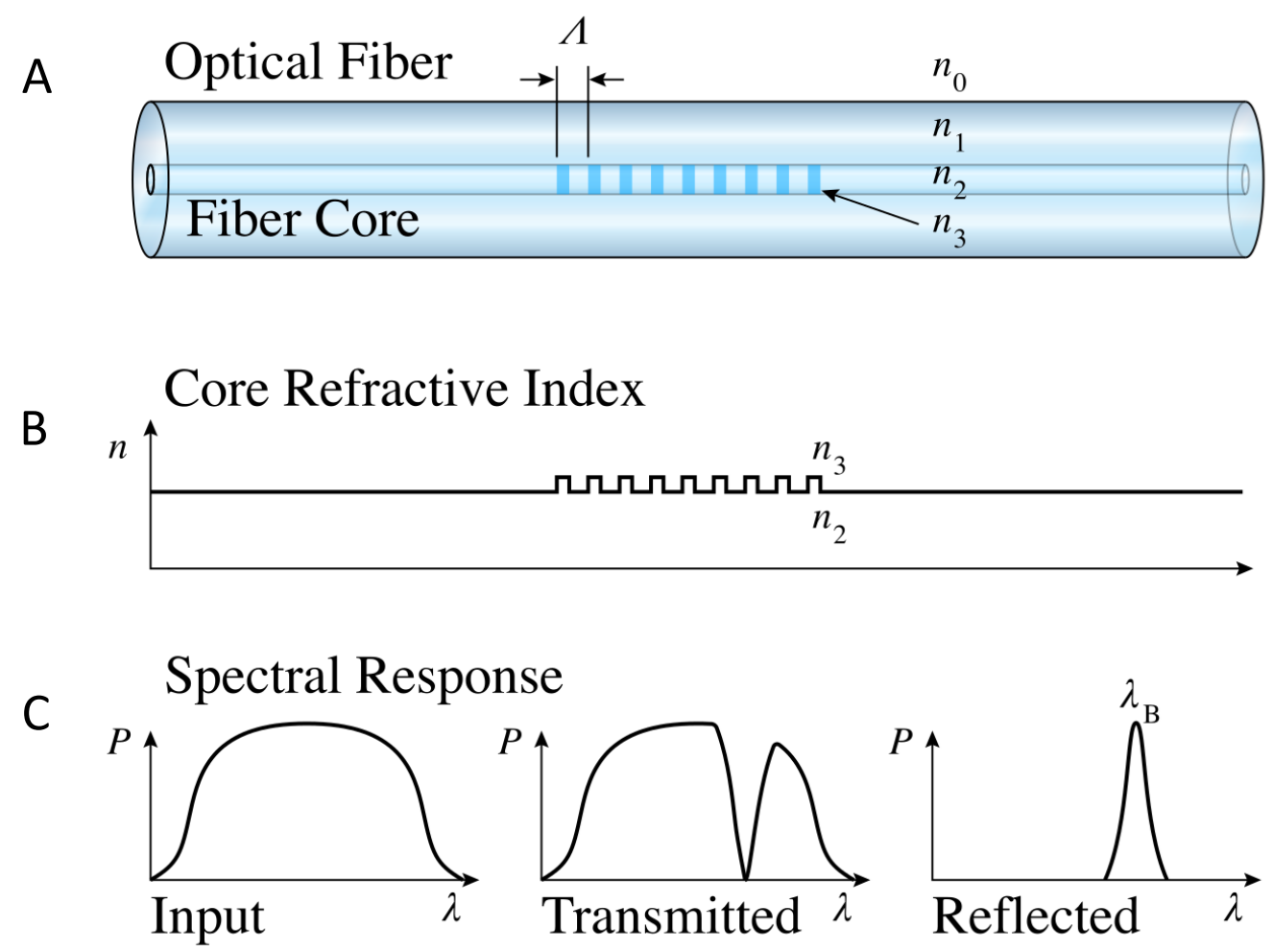

Figure 2-12. Optical fibre function with a Bragg grating written in the fibre core. (A) An FBG written in a fibre optic core. Refractive indices are $n_{3}>n_{2}>n_{1}>n_{0}$, while $\Lambda$ reflects the periodicity of the grating itself. (B) Refractive index in the core of the optical fibre spikes in the grating region periods. (C) Spectral response when monitoring a grating in transmission mode. Similar spectral responses can be generated using a reflection setup provided by a mirror downstream of the grating as depicted in the work of Lepinay et al. (Lepinay, Staff, lanoul, \& Albert, 2014).FBG $($ (c) Sakurambo. (CC BY-SA 3.0) 

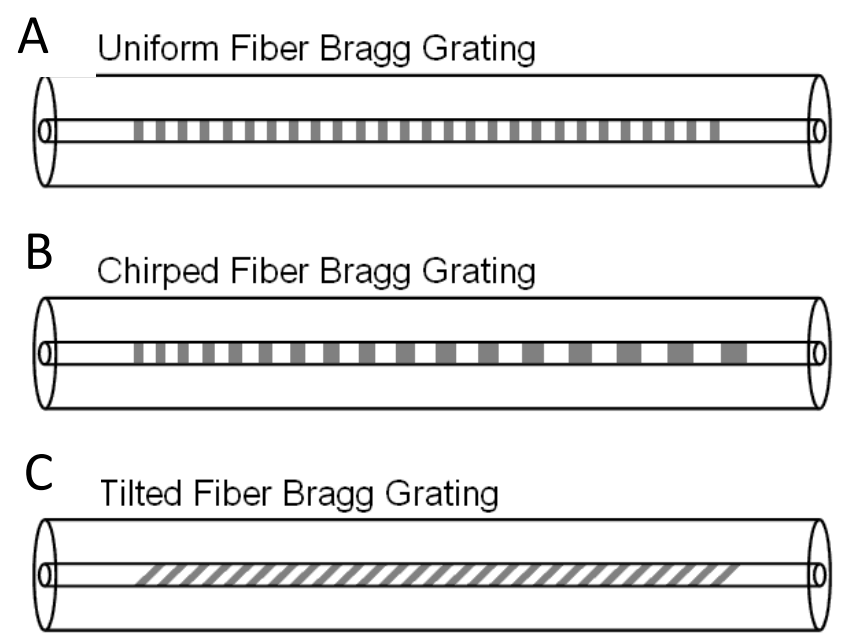

Figure 2-13. Fibre Bragg Grating (FBG) devices that have been used in fibre optic cores. (A) Representation of a standard FBG. (B) Chirped FBG used for large band spectral reflection. Such a grating can also replace a mirror and therefore be used in combination with an in-fibre grating. (C) Tilted Fibre Bragg Grating (TFBG) capable of coupling light of a desired wavelength out of the fibre core. FBG3.gif (c) Grahamwild. (CC BY-SA 3.0). 


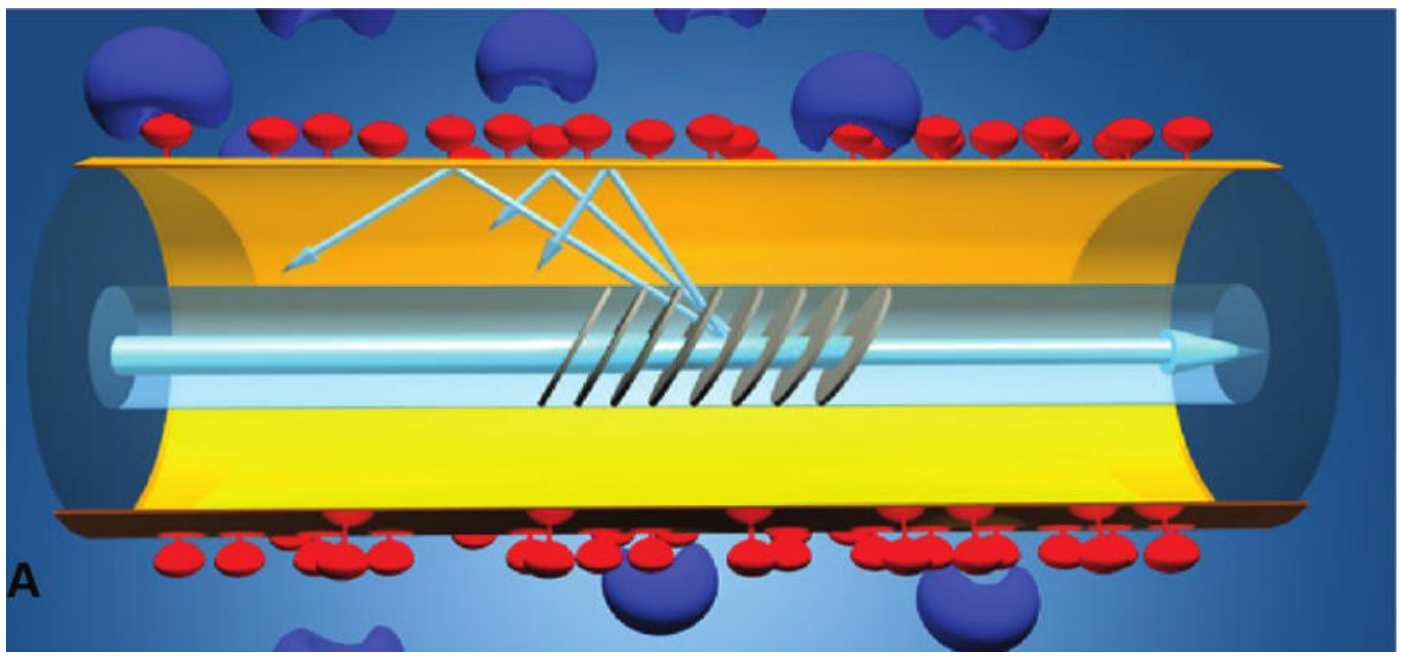

Figure 2-14. TFBG surface interaction probing mechanism. Light is diverted from the fibre core through interaction with the tilted grating. This light can interact with the surface of the optical fibre. Reprinted with permission from (Shevchenko et al., 2011). Copyright (2011) American Chemical Society.

\subsubsection{Fibre Bragg Gratings in Wind Anemometers}

Recently, fibre optics have been used as hotwire devices by using laser-based heating of a target area on the fibre surface. One of the first uses of such hotwire FBG devices is in the field of wind anemometers (devices that monitor wind speed). These anemometers use fibres with laser heating and spectral monitoring to analyse the cooling response of airflow over a fibre surface. This allows a translation of temperature readings into a quantitative wind speed measurements. An FBG device is used within the anemometers to both create the heat and monitor the temperature. The basic principle of a wind anemometer uses a laser source that allows for heating to occur in the fibre around an FBG while airflow around this FBG region causes a blue shift in the fibre optic probing (Cho, Lu, Zhang, \& Tam, 2013; Gao, Zhang, Tam, Cho, \& Lu, 2011; Wang et al., 2013, 2014; Xinyong Dong, Yan Zhou, Wenjun Zhou, Jia Cheng, \& Zhongdi Su, 2012). Figure 2-15 depicts a typical wind anemometer testing setup for fibre optical devices as used by Wang et al. (Wang et al., 2013). The most important aspect of the wind anemometer device is the heating capacity of the fibre optic components that is specific only 
to the target region. There are several different strategies for heating an FBG region with a laser source. Figure 2-15 depicts a fibre that couples laser light from a fibre core to a fibre cladding by introducing a 'free space' region in the form of a no-core fibre segment (Wang et al., 2013). This design involves the use of a silver film for absorption of laser light to convert into heat.

Figure 2-16 and Figure 2-17 depict the same usage of silver coatings for FBG region heating with a core offset and bitaper coupling mechanism respectively. Another option for a fibre heating mechanism is represented by Light Absorption Fibre Devices (LAFDs) as seen in Figure 2-18. This option uses an FBG inscribed in a fibre that is doped with cobalt or neodymium (Gao et al., 2011). By having laser light interact with a light absorbing fibre fragment, light does not need to be coupled out of the core and losses of light can be minimized through increased simplicity of manufacturing.

Regardless of the fibre heating mechanism, the spectral blue shift based on temperature changes allows for the quantitation of wind speed. The spectral readouts from a typical spectral shift and the calculated wind speed values are depicted in Figure 2-19. 


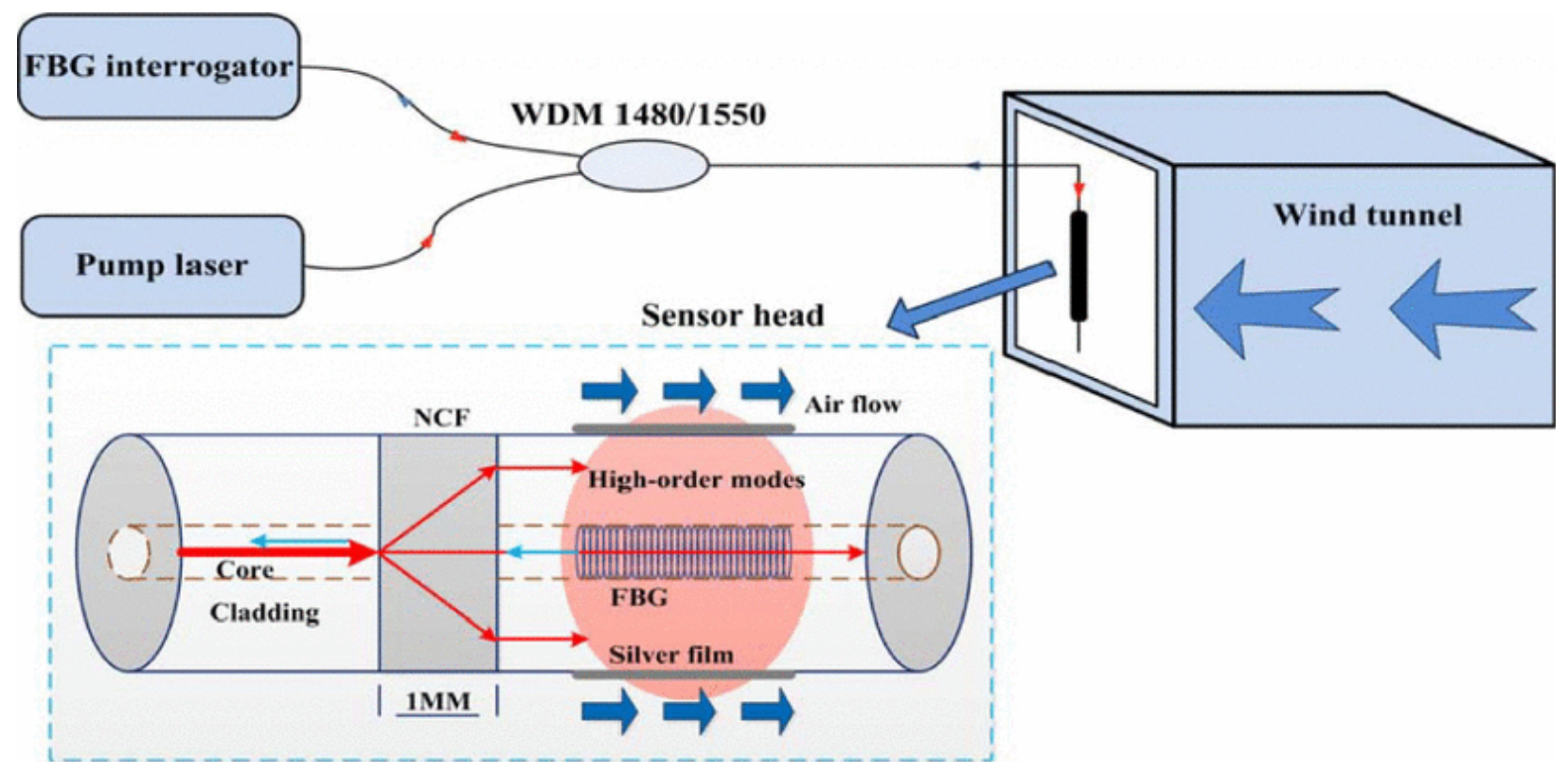

Figure 2-15. Fibre wind anemometer device apparatus using a fibre FBG with a No Core Fibre (NCF) segment. The NCF segment allows for the partial coupling of IR light to the cladding of the fibre for interaction with the silver film to allow heating of the silver film region. This configuration continues to permit light reflected by the grating to return to the detector. The examples of anemometers in Figure 2-16, Figure 2-17, and Figure 2-18 are all used in this wind tunnel and laser/interrogator setup depicted here (Wang et al., 2013) @ 2011 IEEE. 


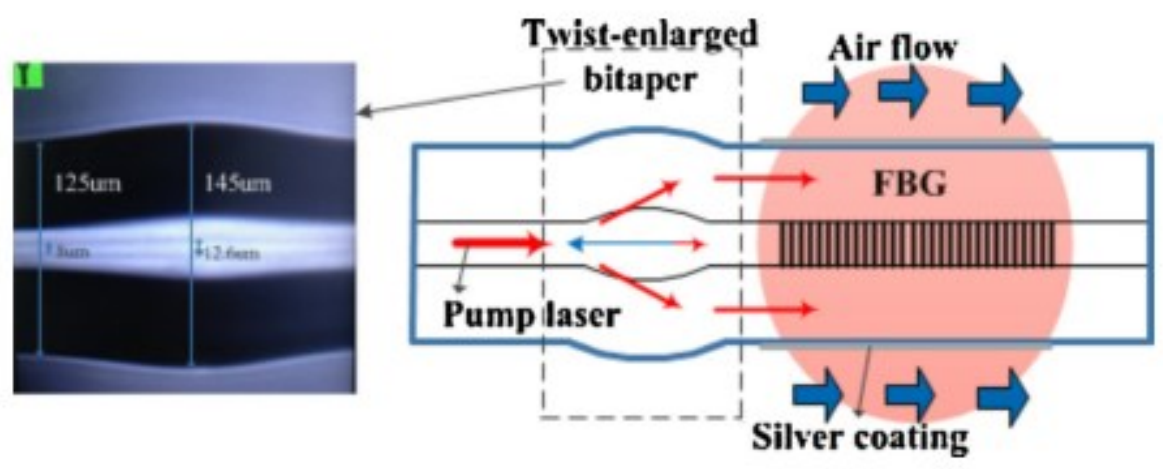

Figure 2-16. Fibre wind anemometer device based on a twisted enlarged bitaper splicing. The bitaper splicing produces a bulge light region in the fibre core that permits partial coupling of light towards the silver film coated region for heating. Reprinted from (X. Wang et al., 2014) with permission from Elsevier.

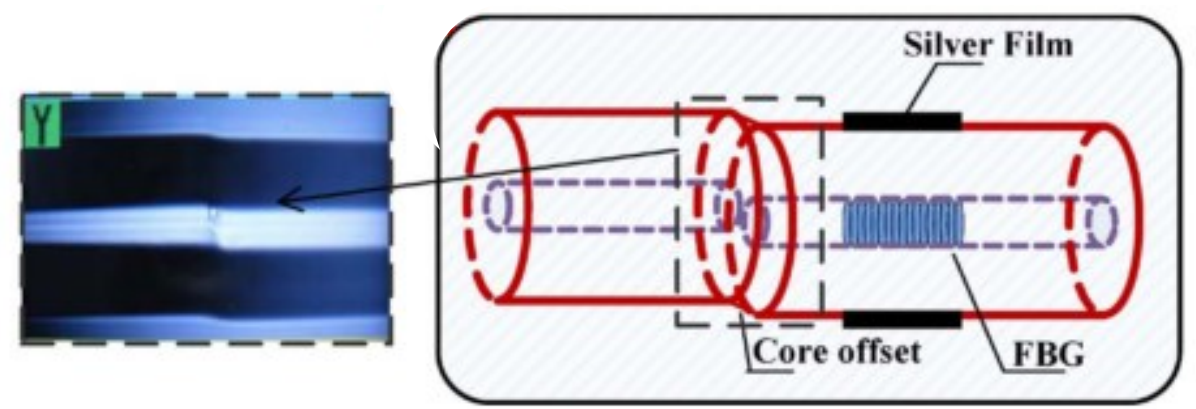

Figure 2-17. Offset coupling mechanism for fibre based heating in a wind anemometer device. The offset coupling permits partial loss of IR light from the fibre core that can then interact with the silver film to produce heating (Xinyong Dong et al., 2012). (C 2012 IEEE. 


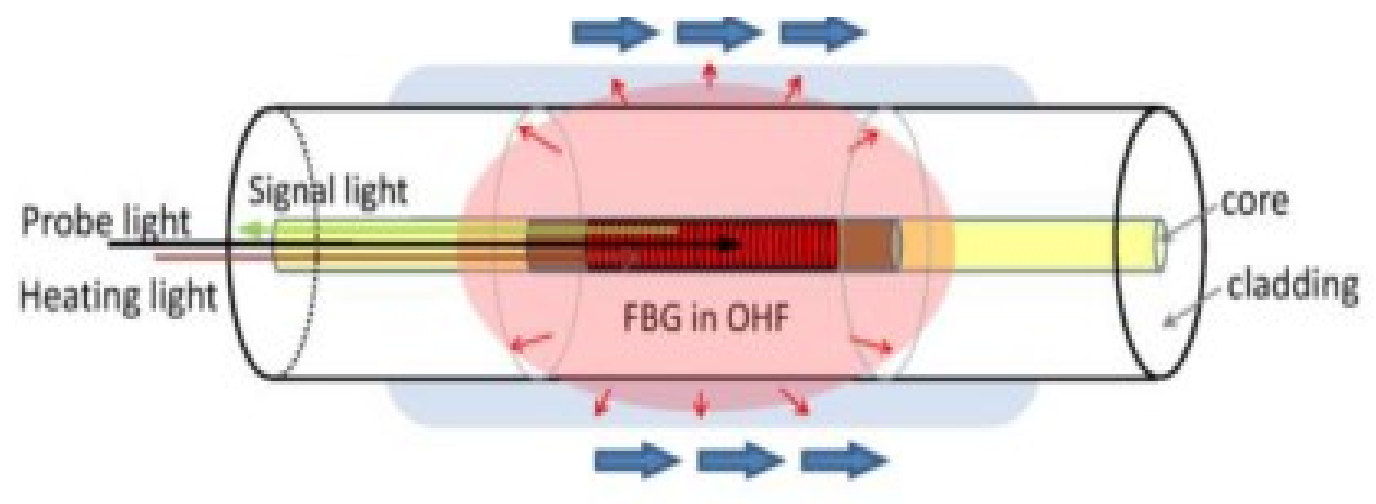

Figure 2-18. Light absorbing fibre device configuration for a wind anemometer. This device configuration does not require a metallic surface coating but does require a segment of doped optical heating fibre $(\mathrm{OHF}$ ) to be inserted between segments of non-doped fibre to localize heating to the OHF region (Gao et al., 2011). 


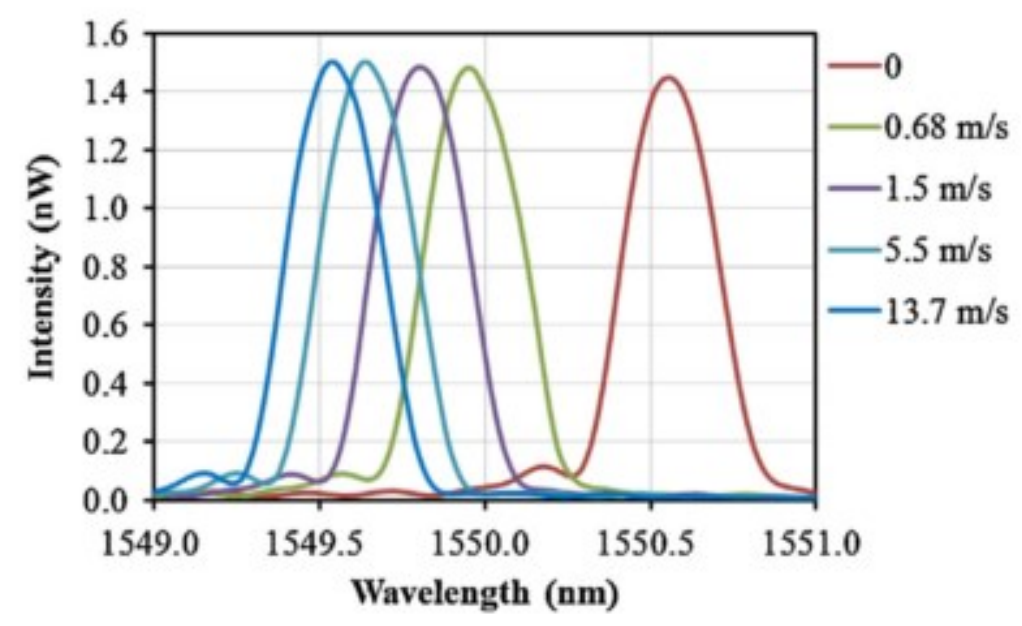

Figure 2-19. Basic measurement principle of a fibre optic wind anemometer device. IR light is pumped at a relatively high power to produce heat in the FBG region. This produces the peak found at 0 when airflow is absent. This peak is the source reflection returned by the grating written in the fibre core. This peak generation is shown in Figure 2-12. As airflow increases in speed over the surface of the heated FBG region, cooling of the region will blue-shift the spectral peak. This blue-shifting allows for a spectral peak conversion into a wind-speed determination. Any of the presented wind anemometer devices will operate in this manner. Reprinted from (X. Wang et al., 2014) with permission from Elsevier.

\subsubsection{Optical Heating for Molecular Diagnostics}

For the purpose of molecular diagnostics, the most relevant aspects of a wind anemometer are the heating and temperature monitoring aspects. By using the heating functionality demonstrated through wind anemometers, precise temperature control and measurement could allow for adaptation of SP-PCR to fibre optic surfaces. In addition to heating a specific region of an optical fibre by using FBGs or TFBGs, the combination of the coupling mechanisms can function with different wavelengths of light. Effectively, any light travelling through the fibre core could be coupled out towards the fibre surface. In this way it is possible to simultaneously couple both light for heating and fluorescence excitation through a single fibre optic device ( Albert, lanoul, Aliaksandr, \& Bottomley, 2015). 


\section{Research Goals}

Here we propose the combination of utilizing fibre optic based heating devices with SP-PCR for the purpose of achieving a small volume, ultrafast, and multiplex-capable device for molecular diagnostics. Such a device should allow for small reaction volumes and small vessel components by utilizing inexpensive fibre optic technologies.

As a subset of the proposed combination project, this thesis will address the goals of: developing an economical DNA coating for fibre optic devices, DNA amplification with confirmation of this amplification on a fibre device surface, and lastly, development of an optical fibre hotwire device capable of internal excitation of fluorescence and Real-Time monitoring of SP-PCR.

When such a device is combined with Spartan Bioscience's buccal swab sample approach, usage in POCT settings would be an optimal application. Three separate contributions are made towards achieving this goal: Firstly, the development of DNA coatings compatible with fibre optic technology is presented in Chapter 4. Secondly, the development of a molecular diagnostic assay that can assess the compatibility of fibres with SP-PCR is presented in Chapter 5. Thirdly, the development of hotwire fibre optic technology, in the context of SP-PCR will be presented in Chapter 6 . 


\section{DNA Coatings Compatible with Fibre Optic Devices}

\subsection{Introduction}

To begin the development of an SP-PCR fibre device, optical-fibre compatible DNA coatings are required. This chapter will concentrate on the experimental assessment and innovation of several approaches for such DNA coatings that we performed in a research setting. The key focus of the coatings portion of this chapter pertains to the search for an economical and reproducible coating methodology that would allow for high throughput experimentation with PCR. Silane-PEG derivatives, DSC (Dissucinimydl Carbonate), EDC (1-Ethyl-3-[3-methylaminopropyl]carbodiimide hydrochloride), and UV cross-linking will be presented and compared in the context of coating fibre surfaces with DNA.

As mentioned above, there are several existing examples of DNA oligomer coatings on the surface of glass fibres. However, few of these methodologies are both compatible with the goal of doing SP-PCR on a fibre device and the economy of application. Several coating methodologies and their associated innovations will be experimentally assessed and compared.

A key focus of this chapter is the feasibility of DNA coatings for application in available lab resource settings. A mass producible medical device for genotyping should be economical and reproducible while being easy to manufacture in the research and development stage. Early successes with a proof-ofconcept device on a minimal budget would allow for future funding and establishment of a dedicated industrial research team. These device requirements mean that the coating of fibre devices should adhere to the same guidelines in order to make a proof of concept device feasible. Work done to create the contents of this chapter operates under the hypothesis that a functional DNA coating must be created economically for the glass fibre surfaces.

42IPage Jason Koppert MASc Thesis 


\subsection{Methods}

The principle contribution of this chapter involves the experimental assessment of DNA coatings on the surface of optical fibre fragments. Ultimately, four different coating technologies were assessed: SI-PEG-FITC, DSC, EDC, and the UV cross-linking. Since standard optical fibre (Corning SMF-28) is highly economical, the use of non-functional fibre fragments allow for lower cost experiments with higher throughput. In the process of developing a fibre-optic-compatible coating, viewing apparatuses were optimized to accommodate the involvement of biological assays. Early experiments in this research made use of fluorescence microscopy (Zeiss Axio Imager M1), which was the most reliable existing methodology for examining fibre coatings. The basics of which can be seen in Figure 4-1. Microscopy slide preparation is further detailed in Appendix A.1.

This microscopy imaging produced high quality images but was unable to do real-time in-solution measurements due to the requirement for glass-slide-mounted samples. To solve this problem, a secondary optical system was developed by Hubert Jean-Ruel. This system can be seen in Figure 4-2. This system was not fully functional during the development and testing of the SI-PEG-FITC, DSC, or EDC coating methodologies. However, for UV cross-linked coatings, which was the last coating technology assessed, all results were collected on the system of Figure $4-2$, as soon as it became fully operational. Figure 4-2 depicts a 3-dimensional rendering of the prototype viewing apparatus for optical fibre coatings. Coated fibres were viewed in a disposable glass capillary tube that was filled with any number of solutions including those involved in real-time assays. The positioning of fibres within the capillary tubes could be adjusted in 3 dimensions as well.

Fibre fragments were coated with one of the follow methods: SI-PEG-FITC, DSC, EDC, or the UV cross-linking. Each of these methods is specifically detailed in the Appendix A.1. The SI-PEG-FITC, DSC, and EDC coating methodologies were all initially tested by using fluorescing coating molecules. SI-PEG-

43 IPage Jason Koppert MASc Thesis 
FITC utilized the fluorescent molecule depicted in Figure 4-3. Figure 4-3C represents the fluorophore that would have been replaced with a DNA oligomer if the methodology had been viable. The fluorescent coatings of DSC and EDC methods were obtained through a fluorescently labelled DNA oligomer of the schematic in Figure 4-4.

It was important to establish the functionality of DNA once attached to the glass. To test the functionality of the DNA on the surface of the fibres coated using DSC, EDC, or UV cross-linking, a hybridization assay was developed (Note: at this point SI-PEG-FITC had been deemed a non-viable coating approach). This hybridization assay is illustrated in Figure 4-5. Non-fluorescent DNA oligomers on the surface of the fibres replaced the fluorescent oligomers of Figure 4-4. These oligomers would have no detectable signal after initially coating a fibre. To detect the presence of these non-labelled DNA oligomers, a fluorescent probe (complementary to the surface bound DNA) would be introduced by placing the fibre in a buffer solution containing the dissolved probe. After a few minutes of incubation, removal of the fibre would allow for microscopy viewing to confirm the hybridization success. Further details of the hybridization assay and buffer components are given in Appendix A.1.

The SI-PEG-FITC, DSC, and EDC coating methodologies were all examined through fluorescence microscopy as presented earlier. This meant that the DSC and EDC coatings could not be analysed in solution or in real-time due to the requirement of glass slides as a mounting platform. To overcome this challenge, a process was developed that could allow for assays to be performed and their results analysed after the assay was finished. The schematic can be seen in Figure 4-6 and involved coating a smaller region of the fibre end than was submerged into a hybridization assay solution. This allowed for measurements to be made to locate a boundary region of coated versus non-coated fibre areas. High contrast between coated and non-coated areas indicated a success of hybridization.

44 Page Jason Koppert MASc Thesis 


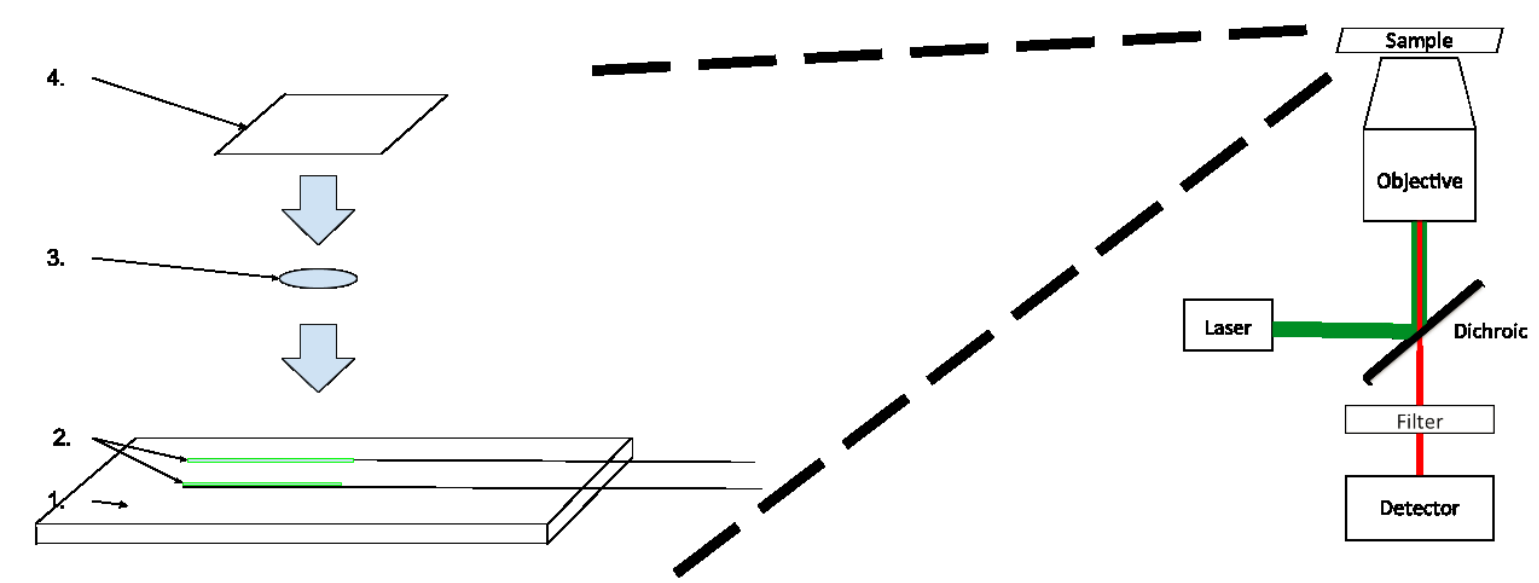

Figure 4-1. Simplistic microscopy apparatus illustrating the setup used to examine fibre optic coatings during the initial phase of the project. The sample slide (1) would be used to mount coated fibre fragments (2). A glycerol based medium (3) would then be placed on top of the fibres and covered with a glass coverslip (4). This slide would then be placed onto the microscope stage for viewing. Modified from Mllynk 2012 (CC BY-SA 3.0). 


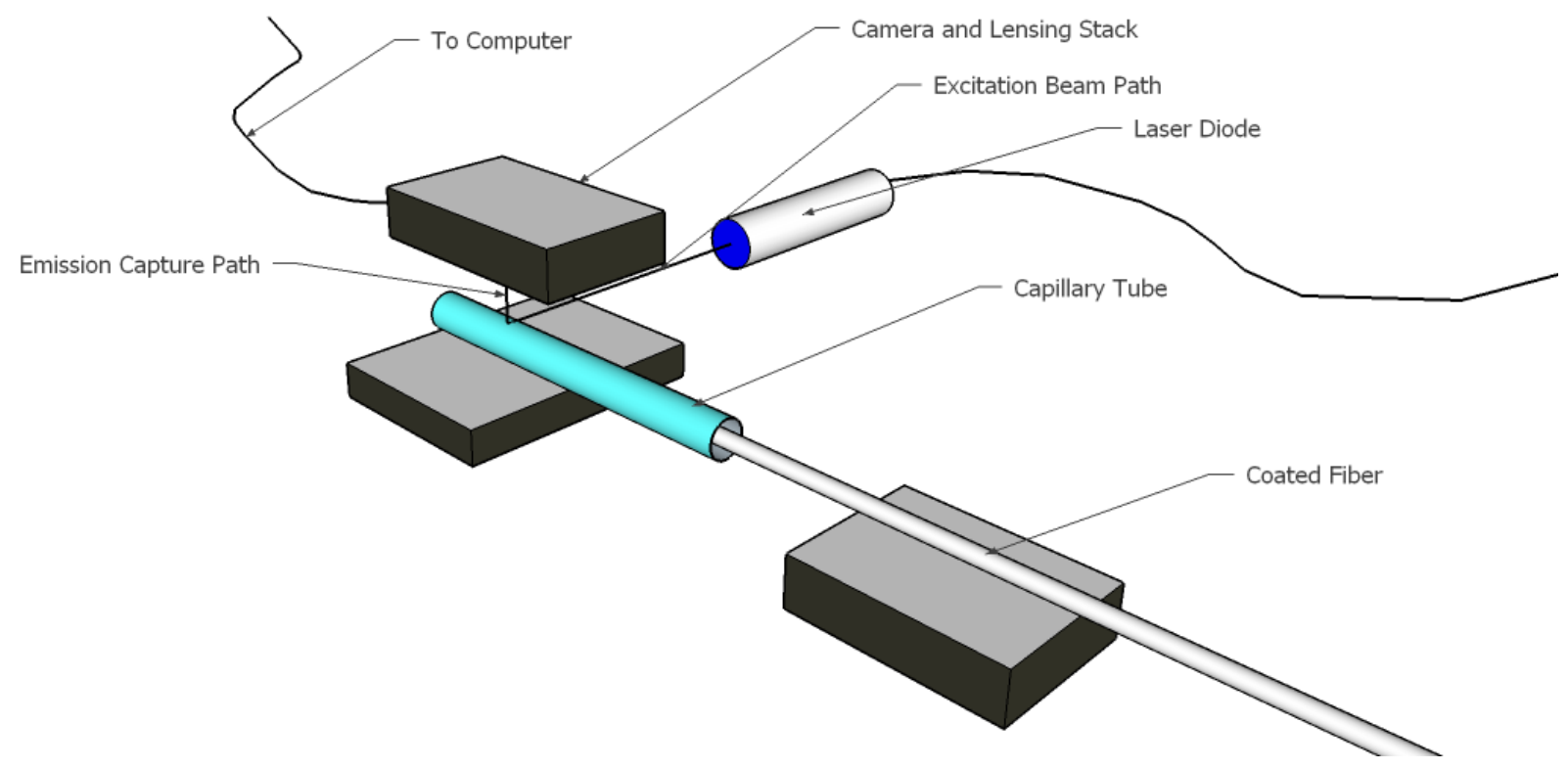

Figure 4-2. Fibre imaging analysis setup used for direct in-solution imaging of coated fibres. This in solution imaging represented enhanced handling of fibres with comparable image quality to fluorescence microscopy. The capillary tube is used to hold liquid around a coated optical fibre with the potential for real time monitoring.

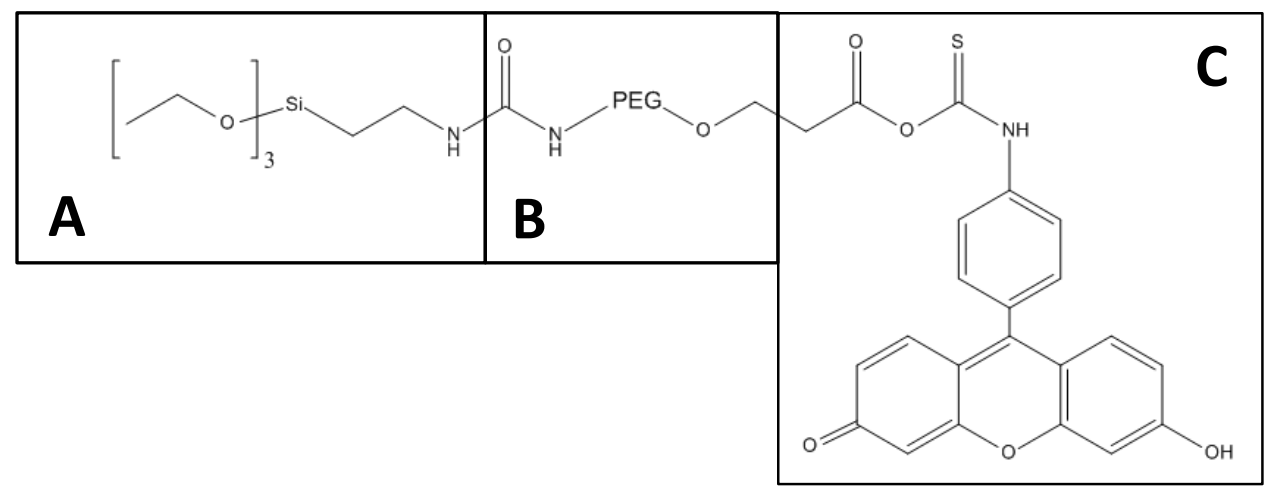

Figure 4-3. Chemical structure depiction of the Si-PEG-FITC molecule. (A) Glass surface reactive entity. (B) Linkage spacer consisting of end functionalized polyethylene glycol (PEG). (C) Fluorescent entity represented here by fluorescein isothyiocyanate. 


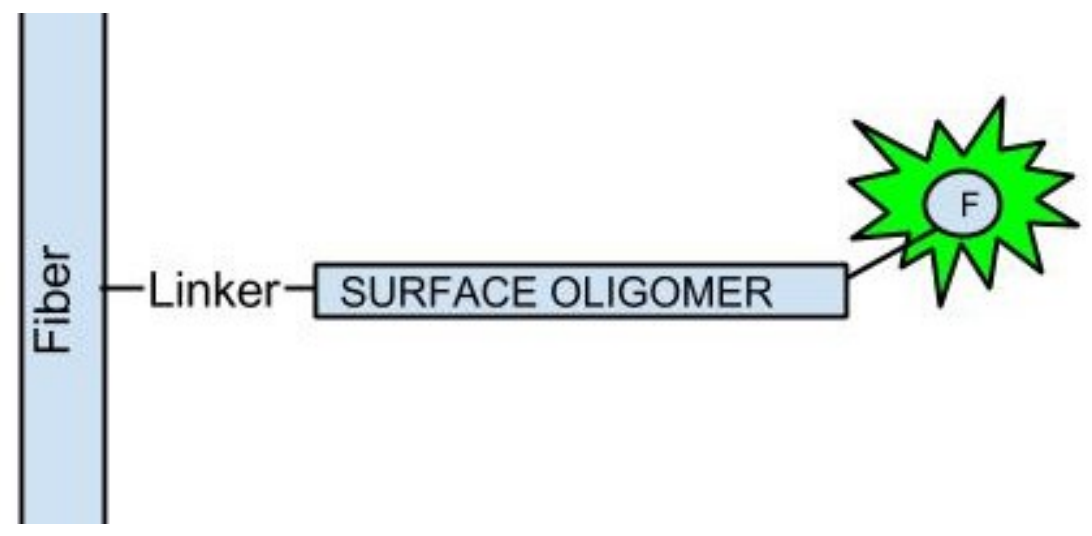

Figure 4-4. Positive control oligomer as used with several coating methodologies for the purpose of direct visual confirmation of coating success. The oligomer has the directionality as an SP-PCR primer would be required.
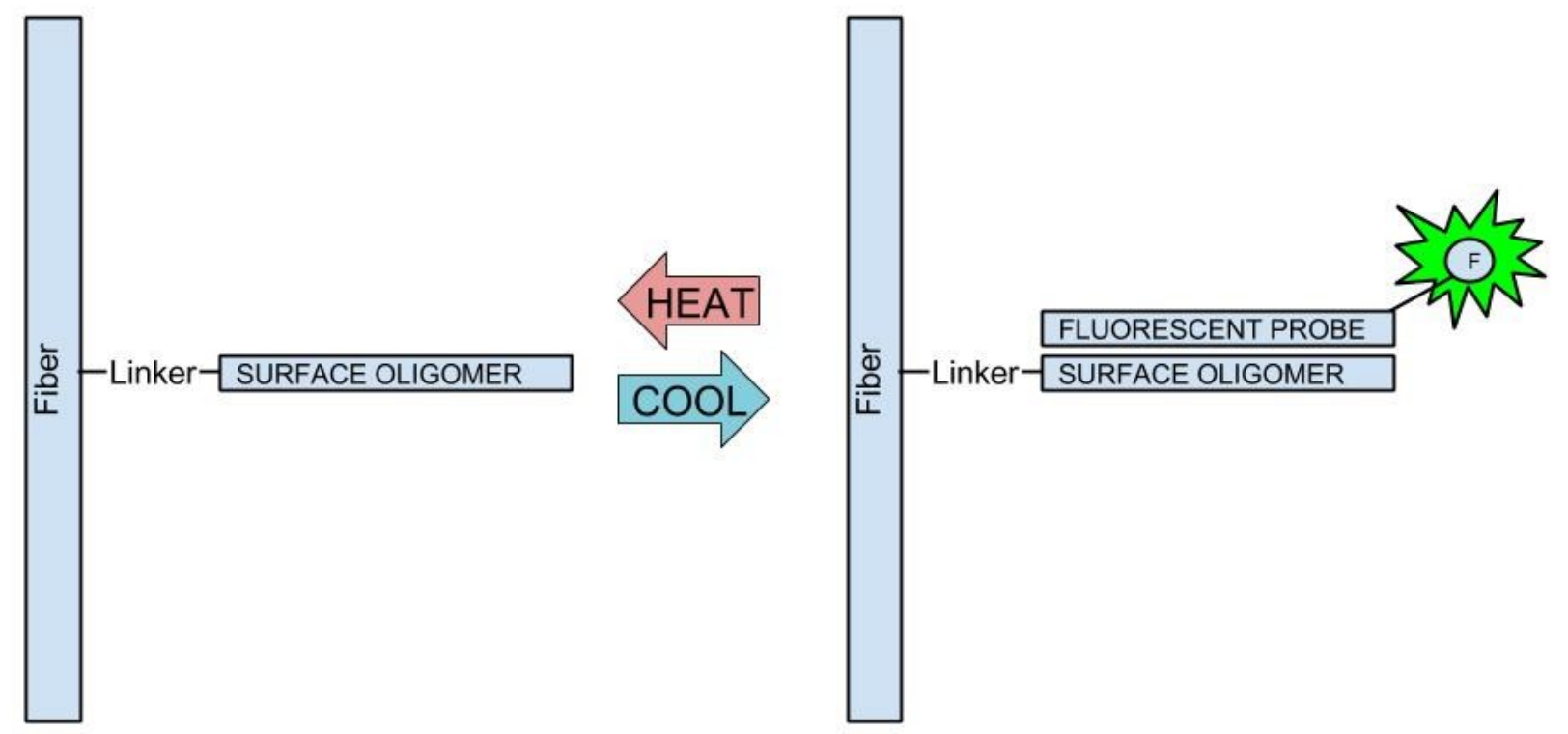

Figure 4-5. Depiction of indirect coating success detection. A fluorescently labelled antiparallel DNA oligomer is brought into hybridization with the surface bound oligomer. This fluorescently labelled oligomer can be removed after checking surface coatings for success. The removal of the probe could be performed thermally or chemically through the introduction of a basic solution. 
$20 \mu$ submerged region

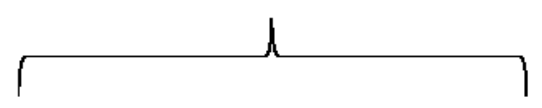

\begin{tabular}{|ll|}
\hline & Optical Fibre \\
\hline
\end{tabular}

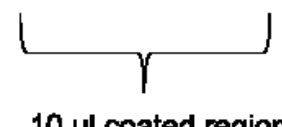

$10 \mu \mathrm{l}$ coated region

Figure 4-6. Inherent control mechanism used to establish an adjacent positive and negative control in fluorescence microscopy. This allows for a more distinct frame of reference and helps to control the amount of variance seen in fluorescence imaging. Effectively, a smaller area was functionalized with DNA relative to the area exposed during the hybridization of a fluorescent probe complement.

\subsection{Results}

The following section presents results from the assessment of four different coating methodologies: (1) Fluorescent Silane-Poly-ethylene Glycol entities (2) Fluorescent DSC coatings and DNA hybridization (3) EDC coating and positive control exploration and (4) UV cross-linking of DNA and hybridization. The final sub-section of the results will compare the key qualitative aspects of the coating methodologies regarding their applications to the proposed proof-of-concept device.

\subsubsection{Coating Option I: Silane Poly-ethylene Glycol Coatings}

The first approach to attempting DNA oligomer coatings on the surface of glass fibres involved simplifying the attachment process. Based on functionalization methods previously mentioned in 
literature as well as the requirement for a spacing molecule between the glass and the DNA substrate, a silane derivative molecule was designed by Spartan Bioscience Inc. and Biosearch Technologies Inc. with the intention of having a single step coating process. The assessment of this strategy was performed with a glass reactive molecule as depicted in Figure 4-3 (Adessi et al., 2000; Schlingman, Mack, Mochrie, \& Regan, 2011). This molecule contains a surface reactive component, Figure 4-3A, in the tri-ethoxy silane functionalization entity, while also containing a PEG spacing molecule as shown in Figure 4-3B. A FITC fluorophore, Figure 4-3C, is used in the position where a DNA oligomer would be incorporated into such a surface attachment strategy. Initial testing of the feasibility of the silane PEG functionalization was performed with the fluorescence analog in order to assess coating success through the visibility of fluorescence on a glass fibre surface. The visible assessment of fibre fluorescence was performed on glass slides as seen in Figure 4-1.

The functionalization of glass fibre surfaces was clearly successful based on the microscopy images that were collected during fibre examination. Figure 4-7 depicts a standard, bare glass, SMF-28, fibre in contrast to the same fibre surface coated with the SI-PEG-FITC molecule. As viewed with primitive preliminary optics in Figure 4-8, the fluorescence is easily viewed with a simplistic optical setup and development board camera (The Imaging Source Cat. No.: DFM 72BUC02-ML). Since fibres were coated through a simple dipping of the fibre into a solution of the fluorescent molecule, the dipping depth could be measured and this region could be inspected to provide a non-fluorescing, negative control region for the fluorescence assessment. This region of coated against non-coated fibre surface is clearly visible in Figure 4-9.

In terms of ease of application, this coating methodology is quite simplistic. The cleaning of fibres and then direct exposure to a solution of Si-PEG-FITC represents the extent of the coating process. However, the coating success is related to concentration of the functionalization molecule in a solution 49 I Page Jason Koppert MASc Thesis 
of DMSO. Figure 4-10 depicts the effect of concentration on the ability to saturate the fibre surface with fluorescent molecules. Saturation of the surface requires concentrations above $100 \mu \mathrm{M}$. This represents a challenge from an organic synthesis perspective due to the high costs of synthesizing and purifying the required quantities of the molecular entity.

An additional concern with this single step coating is product shelf life. As Figure 4-3A depicts, there are reactive silane groups on the terminal end of the molecule. These groups are reactive with water as well as glass and will therefore eventually self-polymerize over time. This creates handling issues as the dissolution of small quantities of powder introduces concentration variances into the coating process. Upon dissolution, the shelf life of the molecule is drastically reduced from several months to several days. 


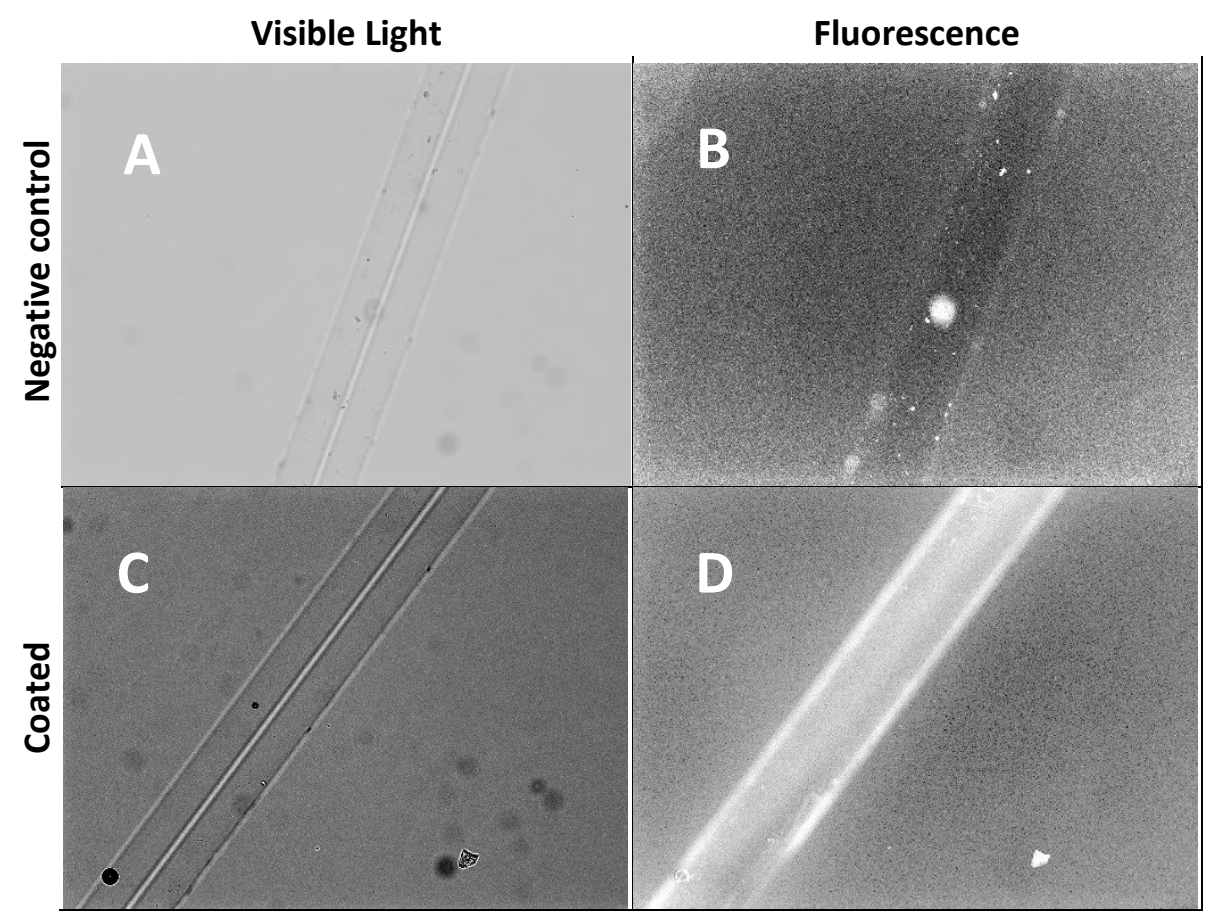

Figure 4-7. Comparison of a Si-PEG-FITC coated fibre (C, D) against an uncoated negative control fibre (A, B). Visible (A, C) and fluorescence (B, D) images are displayed for each fibre demonstrating the apparent fluorescence of the Si-PEG-FITC coated fibre relative to both a negative control and a visible image of the same fluorescent fibre. Note that there are auto contrast settings with the microscope software that cause the images to appear similar despite large pixel density differences. 


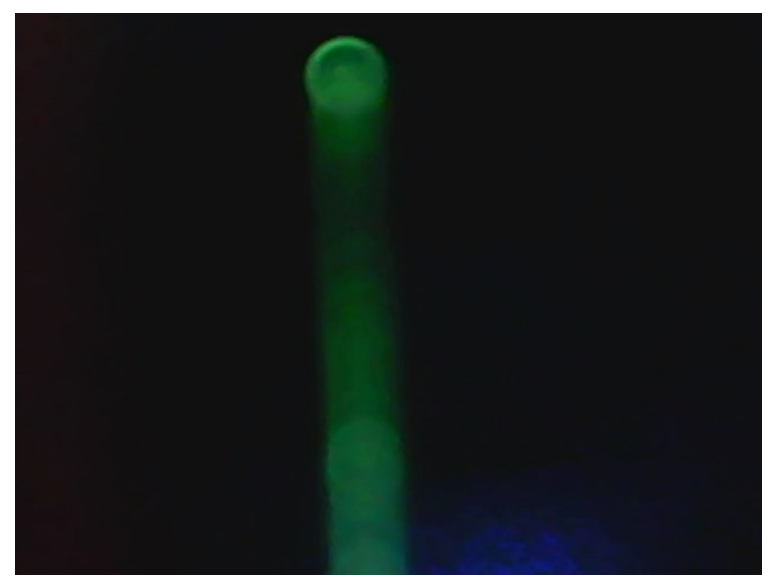

Figure 4-8. Bare, glass, TFBG Fibre coated with Si-PEG-FITC and probed by a preliminary basic optical setup containing a fibre coupled laser Argon-ion laser, a band pass filter and development board camera.

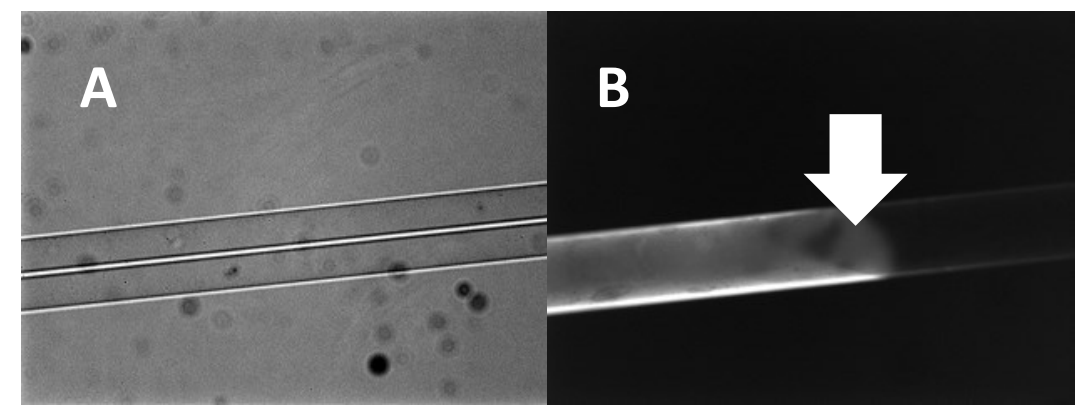

Figure 4-9. (A) SMF-28 fibre partially coated with Si-PEG-FITC as examined under visible microscopy. (B) Boundary between coated and uncoated regions on the same fibre location when viewed under fluorescence microscopy. This boundary region, indicated by the white arrow, is created as an artefact of the dipping process where fibres are vertically submerged into a solution of the Si-PEG-FITC molecule. The boundary effect marks the meniscus of the Si-PEG-FITC coating solution. 


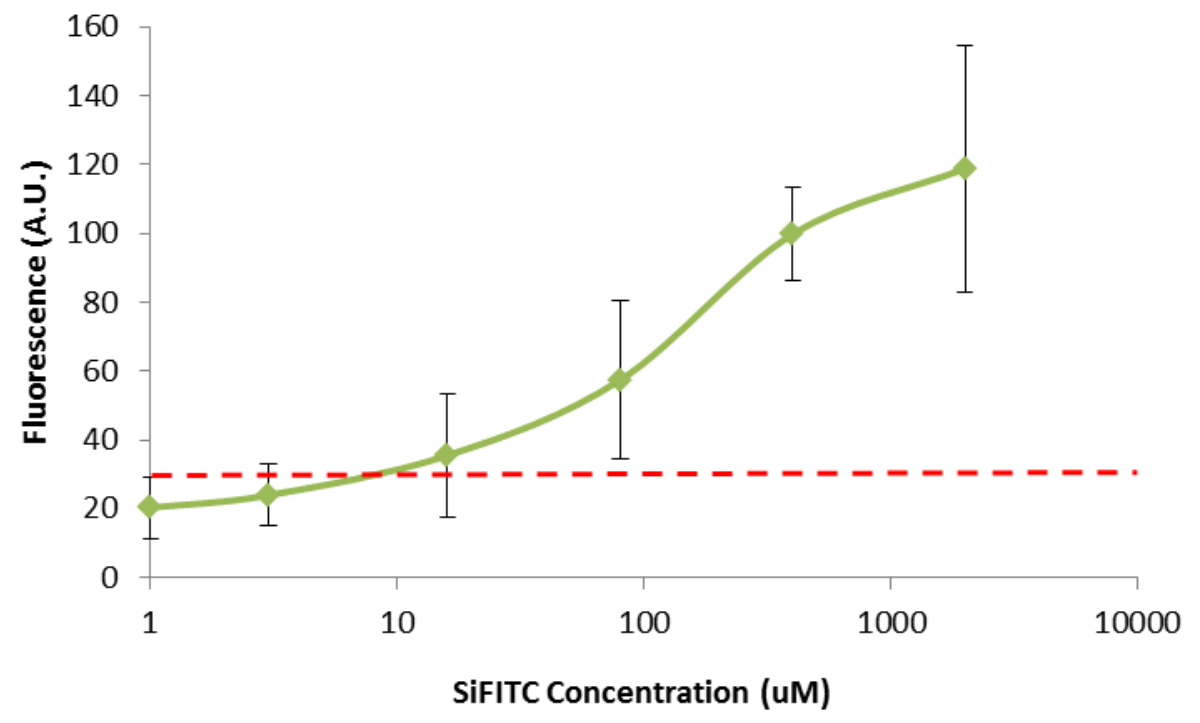

Figure 4-10. Fluorescence of fibres coated with Si-PEG-FITC solution. Various Si-PEG-FITC concentrations were utilized and appear to demonstrate an increase in fluorescence with increasing concentrations. This fluorescent increase appears to overcome the background fluorescence around the $100 \mu \mathrm{M}$ level. The background signal is represented by the red line. The concentration increase affect appears to plateau around $1000 \mu \mathrm{M}$ and therefore $750 \mu \mathrm{M}$ was chosen as the optimal return of fluorescence for reagent cost. Error bars in this figure represent standard deviation of the population of fibres examined by fluorescence microscopy.

\subsubsection{Coating Option II: DSC (Disuccinimidyl Carbonate).}

A secondary methodology of attaching oligomers to glass surfaces involves a step-wise functionalization that leaves a reactive cross-linking molecule on a fibre surface. A process was adapted from that designed by Xia et al. using disuccinimidyl carbonate, a homobifunctional cross-linker, between amine groups on the surface of a glass fibre and amine groups on the $5^{\prime}$ end of a fluorescently labelled DNA oligomer (Xia et al., 2006a). The step-wise process utilized for coating of fibres is depicted in Figure 4-11. This process has been previously used for microarray functionalization and represents an economically feasible coating approach for the conditions required to coat glass fibres. 
Initial coating experiments with the DSC coating methodology were performed with a fluorescently labelled oligomer to achieve the schematic as depicted in Figure 4-4. This configuration allowed for minimization of variables involved in the qualitative examination of fibre coating success. Negative controls for each step of the coating process, as shown in Figure 4-11A-C, were performed and contrasted to the successful surface functionalization as seen in Figure 4-11D. Based on the recommendations of DSC usage in microarray technologies, coatings were performed using low concentrations of the fluorescent oligomer (Beier \& Hoheisel, 1999). Recommended concentrations appeared to be difficult to visibly assess due to low signal-to-noise ratios and may have been a misrepresentation in the literature (Beier \& Hoheisel, 1999). This was addressed through a concentration range test as seen in Figure 4-12. Applied concentrations around $10 \mu \mathrm{M}$ were used to avoid increasing density of DNA on the surface of fibres to the point of creating steric hindrance of incoming molecules (Beier \& Hoheisel, 1999).

Once results of Figure 4-11 indicated that DNA attachment to the surface of glass fibres was successful, variation of the oligomer was possible by designing DNA sequences with amine functionality on the $5^{\prime}$ end of the oligomer. Since the purpose of these oligomers is to allow SP-PCR they cannot be attached by the $3^{\prime}$-end and should not be fluorescent due to potential interference with signals generated by a PCR reaction. Without a fluorescent signal, confirmation of coating success requires an indirect method of detection. This can be done with a hybridization assay that functions as depicted in Figure 4-5. A hybridization protocol was adapted from those used in microbead and microarray assays (Walsh, Wang, \& Weimer, 2001). This hybridization was clearly visible in fluorescence microscopy and was reversible through a heating of the hybridized surface to a point past the melting temperature of the oligomer strands. Figure 4-13 demonstrates the difference in surface fluorescence based on the hybridization and removal imaging steps. The boundary visible in Figure 4-13 is a result of the control mechanism as depicted in Figure 4-6. This mechanism effectively submerged the fibre in a hybridization 54 IPage Jason Koppert MASc Thesis 
liquid beyond the point of oligomer coating in order to control the amount of background signal through provision of a distinct, measurable boundary.

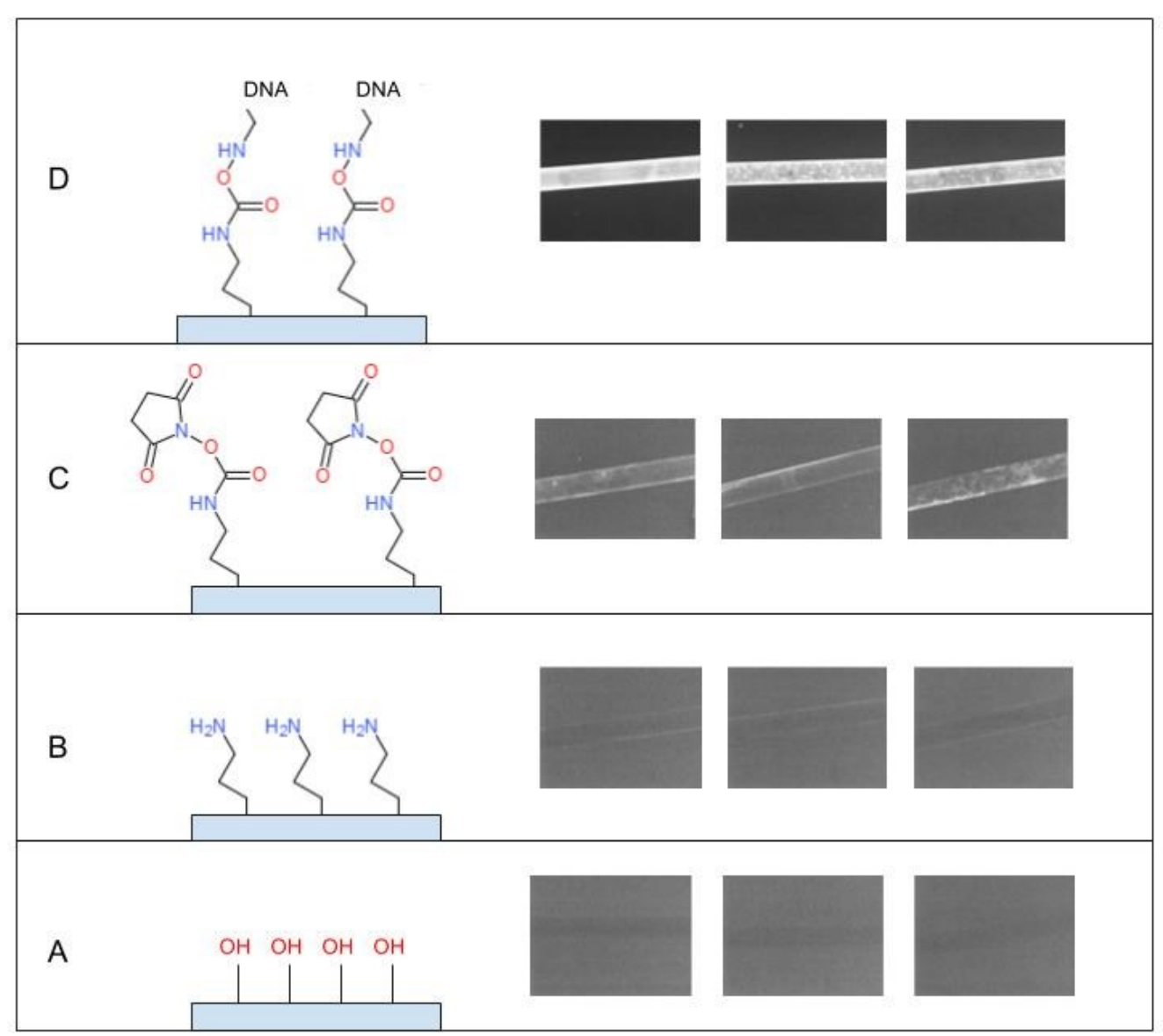

Figure 4-11. DNA immobilization with DSC chemistry on the surface of a glass substrate (A), the aminosilane compound, APTMS, reacts with the hydroxyl groups, leaving an amine terminated surface (B); the homobifunctional DSC binds to the amine groups, terminating the surface with $\mathrm{N}$-hydroxy succinimide (NHS) (C); finally, an oligonucleotide with 5'-amine modification is covalently bound to the surface (D). In this case, the oligonucleotide also possessed a terminal fluorescence modification. The images associated with each step pertain to negative controls for steps A-C while the successful attachment is shown in Step D. This fluorescent DNA attachment is depicted in Figure 4-4. 


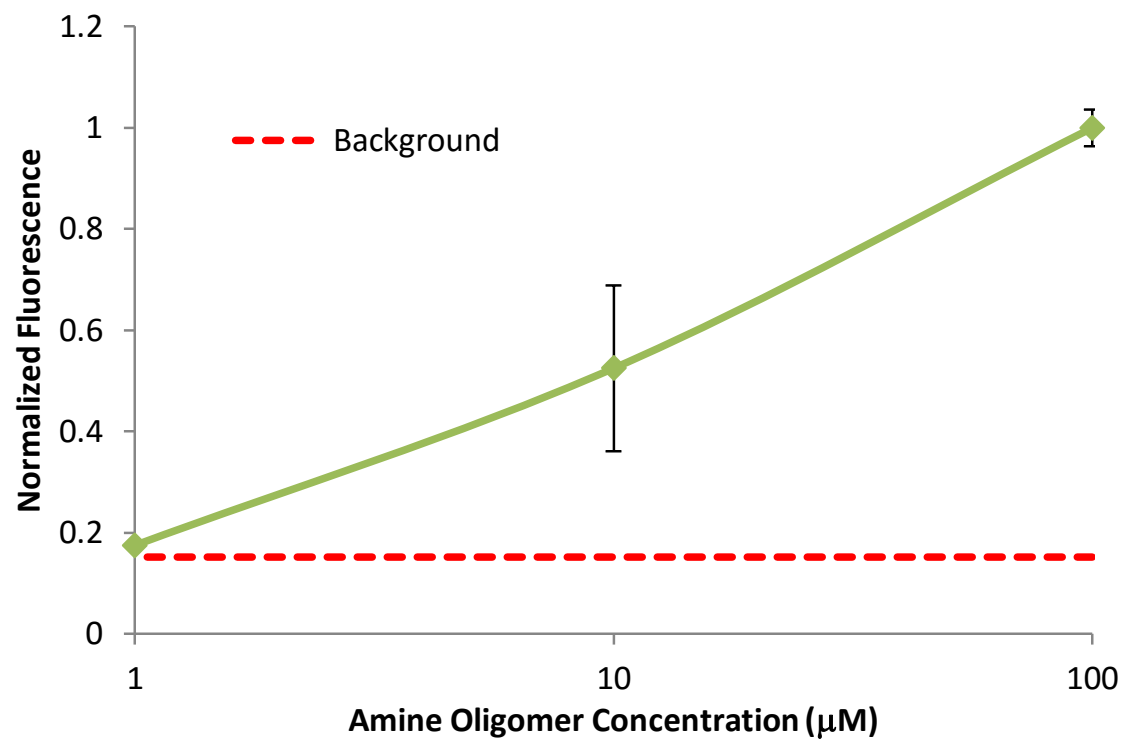

Figure 4-12. Fluorescence of fibres coated with the DSC methodology. Various amine functionalized DNA oligomer concentrations were utilized and appear to demonstrate an increase in fluorescence with increasing concentrations. Literature searches suggest the usage of oligomer around $1 \mu \mathrm{M}$ but it appears that $10 \mu \mathrm{M}$ is needed to have sufficient signal above the background signal. 


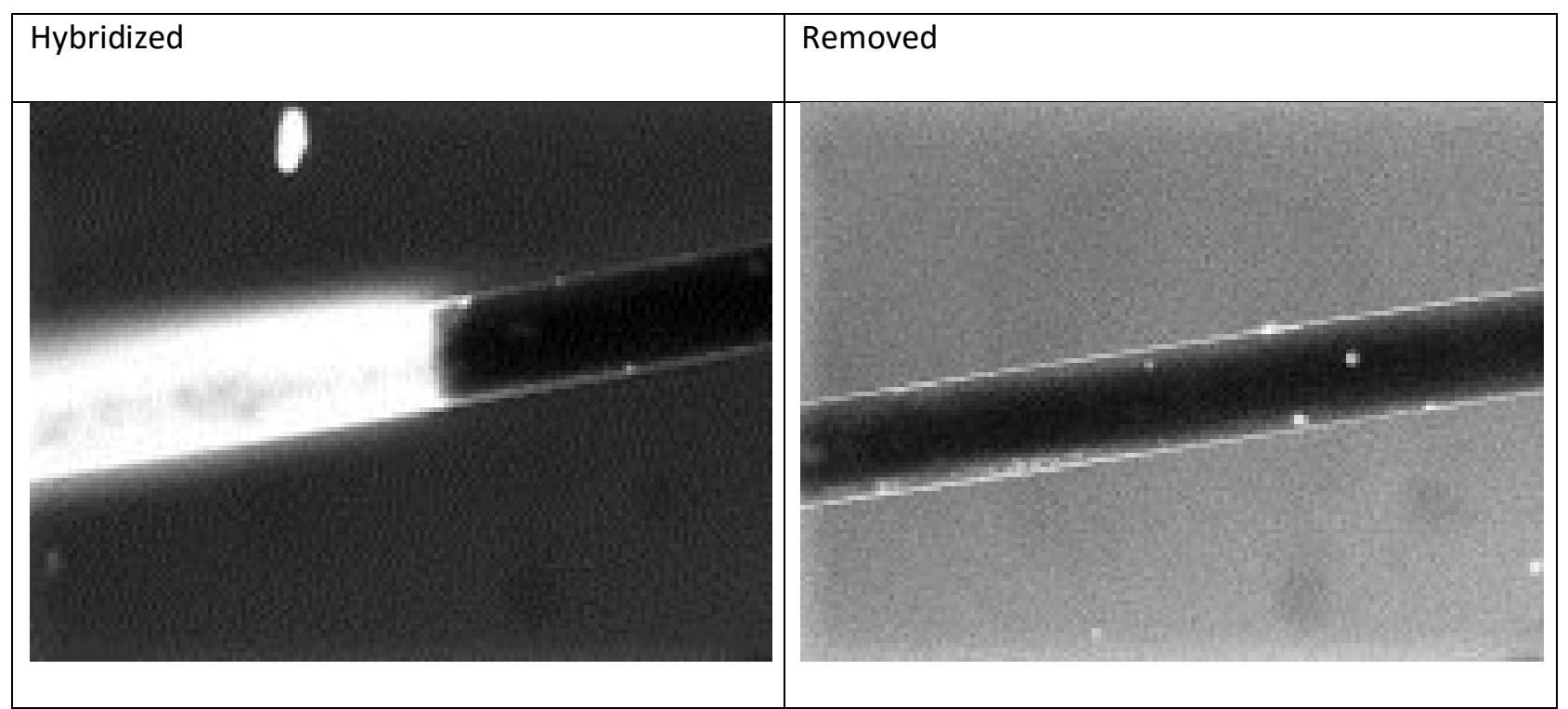

Figure 4-13. Fluorescent microscopy imaging of the hybridization and subsequent removal through a melting application of the oligomer coated fibre. The hybridized surface coating region has a clear termination boundary visible on the fibre surface. This boundary is created as a result of the coating control mechanism depicted in Figure 4-6.

\subsubsection{Coating Option III: EDC Coating}

Although DSC is an economical and feasible approach to covalent linkage of oligomers to glass fibre surfaces, there is minimal precedent pertaining to its usage in SP-PCR. In order to compare the DSC coating methodology to a SP-PCR compatible coating it was necessary to examine the hybridization of fluorescent DNA oligomers to surfaces coated with an EDC coating approach. The EDC methodology is significantly more costly than the DSC methodology when pertaining to fibres due to environmental requirements during the coating process and requires a significantly longer exposure time to coating buffers.

In order to initially validate the EDC coating methodology, a fluorescent oligomer was used in a similar methodology to the DSC validation method. However, in this instance the fluorescence oligomer possessed a $5^{\prime}$ phosphate functionalization in place of a $5^{\prime}$ amine functionalization. Figure 4-14 depicts a fibre coated with the fluorescent oligomer through an EDC exposure and an exposure to the fluorescent 
oligomer without EDC. Without EDC there should be minimal oligomer coverage on a fibre surface. However, Figure 4-14 indicates that there is significant fluorescent oligomer retention even without the active heterobifunctional cross-linker element. This represents a problem that could potentially interfere with the usage of such a coating in our fibre detection system.

A major requirement of SP-PCR is that the coating be covalently attached in order to survive the extensive thermal cycling of PCR (Hoffmann et al., 2012a). While Figure 4-15 indicates that the boundary region can clearly be utilized to prove the functionality of the hybridization assay on an EDC coated surface, Figure 4-16 depicts the potential source of error pertaining to this coating methodology. It appears as though a portion of DNA that attaches to the surface may not be due to the EDC binding but rather some other mechanism of binding. This is problematic considering that non-covalent binding could potentially decrease signal to noise ratios during SP-PCR development processes as well as contributing to the loss of surface-bound DNA during a thermal cycling process.

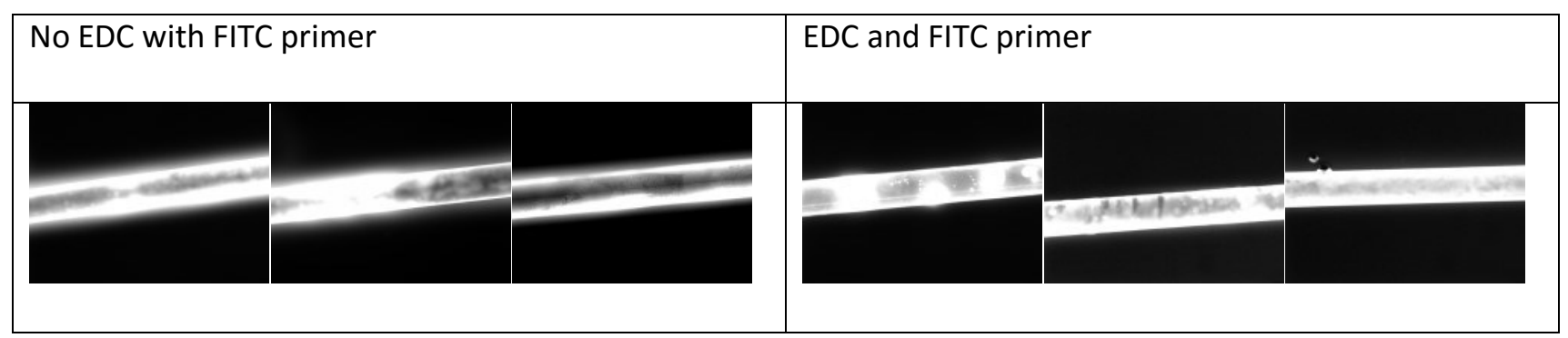

Figure 4-14. Depiction of negative and positive controls for the covalent attachment of DNA to glass fibre surfaces with the EDC cross-linking methodology. The images taken without EDC in the coating process represent an undesirable result. 


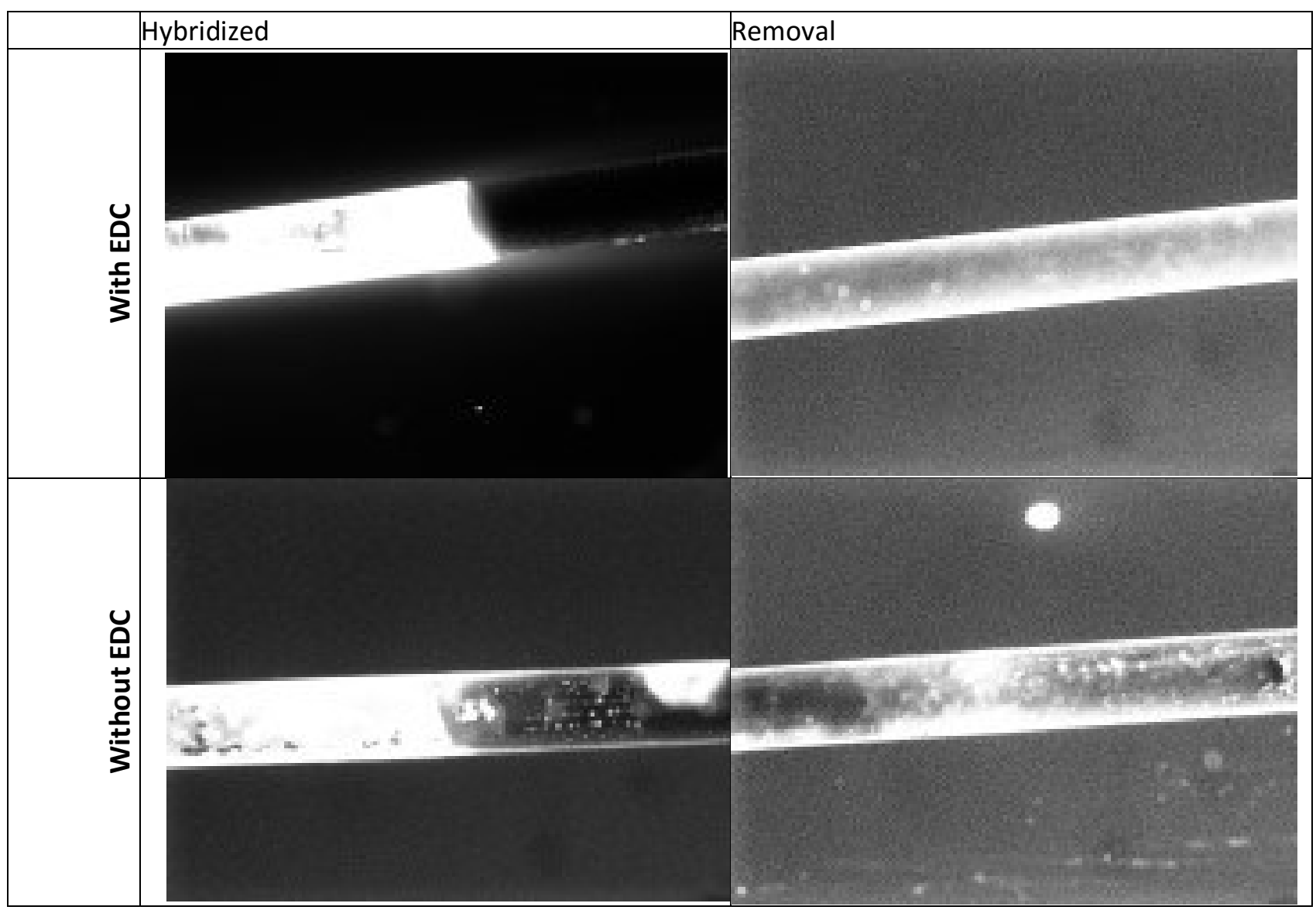

Figure 4-15. Hybridization and attempted removal utilizing coatings functionalized with EDC. Microscopy image processing auto adjusts some fluorescence to appear darker in regions of lower fluorescence. Therefore, pixel density analysis was performed as seen in Figure 4-16. Significant fluorescence background remains on the fibre surface after probe removal and in the negative control samples. 


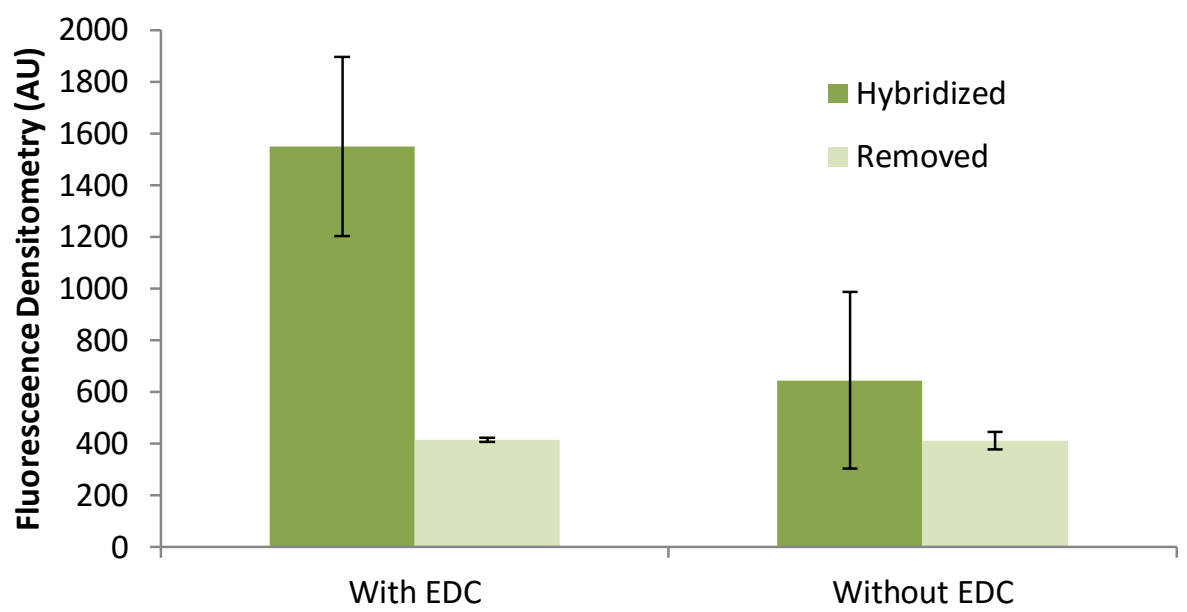

Figure 4-16. Densitometry measurements with the EDC hybridization and negative control samples. The hybridization assay can be seen to work with the densitometry delta that occurs upon removal of a surface hybridized probe. This hybridization works when the covalent linker, EDC, is not present thereby indicating that a portion of the successful signal, when EDC is used, may be non-specific. Error in these measurements is representative of a large population of EDC coated fibres.

\subsubsection{Coating Option IV: UV coating}

In the search of an economical and SP-PCR suitable coating for glass fibres, the usage of UV cross-linking presents a high-potential option. This methodology does not use oligomer modifications, nor an incubation step with a cross-linking agent. In this way it presents a simplistic, quick, and economical coating methodology while improving coating safety and reducing reagent costs.

At this point of the coating investigation project, coating examinations could be performed with an optical setup as depicted in Figure 4-2. This method of imaging allows a comparable quality of imaging to that of the microscope with the added flexibility of not contacting the fibres against glass slides and coverslips thereby minimizing coating damages during handling. Additionally, Figure 4-2 demonstrates the introduction of a capillary tube. This capillary tube allows for liquid to surround the 
fibre during imaging and represents an important step forward towards preparing for examination of SPPCR in real-time.

One of the problems with this method is the inability to introduce fluorophores onto a surface for direct visible coating assessment. Most fluorophores will be destroyed by the UV energies required for this cross-linking procedure. Since fluorophores are destroyed through the cross-linking, the only methodology of detecting surface bound oligomers is through the hybridization assay.

Two methodologies of using UV cross-linking were examined. The first method involves a surface functionalization with a charged molecule. This step is identical to the first step of both the EDC and DSC procedures in that a positively charged surface can be dipped into a liquid containing the desired oligomer. However, since a reaction does not occur, incubation of the fibre in the liquid is not necessary and the fibre can be immediately removed after dipping since removal of the fibre does not interrupt non-specific binding interactions.

Figure 4-17:A-C demonstrates the results of the UV treatment with one of the oligomer dipped fibres. The fibre treated with UV demonstrated the ability to clearly hybridize, as seen in Figure 4-17B, to the template in a reversible fashion. Notably, this coating treatment had significantly variable and uneven coverage of template DNA in the hybridized form.

Since a goal of this project was to allow for the eventual production of a multiplex SP-PCR, banding of spots was one of the theoretical approaches that would allow for multiple DNA spots to be presented in spatial separation along the length of a fibre. Previous usage of printing technologies for UV cross-linking by Sun et al. led to the experimentation of regional spot introduction (Yi Sun et al., 2012). This process involved the physical introduction of droplets of oligomer onto a fibre surface prior to UV cross-linking exposure.

61 Page Jason Koppert MASc Thesis 
Figure 4-17D and E depict two replicates of a double spotting procedure. The spatial separation of the spots allows for clear resolution of the hybridization event with a negative control region in between the spots. The fibres shown in Figure 4-17 all depict a successful hybridization (B, D, E) of the DNA probe to the surface bound DNA. This hybridization was reversed through heating of the fibre to remove the DNA probe (Figure 4-17: C, F, G). 


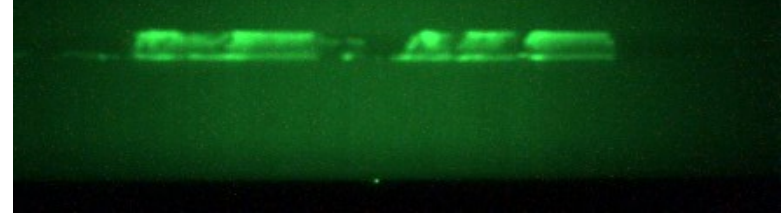

Figure 4-17. (A) Glass TFBG fibre coated with the UV cross-linking method. The central white line visible in all of the images is a photoluminescent effect of a TFBG. (B) Hybridization of fluorescent probe on the surface of a fibre coated with DNA oligomer through a UV coating exposure. Clear non-uniformity is visible in the hybridization step of the procedure. (C) Thermally induced removal of the fluorescent probe from the fibre surface. (D, E) Depiction of probe hybridized, DNA spotting resolution of the DNA oligomers coated onto a glass fibre using the UV coating methodology. Areas between the fluorescent spots do not have DNA oligomer on the surface and thereby are unable to bind the fluorescent probe when the fibre is exposed to a fluorescent probe solution. $(F, G)$ Correspond to (D), (E) respectively and represent the melting effect when the fluorescent probe is removed through a heat treatment. The excitation source in all images is a $488 \mathrm{~nm}$ laser. 


\subsubsection{Comparison of Coatings}

Once functionality had been demonstrated on the SI-PEG-FITC, DSC, EDC, and UV cross-linking functionalization methods, it was important to compare the methods and select the most suitable approach for moving forward. Table 4-1 depicts a list of qualitative aspects pertaining to each of the coating methodologies, summarizing all factors considered in the assessment.

Signal to noise ratios were normalized between all functional methodologies and plotted in Figure 4-18. It is apparent that the hybridization of the fluorescent oligomer is of comparable quality between all of the methods. It is important to note that the errors associated with the measurements are reflective of the imaging methodologies used to evaluate the coatings and not the reproducibility of the coating methodology itself.

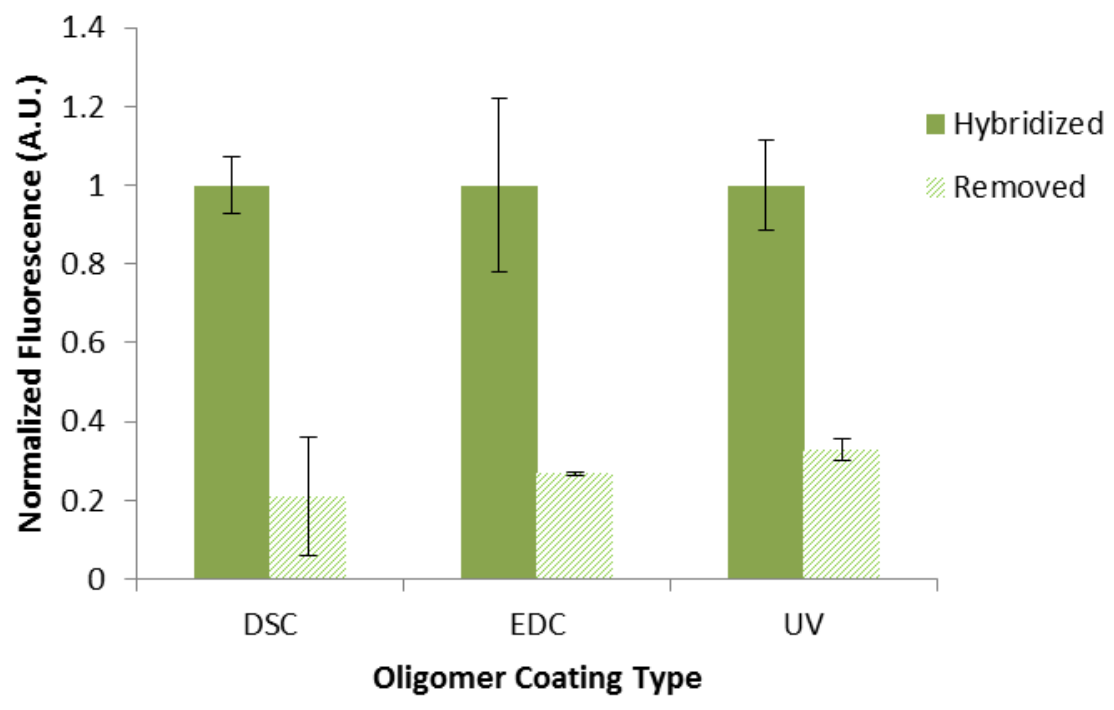

Figure 4-18. The densitometry measurements depict a population of fibres hybridized with a fluorescent complement probe after coating with DNA. The difference in error in the measurements across the different coating types is due to different image capture methodologies being used to evaluate each. All the depicted measurements are normalized. 
Table 4-1. Qualitative comparison of coatings regarding crucial aspects of coating economy and functionality.

\begin{tabular}{|l|l|l|l|l|}
\hline Coating Property & $\begin{array}{c}\text { SI-PEG- } \\
\text { FITC } \\
\text { Option I }\end{array}$ & Option II & Option III & Option IV \\
\hline Fluorophore Compatible & Y & Y & Y & N \\
\hline Hybridization Compatible & N & Y & N & Y \\
\hline Low Background & Y & Y & N & Y \\
\hline Cost & $\$ \$ \$$ & $\$ \$$ & $\$ \$ \$$ & $\$$ \\
\hline Ease of Labeling & + & +++ & +++ & + \\
\hline Banding Capable & N & N & N & Y \\
\hline Heat Resistance & N & N & N & Y \\
\hline Process length & $\sim 1$ hour & $\sim 4$ hours & $>8$ hours & $\sim 2$ hours \\
\hline
\end{tabular}

\subsection{Discussion}

In order to achieve a solid phase PCR reaction on the surface of a hotwire optical fibre, surface chemistry that connects DNA to glass must be compatible with the reaction parameters itself. A PCR reaction involves the thermal cycling of liquids as well as the involvement of aqueous reaction conditions. Therefore surface-linked DNA sequences must be able to endure these conditions. Hoffman et al. have demonstrated that thermal cycling of PCR reactions can destroy any non-covalently bonded DNA that is connected to a surface (Hoffmann et al., 2012a).

Ideally there would be no loss of DNA from the solid phase support during a PCR reaction since loss of any fragments would mean that detached primers would then participate in solution-based reactions and could compete with SP-PCR. However, it appears that even covalent linkages suffer losses of $30-60 \%$ of the initially bound surface population with the strongest of single point covalent attachments (Haukur Gudnason et al., 2008). There does not appear to be agreement in the literature 
on the exact bond strength requirements for surface bound primers in SP-PCR. For instance, sulphide linkages, despite being thermally labile, have been used in SP-PCR under certain circumstances such as the works of Cao and Pollet (Cao et al., 2012; Pollet et al., 2011). However, losses of surface bound DNA with sulphides are known to be over $60 \%$ of initial surface populations and questions the validity of some of the results seen in certain studies (Pollet et al., 2011).

An additional requirement of SP-PCR appears to be the incorporation of a molecular spacer between the surface and any DNA sequence to be used for molecular analysis (Hoffmann et al., 2012a). The importance of a molecular spacer in between any surface and a DNA sequence appears to be due to both hybridization efficiency of aqueous DNA sequences and steric hindrances based on DNA polymerase access to the solid phase bound DNA (Carmon et al., 2002; Halperin et al., 2006). In all of the strategies considered here, a spacer has been introduced according to previous literature findings. SiPEG entities contain a large polymeric chain of ethylene glycol (see Figure 4-3B) that has been shown to allow enhanced polymerase activity (Carmon et al., 2002). Although the Si-PEG-FITC entity was not used for a DNA linkage strategy, substitution of the FITC with a DNA sequence would have resulted in a PCR compatible linkage. The SI-PEG-FITC method was abandoned due to high cost of manufacturing and handling. The DSC and EDC methodologies incorporated a spacer into the linkage strategy in the form of a string of consecutive Thymine bases just prior to the sequence of interest. This DNA base spacer strategy has been shown to allow PCR functionality and increased hybridization efficiency (Guo et al., 1994; Halperin et al., 2006). The Thymine and Cytosine repeat region of the TC tag used in UV crosslinking appears to function both in the reaction mechanism itself while simultaneously acting as a spacer as well (Haukur Gudnason et al., 2008).

The initial approach towards the coating of fibres with DNA was designed with a focus on process simplicity. To achieve simplicity, a single entity molecule was designed that would allow for 66 IPage Jason Koppert MASc Thesis 
single step treatment procedures. This molecular strategy is depicted in Figure 4-3 with a fluorescent molecule (Figure 4-3C) in place of a DNA sequence. A fluorophore would allow for a single step confirmation of a coating application's success when viewed through the schematic seen in Figure 4-2.

The results of the Si-PEG-FITC molecule's application indicate that a fluorescent coating was successful on a glass fibre surface. Figure 4-7 displays a non-coated glass fibre under visible and fluorescent filter viewing (Figure 4-7; A and B respectively). Identical imaging revealed a fluorescing fibre (Figure 4-7D) when treated with the Si-PEG-FITC. The imaging demonstrated in Figure 4-7 was performed with a fluorescence microscope and the schematic of Figure 4-1. Concurrent to this initial exploration of fibre coating methods, an economical method of viewing fluorescence on fibres was being developed. Figure 4-8 illustrates the imaging quality of the prototype optics setup with the Si-PEGFITC coating. Due to lack of imaging quality compared to microscopy imaging, quantitative experimentation could only be performed with microscopy at this stage.

The optimization of the Si-PEG-FITC coating process involved the exploration of optimal concentration of the required coating solution. Figure 4-10 illustrates the concentrations of Si-PEG-FITC solution and the effect on final fluorescence of the fibre surface. Saturation of the surface occurs around concentrations of $1000 \mu \mathrm{M}$. Even with the lowest concentrations required to overcome the background fluorescence, depicted by the red line of Figure 4-10, this represents a significant quantity of the Si-PEGFITC molecular entity. When combined with the sensitivity of the molecular stocks to degradation, the process of manufacturing fibres with such a coating strategy immediately became costly and impractical.

While simplicity of the manufacturing helps to avoid extensive quality controls, performing a step-wise reaction approach represented a potential pathway towards to cost savings. The usage of disuccinimidyl carbonate (DSC) for DNA coatings has precedence in microarray design as well as enzyme linkage strategies (Beier \& Hoheisel, 1999; Xia et al., 2006b). DSC uses identical surface reaction 
mechanisms to those of the Si-PEG-FITC molecule. However, as Figure 4-11 illustrates, the process builds out from a glass surface instead of using a single step silane-glass reaction. This allows for sensitive reagents with short shelf lives to be handled more easily and minimizes costs associated with large molecule synthesis and purification. Although there exist many alternatives to DSC as a cross-linker in organic chemistry, many of these methodologies involve harsh compounds which can prove costly (Heise \& Bier, 2006).

To easily view the success of this coating methodology, fluorescently labelled DNA oligomers can be incorporated into the final reaction of the process as seen in Figure 4-11D. The final results of this schematic are seen in Figure 4-4 and result in a fluorescent coating similar to that seen in the Si-PEGFITC approach. The concentration analysis of required reagents applied to the Si-PEG-FITC approach was repeated with the DSC approach. The results of this analysis can be seen in Figure 4-12. Amounts of reagents required with the DSC approach are significantly more affordable than the Si-PEG-FITC approach. This is due to the cheaper individual component replacement value. The monitoring of each of the steps of the reaction process, as seen in Figure 4-11 through fluorescence imaging, reveal that the introduction of a fluorescently labelled DNA oligomer causes visible fluorescence on the surface of a glass optical fibre.

Since DNA oligomers could be incorporated onto the surface of a fibre in a controlled manner, testing the functionality of these oligomers would be required. This functionality testing needed to ensure that DNA was not fully bound along the glass surface in a manner that would make access impossible (Heise \& Bier, 2006). Although the ideal testing of DNA oligomer functionality on a surface would be the immediate introduction of successful PCR amplification of surface bound DNA, such a process would expose a fibre to potential delamination of surface DNA oligomers and could produce false negative results due to cross interactions in a PCR process. A more simplistic approach to validation

68 IPage Jason Koppert MASc Thesis 
of surface-bound DNA oligomer functionality was through the use of a microarray hybridization assay. Such an approach would effectively operate according to the schematic depicted in Figure 4-5.

The hybridization assay was developed for the examination of coating quality and functionality assessment. It represents an adaptation of widely used microarray hybridization methods. A depiction of this assay functionality is seen in Figure 4-5. The hybridization assay involves the use of aqueous, fluorescently labelled, DNA sequences in a high salt solution (Walsh et al., 2001). Such solutions have been used in numerous applications with sequence specific hybridizations being easily obtained (Dufva et al., 2004; Fedurco, Romieu, Williams, Lawrence, \& Turcatti, 2006; Haukur Gudnason et al., 2008; Walsh et al., 2001). Such hybridization can also be reversed quite easily through either introduction of heat or chemical treatments that would prevent hydrogen bonding between two strands of DNA (Walsh et al., 2001). Despite being a rather widely used and simplistic strategy, fluorescent probe hybridization to a DNA coated surface allows for critical assessment of the DNA coating success. This hybridization of surface-bound DNA to a fluorescently labelled, aqueous, DNA complement is especially important in cases where fluorescent DNA cannot be directly bound to a surface. Such an example is found in the UV cross-linking method linking of DNA to surfaces. UV cross-linking will be further discussed below.

One of the major drawbacks of the DSC methodology was that it lacked previous research pertaining directly to the linkage strategies used in SP-PCR. While the hybridization and covalent bonding of the linkage indicate that it could be a suitable strategy for SP-PCR, it needed to be validated through comparison to a known SP-PCR compatible surface strategy. This would allow elimination of variance from variables, such as surface density and thermal resilience, to be evaluated (Halperin et al., 2006). EDC is an organic cross-linker molecule that uses a similar strategy to DSC. EDC however, acts as a cross-linker between phosphates and amines and is thereby a heterobifunctional cross-linker (Heise \& Bier, 2006; Xia et al., 2006b). Our initial analysis of cost associated with EDC cross-linking had led to the 69 IPage Jason Koppert MASc Thesis 
conclusion that it would be impractical for large scale manufacturing but that it could be practical for small scaling testing. The use of EDC in SP-PCR was demonstrated on several occasions and therefore would allow for a positive control testing method for a more economical approach that was represented by DSC (von Nickisch-Rosenegk et al., 2005; von Nickisch-Rosenegk, Marschan, Andresen, \& Bier, 2008).

The EDC methodology was initially evaluated with the usage of the fluorescent primer strategy applied to the DSC as seen in Figure 4-4. In Figure 4-14, EDC cross-linking appears to cause a significant background signal presence. To further explore the EDC cross-linking methodology, the previously mentioned hybridization assay was used. Hybridization results confirmed the background issues seen with fluorescently labelled DNA oligomers. Figure 4-15 illustrates EDC cross-linking can be used with the hybridization assay and that hybridization of fluorescently labelled complements can be reversed. However, when EDC was not included in the coating process there appears to be some hybridization functionality as well that may have been a result of non-specific binding. Quantitative analysis of this effect revealed that the EDC enhanced the hybridization assay (Figure 4-16). This is an effect not demonstrated with DSC and, in theory, should not be present in microarray designs since it could drastically affect microarray sensitivity through increased limits-of-detection due to higher background signals.

This phenomenon of background fluorescence and hybridization functionality in negative controls is explained through potential electrostatic interactions between glass surfaces and DNA oligomers (Heise \& Bier, 2006). This effect is most likely more presented with EDC cross-linking because of interactions between the positively charged aminated glass and negatively charged 5' phosphate DNA functionalization, in addition to DNA oligomer backbone phosphates. This charge interaction is not seen with DSC as DSC uses amine coated surfaces and amine labelled DNA oligomers which would be electrostatically identical and therefore unfavourable relative to the interactions seen with EDC.

70 IPage Jason Koppert MASc Thesis 
The results of EDC coatings presented significant challenges to the creation of an SP-PCR positive control for two major reasons. Primarily, EDC results previously reported with SP-PCR do not mention proper negative controls for the observed background phenomenon and lend doubt to the validity of the reported results. Secondly, the difference between DSC and EDC results lends doubts to DSC's usage for SP-PCR functionality. Therefore EDC was not chosen as a positive control pathway. Since a positive control was still needed a new strategy was employed. This strategy involved the usage of UV cross-linking of DNA to glass surfaces.

At this point of the project, UV cross-linking appeared to be the ideal strategy for a hotwire optical fibre SP-PCR strategy for several reasons. Table 4-1 lays out important qualitative considerations for the selection of a DNA attachment strategy. UV cross-linking has been demonstrated in literature to outperform the other considered linkage strategies for thermal resistance. Additionally, it is significantly less expensive than other strategies due to a simple DNA base tag requirement. This tag does not require the same molecular end functionalization of DNA as seen with other linkage strategies which normally require expensive purification steps and also result in lower product yields. For the purposes of hotwire fibre optic PCR in of this project, cost considerations are also of significant concern. UV crosslinking does not require humidity-regulated chambers that would be optimally required for the DSC and EDC methodologies. Additionally, the expediency of the entire process allows for high throughput of optical fibre coatings.

The largest disadvantage of the UV cross-linking method is its inability to incorporate fluorescently labelled DNA sequences onto a surface. The high energy $254 \mathrm{~nm}$ UV light is not compatible with fluorophores and effectively bleaches all fluorescence before any experimentation is done (data not shown) (Van Den Engh \& Farmer, 1992). For this reason, UV cross-linking was not initially considered as a linkage approach due to the lack of a methodology for validation of the coating process's success.
71 I P a g e
Jason Koppert MASc Thesis 
After utilizing DSC and EDC coatings for testing and development of a hybridization assay, this main disadvantage can be overcome through introduction of a fluorescently labelled oligomer after UV exposure is utilized. The only instance where surface losses due to thermal cycling are negligible appears to be in the case of UV cross-linkage procedures when DNA is labelled with a Thymine and Cytosine tag (Haukur Gudnason et al., 2008). The exact mechanism of binding for this UV cross-linking is unknown but it has been theorized to involve breakage of the ring structures of DNA bases and subsequent reaction with hydroxyl groups on a surface such as glass (Douki, Zalizniak, \& Cadet, 1997; Haukur Gudnason et al., 2008). It has been shown that the Thymine and Cytosine bases are required for the strongest UV-induced binding to glass (Dufva et al., 2006). These two bases are known to form cyclobutane dimers in the presence of $254 \mathrm{~nm}$ UV light (Douki et al., 1997). If this dimerization happens on the surface of glass, it appears to form the strongest DNA surface linkage available (Haukur Gudnason et al., 2008).

UV cross-linking can be done with non-TC tagged DNAs on APTMS coated surfaces in similar fashion to linkages with TC tags (Haukur Gudnason et al., 2008). However, such UV cross-linking appears to result in up to $40 \%$ surface losses similar to those seen with most single point covalent linkages (Haukur Gudnason et al., 2008; Hoffmann et al., 2012a). Gudnason et al. have surmised that the involvement of APTMS in any linkage of DNA always results in around $40 \%$ surface DNA loss due to delamination of the glass during thermal cycling (Haukur Gudnason et al., 2008). This conclusion appears supported by the observation that removal of APTMS functionalization and substitution of TC tags on DNA allow for negligible losses of surface bound DNA molecules despite exposure to high temperatures for long periods of time (Haukur Gudnason et al., 2008). Figure 4-17 shows the ability of the UV crosslinking to hybridize to fluorescently labelled DNA oligomers in solution. Several variants of the UV crosslinking were developed using this hybridization assay. Figure 4-17A, B, and C all involve the dipping of a fibre into a solution of DNA for introduction of DNA onto the glass surface prior to cross-linking. This 72 IPage Jason Koppert MASc Thesis 
methodology demonstrated significant non-uniformity compared to results previously seen with EDC and DSC but remained functional despite this feature. An important realization pertained to the usage of this feature would increase the functionality of the UV cross-linking method itself. By spotting DNA oligomers onto the surface of a glass fibre instead of dipping the fibre into a solution of DNA, distinct areas of functionality could be created. Figure 4-17D and E demonstrate this spotting ability. These spots retained the functionality of the hybridization assay and could be reversibly removed, through heating, as demonstrated in Figure 4-17F and $G$ corresponding to the images $D$ and $E$ respectively. Conventionally, spotting of microarray surfaces has been done with complex printing devices that represented a significant overhead cost. However, the functional spots shown in Figure 4-17D and E were able to be made through careful application of the spots by hand.

\subsubsection{Optimization of Viewing Apparatus}

In the process of developing and characterizing coatings for use with a hotwire optic fibre, the viewing apparatuses utilized for examination of the coatings were being developed and optimized in parallel by Hubert Jean-Ruel. This optimization was necessary due to the requirements of real-time imaging for the final hotwire SP-PCR assay. Initially, coatings were examined with conventional fluorescence microscopy. Figure 4-1 illustrates the usage of a microscope slide, mounting solution and a cover slip to hold fluorescently labelled fibres for microscopy viewing. This methodology allows for the imaging and analysis of coatings but has several drawbacks. The use of microscopy is limited due to the inability to view interactions of surface bound DNA with aqueous solutions and thereby can only be used in an endpoint analysis approach (i.e. only viewing fibres after an assay has been performed with them) The end point imaging of coatings before and after a treatment is difficult due to physical contact damage occurring when fibres are sandwiched between two abrasive glass surfaces (data not shown). While modification of a fluorescence microscope could possibly allow for real-time monitoring and an 
apparatus designed for minimal coating damage, such microscopes are prohibitively expensive and the risk associated with modification of such a microscope would be outside the budget of this project.

Despite these disadvantages, endpoint analysis of fibres was permitted through careful controlling of the coating procedures and assays. Figure 4-6 depicts the controls used to enable microscopy functionality with hybridization assays. It also shows the ' $10 \mu \mathrm{L}$ coated region' which represents the region of the fibre coated by dipping into a reaction vessel with $10 \mu \mathrm{L}$ of functionalized DNA that would bind to the surface covalently. This dipping process allowed for measurement of the boundary between the coated and uncoated regions relative to the end of a fibre. When using a DNA coated fibre in a hybridization assay, the aqueous, fluorescent, DNA complement would be exposed to a measurably larger region of the fibre than the region that was coated. The carefully measured boundary between coated and uncoated regions could then be located using microscopy stage tracking. This tracking methodology was applied in results such as those seen in Figure 4-9, Figure 4-13, and Figure 4-15.

To overcome the viewing constraints of a fluorescence microscope while retaining the image quality, an optical system was designed as seen in the schematic of Figure 4-2. This optical system allowed for transparent capillary tubes to be filled with liquids while allowing for non-contacting fibre insertion. This system has greatly reduced complexity relative to a microscope and allows for independent component alignment to accommodate a wide range of experiments. Such experiments include the introduction of external heating devices, varying wavelength laser diodes, and varying lengths of optical fibre that could be used in a reflection or transmission sensing strategy. The optical system of Figure 4-2 additionally satisfies the requirements (real-time acquisition, heating compatibility, and assay compatible vessel) that a real-time PCR device would need to demonstrate therefore allowing 
for a system that could be used with a hotwire SP-PCR assay. These real-time capabilities are also necessary for any real-time characterization of a hybridization assay.

Although evolving viewing apparatuses were used in the progression of this project, comparison of the functional coating methodologies was still possible. Figure 4-18 compares the hybridization functionality of large sample populations of each type of coating strategy.

\subsubsection{Relation to Previous Studies}

Although each of the presented surface functionalization strategies have been used in the study of microarrays, the usage of the presented strategies with fibre optic devices is limited with little work examining EDC linkages for purposes other than SP-PCR (Delport et al., 2012). This is most likely due to lack of usage of optical fibres in both SP-PCR strategies as well DNA diagnostic applications. Only Pollet et al. have used fibres in SP-PCR although their application was simply to develop a fluorescence free detection strategy for PCR (Pollet et al., 2011). The SP-PCR application of Pollet et al. additionally uses a strategy of sulphide linkages (Pollet et al., 2011). These linkages are suspect in quality and suitability for PCR as they are heavily criticized by an original landmark study by Adessi et al. for their heat labile nature (Adessi et al., 2000). Most crucially, fibre optic devices have never been used as a source of heat for an SP-PCR reaction. This drastically diminishes the pool of candidate coating strategies for this project due to the aforementioned requirements of durability and economic viability.

\subsection{Conclusion}

This investigation reveals that the DSC and UV cross-linking strategies may be suitable for continued research with SP-PCR. However, the viability of the coatings examined for a proof-of-concept device varies considerably. The results of Table 4-1 have shown the approximate qualitative rankings of each examined coating methodology. For the purpose of this project, emphasis has been placed on the cost of the coating methodology and process simplicity. The UV coating methodology is clearly the superior 
combination of these two aspects while additionally being able to demonstrate banding capabilities that would be necessary for early-stage multiplex testing. As previously mentioned, the inability to bind fluorescent molecules, due to fluorophore damage by UV light, can be overcome through the use of the hybridization assay.

This chapter also demonstrates the first known usage of DSC and UV cross-linking for DNA functionalization of optical fibre surfaces. Importantly, the usage of UV cross-linking for SP-PCR has only existed since 2011 (Yi Sun et al., 2011). Both the DSC and UV cross-linking methods represent viable strategies for research applications in this device development phase due to economy and simplicity. 


\section{Assessing Surface Compatibility with SP-PCR through Real-time Monitoring}

\subsection{Introduction}

Once the best way of coating a glass fibre with DNA sequences was decided, it remained to be determined how to use such a coating for SP-PCR. This chapter will detail the development of assays that were used to assess the compatibility of DNA coated fibre optic surfaces with SP-PCR. To the best of our knowledge, SP-PCR on glass fibres has not previously been attempted. Current SP-PCR assays available in literature have been run with chip-based devices and have been viewed with extensive probing after a PCR reaction with rinsing steps and introduction of multiple hybridization probes. Additionally, the morphology of such devices is planar and they are frequently made of polymers. Since hotwire fibres had not previously been used with SP-PCR, a development pathway was identified to address this.

It is important to note that at this stage of development, a hotwire fibre optic device was not sufficiently stable to permit the reproducibility and throughput of fibre experiments that would be needed to develop an SP- PCR assay. Therefore a significant portion of the SP-PCR experiments that would ideally be performed on hotwire fibres were offloaded to other development strategies. Such strategies included utilizing off-the-roll glass fibre fragments without heating functionality and utilizing high speed PCR assays.

\subsection{Methods}

Once the connection of DNA to the surface of glass fibres was clearly established to be suitable for hybridization assays, it was important to transition DNA coated fibre research towards application in SP-PCR. To do this, a gene target, known as ABCB1, was adapted from a PCR assay previously developed by Spartan Bioscience. This PCR assay involved the usage of genomic DNA as a starting template 
material and took approximately 1 hour to perform on Spartan Bioscience's thermocycling device. The specific details of the reaction contents are divulged in Appendix A.2.

This assay was validated through real-time PCR monitoring with SYBR green I intercalating dye and analysed using a Spartan DX-12 thermocycler. To further confirm that the ABCB1 PCR assay produced a single amplicon product, the post-PCR reaction contents were analysed using gel electrophoresis. This technique involves the application of high voltage across an agarose-based gel. A PCR reaction that has a single DNA amplicon product will produce a single narrow banding pattern upon imaging of the gel. If multiple DNA products are present, they will be separated based on their speed of migration through the gel. The speed of migration is a function of the size and charge of the DNA products.

During the initial phases of the SP-PCR and fibre-coating-compatibility testing, thermal ramping rates involving fibres were very slow due to the requirement to heat larger volumes of reactions and our inability to seal the vessel due to placement of lengthy fibres into small vessels. To address this issue, higher template concentrations were used in the place of standard, low copy number, genomic DNA.

To develop a detectable SP-PCR assay on fibre surfaces, a tool kit of fluorescence probing strategies was necessary. The complete suite of probing strategies used to develop a fibre-based SP-PCR assay is depicted in Figure 5-1. Sub-figures A-E depict molecular probing tools that were designed for specific, separate usage to detect key steps during the SP-PCR detection process from fibre coating manufacturing through to SP-PCR detection. Figure 5-1A depicts the hybridization of a fluorescent complement to a surface-linked DNA primer. This probe allows for confirmation of DNA coating success on a fibre surface. The fluorescent probe of Figure 5-1B allows for the detection of a PCR starting template. This binding is twofold, in that it confirms the detection of the PCR starting template on the surface of the fibre and simultaneously confirms functionality of DNA surface coatings. Without 
successful binding of the template, surface signal production would not be possible. Figure $5-1 \mathrm{C}$ is a similar methodology that allows the detection of surface bound template. The Molecular Beacon probe incorporates a quenching entity that minimizes the fluorescence signal of the probe when it is not bound to its complement. Figure 5-1D incorporates an intercalating dye into a successfully extended surface bound primer. This probing method does produce a background signal before extension has occurred, but the binding of the intercalating dye is proportional to the amount of dsDNA present. Therefore, an increase in the presence of dsDNA produces an increase in fluorescence signal and can potentially be realized in real-time. Figure 5-1E depicts the final detection strategy of PCR. This methodology allows for detection of PCR success after the reaction has been performed. This probe requires the removal of the single stranded DNA template that would be fully complementary to the surface bound DNA copy after PCR. The fluorescent probe in Figure 5-1E binds to a sequence of DNA that would only exist on a fibre surface if successful PCR has occurred. Specific application of each of these probing strategies is further detailed in Appendix A.2. 


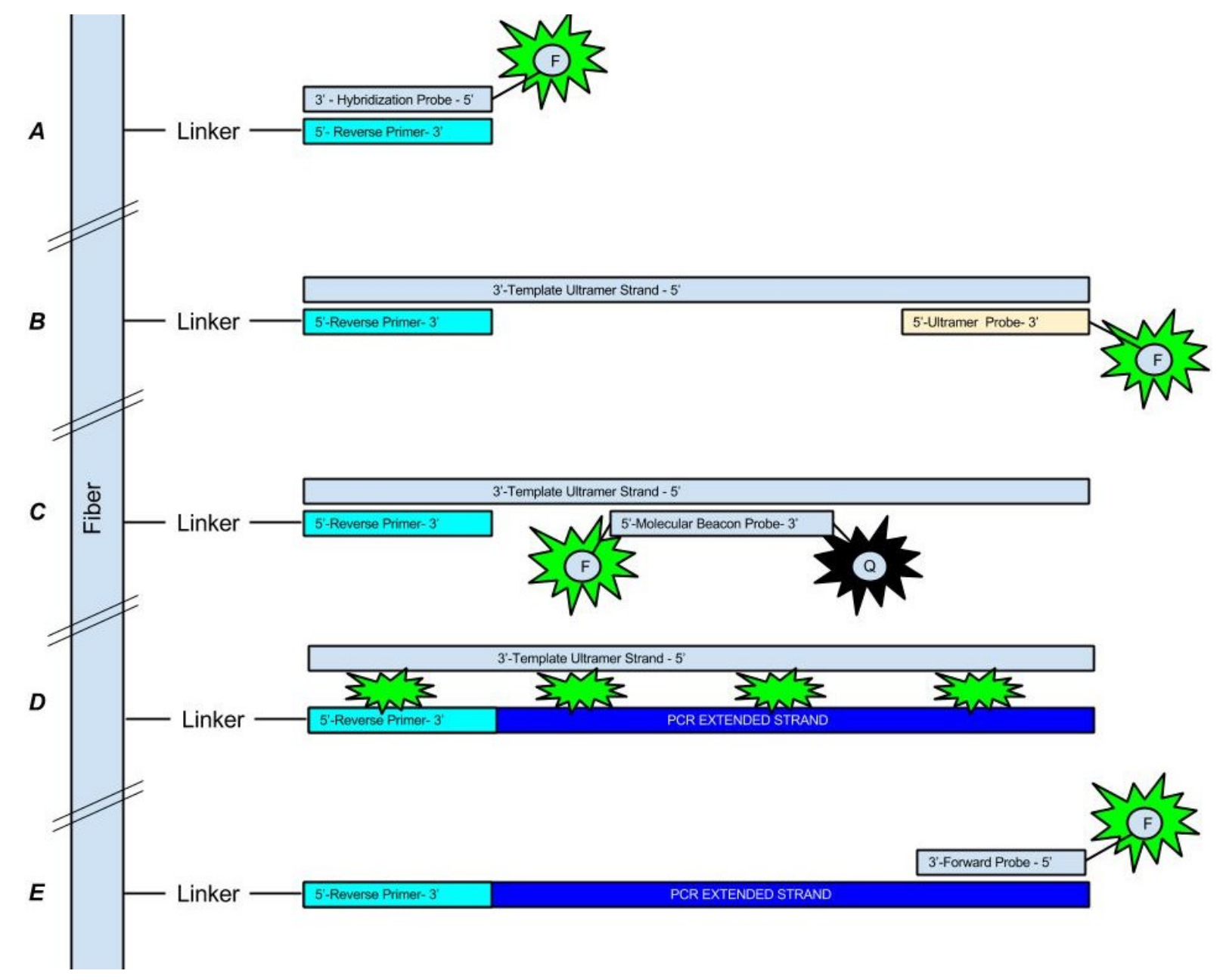

Figure 5-1. Depiction of all utilized probing strategies for examination of $A B C B 1$ DNA coating functionality and PCR compatibility. (A) Hybridization of fluorescent probe to the surface bound DNA oligomer. (B) Binding of a hybridization probe to the surface of the Ultramer sequence which is in turn bound to the surface connected oligomer. (C) A similar strategy to (B) with the usage of a Molecular Beacon probe. Such a probe can lower background in solution when not bound to the Ultramer sequence. (D) Surface bound reverse primer in its extended format. This extension occurs during binding of the Ultramer and exposure to a polymerase as in PCR. Detection of dsDNA is observed with an intercalating dye. (E) Reverse primer and its extension upon removal of the dye and template strand as seen in (D) a forward primer probe binds to the extended region of the newly created surface bound oligomer section. Note that for all the fluorophores depicted here the default color is green although fluorophores of any color can be interchanged. 


\subsection{Results}

The following section presents the adaptation of a PCR assay to glass optical fibre surfaces. An existing PCR assay, sourced from Spartan Bioscience, was adapted to usage with SP-PCR conditions. This was attained by shortening required reaction time and by encouraging PCR asymmetry. The presentation of results concludes with the novel contribution of a solid phase polymerase enzyme activity assay.

\subsubsection{Part I: Target selection and optimization}

The goal of this hotwire optical fibre-based PCR development project is to create a functional SP-PCR assay with multiplexing for the purpose of obtaining more diagnostic information per test. A previously developed but discontinued PCR target would be the ideal choice for development of a fibre product when used in a research environment due to its expired intellectual property value and complete characterization. Such a target, known as $A B C B 1$, had been previously developed by Spartan Bioscience Inc. until statistical analysis revealed that removing the target from a screen would have no effect on genetic information value (Wallentin et al., 2010). This target was developed to be performed using two-phase PCR with buccal material as a template. Figure 5-2 depicts the real-time run profile of the $A B C B 1$ genetic test as detected through the usage of Molecular Beacon ${ }^{\mathrm{TM}}$ probes. These probes are used under specifications from Spartan Bioscience and are known to be target-specific under these conditions. The inset of Figure 5-2 depicts a gel electrophoresis result run with the post PCR gene product. The gene product is therefore additionally confirmed to be singular in nature without creation of other non-specific products. Figure 5-3 further supports the specific product conclusion as a melting profile of the post run reaction with addition of a DNA intercalating dye. The melt peak appears at the expected temperature for the ABCB1 amplicon. The negative control in Figure 5-3 contains the PCR product as well but lacks the addition of an intercalating dye. As expected, no melting peak signal is present.

81 I Page Jason Koppert MASc Thesis 
One of the downsides of running the $A B C B 1$ PCR assay is the 50 cycle requirement. This thermal cycling takes up to 1 hour for a single test. Using a shorter test length with less thermal cycling would both increase throughput during the initial stages of fibre prototype development and reduce potential thermally induced damage before optimization is possible. This led to the development of a 10 cycle PCR reaction to shorten the required total thermocycling time. Such a reaction utilizes high initial template concentration to start the reaction. This effectively reduces the need for the initial 20 thermal cycles as seen in a 50 cycle PCR like that of Figure 5-2. Figure 5-4 illustrates the effect of raising the concentration of PCR's starting DNA template to several thousand times that of a buccal swab or genomic DNA sample. Figure 5-4A illustrates that normalization of the PCR run data to the initial background signal does not allow for a detectable increase in fluorescence when the starting template concentration is too high. When concentrations are too high, the detectable exponential portion of the PCR curve has already been passed. An initial concentration of 0.5 or $5 \mathrm{nM}$ starting template would therefore be desirable if an increase in signal is to be observed as the metric whereby PCR will be detected. Although signal increases vary from large to none in Figure 5-4A, all of these starting template concentrations possess an identical melting profile in post PCR analysis, as seen in Figure 5-4B, thereby indicating that an amplification plateau was reached. This reaction allows for quicker reaction throughput and lower thermal stresses on preliminary fibre optic devices. 


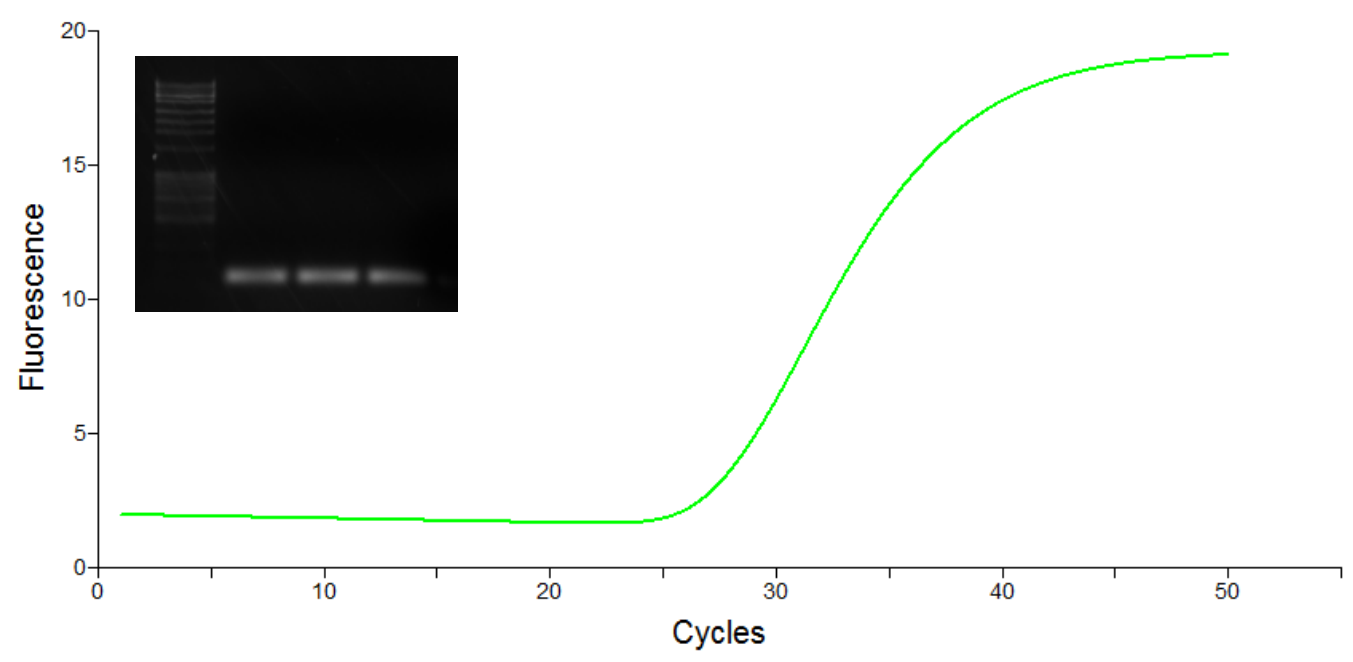

Figure 5-2. Real-time PCR run profile with the $A B C B 1$ gene target run from a buccal swab sample. This PCR was run with Molecular Beacons ${ }^{\mathrm{TM}}$ designed by Spartan Bioscience to provide a signal specific for the correct target. The post PCR products, shown in triplicate on the electrophoresis gel inset, are of the same length (132 base pairs) without secondary products.

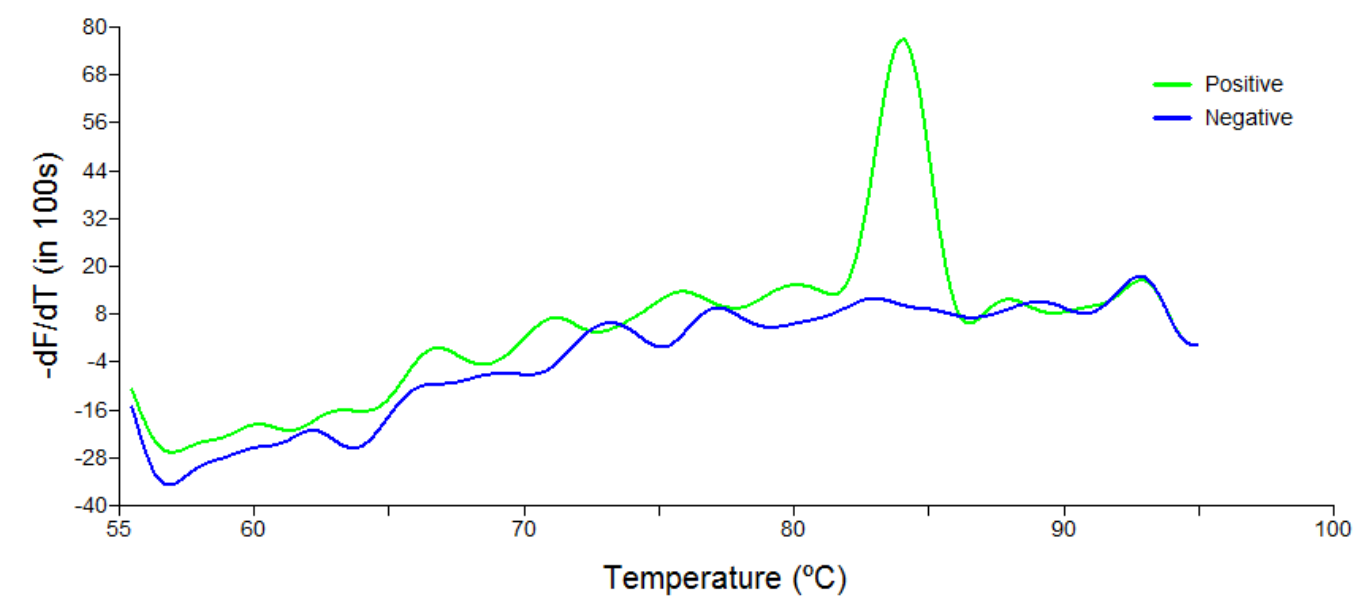

Figure 5-3. Melt curve of the ABCB1 PCR product with both Molecule Beacons and post run addition of SYBR green intercalating dye. The negative control does not contain SYBR green. The melting peak, at approximately 84 degrees Celsius, is that associated with the specific gene product. 

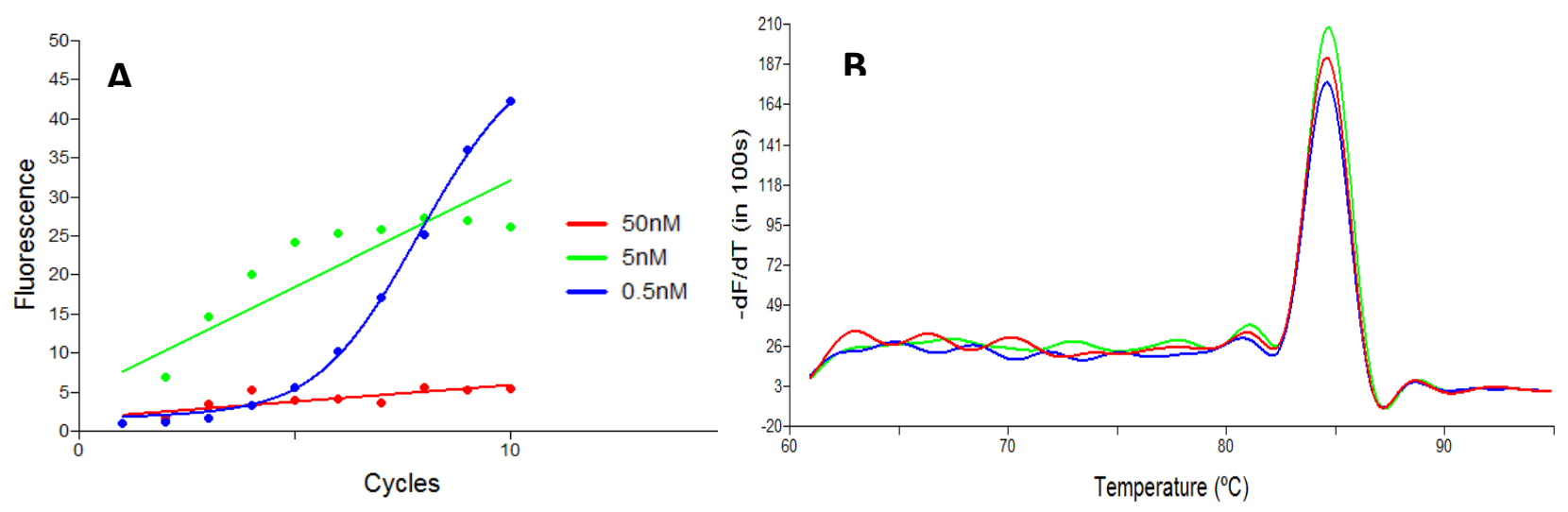

Figure 5-4. (A) Concentration optimization of the 10 cycle PCR reaction through starting template variance. (B) All of the amplifications produced identical melt peaks as seen on the right. However, saturation is reached before the first cycle is completed with a $50 \mathrm{nM}$ starting template concentration. Normalization to the initial data point was performed on data in the PCR run profiles of $(A)$ to examine change in reaction signal.

\subsubsection{Part II: Asymmetric PCR}

One of the notable differences between solid phase PCR and liquid based PCR is the binding kinetics of primers to template strands. Conditions in liquid based PCR are much more favourable for the hybridization of primers to a template. It is therefore necessary to design reactions that allow the solution-based PCR to assist with the binding of DNA to the surface of a fibre. This can be done through the overproduction of a surface binding DNA strand in a solution-based PCR as explained in Chapter 2. In order to ensure that the surface was not competing with the liquid PCR solution, an asymmetric PCR reaction was designed under the requirement of a 10 cycle completion time. This asymmetry in amplicon/template production was caused by the variance in the forward and reverse primer ratios in PCR. The effects of this asymmetric approach are discussed in Chapter 2. Figure 5-5A shows the effect of varying the primer ratios during a PCR reaction. Lowering of the concentration of a single primer causes the exponential phase of the PCR curve to appear diminished when detected through the usage of an intercalating dye. The intercalating dye does not have a signal in the presence of an overproduced 84 Page Jason Koppert MASc Thesis 
single-stranded DNA product and thereby does not appear as a part of the signal. Figure 5-5B illustrates that the same DNA product is produced in all the reactions despite the variation in the primer ratios. However, the absolute signal of the melting peaks of Figure 5-5B illustrates that the amount of dsDNA product has decreased proportionally to the decrease of the corresponding DNA primer.

Figure 5-6 completes the picture of the asymmetric PCR reaction. This reaction was probed using Molecular Beacons ${ }^{\mathrm{TM}}$. Since Molecular Beacons ${ }^{\mathrm{TM}}$ operate through detection of a single strand of a PCR reaction they can be used to specifically detect overproduction of an ssDNA fragment during asymmetric PCR. The use of Molecular Beacons ${ }^{\mathrm{TM}}$ indicates that this strand overproduction decreases as ratios approach 1:8 (reverse: forward) primer concentrations. As a balance between maximal asymmetric PCR and PCR efficiency, a ratio of 1:8 appears to be ideal.
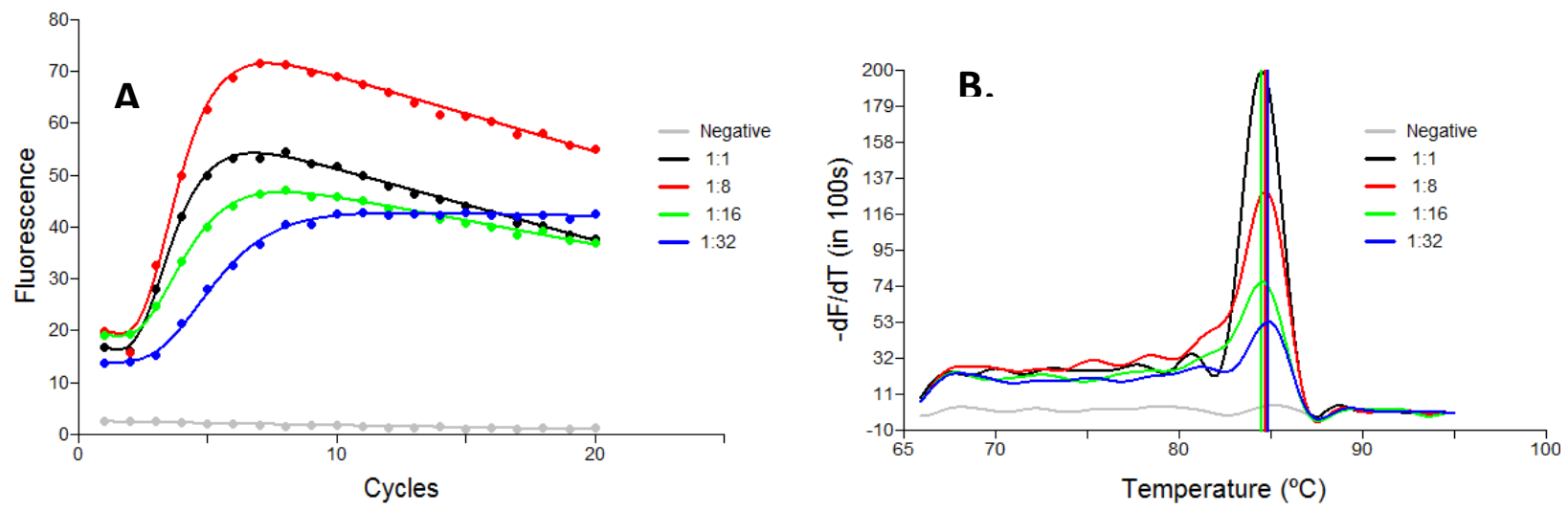

Figure 5-5. Asymmetric PCR depiction during run profile and melting curves. (A)The normalized run profiles on the left between 1:1 and 1:16 depict very similar PCR plateauing which would indicate that the efficiency of PCR has not changed significantly. (B) Melting curves depict that these corresponding plateaus have significantly decreased double stranded DNA presence. The initial PCR primer ratio is proportional to the dsDNA that generates a fluorescent signal. 


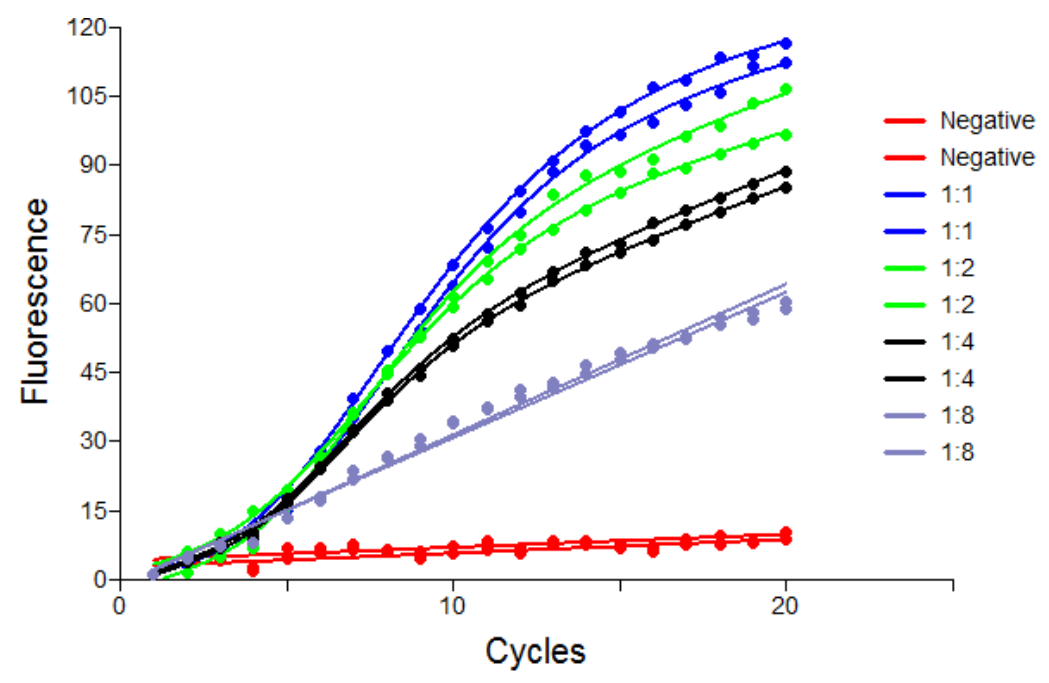

Figure 5-6. Molecular Beacons ${ }^{\mathrm{TM}}$ with asymmetric PCR reverse: forward Primer ratios. The continued amplification beyond the plateau regions of the SYBR green based detection method indicates that the production of single stranded amplicon continues in an asymmetrical manner.

\subsubsection{PART III: Surface Binding and Extension}

The development of a 10 cycle, asymmetric PCR allowed for the preparation of a kinetically favoured SP-PCR assay. In order for a detectable fluorescence signal to be generated on the surface of a fibre, binding of the single stranded DNA template must be optimized to allow polymerase action to extend a surface bound primer. This single-stranded DNA template is the same template that would be overproduced through the asymmetric PCR developed in Section 5.3.2 of this chapter. With all conditions identical to those as required by a PCR buffer solution, the most important variable regarding surface binding success is the concentration of magnesium chloride. Figure 5-7 shows the fluorescence signal of single stranded PCR template binding to the surface of a glass fibre with optimized magnesium chloride concentration. This interaction was examined with the probing strategies depicted in Figure 5-1B and Figure 5-1D. Using Figure 5-1D to probe the same interaction as Figure 5-1B results in a 
theoretically lower but still detectable signal as the presence of dsDNA in surface bound primer binding region is enough to generate a signal through an intercalating dye.

Once a DNA template is hybridized to a surface-bound DNA primer in the presence of a polymerase-free PCR reaction mix, introduction of a polymerase enzyme allows for the immediate detection of increasing fluorescence through the incorporation of an intercalating dye into newly generated dsDNA template. The introduction of polymerase enzyme is denoted as a star in Figure 5-8. Prior to the injection of the polymerase, the reaction displays a slowly plateauing surface signal generation. This interaction is due to the binding kinetics of the DNA template to the surface. Upon polymerase injection the fluorescence signal becomes markedly increased. This signal continues until the surface extension becomes saturated and the reaction plateaus. The inset images of Figure 5-8 depict the change in brightness on the fibre surface.

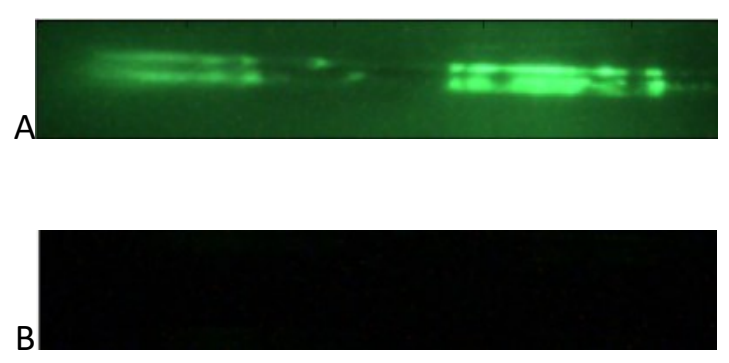

Figure 5-7. Binding of Ultramer template to the surface of the spots coated on a glass fibre. Ultramer binding is made fluorescent through usage of the Ultramer Probe as depicted in Figure 5-1B. (A) Binding of the Ultramer hybridization probe at a typical PCR annealing temperature. (B) Removal of the complex through a heat treatment. Excitation was performed externally with an Argon-Ion laser. 


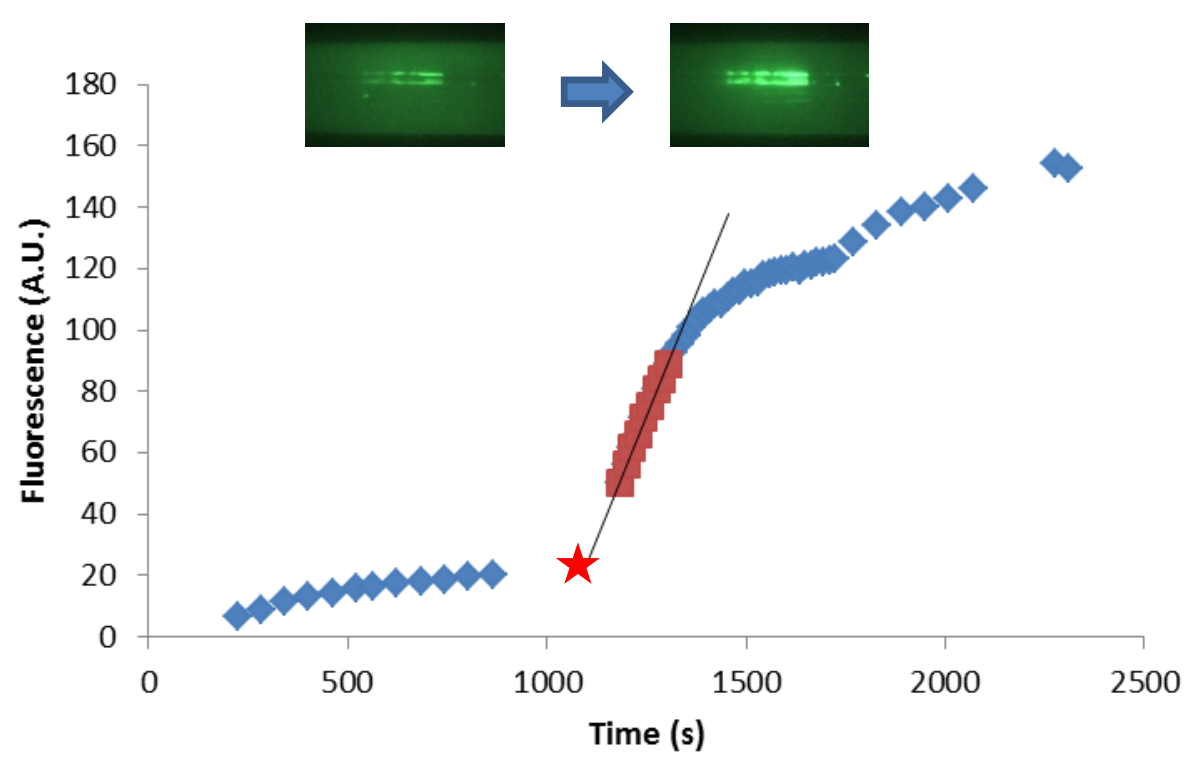

Figure 5-8. Polymerase extension detection in real-time on the surface of a DNA primer coated glass fibre. The polymerase injection point is marked by the star around 1100 seconds. The fluorescence signal is generated through the binding of SYBR green to the newly created double stranded DNA on the surface of the fibre. The inset images depict the progression of the surface extension of template. Left inset: 0-1000 seconds. Right inset: 1500 seconds. Extension of templates in solution is not possible due to the lack of a primer for the template.

\subsection{Discussion}

The involvement of PCR with a solid phase surface impacts several aspects of the SP-PCR development process. With a standard real-time PCR reaction, optimization of reaction parameters involves modification of concentrations of salts, primers, enzymes, probes, and melting temperature lowering additives such as DMSO (Montgomery \& Wittwer, 2014). With an SP-PCR reaction, the surface itself must be involved with DNA templates in the solution surrounding the surface. This could involve 
amplification in a method where both forward and reverse primers are grafted to a surface. The method is known as bridge amplification and involves extension of primers on the surface. Extended surface primers then bend back towards the surface and amplify in an opposing direction with the opposing direction primer (Shin, Kim, \& Lee, 2014). This method is known to have slower kinetics of amplification compared to other forms of SP-PCR and is therefore not ideal for high speed diagnostics when used alone (Khan et al., 2008).

Alternative strategies for SP-PCR include the usage of an asymmetric PCR reaction. Typically, real-time PCR involves nearly equivalent concentrations of forward and reverse primers to allow matched kinetics in both directions for maximum efficiency of reaction (Sanchez et al., 2004). When a surface with primers is introduced to a standard real-time PCR reaction, the kinetics of primer binding to templates in solution are more favourable than the binding of surface primers to solution-based templates (Hoffmann, Hin, Stetten, Zengerle, \& Roth, 2012b). To account for this imbalance between the kinetics of solid phase primers and solution-based primers, a solution-based PCR can be designed to minimize competition between the surface and the solution. This involves the overproduction of the ssDNA template that is associated with binding to the surface bound primer. This means only one primer directionality is attached to a solid surface.

The development pathway chosen for this project involved the characterization of a standard solution-based real-time PCR assay for adaptation to SP-PCR. Once characterized, the assay would be adapted to analyse and optimize a fibre hotwire SP-PCR through increasing of reaction speed and lessening thermal stresses on glass surfaces. Spartan Bioscience Inc. possesses a significant library of proprietary PCR diagnostic assays which could function for this research project. Figure 5-2 illustrates the real-time PCR run profile for the diagnostic assay target selected for this project. The target of this assay is a region of a gene known as $A B C B 1$. Therefore, the assay is referred to by this name. The inset of 89 IPage Jason Koppert MASc Thesis 
Figure 5-2 depicts the final product of the reaction when run on an electrophoresis gel. The gel banding indicates that a single product is produced through the PCR reaction. This single product nature is important since it allows for the minimization of interference from side products in a reaction which could interfere with the SP-PCR on a fibre surface. This electrophoretic banding also validates the results of the melting curve seen in Figure 5-3.

Melting curves are characteristic, to a certain degree, of the dsDNA product of a PCR reaction. Any variations in sequence of a PCR product even as small as a single base pair substitution can be detected if resolution of a melt curve is high enough (Dwight et al., 2011). With respect to the development of an SP-PCR assay, melting curves represent a valuable method of quickly and cleanly validating the success of a reaction. The presence of the sharp peak in the melting profile seen Figure 5-3 is characteristic of a successful reaction whereas the negative control would not possess this peak. The value of this melting property of DNA hybridization has been previously demonstrated with fibre optic technologies. Delport et al. utilized EDC cross-linking of DNA to a gold coated fibre surface (Delport et al., 2012). Their methodology employed a phenomenon known as Surface Plasmon Resonance (SPR) that allowed for the monitoring of multiple hybridization phenomena to produce accurate melt curve profiles. The application, in this thesis, of detectable hybridization on the surface of a fibre device represents an important first step in the development of a hotwire fibre based SP-PCR assay. Using the hybridization assay developed in Chapter 3, it would be possible to monitor melting profiles of surface binding events in real-time to probe reaction conditions necessary for SP-PCR. Such work is done in the next chapter.

The total running time of the $A B C B 1$ PCR reaction used in the development of SP-PCR, as seen in Figure 5-2, is approximately 1 hour when used with Spartan Bioscience's thermocycling device. However, during the initial phases of fibre hotwire development slow ramp rates were used which 90 IPage Jason Koppert MASc Thesis 
resulted in the same process taking nearly 3 hours. When this time is considered in combination with the setup and clean-up times of initial hotwire fibre SP-PCR experiments the throughput would only allow for a few experiments on a weekly basis. This represented a large challenge with regards to the ease of PCR optimization and the performance of replicates since conventional PCR assay development requires experimental validation of many possible variable interactions. Although experimental design methodologies such as fractional factorial approaches can be used to minimize experimental points required to probe variable interactions, a simple 5 -factor optimization process would require a minimum of 8 successful and quantitative interactions with a uniform variability across the sample population (Boleda, Briones, Farres, Tyfield, \& Pi, 1996). Manufacturing challenges in the initial stages of fibre optic hotwire production prompted the need for minimal variability to be probed through direct fibre optic experimentation. To achieve a more optimized research process, the $A B C B 1$ assay needed to minimize thermal exposure, minimize cycling time, and allocate as much development as possible to solution-based reactions without fibre optic variables taking play. The assay would then be then ported onto hotwire optical fibres once manufacturing had been stabilized.

To increase the speed of the reaction, there were several potential possibilities. The first possibility is to decrease the cycling time of the reaction by increased thermal ramping rates (ElenitobaJohnson et al., 2008). A second possible way of increasing the speed of a reaction is to increase concentrations of primers and polymerase enzymes (Montgomery \& Wittwer, 2014). However, increased thermal ramping rates and reagent changes are not independent and frequently require iterative design processes which become more complex if thermal ramp rates are unstable. The fastest PCR reactions would be the most sensitive to thermal changes and may experience complete loss of function if thermal parameters vary (Elenitoba-Johnson et al., 2008).

91 IPage Jason Koppert MASc Thesis 
During the initial phases of the fibre hotwire development project, fibre heating rates were quite variable and represented a challenge to any PCR reaction that was increased in speed through either quicker cycling or increased reagent concentrations (data not shown). For this reason, the optimal methodology to increase reaction speed and therefore result throughput would be to increase the initial concentration of DNA starting template.

The effect of increased starting DNA template concentration on the ABCB1 PCR assay is shown in Figure 5-4A. As the concentration of the initial template increases past a certain point there is no detectable change in signal produced by thermal cycling the PCR reaction. This phenomenon occurs due to signal and production saturation and means that minimal DNA amplification is occurring in a reaction vessel. Figure $5-4 B$ shows that the melting profiles of each of the three template concentrations of Figure 5-4A produce identical melting peaks and therefore contain identical products. However, only the 0.5 and $5 \mathrm{nM}$ starting template concentrations produced new amplification while the $50 \mathrm{nM}$ melting profile is that of the starting template material alone. The ideal starting template concentration would therefore be $0.5 \mathrm{nM}$ due to the largest signal increase generated per 10 thermal cycles. By decreasing the number of thermal cycles from approximately 25 to 5 , thermal exposure of hotwire fibre devices is decreased and experiment throughput is increased with minimal sacrificing of the SP-PCR optimization process.

Part II of this chapter pertains to the further optimization of PCR for solid phase application without direct experimentation with hotwire fibres. Using a single primer as the immobilized primer on the surface of a fibre, a template that is overproduced in solution-based PCR can maximize the chances of SP-PCR success through intentional favouring of solution-based templates binding to surface linked primers (Hoffmann et al., 2012b; Khan et al., 2008; Yi Sun et al., 2011). Conventionally, the ABCB1 gene target assay is run in a symmetric approach and therefore would not favour surface binding. In order to 92 IPage Jason Koppert MASc Thesis 
optimally use this assay for a fibre hotwire, it had to be adapted for overproduction of the surfaceprimer corresponding template.

The simplest approach to overproduction of a single stranded product in the ABCB1 assay can be seen in Figure 5-5A. Total product created through a PCR reaction is proportional to area under curve of the associated melting profile (Gudnason et al., 2007). Although not particularly useful from a quantitative standpoint, the relative value of area under curves can be seen in Figure 5-5B. This figure demonstrates that increasing primer ratio imbalance causes a significant decrease in dsDNA product as detected by an intercalating dye. This provides evidence that an SsDNA product is being overproduced since a PCR signal was generated for a similar time frame with all ratios of Figure 5-5A thereby indicating template generation continued despite lowered dsDNA product. The most important evidence of successful asymmetric PCR can be seen in Figure 5-6. Under identical conditions as those in Figure 5-5, a drastically changed signal is demonstrated with the use of a Molecular Beacon probe. The Molecular Beacon probe signal is proportional to the amount of the overproduced ssDNA. Over the course of 20 cycles, ssDNA production plateaus in a symmetric PCR while demonstrating increased linearity of signal towards more asymmetric PCR primer ratios.

In a standard asymmetric PCR reaction, the efficiency of the reaction will lower with the increasing imbalance of the forward and reverse primers. This problem can normally be resolved through the use of Linear After The Exponential (LATE) PCR (Sanchez et al., 2004). Generally in asymmetric PCR, lowering the concentration of a primer causes unfavourable kinetics between that primer and its target. This can be corrected through increasing the binding efficiency of this primer and its template (Sanchez et al., 2004). This methodology has been applied in SP-PCR as well (Khan et al., 2008).

93 I Page Jason Koppert MASc Thesis 
Since asymmetric PCR functioned well here with both intercalating dyes and Molecular Beacon probes, as seen in Figure 5-5 and Figure 5-6 with the 1:8 primer ratio, the LATE PCR strategy does not appear necessary. The lack of a need for LATE PCR strategies in this asymmetric reaction may be due to the high concentration of starting template used. High concentrations of starting template alleviate the effects of low primer concentrations that would normally occur in the beginning of a PCR reaction when template concentrations are low. A similar effect is alleviated in multiplex PCR assay strategies where increased template concentrations can reduce biases of amplification (Polz \& Cavanaugh, 1998).

Once the $A B C B 1$ assay was adapted to allow for favourable kinetics in SP-PCR through introduction of asymmetric PCR and high starting template concentrations, porting of PCR parameters to optical fibre surfaces was necessary. As seen in Figure 5-1, a suite of molecular probing strategies was designed to allow for detection of surface binding phenomenon, including the actual PCR event itself. Figure 5-1A reiterates the probing strategy used in the hybridization assay of the previous chapter. This probe continued to be useful in the manufacturing of fibres for PCR by allowing a quality control mechanism for coating successes.

The hybridization of a fluorescent probe and the hybridization of a primer and the DNA template required for PCR were fundamentally different due to the buffer used to allow the hybridization events. The hybridization of Figure 5-1A occurred in a buffer that allowed optimal binding but contained monovalent salt concentrations that were too high to allow polymerase activity (Montgomery \& Wittwer, 2014). Due to this, confirmation of the hybridization of DNA template and surface bound primer was performed by another fluorescent hybridization probe as seen in Figure 5-1B. This methodology allowed for testing and optimization of PCR buffer solutions. The results of this strategy are seen in Figure 5-7 indicating that the successful hybridization (Figure 5-7A) was reversible (Figure 5-7B) under the optimized buffer conditions.

94 IPage Jason Koppert MASc Thesis 
Another strategy to monitor the binding event of template to the surface was the use of a Molecular Beacon ${ }^{\mathrm{TM}}$ as seen in Figure 5-1C. The result would be similar to those of Figure 5-1B with greatly lowered fluorescence of the probe when not bound to the template. Molecular Beacons ${ }^{\mathrm{TM}}$, and their design process, come at a significant cost in both time and financial resources and therefore represented a less than ideal strategy. Alternatively, the binding of surface primer to the DNA template strand could be detected through a mechanism similar to Figure 5-1D, albeit with a lower fluorescence due to less dsDNA.

Detection of successful SP-PCR itself would be done through the strategies of Figure 5-1D and E. The former strategy involved the usage of an intercalating dye to detect the binding event of template to the surface bound primer. During polymerase activity, the fluorescence signal would increase as the surface primer was extended to create more dsDNA. The strategy of Figure 5-1E represents a follow-up probing method for SP-PCR success confirmation. If SP-PCR was successful, a new surface bound sequence would be generated and a probe specific to this region would be introduced after a heat treatment removed the competing solution-based DNA template.

SP-PCR requires the ability of polymerase enzymes to extend surface bound primers. To verify that polymerase activity was functional in the given primer coating methodologies and buffer conditions, an enzyme activity assay was designed. Successful hybridization of the surface primer to the DNA template was confirmed with an intercalating dye as in Figure 5-1D. Polymerase enzyme was then injected into the solution and fluorescence was monitored over a time course. The injection of polymerase is denoted through the star in Figure 5-8. The generation of increased fluorescence signal immediately follows this polymerase introduction and eventually plateaus once the surface extension has been saturated. The results of fibre surface based polymerase activity monitoring qualitatively resemble those of solution-based assays done with Molecular Beacons ${ }^{\mathrm{TM}}$ and intercalating dyes (Ma et 
al., 2006; Montgomery \& Wittwer, 2014). This assay was not used qualitatively in the context of this project. Rather, the assay was used to confirm that polymerase activity was possible under the given conditions. Further development of this assay would be necessary to allow for quantitative optimization of enzyme activity on glass surfaces.

This assay is different from actual SP-PCR in only the aspect of thermal cycling. Although thermal cycling is a critical aspect of PCR, all the key molecular functionalities required for SP-PCR were demonstrated upon success of this assay. This chapter signifies the first known application of an assay for monitoring of enzyme activity on a solid surface. Although this project did not involve the use of fibres for further development of polymerase activity assays, fibre technology could represent an accurate method for characterizing the activity of polymerases and the effects of reagents and temperature with regards to solid phase polymerase activity in real-time. The lack of detailed existing knowledge of SP-PCR polymerase activity could be a reason for minimal activity in this research area.

\subsection{Conclusion}

This chapter illustrated the development of a specialized high speed PCR assay that allowed for the simplification of the fibre optic device design process. Additionally, all of the key components of SP-PCR were shown to be able to function separately when using non-heating fibre optic surfaces. The asymmetric PCR design allowed for favourable SP-PCR kinetics while maintaining a 10-cycle reaction approach.

The novel contribution of this chapter involved the usage of components of the adapted asymmetric PCR assay to allow for real-time probing of polymerase activity on a fibre optic surface. To our knowledge this is the first instance of real-time polymerase activity monitoring on a solid surface. At this stage of the device development process, it appears as though all of the major PCR-specific variables have been addressed and understood by using fibre fragments without gratings or hotwire functionality.

96 IPage Jason Koppert MASc Thesis 
This is an important milestone since it allows for simplified porting of reaction parameters onto hotwire fibre devices and led to considerable cost savings. Without this approach, hotwire fibre devices would have been used inefficiently in the SP-PCR assay adaption process when production numbers were low. This would have slowed down the development process and would not have been an economically feasible approach at this stage of the project.

Although this project did not involve the use of optical fibres for further development of polymerase activity assays, fibre technology could represent an accurate method for characterizing the activity of polymerases and the effects of reagents and temperature with regards to solid phase polymerase activity in real-time. The lack of detailed existing knowledge of SP-PCR polymerase activity could be a reason for minimal activity in this research area. If work with SP-PCR kinetic knowledge was applied in similar fashion to the efforts of Carl Wittwer with conventional Real-time PCR, it is easily imaginable that SP-PCR assays could become much more widespread (Montgomery \& Wittwer, 2014). 


\section{Application of optical fibre hotwire devices in molecular assays and SP-PCR}

\subsection{Introduction}

This chapter acts as the culmination of the previously accumulated knowledge pertaining to the molecular assays and surface coatings. Here, the hybridization assays and SP-PCR assays will be adapted onto three variants of a functional optical hotwire device. As the assays were adapted to the devices, the requirements and specifications of the devices improved according to the detection needs of these assays. For that reason, we will discuss the use of two different devices leading into the final successful hotwire fibre device used with a real-time SP-PCR assay. This chapter specifically details the successful functioning of the proof-of-concept device that was initially hypothesized at the formation of the industrial and academic collaborations.

All existing literature concerning PCR analysis with fibre optic devices either analyse PCR retrospectively or represent a probe in a reaction vessel with external thermocycling. This chapter focuses on development of a prototype fibre optic device that provides heating to a reaction while still permitting visible monitoring of the fluorescence signals of PCR. The previously developed coatings and assay parameters will act as the fundamental components to be combined on a fibre optic based thermal cycling and fluorescence excitation platform for use with a diagnostic assay.

\subsection{Methods}

Fibre optic device development was a concerted effort between biological, chemical, and optical expertise on the proof-of-concept development team. Several different fibre devices were developed with the same end functionality in mind: on-fibre SP-PCR. These devices all possessed heating functionality and the ability to provide temperature feedback, however, the technologies employed to 
achieve these two goals differed in each design. Figure 6-1 depicts the three devices used to achieve onfibre PCR functionality presented in this chapter. Figure 6-1A and B utilize nanoparticle coatings as functional coatings. Silver nanowires are used for heating while gold nanoparticles and electroless deposition are used for reflection of light in the core of the fibre. In Figure 6-1A the TFBG allows the IR source light to be redirected from the core of the fibre to the surface-bound nanoparticles for heating. This TFBG also provides a traceable Bragg peak for temperature feedback. Figure 6-1B depicts an FBG for temperature feedback where an MMF:SMF (multimode fibre: singlemode fibre) bulge splice provides coupling of infrared (IR) light from the core to the surface-bound nanoparticles. This method does not selectively couple IR light from the fibre core to the cladding and therefore all core travelling modes will be subjected to a large percentage of loss. These losses can be controlled to permit heating of surface coatings and can allow simultaneous excitation of fluorescence on the fibre surface. The final design illustrated in Figure 6-1C shows the usage of an MMF fibre segment for coupling of visible light separately from IR coupling. The IR light is not coupled out of the core in this schematic. A segment of single mode light absorbing fibre is used here in place of silver nanoparticles. The light absorbing core provides heating functionality on the same calibre as the nanoparticles. A chirped grating is used in place of a mirror. This grating type allows for reflection of all relevant heating light from the IR pump source. The three devices and their respective temperature monitoring, heating mechanisms, and fluorescence excitation methods are compared in Table 6-1.

The aforementioned fibre devices were all utilized on an optical setup. This setup incorporated the necessary light sources and coupling splits for the incorporation of heating and fluorescence excitation at the desired location of the DNA spots on the fibre. This apparatus schematic is illustrated in Figure 6-2. 
The hybridization reaction performed with the hotwire fibre devices in this chapter was done with the hybridization assay of Chapter 4 as seen in Figure 4-5. Using the device schematic of Figure 6-2, a LabView $^{\mathrm{TM}}$ (National Instruments) interface controlled the IR laser power required to heat the fibre devices or to allow the devices to cool passively. Thermal cycling was coordinated with imaging to allow for stable temperature during image collection. The LabView ${ }^{\mathrm{TM}}$ interface allowed for thermal cycling and melt curve analysis to be performed. The hybridization reaction could be viewed through both external and internal excitation through the switching of the visible laser input of Figure 6-2. Additionally, for optimal comparison of the internal versus external fluorescence monitoring the FAM (6-carboxy fluorescein) fluorophore was optionally replaced with Texas red, a red-yellow fluorophore.

The specific, detailed processes for coating (both nanoparticles and DNA) and manufacturing the fibre devices of Figure 6-1 are provided in Appendix A.3.

The mathematical methods and software for calculating the derivatives of the melting curve were designed by Hubert Jean-Ruel and are detailed in the Appendix A-3. The melting profile of the fluorescence versus time was collected in real time with melt peaks analysed after data collection.

A PCR mastermix, based on the development parameters of the previous chapter, was placed into the glass capillary tube of the apparatus previously mentioned in Figure 4-2. Thermocycling of the capillary contents was controlled by the LabView ${ }^{\mathrm{TM}}$ (National Instruments) interface. Only LAFDs were used for the optical fibre hotwire SP-PCR. The melting curve data was monitored after the SP-PCR thermocycling by slowly ramping up the fibre hotwire power and collecting fluorescence image measurements throughout the process.

After running of the melt curve with the post SP-PCR product, the fibre device was rinsed without adjusting the position of the LAFD. After replacing solutions in the glass capillary tube for rinsing, the fluorescent probe solution, specific for the primer region of the DNA surface coating, was introduced 
(See Figure 5-1). This probe was then heated for melt curve monitoring after hybridization signal on the fibre surface had been maximized. In this manner the melting peak difference between the post SP-PCR product and the surface primer-probe could be analysed to examine the success of SP-PCR. The specific details of the PCR reaction solution as well as the thermal cycling parameters are provided in Appendix A.3.

Table 6-1. Comparison of temperature monitoring, heating method, and fluorescence excitation approaches for each of the three fibre devices depicted in Figure 6-1

\begin{tabular}{|c|c|c|c|}
\hline & $\begin{array}{l}\text { TFBG hotwire } \\
\text { (Figure 6-1A) }\end{array}$ & $\begin{array}{c}\text { Bulge hotwire } \\
\text { (Figure 6-1B) }\end{array}$ & $\begin{array}{l}\text { LAFD Hotwire } \\
\text { (Figure 6-1C) }\end{array}$ \\
\hline Temperature monitoring & \multicolumn{3}{|c|}{ Bragg Peak tracking with Broad-Band IR Source } \\
\hline Heating method & \multicolumn{2}{|c|}{ Absorptive Coating } & Absorptive Core \\
\hline Fluorescence Excitation & External Only & Exte & ternal \\
\hline
\end{tabular}



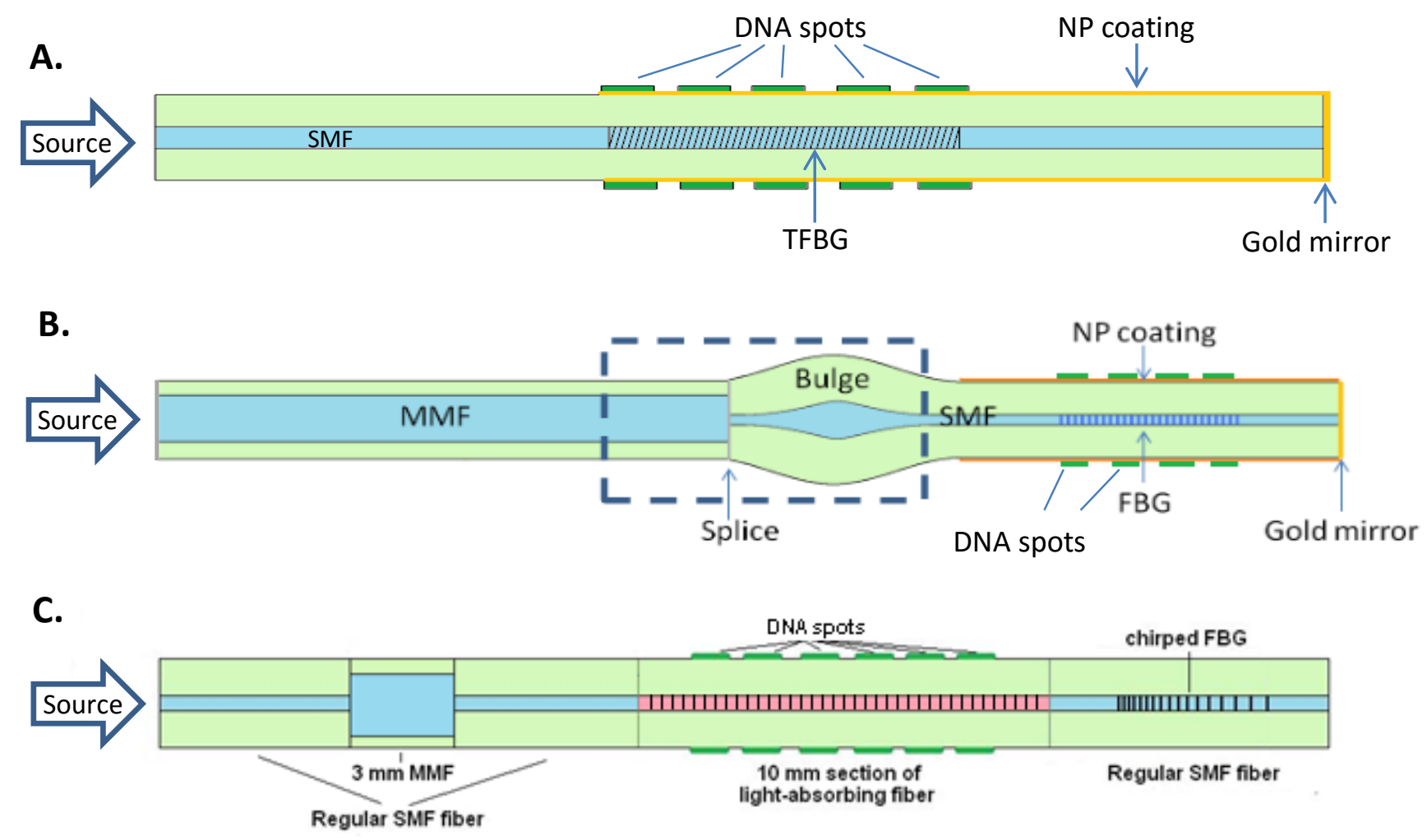

Figure 6-1. All types of fibre devices utilized in this chapter. Research progression led from $A$ to $C$ as the devices were adapted to SP-PCR. (A) TFBG written in an SMF 28 fibre. The heating mechanism occurs at the fibre surface and utilizes an absorptive nanoparticle coating. A gold mirror ensures the reflection of temperature signal and a second passage of IR wavelengths through the TFBG. (B) Bulge-based heating device. The bulge couples light from the MMF fibre into the cladding of the SMF 28 fibre where light can interact with the nanoparticle (NP) coating for heating. An FBG is used for temperature inquiry. (C) Light absorbing fibre device. This device is created by splicing a segment of proprietary Corativ ${ }^{\mathrm{TM}}$ light absorbing fibre along with SMF-28 fibre (Corning). Heating occurs in the core of the device where an FBG allows for temperature monitoring. DNA spots exist as green spots on the surface of the fibres in all these device depictions. The source of the IR and visible light needed for PCR are indicated by arrows. 


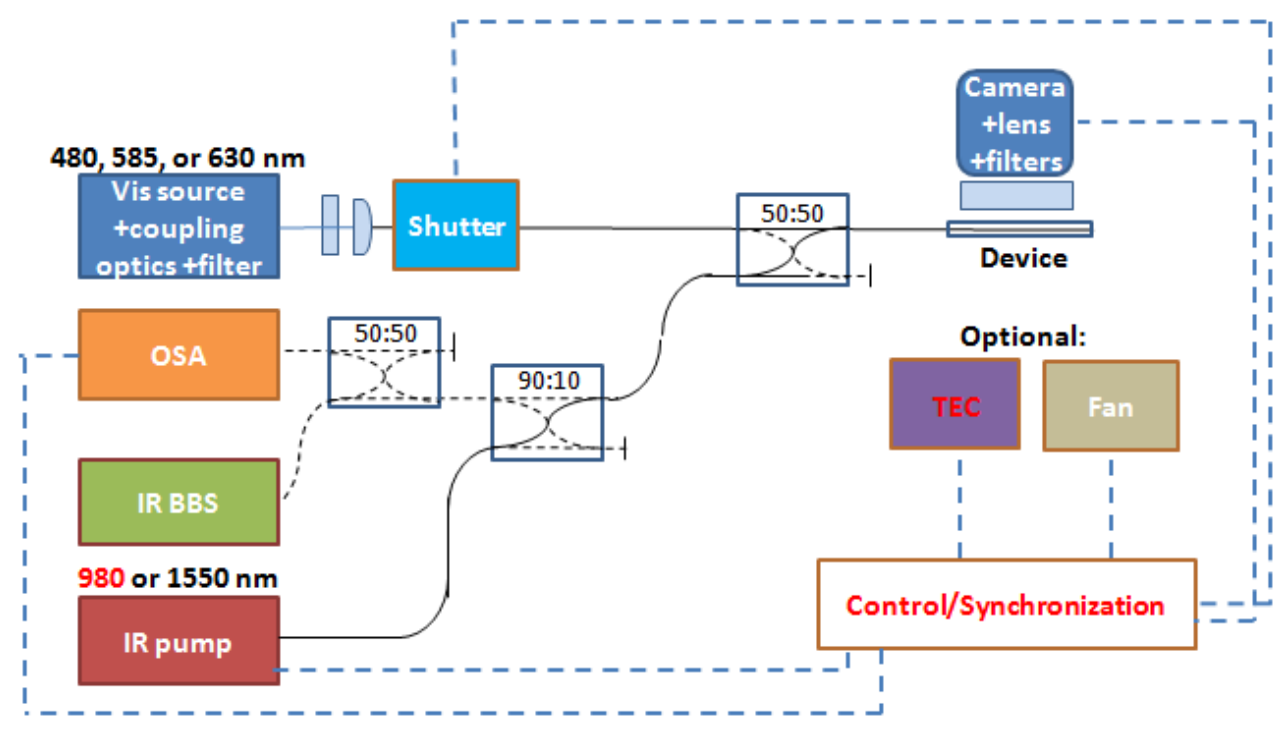

Figure 6-2. Prototype Hotwire-Fibre Rapid Thermal Cycling Device setup. Light sources include an IR broadband source (BBS), an IR pump, and a visible light source. The visible light is coupled into a fibre optic connection after passing through a shutter control. Visible light, BBS, and IR light for heating are all coupled into the fibre device simultaneously. The device consists of one of the schematics outlined in Figure 6-1. Such a device is contained in a capillary vessel for introduction of liquids such as hybridization and PCR solutions. All devices are used in reflection mode therefore returning an optical signal based on Bragg grating interaction, back through the couplers to the Optical Spectrum Analyser (OSA). All devices are controlled through Labview ${ }^{\mathrm{TM}}$ integration software at the control/synchronization centre. Optional devices include a Peltier Thermo Electric (TEC) Cooling Module and a fan for assisted heating and cooling of fibre devices. Diagram is courtesy of Hubert Jean-Ruel. 
A.
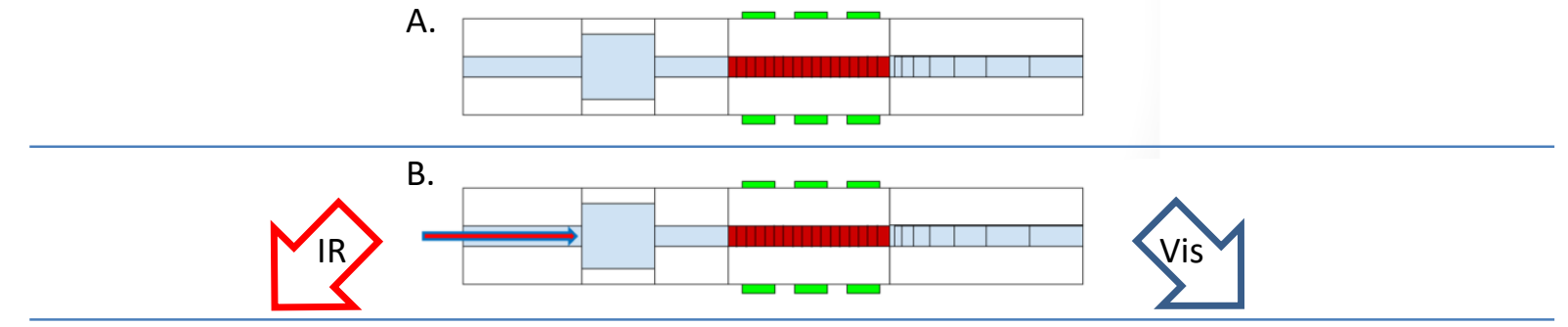

C.

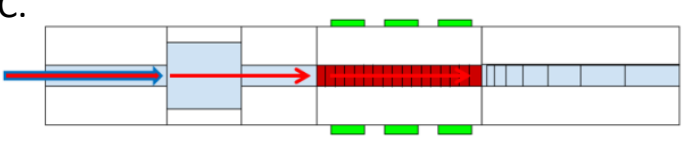

D.

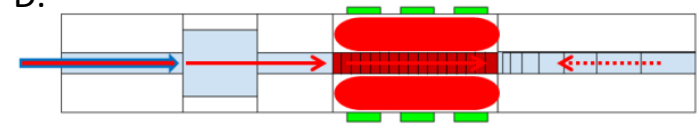

E.

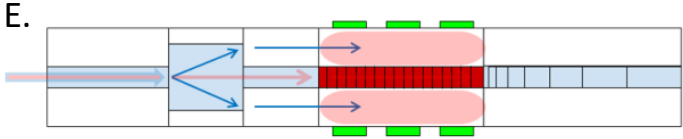

F.

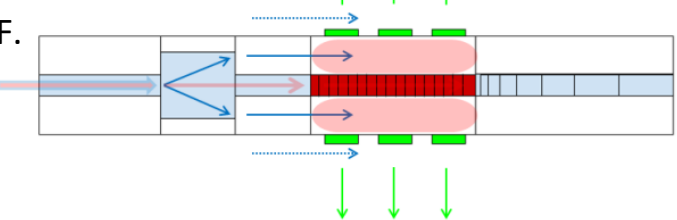

Figure 6-3. (A): The final, functional, fibre hotwire device. Refer to Figure 6-1 for the component labelling and fibre core size break down. (B): Three light sources, IR, BBS, and Vis light, enter the fibre simultaneously. The functionalities of the IR light and Vis light are separated in ' $\mathrm{C}$ ' and ' $\mathrm{E}$ ' but occur simultaneously. (C): IR and BBS light pass through the MMF segment with minimal loss of power. BBS light reflected by the grating is used to probe the temperature of the Light Absorbing Fibre device. (D): IR light then interacts with the Light Absorbing Fibre to generate heat. IR light is also reflected by the chirped FBG to allow a second pass of light through the Light Absorbing Fibre. (E): Vis light experiences relatively more loss of light to the fibre cladding than the IR light. (F): Vis light propagating through the fibre cladding creates an evanescent wave that travels parallel to the surface of the fibre. This evanescent wave allows for excitation of the DNA spots. Fluorescence created at these spot locations is then captured at a perpendicular location to the fibre device. 


\subsection{Results}

This section details the adaptation of the previously discussed DNA surface coatings and molecular assays to the surface of hotwire optical fibre devices. The progressive development and evolution of the hotwire fibre device requirements is detailed through the influence of parameters such as fluorescence excitation methodology, heating mechanism, and SP-PCR reaction compatibility.

\subsubsection{Part I: Fibre heating and excitation functionality with DNA coatings}

The primary focus of fibre device development pertained to the ability of such a device to reproducibly thermal cycle a specific local of the fibre where DNA spots were coated. To demonstrate this purpose and to validate the overall optical setup, a TFBG fibre device was coated with DNA spots and nanoparticles. Such a device is depicted in Figure 6-1A. This device was hybridized with a DNA probe complementary to the sequence of the surface-bound DNA oligomer. This was performed in a solution of the probe and was monitored in real-time. Upon binding of the probes, the surface DNA spots would fluoresce at significantly higher signals than the solution itself. This allowed for the application of IR heating to the fibre solution while imaging occurred in real-time. Figure 6-4 depicts a 4 spot array of identical DNA spots hybridized with fluorescent probes just prior to application of IR heating. This image and respective normalization to the solution background also represents the initial signal of the melting profiles of Figure 6-5. As IR light source power was increased, the spots would measurably disappear as demonstrated in the end point analysis of both Chapters 4 and 5. This decrease in signal was monitored in real-time as temperature was increased and this produced the plot of Figure 6-5A. The negative derivative of this plot was calculated to analyze the specific melting profile of the fluorescent probe and the surface bound DNA. This derivative plot, as shown in Figure 6-5B, reveals the melting temperature of the probe and its complement to be around 60 degrees Celsius. This melting temperature is near the expected value for the dsDNA sequence when using melting temperature calculations according to uMelt software ${ }^{\mathrm{SM}}$ (Dwight et al., 2011) .

105 IPage Jason Koppert MASc Thesis 
Two significant issues were encountered with the TFBG devices pertaining to the monitoring of fluorescing DNA spots in real-time. The first issue pertains to a luminescent effect that occurs in a TFBG when visible laser sources are directed through the core area of the TFBG. This luminescence effect is greatest towards the shorter wavelength side of the visible spectrum but persists through all visible wavelengths (data not shown). This effect is demonstrated through the usage of bare glass fibres containing TFBGs and coated with DNA as seen in Figure 6-6 and Figure 6-7A. The effect persists despite removal of the probe and is difficult to remove with filtering due to the relatively intense signal of the luminescence, compared to the fluorescence signal. The luminescence effect appears to overwhelm a large spectral bandwidth including the fluorescence signal. This core luminescence could be manageable if the luminescence remained confined to the centre of the fibre as seen in Figure 6-6 and Figure 6-7A. However, nanoparticles, required for heating, disperse and scatter light that is coupled from the core and therefore effectively saturate the entire area of interest and block any potential fluorescent measurements. A solution to this problem is to excite fluorescence on the surface of the fibres with an external light source as done in the previous two chapters. When compared under ideal conditions as seen in Figure 6-7, the internal excitation in Figure 6-7A appears to be drastically inferior to the external excitation of Figure 6-7B.

This leads to the second problem pertaining to fluorescence excitation of TFBG-based heating fibres. When excited with external light sources such as a laser diode, or an LED, the signal appears to produce a satisfactory signal-to-noise ratio. However, Figure 6-8 depicts the issue with utilizing external light sources especially when using fibres as heating devices. The excitation window of the fibre surface is rather narrow due to the desire to minimize fluorescence of the solution. This leads to motion sensitivity of fibres contained in a reaction vessel. When the fibre moves in this excitation window the signal can vary widely. This problem is more pronounced during heating of capillaries as the fibres can at 
times stick to the glass capillary walls and outgassing (of vessel and reaction components) can temporarily produce bubbles that nudge the fibre.

To solve these issues, two alternative fibre optic devices were developed. These devices, illustrated in Figure 6-1B and C, utilize non-luminescing FBG gratings. Both of these devices utilize Total Internal Reflection Fluorescence (TIRF) based excitation methodologies. Figure 6-9 depicts the fluorescent probe hybridization to surface DNA spots on the bulge-based device of Figure 6-1B. Figure 6-9A uses internal excitation and displays high spot signal with minimal solution-based fluorescence background. Figure 6-9B depicts the identical fibre imaged with external excitation. Background fluorescence lowers the signal-to-noise ratio. Analysis of a population of bulge-based devices, as seen in Figure 6-10, shows that internal excitation produces a significantly higher signal-to-noise ratio than is ideally possible with external excitation. It is important to note that the conditions during real-time thermal treatment are frequently not ideal and therefore the signal-to-noise ratio of external excitation is frequently lower and also variable. The internal excitation ratio remains consistent regardless of the 3dimensional movement of a fibre in a glass capillary. The variability of motion with internal excitation is captured in Figure 6-10. 


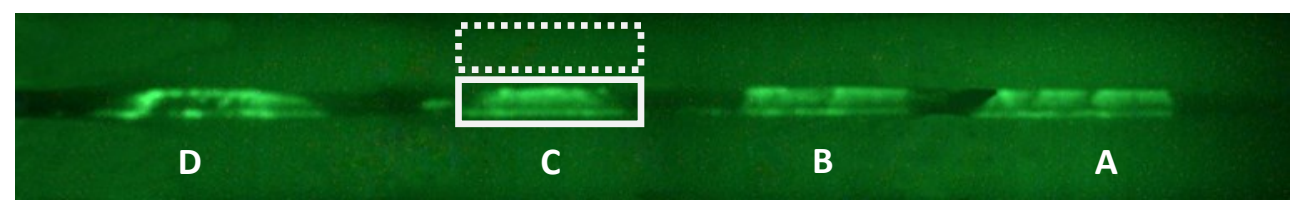

Figure 6-4. Composite image of different DNA spots on a nanoparticle coated TFBG fibre. The fibre functionality schematic can be seen in Figure 6-1A. The DNA spots are hybridized to a fluorescent probe. Spots A-D are unique entities representative of potential multiplexing ability on the surface of a fibre. The solid border box encloses the area of the spot used for analysis with the dotted enclosure representing the region used for background measurements.
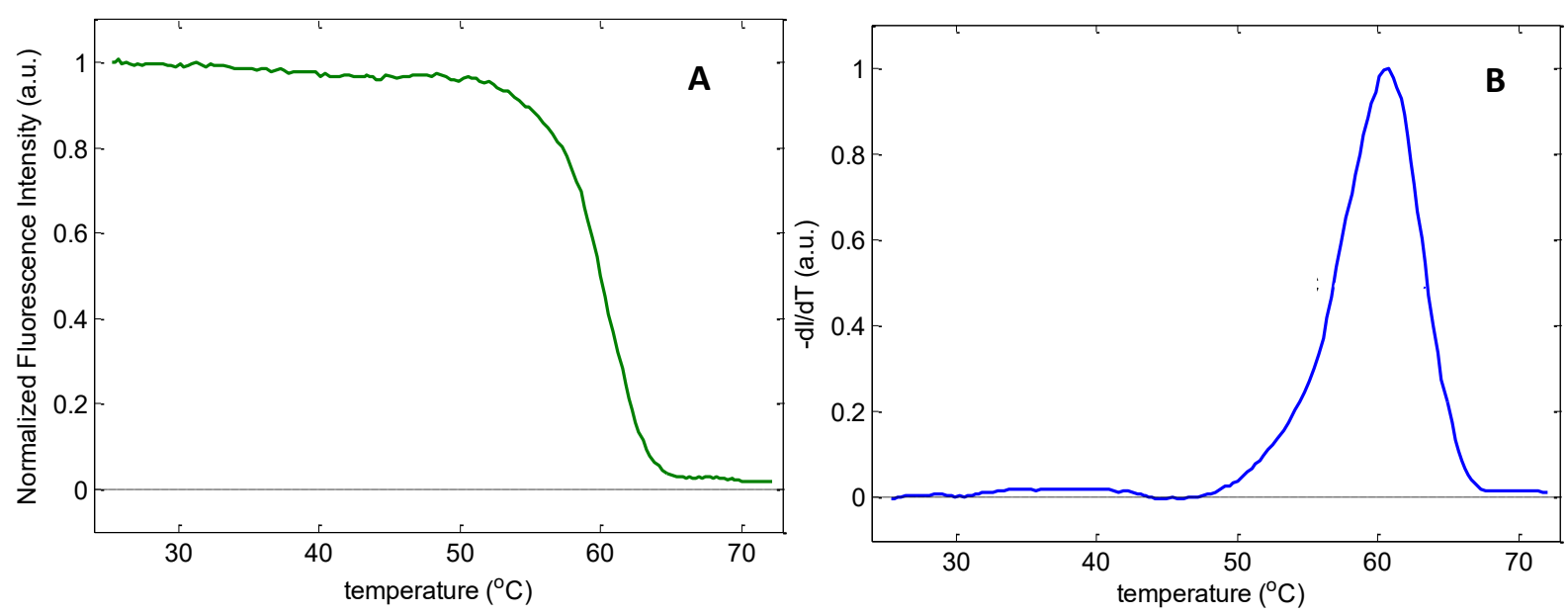

Figure 6-5. (A) Normalized fluorescence intensity versus TFBG temperature for Figure 6-4 spot C. The average intensity within the area represented by the solid white rectangle is normalized to the average intensity within the area represented by the dotted white rectangle (corresponding to the solution adjacent to spot C). The latter is also subtracted from the former to provide a more accurate baseline. The data presented were not smoothed. (B) Corresponding melt curve for spot C. A boxcar smoothing was applied. 


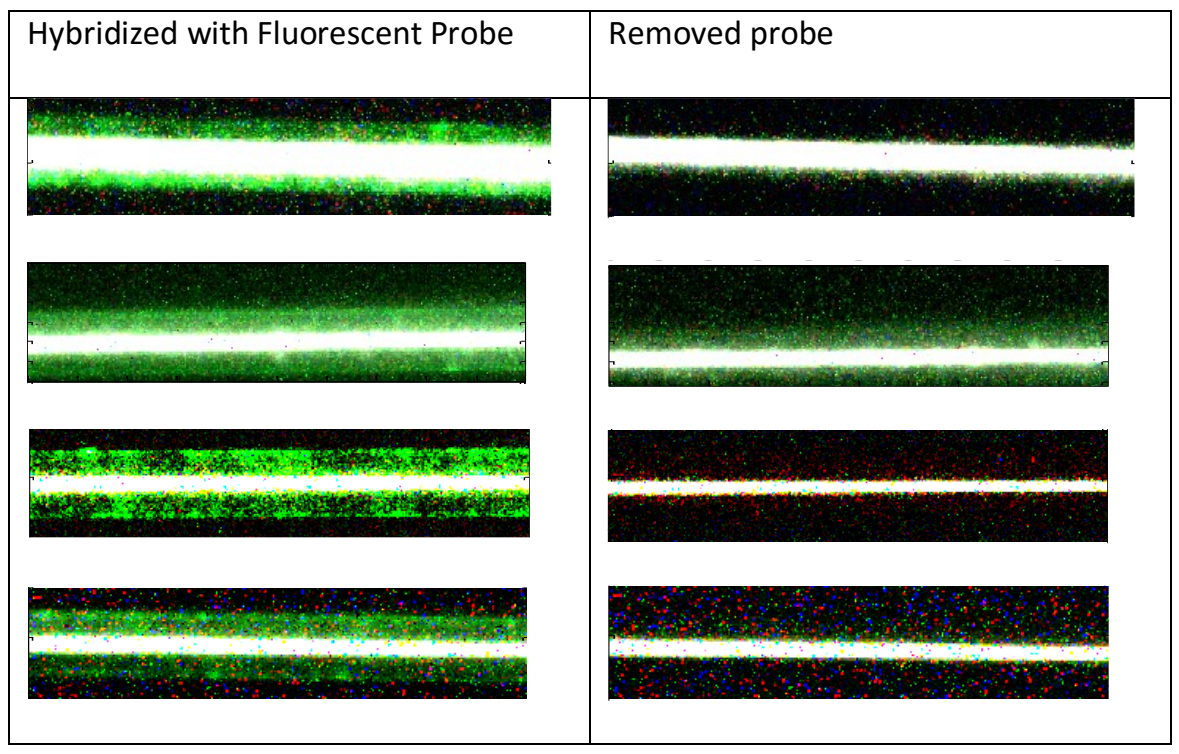

Figure 6-6. Interference caused by TFBG luminescence effect. The effect is pronounced with $488 \mathrm{~nm}$ excitation light and varies in intensity between fibre devices. For this reason, measurements are difficult to take with internal excitation with a TFBG device. This collection of images corresponds to bare glass fibres possessing no functional coatings for heating. Such coatings scatter light emitted from the fibre core and thereby exacerbate this luminescence problem. 


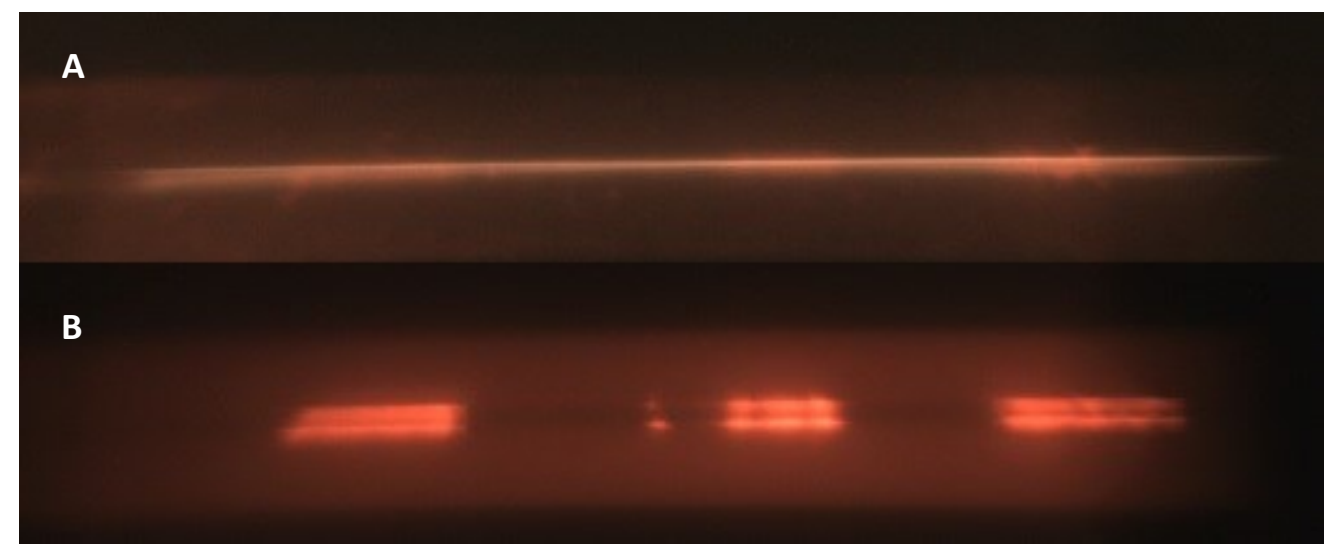

Figure 6-7. Comparison of a TFBG fibre with hybridization probe binding with both internal excitation (A) and external excitation (B). The internal excitation does not appear to function well in this instance although there are some visible perturbations where spots are present in the external excitation image. The red spots are an effect of utilization of Texas Red dye in place of fluorescein on the probe used in the hybridization assay. Texas Red dye was used due to its excitation line being at $590 \mathrm{~nm}$. This laser line produces less luminescence in the TFBG core compared to $488 \mathrm{~nm}$ excitation. 


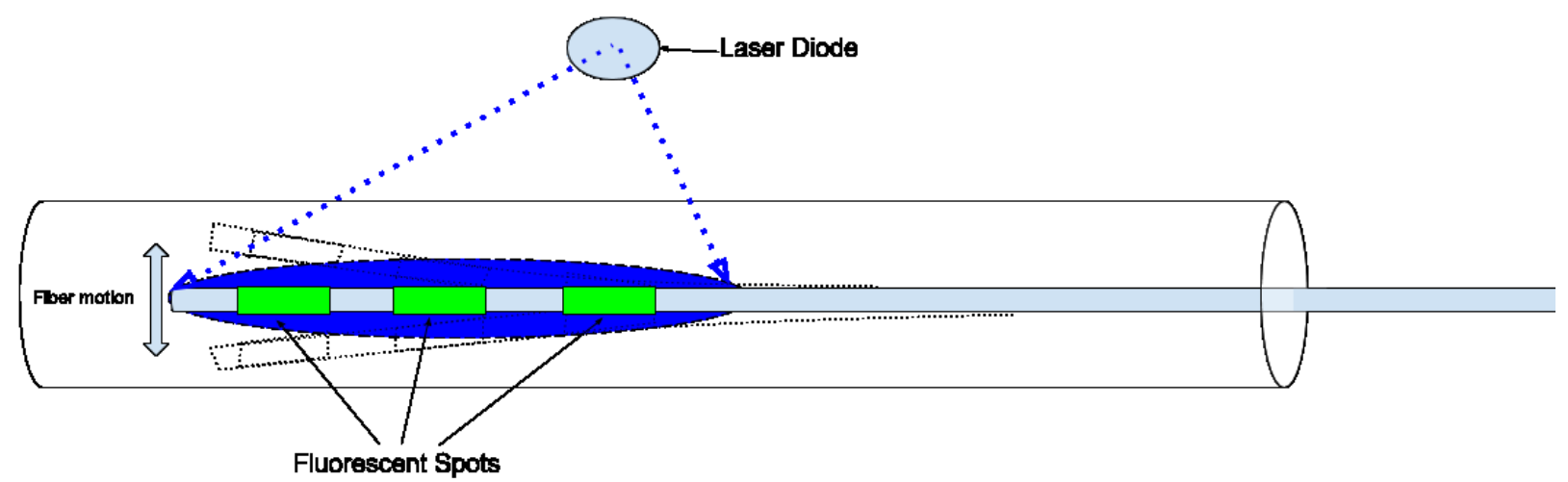

Figure 6-8. Simplistic depiction of a common problem with fibres and external excitation of fluorescent spots. The excitation of the fluorescence is performed through a laser diode. Excitation has an effective beam region that is depicted by the blue ovoid shape. Outside of this region fluorophores will have minimal fluorescence. This beam shape is an effect of the cylindrical glass capillary and laser beam shape. Because of this regional effect, movement of the fibre can cause fluorescent spots to vary in intensity especially during thermal applications. 
Figure 6-9. MMF-SMF bulge device with internal excitation (A) and external excitation (B) methodologies. This represents the identical hybridization assay conditions as seen in Figure 6-7.

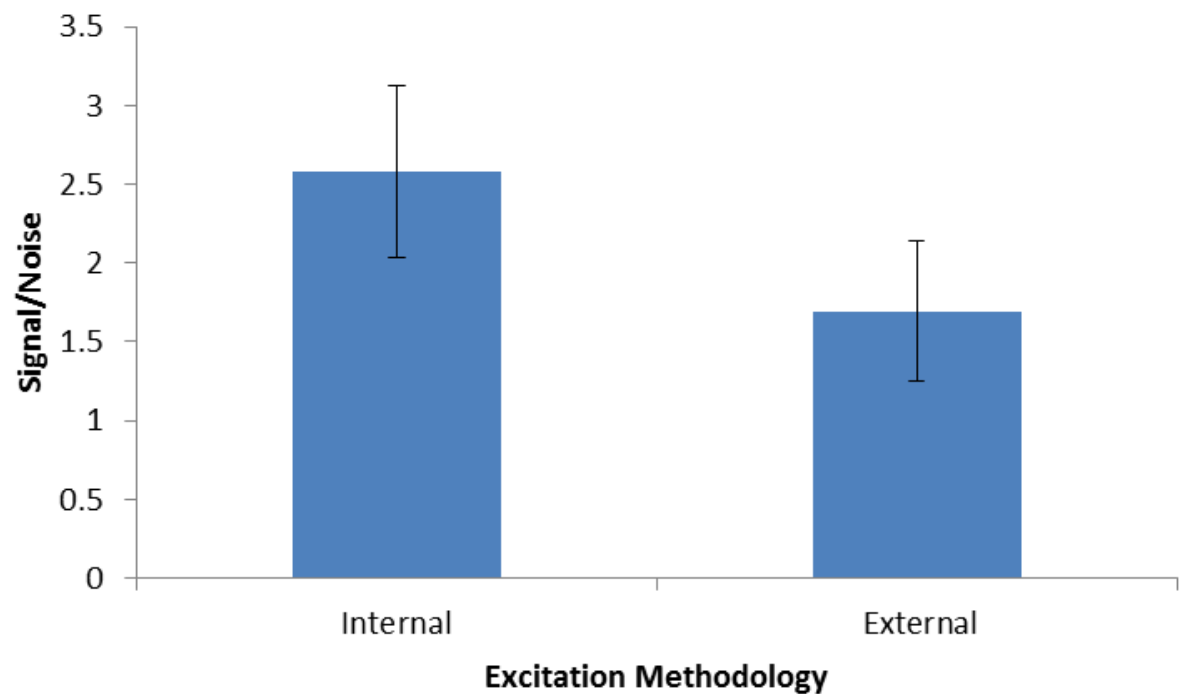

Figure 6-10. Comparison of signal to noise ratios for external versus internal excitation methodology. A significant caveat here pertains to the quality of the external excitation readings. In this experiment, external excitation was maximized through proper alignment. This alignment is frequently sub-optimal during real-time image acquisition. 


\subsubsection{Part II: Thermal Cycling and Solid Phase PCR with a Fibre Device}

The common requirement of all three fibre devices of Figure 6-1 pertains to their ability to perform the thermal cycling required by PCR. To test the thermal cycling ability of the fibres with a biological assay, the hybridization probe was used again. To prove that the fibre devices could thermal cycle sufficiently for DNA binding on the surface of a fibre, the binding interaction seen in Figure 6-4 and Figure 6-5 was repeated in sequence with IR power application and removal. Figure 6-11 illustrates the effect of DNA hybridization and removal in real-time with a fluorescence signal. The removal of the IR power allowed for the open air cooling of the capillary device and the re-hybridization of the fluorescent probe from the solution to the surface. This cycling experiment allowed for the optimization of thermal cycling parameters while demonstrating surface-bound DNA functionality.

Due to the small batch complexity of manufacturing bulge devices, the Light Absorbing Fibre Device (LAFD) displayed in Figure 6-1C was chosen for the incorporation of SP-PCR on a fibre surface. A DNA spotted LAFD was combined with the ABCB1 asymmetric PCR master mix of Chapter 5. It was temperature controlled utilizing Bragg peak tracking to thermal cycle the fibre device and the surrounding solution. This device was used with internal excitation to minimize solution-based background from interfering with an SP-PCR signal. Figure 6-12A shows the progression of an LAFD through a 15 cycle asymmetric PCR reaction. Figure 6-12B shows the signal increases of both the solution and the fibre surface signal as probed with a SYBR green DNA intercalating dye. The surface fluorescence signal is not inherently obvious until the solution signal is removed from the surface signal as seen in the inset Figure 6-12B. The SP-PCR appears to saturate around the 6 cycle mark. Image analysis of the post PCR product, as seen in Figure 6-13, reveals that it melts off of the surface at around 85 degrees Celsius. The exact fibre spot reveals a melting temperature of around 65 degrees Celsius after the PCR product is removed and the primer sequence probe is introduced. The important indicator of successful PCR amplification is the temperature delta between the post PCR product and the 
fluorescent probe surface removal temperatures due to the melt curve analysis discussed in section 2.2.2.

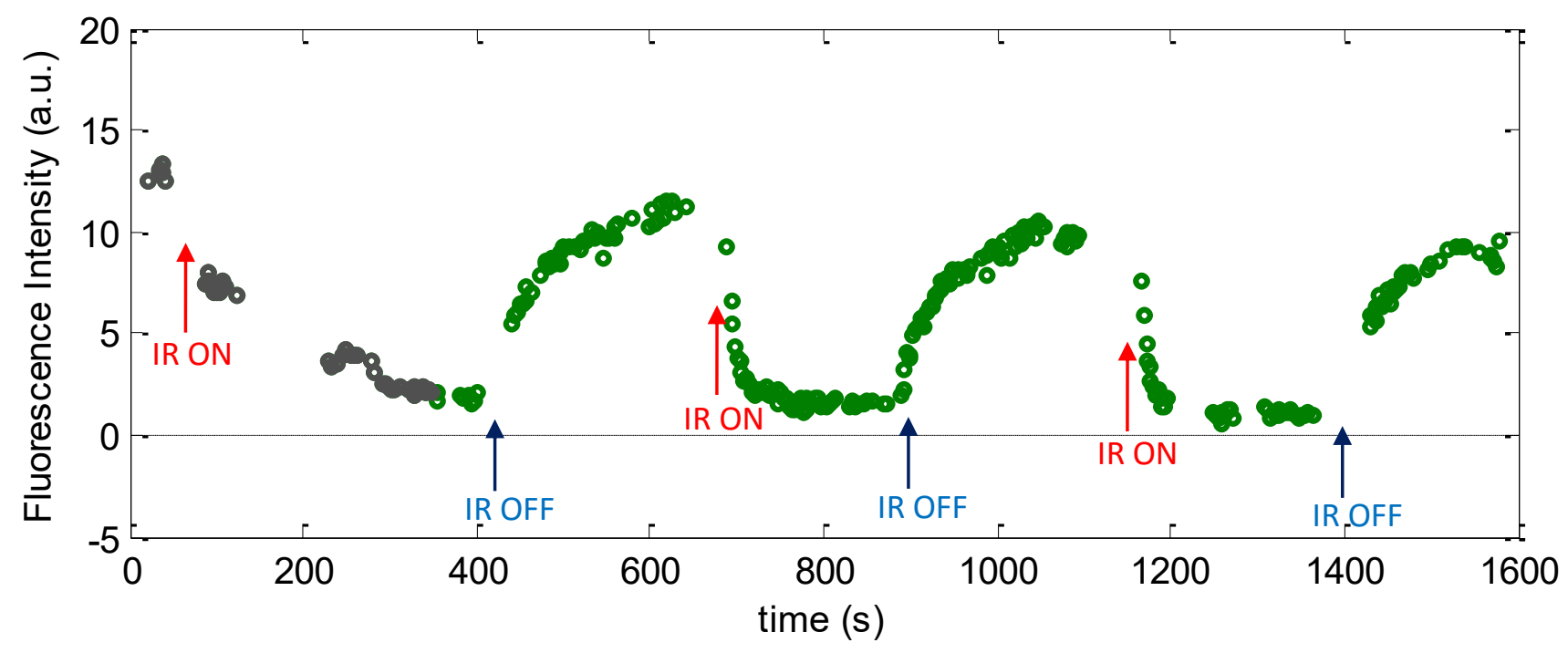

Figure 6-11. Green intensity (fluorescence intensity) as a function of time, with 1 sec exposure, as the IR power is cycled between 0 and $700 \mathrm{~mW}$. A smaller portion of the TFBG (approximately $0.5 \mathrm{~mm}$ length) is considered for improved contrast and the core luminescence was excluded. The fluorescence measurements were collected via external excitation with $488 \mathrm{~nm}$ light. Although the results shown here are from Device A of Figure 6-1, these results have been reproduced with all three of the fibre devices shown in this Figure 6-1. The duplicated results of the sequentially developed devices are not shown but were entirely consistent with that shown in Figure 6-10. 
A

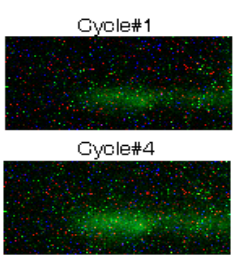

Gyole\#7

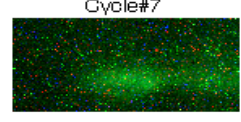

Gycle\#10

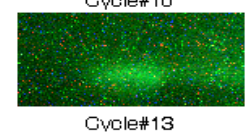

Gvile\#13

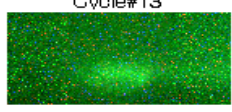

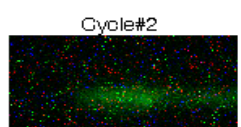

Gycle\#5

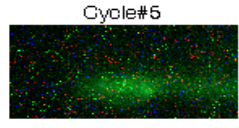

Gvole\#8

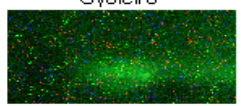

Gycle\#11

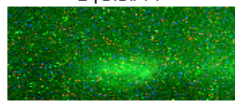

Gvicle\#14

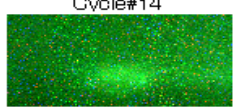

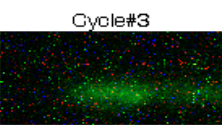

Gycle\#6

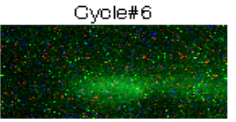

Gycle\#9

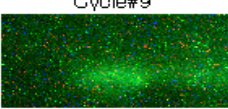

Gycle\#12

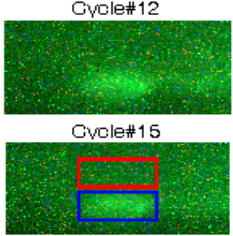

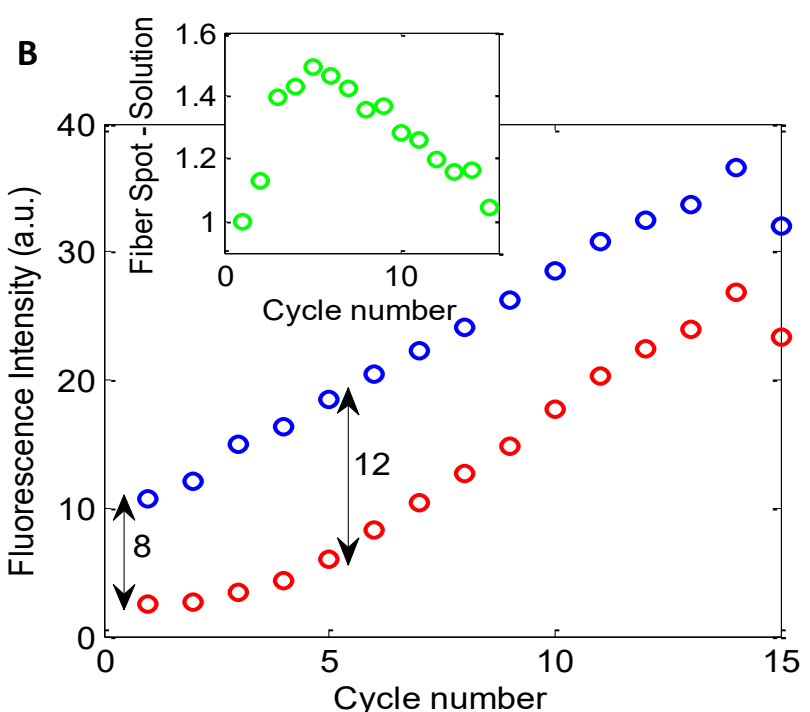

Cycle number

Figure 6-12. (A) Fluorescence image acquired at each cycle. The image intensity was multiplied by 5 in each case to improve visualization. Only a sub-region of the image is shown here and considered for this analysis. (B) Corresponding fluorescent intensity count for the fibre spot (blue) and for the background solution (red). The inset shows the difference in intensity between the spot and the background. 


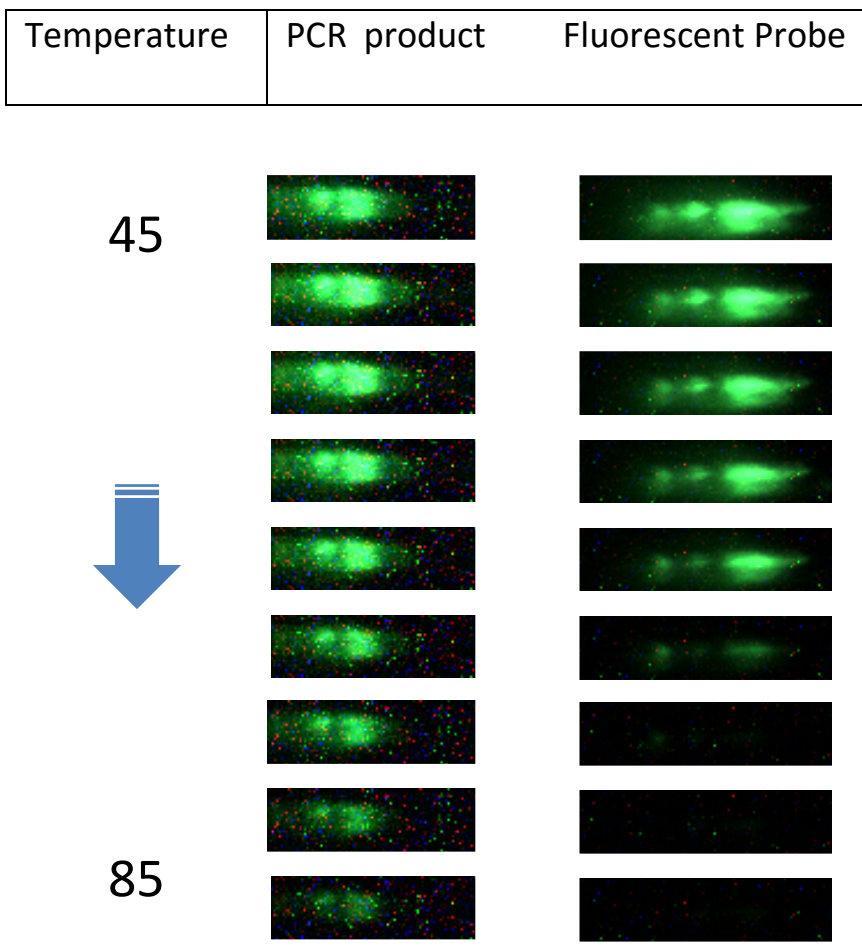

Figure 6-13. Depiction of the template melting difference between the PCR extended oligomer and the fluorescent hybridization probe. The observed delta is approximately that of the expected theoretical differential between the probe and the produced template.

\subsection{Discussion}

The previous chapters have focused on the development of surface coatings and molecular assays that would be compatible with hotwire fibre SP-PCR. However, the critical component of SP-PCR pertains to the ability of an optical fibre to perform thermal cycling. This component represented the 
most novel development component in the hotwire fibre optic SP-PCR project. Only recently have fibre optic technologies been used for non-end based heating applications (Gao et al., 2011). Several hotwire fibre optic strategies have been previously demonstrated to function as wind anemometers. However, the potential for these hotwire applications to be used in PCR or SP-PCR has yet to be proven elsewhere.

To allow for experimentation to begin with hotwire based SP-PCR, several fibre optic based hotwire devices were developed. These devices can be seen in Figure 6-1. Each of these hotwire devices had to permit the usage of a DNA attachment strategy while still retaining the ability to heat and cool PCR solutions surrounding the fibre. Figure 6-1A, represented a novel strategy for hotwire experiments. Light originating from an IR laser source would travel down the fibre core until it encountered an in-fibre TFBG. This TFBG allows for the removal of specific wavelengths of light from the fibre core for coupling towards the surface of the fibre ( Albert, Shao, et al., 2013). At the surface, this redirected light would interact with nanoparticle coatings and their plasmon resonances would allow heating (Russell, McKnight, Hestekin, \& Roper, 2011). There are many potential types of surface coatings that would allow heating. These include silver, gold, (in the form of uniform films) or nanoparticle coatings (Simoncelli et al., 2015; Son et al., 2015; Xinyong Dong et al., 2012).

Since the gratings in the core of the devices are produced through a manufacturing process that involves writing the grating with UV laser exposure through a phase mask, using UV light to crosslink DNA onto the surface of a grating containing device could theoretically interfere with grating function. No observable changes were noticed regarding FBG spectra after the UV coating was used for DNA attachment (Data not shown).

When a TFBG device was created according to the schematic of Figure 6-1A and coated with 4 spots DNA spots using UV cross-linking, the hybridization assay produced the results of Figure 6-4. The hybridization closely resembles that of the non-functional fibres depicted in Chapter 2 . Since the fibre 
was designed to allow IR light interaction with nanoparticles on its surface, the heating capability of the fibre could then be tested through a real-time monitoring of the hybridization assay. Figure 6-5A depicts a run profile of the fluorescence of Figure 6-4 spot ' $C$ ' normalized to the dashed-box area directly above the spot. As the fibre was heated from $40-70^{\circ} \mathrm{C}$, the fluorescence quickly dropped at around $55^{\circ} \mathrm{C}$. The negative derivative of fluorescence, depicted in Figure 6-5B, reveals a melting peak centred around $60^{\circ} \mathrm{C}$. This melting peak corresponds with the approximate $\mathrm{Tm}$ of the fluorescent probe and surfacebound primer used in the hybridization assay.

Fibre optics have been previously used with melting curve analysis of hybridization events for the purpose of mutation detection and PCR monitoring (Abel, Weller, Duveneck, Ehrat, \& Widmer, 1996; Arghir, Delport, Spasic, \& Lammertyn, 2015; Delport et al., 2012; Knez, Janssen, Pollet, Spasic, \& Lammertyn, 2012; Marazuela \& Moreno-Bondi, 2002; Pollet et al., 2011). However, no literature has been found utilizing hotwire fibre schematics for molecular assays such as hybridization monitoring. Temperature control demonstrated by real-time monitoring of a hybridization assay indicated that the hotwire fibre possessed immense potential for the purposes of developing SP-PCR with hotwire fibre optics. Additionally, this real-time assay demonstrated the ability to distinctly produce spots that are spatially separated and represents the opportunity to multiplex DNA spotting on the surface of a functional fibre optic hotwire device. Each spot could be a different SP-PCR target!

Although the technology and expertise of the project team were heavily centred on TFBG grating hotwires, a critical phenomenon presented a major disadvantage to using the TFBG device schematic versus the other options of Figure 6-1. This disadvantage pertained to the inability to simultaneously couple IR and visible wavelengths to the fibre surface without major background light pollution. Figure 6-6 depicts the level of light pollution on a fibre that centres heavily around the core. In this figure, the hybridization signal is dominated by camera saturation due to a luminescence effect in 
the TFBG. This effect persists even after the hybridization effect is reversed. Fibres represented in Figure 6-6 were not functionally capable of performing thermal cycling because they lacked metallic or nanoparticle coatings that would allow for heating. These coatings were not included to demonstrate the source of the luminescence phenomenon. When nanoparticle coatings were used on the fibre surface, they would scatter this core luminescence effect and effectively saturate the entire region of interest (data not shown).

This luminescence is more pronounced towards the blue side of the visible light spectrum but it can still be seen even when red light is used as the exciting light (Barba et al., 2014). Figure 6-7 depicts the difference between internal excitation (Figure 6-7B) and external excitation (Figure 6-7A) when used with longer wavelength visible light. The usage of external excitation may therefore seem to be an optimal optical setup configuration. However, as seen in Figure 6-8, external excitation functions optimally in a static system where fibre motion would not change the fluorescence signal that emanates from the surface. Motion can originate from heating and cooling of the fibre in liquid solution which generates small bubble formation and can push the fibre out of the optimal external excitation window. This represents a large problem in SP-PCR due to the amount of thermal cycling during a reaction which tends to cause minor disturbances in the fibre position.

To address this problem, the devices of Figure 6-1 [B and C] were developed. The device of Figure 6-1B permitted the elimination of the TFBG and allowed the elimination of the luminescence effect during hybridization experiments. The comparison of the improved internal excitation and unstable external excitation can be seen in Figure 6-9. This external excitation in this image represents a more extreme case where motion sensitivity can impair the signal-to-noise ratio of fluorescence spots on the surface of the fibre. When a larger population of these devices was characterised under ideal conditions, the improved signal-to-noise ratio can be seen with the internal excitation in Figure 6-10.

119 IPage Jason Koppert MASc Thesis 
Because the signal amplitudes that would be associated with SP-PCR are of unknown magnitude, internal excitation was clearly a better pathway for research progression.

Internal excitation does not only improve the fluorescence signal-to-noise ratios through minimization of motion, it also appears to improve the ratios through a phenomenon known as Total Internal Reflection Fluorescence (TIRF) (Axelrod, 2003). This phenomenon exploits the evanescent waves produced by light on the opposite side of an interface where total internal reflection has occurred (Tedeschi, Domenici, Ahluwalia, Baldini, \& Mencaglia, 2003). This evanescent wave excites fluorophores that are in close proximity to the surface. The exponentially decreasing nature of the evanescence wave allows minimal interference with the reading of fluorescence on a TIRF surface since the wave itself does not penetrate significantly into the solution, thus causing essentially no background signal. Usage of TIRF in microscopy has allowed for significantly improved signal-to-noise ratios of fluorescence over background and has thereby allowed more sensitive limits of detection (Axelrod, 2003).

To date, TIRF does not appear to have been used with respect to DNA binding events on the surface of fibre optic devices, although it has been used on glass slide surfaces and with fibre optic antibody applications (Preininger, Mencaglia, \& Baldini, 2000; Simoncelli et al., 2015).

All three of the presented device schematics permit the reflection of core contained light back towards the light source after contacting either a gold mirror or a reflective grating. This feedback to the source is then coupled into a detector thereby allowing temperature feedback information to be monitored pertaining to the area around the DNA coatings. The schematic for this signal acquisition and its ability to incorporate visual data from fibre imaging can be seen in Figure 6-2. The usage of temperature feedback represents a critical advantage to using fibre optic gratings in PCR since it minimizes a common problem present in thermistor based temperature control systems. To date, there appear to be very few real-time PCR reactions that have no thermal lag present in the system (Sanford \& 
Wittwer, 2013). Thermal lag is a phenomenon that occurs when thermistor readings of thermal cycling instruments are different from the actual temperature in the PCR solution contained by a reaction vessel (Sanford \& Wittwer, 2013). This lag varies between different types of vessel material and between different types of thermistors (Elenitoba-Johnson et al., 2008; Sanford \& Wittwer, 2013). Lag has conventionally just been incorporated into the reaction design process through assumption of lag uniformity among instrumentation and consumables but this has potentially led to drastic differences from one thermal cycler to the next (Sanford \& Wittwer, 2014). A thermistor placed into direct contact with solution would potentially solve this lag issue. However, in most thermocyclers this is not possible due to the risk of contamination from one PCR solution to the next as well as the possibility of PCR inhibition due to thermistor material (Sanford \& Wittwer, 2013). In hotwire fibre SP-PCR this thermal lag will not be experienced due to the contact of the fibre with the PCR solution itself. Fibre contact with PCR reaction is also not problematic with regards to material or contamination concerns because of the glass surface compatibility with PCR and the ability to seal fibres into disposable vessels due to low fibre optic costs.

The real-time monitoring of a hybridization assay with a TFBG fibre hotwire indicated that fibrebased heating was compatible with coatings. However, this heating was not cyclical as would be required by an SP-PCR assay. Figure 6-11 shows the results of using the hybridization assay when used with a thermal cycling treatment on a fibre hotwire. The fluorescence of spots on the surface is clearly shown to respond to the heating and cooling of the fibre by modulation of the IR light source. This experimental result supported the theory that fibre hotwires could thermal cycle based on internal heating while supporting the attachment of functional, surface bound DNA molecules.

The penultimate experiment of this project is encapsulated through Figure 6-12 and Figure 6-13. Both of these figures pertain to the same successful experiment designed to probe the functionality of 
the hotwire fibre SP-PCR. These experiments were performed with the Light Absorbing Fibre Device (LAFD) depicted in Figure 6-1C. This device was chosen for this experiment due to its optimal properties in manufacturability and resilience.

The LAFD is improved upon the other available device schematics in its simplicity of manufacturing. This device type utilizes a small segment of Light Absorbing Fibre. Light Absorbing Fibre is created through the doping of regular optical fibres with a metal such as cobalt (Gao et al., 2011). The doping process allows for the IR laser-stimulated generation of heat in the fibre core which is functionally equivalent to the nanoparticle heating on a fibre surface. However, this light absorbing fibre removes the requirement to coat, protect, and quality control nanoparticles on a fibre surface. The lack of nanoparticles drastically shortens manufacturing time of LAFD devices relative to 'Bulge' or TFBG devices while additionally lowering costs and increasing manufacturing throughput. When an FBG grating is written in this fibre type, functionality is equivalent to the other two devices of Figure 6-1.

A weakness in device manufacturing that was addressed in the LAFD design pertains to the usage of a gold mirror. Gold mirrors tended to be fragile and frequently damaged during handling of fibre devices. Mirror damage could frequently terminate SP-PCR experiments due to sudden IR light pollution in the reaction vessel and subsequent boiling of reaction liquids. The usage of a chirped grating allowed for significantly improved handling of fibre devices due its location in the core of the fibre. While chirped gratings could have been used to improve the TFBG and Bulge Devices, the disadvantages of nanoparticle coatings rendered the LAFD as the optimal research device at this stage of development. This optimal LAFD device is depicted in Figure 6-1C.

Importantly, the LAFD retained the TIRF functionality of the Bulge devices through the introduction of a small segment of MMF fibre. This section of MMF used in the device is depicted in Figure 6-1 with the functionality of the segment depicted in Figure 6-3. It is meant to minimize loss of IR 122 IPage Jason Koppert MASc Thesis 
to the cladding while maximizing core loss of the visible excitation wavelengths. Increasing the length of this segment of MMF would increase the loss of visible wavelengths to the cladding but also increase the loss of IR wavelengths to the cladding. Optimization of the length of the MMF section was performed by Hubert Jean-Ruel and will not be discussed further in this thesis (Data not shown). This discrimination between visible and IR wavelengths of light allowed for retention of the majority of IR light needed to allow heating without interrupting the back-propagation of IR signal used for temperature monitoring.

Figure 6-12A shows imaging performed at the end of an extension phase during PCR thermal cycling. Since the PCR reaction mixture in this experiment utilized liquid asymmetric PCR in conjunction with SP-PCR, fluorescence signal increases can be seen in both the liquid surrounding the fibre and the surface spot on which the image is focused. This phenomenon occurs due to incomplete TIRF with some light pollution in the capillary reaction vessel most likely occurring due to a small amount of direct coupling of visible light out of the fibre core. This low level light pollution could be caused by losses experienced during fibre splicing in the manufacturing process or by leakage due to fibre-capillary contact. However, based on the previously discussed phenomenon of external excitation variability, exploitation of the TIRF phenomenon is undoubtedly critical to the results seen here in real-time.

Despite the presence of some non-ideal light pollution in the capillary vessel, the comparison of increases of the solution background signal to the increases of the fibre spot signal provides additional crucial reaction information. As seen in Figure 6-12B, the increases in background signal versus spot signal are mismatched. When the difference between these two signals is used to generate the inset of Figure 6-12B, evidence is put forward that indicates the extension of surface primers through SP-PCR is saturated before the solution PCR has plateaued. The decreasing peak-like nature of the inset graph indicates that further elimination of the background liquid PCR signal could improve the monitoring of

123 I Page Jason Koppert MASc Thesis 
real-time SP-PCR. This could be achieved by ensuring complete TIRF excitation through elimination of light pollution of the capillary vessel by correcting splicing-induced losses.

Without the results of Figure 6-13, indications of SP-PCR in Figure 6-12 A and B could have been slightly ambiguous. The melting images of Figure 6-13 illustrate the clearly visible differences between the melting temperature of the hybridization probe to DNA (Figure 5-1A) and the post-SP-PCR product (Figure 5-1D). It is important to note that the hybridization probe was introduced after SP-PCR melt curve data was generated. In this manner, there is clear differentiation between the melting temperature phenomenon occurring on the identical fibre surface spot between probing events. This is fundamentally indicative that the generation of a longer surface bound DNA strand was created through the usage of SP-PCR on an optical fibre hotwire device. Such successful hotwire fibre SP-PCR was reproduced several times with similar results as those presented in Figure 6-12 and Figure 6-13.

\subsection{Conclusion}

This chapter has brought forward evidence needed to support the hypothesized fibre optic hotwire device that would be capable of performing SP-PCR. This device has been shown to work in real-time and can be manufactured reproducibly in a research environment. Adaptations to the method of exciting fluorescence on the surface of these hotwire fibre devices add an additional layer of novelty to the contribution depth. Not only do the LAFDs enable the performance of SP-PCR, which is novel in itself, but they enable the performance of PCR with TIRF.

The proof-of-concept device developed in this chapter illustrates the value of applying novel advances in seemingly unrelated fields, such as telecommunications, to the field of biomedical engineering and medical devices. This device will encourage further investment and development by the industrial partner of this project as it alleviates a significant portion of the risk involved in establishing a new development direction.

124 IPage Jason Koppert MASc Thesis 


\section{Thesis summary and Future Recommendations}

\subsection{Conclusions}

The work put forward in this thesis has combined all the necessary components for a proof-ofconcept POCT molecular diagnostic device. The hotwire fibre SP-PCR device that ultimately developed in this thesis demonstrates the ability to produce a surface-bound DNA oligomer. This oligomer has been demonstrably detectable in real-time as well as in a post run analysis.

Although this device functions in its current capacity, it has not yet demonstrated multiplex functionality. Since this spotting and spatial separation features were clearly functional in the hybridization assays of the previous chapters, we believe there is a high potential to multiplex such a device.

This device's functionality was not assessed in terms of reaction speed. However, its potential is clearly obvious when considering the conventional problems of PCR discussed previously. This device addresses the PCR lag issue by having an in-vessel temperature probe. Additionally, the small volume of the reaction vessel and scalability of IR laser power promises the potential for extremely fast PCR.

\subsection{Summary of Contributions}

Over the course of this development project, many novel contributions were made. In part, the lack of resources forced the use of creative solutions to non-conventional problems. The first contribution pertains to the usage of UV cross-linking of DNA on fibre optic surfaces. Currently, the available optical fibre coating methodologies involve volatile chemicals with limited shelf lives and the requirement for significant chemicals, equipment, resources and expensive DNA functionalizations. The usage of UV cross-linking allows for an incredibly fast, simplistic, and easily controllable method of functionalizing the valuable platform of optical fibre gratings.

125 IPage Jason Koppert MASc Thesis 
Real-time enzyme assays are typically performed in solution with intercalating dyes and, as mentioned previously, have led to a significantly advanced understanding of the variables of real-time PCR. Adapting real-time enzyme assays to fibre surfaces promises the potential to provide similar advancements in the SP-PCR world. This assay also represents an economical method of assessing numerous DNA surface coatings for functionality with SP-PCR.

The paramount contribution of this thesis is the application of hotwire optical fibre gratings to the field of SP-PCR. The novelty of this contribution cannot be understated. It is very possible that without the usage of fibre optics in combination with TIRF it may not have been possible to assess SP-PCR in realtime with fluorescent probes. The fact that nearly all of the major aspects of this device's functionality are contributions to the field of biomedical sensor development is a testament to the value of the project's collaborative nature.

The success of this proof-of-concept SP-PCR device has the potential to open up a new field of molecular diagnostic devices. Considering the value of industry and academic collaborations in modern science, this device represents the extent of interdisciplinary research necessary to make large breakthroughs in medical science. Additionally, the success of this device development actively increases the potential to create similar projects among the research settings of Carleton University.

\subsection{Recommendations for Future Work}

Further development beyond the scope of this thesis has been commenced by new personnel hired onto the collaboration after the demonstration of a successful proof-of-concept device. This work includes the design of a prototype POCT cartridge that would allow for development of a testable cartridge assay. Figure 7-1 shows a prototype device that was conceptualized by a design firm.

126 IPage Jason Koppert MASc Thesis 


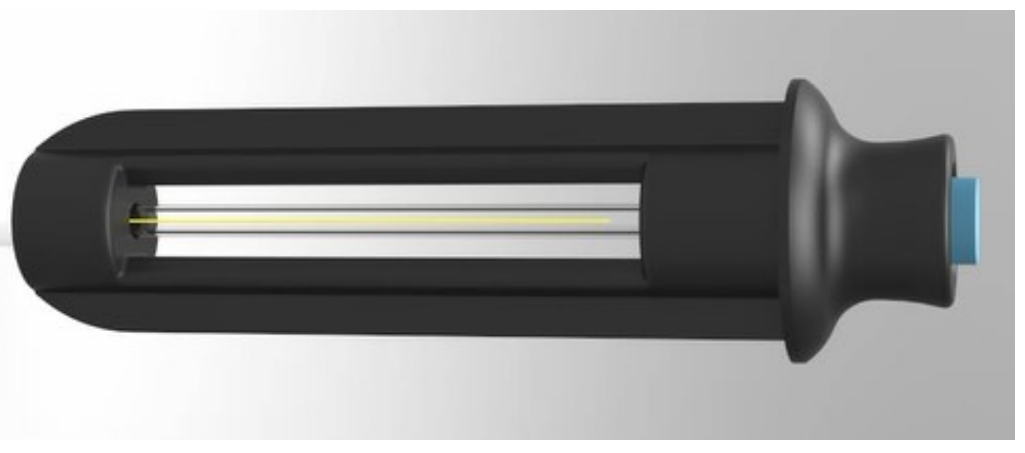

Figure 7-1. Concept LAFD incorporated into a cartridge for use in POCT environments.

The platform needs significant development to become a stable environment on which to introduce novel assays. This stability will become increasingly necessary as speed and multiplex capabilities are tested and developed. Stability will come in the form of manufacturing reliability and consistency in fibre heating. The fibre platform will also need to be able to thermal cycle more than the current 15-20 cycle capacity. Multiplexing with spotting and spatial separation needs to be confirmed and developed, in order for the fibre device to viably compete with current tests available on the market.

The market value of a device of this nature should be investigated further as well. Once an analysis of manufacturing costs has been completed for larger scale production, specific markets could be targeted based on the cost of marketing and development in specific medical diagnostic areas.

The nature of the collaboration that produced this device allows for the patenting of such novel devices. Although many aspects of this project are in the process of patent protection, future emphasis needs to include establishing a patent portfolio around the technology present in this thesis. Patents would allow for the establishment of future income streams for the purpose of funding more collaborative research. 


\section{References}

Abel, A. P., Weller, M. G., Duveneck, G. L., Ehrat, M., \& Widmer, H. M. (1996). Fiber-optic evanescent wave biosensor for the detection of oligonucleotides. Analytical Chemistry, 68(17), 2905-2912. http://doi.org/10.1021/ac960071+

Adessi, C., Matton, G., Ayala, G., Turcatti, G., Mermod, J., Mayer, P., \& Kawashima, E. (2000). Solid phase DNA amplification : characterisation of primer attachment and amplification mechanisms, 28(20).

Agrawal, N., Hassan, Y. A., \& Ugaz, V. M. (2007). A pocket-sized convective PCR thermocycler. Angewandte Chemie (International Ed. in English), 46(23), 4316-9. http://doi.org/10.1002/anie.200700306

Albert, J., lanoul, A., Aliaksandr, B., \& Bottomley, A. (2015, April 29). Optical fiber with grating and particulate coating. Retrieved from https://www.google.ca/patents/EP2864827A2?cl=en\&dq=spartan+bioscience\&hl=en\&sa=X\&sqi=2 \&pjf=1\&ved=0ahUKEwiOxbfBkuHJAhWK44MKHUmnAPgQ6AEIMDAD

Albert, J., Lepinay, S., Caucheteur, C., \& DeRosa, M. C. (2013). High resolution grating-assisted surface plasmon resonance fiber optic aptasensor. Methods, 63(3), 239-254.

http://doi.org/10.1016/j.ymeth.2013.07.007

Albert, J., Shao, L.-Y., \& Caucheteur, C. (2013). Tilted fiber Bragg grating sensors. Laser \& Photonics Reviews, 7(1), 83-108. http://doi.org/10.1002/Ipor.201100039

Arghir, I., Delport, F., Spasic, D., \& Lammertyn, J. (2015). Smart design of fiber optic surfaces for improved plasmonic biosensing. New Biotechnology, 32(5), 473-484.

http://doi.org/10.1016/j.nbt.2015.03.012

Axelrod, D. (2003). Total internal reflection fluorescence microscopy in cell biology. Methods Enzymol, 361(2), 1-33. Retrieved from http://www.ncbi.nlm.nih.gov/entrez/query.fcgi?cmd=Retrieve\&db=PubMed\&dopt=Citation\&list_u ids $=12624904$

Barba, D., Martin, F., Tagziria, K., Nicklaus, M., Haddad, É., \& Rosei, F. (2014). characterization of fiber Bragg gratings Photoluminescence mapping of oxygen-defect emission for nanoscale spatial characterization of fiber Bragg gratings, 064906. http://doi.org/10.1063/1.4892985 
Beier, M., \& Hoheisel, J. D. (1999). Versatile derivatisation of solid support media for covalent bonding on DNA-microchips. Nucleic Acids Research, 27(9), 1970-1977.

http://doi.org/10.1093/nar/27.9.1970

Belgrader, P., Benett, W., Hadley, D., Long, G., Mariella, R., Milanovich, F., ... Stratton, P. (1998). Rapid pathogen detection using a microchip PCR array instrument. Clinical Chemistry, 44(10), 2191-4. Retrieved from http://www.ncbi.nlm.nih.gov/pubmed/9761255

Boleda, M. D., Briones, P., Farres, J., Tyfield, L., \& Pi, R. (1996). Experimental Design : A Useful Tool. BioTechniques, 21(1), 134-140.

Bustin, S. a. (2009). The PCR Revolution: Basic Technologies and Applications. http://doi.org/10.1017/CBO9780511818974

Bustin, S. A., Benes, V., Garson, J. A., Hellemans, J., Huggett, J., Kubista, M., ... Wittwer, C. T. (2009). The MIQE guidelines: minimum information for publication of quantitative real-time PCR experiments. Clinical Chemistry, 55(4), 611-22. http://doi.org/10.1373/clinchem.2008.112797

Cao, C., Birtwell, S., Høgberg, J., Morgan, H., Wolff, A., \& Bang, D. (2012). Gold Nanoparticles-Coated SU8 for Sensitive Fluorescence-Based Detections of DNA. Diagnostics, 2(4), 72-82. http://doi.org/10.3390/diagnostics2040072

Carmon, a., Vision, T. J., Mitchell, S. E., Thannhauser, T. W., Müller, U., \& Kresovich, S. (2002). Solidphase PCR in microwells: Effects of linker length and composition on tethering, hybridization, and extension. BioTechniques, 32(2), 410-420.

Cho, L.-H., Lu, C., Zhang, a. P., \& Tam, H.-Y. (2013). Fiber Bragg Grating Anemometer With Reduced Pump Power-Dependency. IEEE Photonics Technology Letters, 25(24), 2450-2453. http://doi.org/10.1109/LPT.2013.2288115

Christensen, T. B., Pedersen, C. M., Gröndahl, K. G., Jensen, T. G., Sekulovic, A., Bang, D. D., \& Wolff, A. (2007). PCR biocompatibility of lab-on-a-chip and MEMS materials. Journal of Micromechanics and Microengineering, 17(8), 1527-1532. http://doi.org/10.1088/0960-1317/17/8/015

Damin, F., Galbiati, S., Ferrari, M., \& Chiari, M. (2016). DNA microarray-based solid-phase PCR on copoly (DMA-NAS-MAPS) silicon coated slides: An example of relevant clinical application. Biosensors and Bioelectronics, 78, 367-373. http://doi.org/10.1016/j.bios.2015.11.091

Delport, F., Pollet, J., Janssen, K., Verbruggen, B., Knez, K., Spasic, D., \& Lammertyn, J. (2012). Real-time monitoring of DNA hybridization and melting processes using a fiber optic sensor. Nanotechnology,

129|Page Jason Koppert MASc Thesis 
23(6), 065503. http://doi.org/10.1088/0957-4484/23/6/065503

Douki, T., Zalizniak, T., \& Cadet, J. (1997). Far-UV-Induced Dimeric Photoproducts in Short Oligonucleotides: Sequence Effects. Photochemistry and Photobiology, 66(2), 171-179. http://doi.org/10.1111/j.1751-1097.1997.tb08639.x

Dufva, M., Petersen, J., Stoltenborg, M., Birgens, H., \& Christensen, C. B. V. (2006). Detection of mutations using microarrays of poly $(\mathrm{C}) 10-$ poly $(\mathrm{T}) 10$ modified DNA probes immobilized on agarose films. Analytical Biochemistry, 352(2), 188-197. http://doi.org/10.1016/j.ab.2006.03.008

Dufva, M., Petronis, S., Jensen, L. B., Krag, C., \& Christensen, C. B. V. (2004). Characterization of an inexpensive, nontoxic, and highly sensitive microarray substrate. BioTechniques, 37(2), 286-296.

Dwight, Z., Palais, R., \& Wittwer, C. T. (2011). uMELT: Prediction of high-resolution melting curves and dynamic melting profiles of PCR products in a rich web application. Bioinformatics, 27(7), 10191020. http://doi.org/10.1093/bioinformatics/btr065

Elenitoba-Johnson, O., David, D., Crews, N., \& Wittwer, C. T. (2008). Plastic versus glass capillaries for rapid-cycle PCR. BioTechniques, 44(4), 487-492. http://doi.org/10.2144/000112722

Elnifro, E. M., Ashshi, A. M., Cooper, R. J., \& Klapper, P. E. (2000). Multiplex PCR : Optimization and Application in Diagnostic Virology Multiplex PCR : Optimization and Application in Diagnostic Virology. Clinical Microbiology Reviews, 13(4), 559-570. http://doi.org/10.1128/CMR.13.4.559570.2000.Updated

Exner, M. M. (2012). Multiplex Molecular Reactions: Design and Troubleshooting. Clinical Microbiology Newsletter, 34(8), 59-65. http://doi.org/10.1016/j.clinmicnews.2012.03.003

Farrar, J., \& Wittwer, C. T. (2015). Extreme PCR: Efficient and specific DNA amplification in 15-60 seconds. Clinical chemistry2.

Fedurco, M., Romieu, A., Williams, S., Lawrence, I., \& Turcatti, G. (2006). BTA, a novel reagent for DNA attachment on glass and efficient generation of solid-phase amplified DNA colonies. Nucleic Acids Research, 34(3), e22. http://doi.org/10.1093/nar/gnj023

Fricke-Galindo, I., Cespedes-Garro, C., Rodrigues-Soares, F., Naranjo, M. E. G., Delgado, A., de Andres, F., ... LLerena, A. (2015). Interethnic variation of CYP2C19 alleles, "predicted" phenotypes and "measured" metabolic phenotypes across world populations. Pharmacogenomics J, (August), 1-11. http://doi.org/10.1038/tpj.2015.70 
Friedman, N. A., \& Meldrum, D. R. (1998). Capillary Tube Resistive Thermal Cycling. Analytical Chemistry, 70(14), 2997-3002. http://doi.org/10.1021/ac971303n

Frueh, F. W., \& Gurwitz, D. (2004). From pharmacogenetics to personalized medicine: a vital need for educating health professionals and the community. Pharmacogenomics, 5(5), 571-9. http://doi.org/10.1517/14622416.5.5.571

Gao, S., Zhang, A. P., Tam, H.-Y., Cho, L. H., \& Lu, C. (2011). All-optical fiber anemometer based on laser heated fiber Bragg gratings. Optics Express, 19(11), 10124-10130. http://doi.org/10.1364/OE.19.010124

Gudnason, H., Dufva, M., Bang, D. D., \& Wolff, A. (2007). Comparison of multiple DNA dyes for real-time PCR: effects of dye concentration and sequence composition on DNA amplification and melting temperature. Nucleic Acids Research, 35(19), e127-e127. http://doi.org/10.1093/nar/gkm671

Gudnason, H., Dufva, M., Duong Bang, D., \& Wolff, A. (2008). An inexpensive and simple method for thermally stable immobilization of DNA on an unmodified glass surface: UV linking of poly(T)10poly(C)10-tagged DNA probes. BioTechniques, 45(3), 261-71. http://doi.org/10.2144/000112905

Guo, Z., Guilfoyle, R. a, Thiel, a J., Wang, R., \& Smith, L. M. (1994). Direct fluorescence analysis of genetic polymorphisms by hybridization with oligonucleotide arrays on glass supports. Nucleic Acids Research, 22(24), 5456-5465. http://doi.org/10.1093/nar/22.24.5456

Gyllensten, U. B., \& Erlich, H. A. (1988). Generation of single-stranded DNA by the polymerase chain reaction and its application to direct sequencing of the HLA-DQA locus. Proceedings of the National Academy of Sciences, 85(20), 7652-7656. http://doi.org/10.1073/pnas.85.20.7652

Halperin, a., Buhot, a., \& Zhulina, E. B. (2006). Hybridization at a surface: The role of spacers in DNA microarrays. Langmuir, 22(26), 11290-11304. http://doi.org/10.1021/la0616606

Hashimoto, M., Chen, P.-C., Mitchell, M. W., Nikitopoulos, D. E., Soper, S. A., \& Murphy, M. C. (2004). Rapid PCR in a continuous flow device. Lab on a Chip, 4(6), 638-45.

http://doi.org/10.1039/b406860b

Heap, D. M., Herrmann, M. G., \& Wittwer, C. T. (2000). PCR amplification using electrolytic resistance for heating and temperature monitoring. BioTechniques, 29(5), 1006-12. Retrieved from http://europepmc.org/abstract/med/11084862

Heise, C., \& Bier, F. F. (2006). Immobilization of DNA on Microarrays, (December 2005), 1-25.

131|Page Jason Koppert MASc Thesis 
Higuchi, R., Fockler, C., Dollinger, G., \& Watson, R. (1993). Kinetic PCR analysis: real-time monitoring of DNA amplification reactions. Bio/technology (Nature Publishing Company).

http://doi.org/10.1038/nbt0993-1026

Hill, K. O., Malo, B., Bilodeau, F., Johnson, D. C., \& Albert, J. (1993). Bragg gratings fabricated in monomode photosensitive optical fiber by UV exposure through a phase mask. Applied Physics Letters, 62(10), 1035. http://doi.org/10.1063/1.108786

Hill, K. O., \& Meltz, G. (1997). Fiber Bragg grating technology fundamentals and overview. Journal of Lightwave Technology, 15(8), 1263-1276. http://doi.org/10.1109/50.618320

Hoffmann, J., Hin, S., Stetten, F. Von, Zengerle, R., \& Roth, G. (2012a). Universal protocol for grafting PCR primers onto various lab-on-a-chip substrates for solid-phase PCR. RSC Advances, 2(9), 3885. http://doi.org/10.1039/c2ra01250b

Hoffmann, J., Hin, S., Stetten, F. Von, Zengerle, R., \& Roth, G. (2012b). Universal protocol for grafting PCR primers onto various lab-on-a-chip substrates for solid-phase PCR. RSC Advances, 2(9), 3885. http://doi.org/10.1039/c2ra01250b

Holland, P. M., Abramson, R. D., Watson, R., \& Gelfand, D. H. (1991). Detection of specific polymerase chain reaction product by utilizing the $5^{\prime}----3$ ' exonuclease activity of Thermus aquaticus DNA polymerase. Proceedings of the National Academy of Sciences, 88(16), 7276-7280. http://doi.org/10.1073/pnas.88.16.7276

Khan, Z., Poetter, K., \& Park, D. J. (2008). Enhanced solid phase PCR: mechanisms to increase priming by solid support primers. Analytical Biochemistry, 375(2), 391-3. http://doi.org/10.1016/j.ab.2008.01.021

Knez, K., Janssen, K. P. F., Pollet, J., Spasic, D., \& Lammertyn, J. (2012). Fiber-optic high-resolution genetic screening using gold-labeled gene probes. Small, 8(6), 868-872. http://doi.org/10.1002/smll.201102209

Lepinay, S., Staff, A., lanoul, A., \& Albert, J. (2014). Improved detection limits of protein optical fiber biosensors coated with gold nanoparticles. Biosensors and Bioelectronics, 52, 337-344. http://doi.org/10.1016/j.bios.2013.08.058

Ma, C., Tang, Z., Wang, K., Tan, W., Li, J., Li, W., ... Liu, L. (2006). Real-time monitoring of DNA polymerase activity using molecular beacon. Analytical Biochemistry, 353, 141-143. http://doi.org/10.1016/j.ab.2006.02.006 
Marazuela, M., \& Moreno-Bondi, M. (2002). Fiber-optic biosensors - an overview. Analytical and Bioanalytical Chemistry, 372(5-6), 664-682. http://doi.org/10.1007/s00216-002-1235-9

Michel, R., Pasche, S., Textor, M., \& Castner, D. G. (2005). Influence of PEG architecture on protein adsorption and conformation. Langmuir, 21(26), 12327-12332. http://doi.org/10.1021/la051726h

Montgomery, J. L., \& Wittwer, C. T. (2014). Influence of PCR reagents on DNA polymerase extension rates measured on real-time PCR instruments. Clinical Chemistry, 60(2), 334-40.

http://doi.org/10.1373/clinchem.2013.212829

Nellåker, C., Wållgren, U., \& Karlsson, H. (2007). Molecular beacon-based temperature control and automated analyses for improved resolution of melting temperature analysis using SYBR I Green chemistry. Clinical Chemistry, 53(1), 98-103. http://doi.org/10.1373/clinchem.2006.075184

Oda, R. P., Strausbauch, M. A., Huhmer, A. F. R., Borson, N., Jurrens, S. R., Craighead, J., ... Landers, J. P. (1998). Infrared-Mediated Thermocycling for Ultrafast Polymerase Chain Reaction Amplification of DNA. Analytical Chemistry, 70(20), 4361-4368. http://doi.org/10.1021/ac980452i

Owczarzy, R., Moreira, B. G., You, Y., Behlke, M. A., \& Walder, J. A. (2008). Predicting stability of DNA duplexes in solutions containing magnesium and monovalent cations. Biochemistry, 47(19), 533653. http://doi.org/10.1021/bi702363u

Pollet, J., Janssen, K. P. F., Knez, K., \& Lammertyn, J. (2011). Real-time monitoring of solid-phase PCR using fiber-optic SPR. Small (Weinheim an Der Bergstrasse, Germany), 7(8), 1003-6. http://doi.org/10.1002/smll.201001984

Polz, M. F., \& Cavanaugh, C. M. (1998). Bias in template-to-product ratios in multitemplate PCR. Applied and Environmental Microbiology, 64(10), 3724-3730.

Preininger, C., Mencaglia, A., \& Baldini, F. (2000). Polymer-coated optical fibres for application in a direct evanescent wave immunoassay. Analytica Chimica Acta, 403(January), 67-76. http://doi.org/10.1016/S0003-2670(99)00642-X

Roberts, J. D., Wells, G. a, Le May, M. R., Labinaz, M., Glover, C., Froeschl, M., ... So, D. Y. F. (2012). Pointof-care genetic testing for personalisation of antiplatelet treatment (RAPID GENE): a prospective, randomised, proof-of-concept trial. Lancet, 379(9827), 1705-11. http://doi.org/10.1016/S01406736(12)60161-5

Roosevelt, G. E., Kulkarni, M. S., \& Shulman, S. T. (2001). Critical evaluation of a CLIA-waived streptococcal antigen detection test in the emergency department. Annals of Emergency Medicine,

133 I Page Jason Koppert MASc Thesis 
37(4), 377-81. http://doi.org/10.1067/mem.2001.114090

Roper, M. G., Easley, C. J., \& Landers, J. P. (2005). Advances in polymerase chain reaction on microfluidic chips. Analytical Chemistry, 77(12), 3887-93. http://doi.org/10.1021/ac050756m

Roper, M. G., Easley, C. J., Legendre, L. A., Humphrey, J. A. C., \& Landers, J. P. (2007). Infrared temperature control system for a completely noncontact polymerase chain reaction in microfluidic chips. Analytical Chemistry, 79(4), 1294-300. http://doi.org/10.1021/ac0613277

Russell, A. G., McKnight, M. D., Hestekin, J. a., \& Roper, D. K. (2011). Thermodynamics of optoplasmonic heating in fluid-filled gold-nanoparticle-plated capillaries. Langmuir, 27(12), 7799-7805. http://doi.org/10.1021/la200078j

Sanchez, J. A., Pierce, K. E., Rice, J. E., \& Wangh, L. J. (2004). Linear-after-the-exponential (LATE)-PCR: an advanced method of asymmetric PCR and its uses in quantitative real-time analysis. Proceedings of the National Academy of Sciences of the United States of America, 101(7), 1933-8. http://doi.org/10.1073/pnas.0305476101

Sanford, L. N., \& Wittwer, C. T. (2013). Monitoring temperature with fluorescence during real-time PCR and melting analysis. Analytical Biochemistry, 434(1), 26-33.

http://doi.org/10.1016/j.ab.2012.10.037

Sanford, L. N., \& Wittwer, C. T. (2014). Fluorescence-based temperature control for polymerase chain reaction. Analytical Biochemistry, 448(1), 75-81. http://doi.org/10.1016/j.ab.2013.11.027

Schlingman, D. J., Mack, A. H., Mochrie, S. G. J., \& Regan, L. (2011). A new method for the covalent attachment of DNA to a surface for single-molecule studies. Colloids and Surfaces B: Biointerfaces, 83(1), 91-95. http://doi.org/10.1016/j.colsurfb.2010.11.002

Shevchenko, Y., Francis, T. J., Blair, D. a D., Walsh, R., Derosa, M. C., \& Albert, J. (2011). In situ biosensing with a surface plasmon resonance fiber grating aptasensor. Analytical Chemistry, 83(18), 70277034. http://doi.org/10.1021/ac201641n

Shin, Y., Kim, J., \& Lee, T. Y. (2014). A solid phase-bridge based DNA amplification technique with fluorescence signal enhancement for detection of cancer biomarkers. Sensors and Actuators B: Chemical, 199, 220-225. http://doi.org/10.1016/j.snb.2014.03.051

Simoncelli, S., de Alwis Weerasekera, H., Fasciani, C., Boddy, C. N., Aramendia, P. F., Alarcon, E. I., \& Scaiano, J. C. (2015). Thermoplasmonic ssDNA Dynamic Release from Gold Nanoparticles Examined with Advanced Fluorescence Microscopy. The Journal of Physical Chemistry Letters, 6(8), 1499-

134 | Page Jason Koppert MASc Thesis 
1503. http://doi.org/10.1021/acs.jpclett.5b00272

Son, J. H., Cho, B., Hong, S., Lee, S. H., Hoxha, O., Haack, A. J., \& Lee, L. P. (2015). Ultrafast photonic PCR. Light: Science \& Applications, 4(7), e280. http://doi.org/10.1038/Isa.2015.53

Sun, Y., Dhumpa, R., Bang, D. D., Høgberg, J., Handberg, K., \& Wolff, A. (2011). A lab-on-a-chip device for rapid identification of avian influenza viral RNA by solid-phase PCR. Lab on a Chip, 11(8), 1457-63. http://doi.org/10.1039/c0lc00528b

Sun, Y., Kwok, Y. C., \& Nguyen, N. T. (2007). A circular ferrofluid driven microchip for rapid polymerase chain reaction. Lab on a Chip, 7(8), 1012-7. http://doi.org/10.1039/b700575j

Sun, Y., Perch-Nielsen, I., Dufva, M., Sabourin, D., Bang, D. D., Høgberg, J., \& Wolff, A. (2012). Direct immobilization of DNA probes on non-modified plastics by UV irradiation and integration in microfluidic devices for rapid bioassay. Analytical and Bioanalytical Chemistry, 402(2), 741-8. http://doi.org/10.1007/s00216-011-5459-4

Tedeschi, L., Domenici, C., Ahluwalia, A., Baldini, F., \& Mencaglia, A. (2003). Antibody immobilisation on fibre optic TIRF sensors. Biosensors and Bioelectronics, 19(2), 85-93.

http://doi.org/10.1016/S0956-5663(03)00173-8

Tyagi, S., \& Kramer, F. R. (1996). Molecular beacons: probes that fluoresce upon hybridization. Nature Biotechnology, 14(3), 303-308. http://doi.org/10.1038/nbt0396-303

Van Den Engh, G., \& Farmer, C. (1992). Photo-bleaching and photon saturation in flow cytometry. Cytometry, 13(7), 669-677. http://doi.org/10.1002/cyto.990130702

Vohr, H.-W. (Ed.). (2016). Encyclopedia of Immunotoxicology. Berlin, Heidelberg: Springer Berlin Heidelberg. http://doi.org/10.1007/978-3-642-54596-2

von Nickisch-Rosenegk, M., Marschan, X., Andresen, D., Abraham, A., Heise, C., \& Bier, F. F. (2005). Onchip PCR amplification of very long templates using immobilized primers on glassy surfaces. Biosensors \& Bioelectronics, 20(8), 1491-8. http://doi.org/10.1016/j.bios.2004.07.007

von Nickisch-Rosenegk, M., Marschan, X., Andresen, D., \& Bier, F. F. (2008). Reverse transcriptionpolymerase chain reaction on a microarray: the integrating concept of "active arrays". Analytical and Bioanalytical Chemistry, 391(5), 1671-8. http://doi.org/10.1007/s00216-008-2154-1

Wallentin, L., James, S., Storey, R. F., Armstrong, M., Barratt, B. J., Horrow, J., ... Becker, R. C. (2010). 
Effect of CYP2C19 and ABCB1 single nucleotide polymorphisms on outcomes of treatment with ticagrelor versus clopidogrel for acute coronary syndromes: a genetic substudy of the PLATO trial. Lancet (London, England), 376(9749), 1320-8. http://doi.org/10.1016/S0140-6736(10)61274-3

Walsh, M. K., Wang, X., \& Weimer, B. C. (2001). Optimizing the immobilization of single-stranded DNA onto glass beads. Journal of Biochemical and Biophysical Methods, 47(3), 221-231. http://doi.org/10.1016/S0165-022X(00)00146-9

Wang, X., Dong, X., Zhou, Y., Li, Y., Cheng, J., \& Chen, Z. (2014). Optical fiber anemometer using silvercoated fiber Bragg grating and bitaper. Sensors and Actuators A: Physical, 214(December 2015), 230-233. http://doi.org/10.1016/j.sna.2014.04.013

Wang, X., Dong, X., Zhou, Y., Ni, K., Cheng, J., \& Chen, Z. (2013). Hot-Wire Anemometer Based on SilverCoated Fiber Bragg Grating Assisted by No-Core Fiber. IEEE Photonics Technology Letters, 25(24), 2458-2461. http://doi.org/10.1109/LPT.2013.2288634

Wang, Z.-Y., Chen, M., Zhu, L.-L., Yu, L.-S., Zeng, S., Xiang, M.-X., \& Zhou, Q. (2015). Pharmacokinetic drug interactions with clopidogrel: updated review and risk management in combination therapy. Therapeutics and Clinical Risk Management, 11, 449-67. http://doi.org/10.2147/TCRM.S80437

Wheeler, E. K., Benett, W., Stratton, P., Richards, J., Chen, A., Christian, A., ... Milanovich, F. (2004). Convectively driven polymerase chain reaction thermal cycler. Analytical Chemistry, 76(14), 40116. http://doi.org/10.1021/ac034941g

Wittwer, C. T. (2001). Rapid Cycle Real-Time PCR. (S. Meuer, C. Wittwer, \& K.-I. Nakagawara, Eds.). Berlin, Heidelberg: Springer Berlin Heidelberg. http://doi.org/10.1007/978-3-642-59524-0

Wittwer, C. T., Herrmann, M. G., Gundry, C. N., \& Elenitoba-Johnson, K. S. (2001). Real-time multiplex PCR assays. Methods (San Diego, Calif.), 25(4), 430-442. http://doi.org/10.1006/meth.2001.1265

Wiviott SD, Braunwald E, McCabe CH, Montalescot G, Ruzyllo W, G. S., Neumann FJ, Ardissino D, De Servi S, Murphy SA, Riesmeyer J, W. G., \& Gibson CM, A. E. (2007). Prasugrel versus clopidogrel in patients with acute coronary syndromes. The New England Journal of Medicine, 357, 2001-2015. Retrieved from http://www.nejm.org/doi/full/10.1056/NEJMoa0706482

Xia, B., Xiao, S.-J., Guo, D.-J., Wang, J., Chao, J., Liu, H.-B., ... Liu, J.-N. (2006a). Biofunctionalisation of porous silicon (PS) surfaces by using homobifunctional cross-linkers. Journal of Materials Chemistry, 16(6), 570. http://doi.org/10.1039/b511175g

Xia, B., Xiao, S.-J., Guo, D.-J., Wang, J., Chao, J., Liu, H.-B., ... Liu, J.-N. (2006b). Biofunctionalisation of 
porous silicon (PS) surfaces by using homobifunctional cross-linkers. Journal of Materials Chemistry, 16(6), 570. http://doi.org/10.1039/b511175g

Xinyong Dong, Yan Zhou, Wenjun Zhou, Jia Cheng, \& Zhongdi Su. (2012). Compact Anemometer Using Silver-Coated Fiber Bragg Grating. IEEE Photonics Journal, 4(5), 1381-1386.

http://doi.org/10.1109/JPHOT.2012.2208946

Zammatteo, N., Jeanmart, L., Hamels, S., Courtois, S., Louette, P., Hevesi, L., \& Remacle, J. (2000). Comparison between different strategies of covalent attachment of DNA to glass surfaces to build DNA microarrays. Analytical Biochemistry, 280(1), 143-150.

http://doi.org/10.1006/abio.2000.4515

Zanger, U. M., \& Schwab, M. (2013). Cytochrome P450 enzymes in drug metabolism: Regulation of gene expression, enzyme activities, and impact of genetic variation. Pharmacology and Therapeutics, 138(1), 103-141. http://doi.org/10.1016/j.pharmthera.2012.12.007

Zhang, C., Xu, J., Ma, W., \& Zheng, W. (2006). PCR microfluidic devices for DNA amplification. Biotechnology Advances, 24(3), 243-84. http://doi.org/10.1016/j.biotechadv.2005.10.002 


\section{A. Appendix}

\section{A.1 Methods: DNA Coatings Compatible with Fibre Optic Devices}

Microscope Slide Preparation. Microscope slides were created by either removing the fibre from the apparatus of Figure A-1 or carefully mounting a fibre on a clean glass microscope slide with a piece of tape. Approximately $20-40 \mu \mathrm{L}$ of an Antifade mounting solution $(1 \mathrm{~mL}$ PBS $\mathrm{pH} 8.75,4 \mathrm{~mL}$ glycerol, $50 \mathrm{mg}$ n-propyl gallate) was applied before the careful addition of a glass cover slide. This schematic can be seen in Figure 4-1. Fibres were located via a visible bright field before using the microscope settings for Green Fluorescent Protein (GFP) filters and excitation. A Zeiss Axio Imager M1 Fluorescence microscope was used. The filter set utilized a $470 / 20 \mathrm{~nm}$ excitation band pass filter with an emission band pass filter of 505-530nm.

Fibre handling. Fibre handling, for procedures such as cleaning and coating, was performed with the apparatus of Figure A-1. This apparatus allowed for the coating of small fibre fragments as well as larger fibres that would be used functionally with FBG gratings. The orange ring allowed for fibres to pass through if they were too long to fit into a tube for protection. 


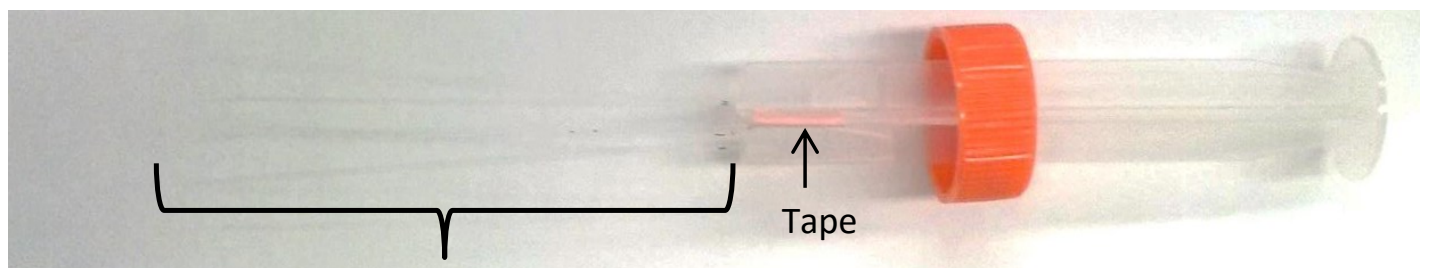

Fibres

Figure A-1. Apparatus made from a syringe plunger used for holding multiple fibres. Although not depicted with TFBG fibres, the orange ring can be removed and re-inserted over a TFBG fibre to accommodate the continuation of the fibre to the coupler and laser/spectrum analyser. This apparatus permits fibre storage in the tube pictured since the orange ring is a modified tube cap with the threading intact.

Fibre cleaning process. Fibres of $\sim 7 \mathrm{~cm}$ lengths were cut from a spool and mounted on a modified syringe setup as seen in Figure A-1. These fibres were then submerged in DiChloroMethane (DCM) for $\sim 30$ secs. Fibre jackets were then easily pulled off of the core by running the fibre between the forefinger and thumb of a gloved hand. A KimWipe, soaked in methanol, was then used to remove any remaining fibre jacket. Cleaned, jacket-free fibres were then submerged for 20 mins $<\mathrm{t}<30$ mins in a freshly prepared Piranha Solution $\left(3: 1, \mathrm{H}_{2} \mathrm{SO}_{4}: \mathrm{H}_{2} \mathrm{O}_{2}\right)$. Fibres were rinsed thoroughly with deionized water and then submerged in fresh deionized water for 5 minutes to completely remove any remaining Piranha solution. Nitrogen Gas was then used to dry the fibres.

SI-PEG-FITC coating procedure. SI-PEG-FITC was freshly dissolved in solvent by weighing $\geq 1 \mathrm{mg}$ quantities and then adding appropriate volumes of solvent based on measured weight. Dilutions were made as required. 10-15 $\mu \mathrm{L}$ of SI-PEG-FITC solution was added to a polymer vessel to be used for dipping fibres. Fibres cleaned according to the fibre cleaning process were then placed into the dipping vessel. 
After incubation, the fibres were removed from the tubes and then rinsed with DMSO for 5 minutes. The fibres were then rinsed with methanol and subsequently dried with nitrogen gas.

DSC coating. Glass optical fibres, cleaned according to the fibre cleaning process, were amine functionalized by dipping in 1\% APTMS (amino propyl trimethoxy silane) in methanol for 20 minutes, followed by rinsing in pure methanol. These fibres were then functionalized with $\mathrm{N}$-hydroxy succinimide (NHS) through a DSC treatment. This treatment used $8.0 \mathrm{mg}$ of DSC in acetonitrile. Cleaned fibres were submerged into the DSC/acetonitrile solution for 7 minutes. Fibres were then washed with pure acetonitrile for 5 minutes and then dried under a stream of nitrogen gas. If fibres were to be used as negative controls, they would be exposed to Tris-EDTA (TE) solution of $\mathrm{pH} 8.0$ for 1.5 hours. If fibres were to be functionalized with DNA they would be incubated in solutions of 1-100 $\mu \mathrm{M}$ amine functionalized DNA in Phosphate Buffered Saline (PBS) at pH 9. Fibres would be rinsed with fresh PBS 9 and then dried under a stream of nitrogen gas.

EDC Coating Protocol. A $50 \mu \mathrm{M}$ stock solution of functionalization DNA was created in pure, autoclaved, deionized water by dissolving the phosphate functionalized DNA. A 2X dilution of the primer was made in a $10 \mu \mathrm{M}$ methylimidazole solution. The phosphate functionalized DNA was then split into two aliquots of $34 \mu \mathrm{L}$; an aliquot for negative and positive controls. $8.5 \mathrm{mg}$ of EDC was added to one of these aliquots and incubated with light shaking for 5 minutes. Amino-silanised fibres were placed into the solution of $25 \mu \mathrm{M}$ Phosphate functionalized DNA for 4 hours. After incubation, fibres were rinsed in a solution of $2 \mathrm{~g}$ succinic anhydride in $50 \mathrm{~mL}$ of DMF for 30 minutes at $37^{\circ} \mathrm{C}$ with stirring. Fibres were then washed by mounting them onto the syringe apparatus and then submerging about $1 \mathrm{~cm}$ of the tips into $\sim 5 \mathrm{~mL}$ of $1 \mathrm{M} \mathrm{Tris} / \mathrm{HCl} \mathrm{pH} 8.0$ and stirred at $37^{\circ} \mathrm{C}$. Rinsing was then performed again with deionized water and then dried under a stream of nitrogen gas.

UV coating protocol. For UV cross-linking performed in a dipping methodology, fibres were cleaned according to the fibre cleaning process, and then amine functionalized by dipping in $1 \%$ 140 Page Jason Koppert MASc Thesis 
APTMS/methanol solution for 20 minutes followed by rinsing in pure methanol. After drying with nitrogen gas these fibres would then be dipped into a solution of a $5^{\prime}$ phosphate labelled oligomer with a 20 thymidine base spacer before the DNA sequence of interest. Fibres were then cross-linked by exposing to a Fotodyne FOTO/Phoresis ${ }^{\mathrm{TM}}$ UV trans-illuminator device for 10 minutes (approximately 0.3 $\mathrm{J} / \mathrm{cm}^{2}$ ). Fibres were then rinsed with $0.1 \mathrm{XSC} / 0.1 \%$ SDS solution with stirring for 10 minutes followed by another 10 minute rinse of the fibres in deionized water. Fibres were then dried under a stream of nitrogen gas.

For UV spotting, fibres did not need to be cleaned with the harsh Piranha treatment step of the fibre cleaning process but did need the polymer jacket to be removed completely. Fibres were secured to a glass microscope slide with pieces of tape. DNA oligomers with a T10C10 tag were dissolved in PBS pH 8 at a final concentration of $25 \mu \mathrm{M}$. Using a 32 gauge needle with a $1 \mathrm{~mL}$ syringe, single drops of the $25 \mu \mathrm{M}$ DNA solution were then careful placed onto fibre surfaces with a predetermined spacing measurement. Liquid spotted fibres were then dried for 10 minutes at $60^{\circ} \mathrm{C}$. UV cross-linking was performed in a Fisher Spectroline XL1000, 254 nm UV cross-linking oven. Total energy used for cross-linking was $0.3 \mathrm{~J} / \mathrm{cm}^{2}$. Fibres were then rinsed with $0.1 \mathrm{XSC} / 0.1 \%$ SDS solution with stirring for 10 minutes followed by another 10 minute rinse of the fibres in deionized water. Fibres were then dried under a stream of nitrogen gas.

Hybridization Protocol. A hybridization solution was created that consisted of $0.1 \mu \mathrm{M}$ of $5^{\prime}$ fluorescently labelled probes prepared in 5x SSC/0.1\% Tween-20. Fibres would be incubated in a fresh aliquot of this solution for approximately 5-10 minutes to achieve maximum hybridization. Removal of the hybridization could occur by removing the fibre from the solution and then heating in a separate solution or alternatively could be performed by heating the hybridization solution itself.

With microscopy, the hybridization protocol was performed in an end-point methodology according to the schematic of Figure 4-6. This schematic involved the dip coating of fibres to a depth 
approximately equivalent to twice the area exposed during a hybridization reaction. This allowed for predictable and measureable boundary localizations during microscopy usage.

In real-time, a glass capillary was used by mounting it to the metal capillary holder of the prototype viewing apparatus of Figure 4-2. The capillary was filled with hybridization solution. DNA coated fibres were then carefully inserted into the capillary to avoid fibre contact with the capillary walls. Imaging was then collected in real-time with the potential for melt curve analysis and thermal cycling procedures when the capillary was placed on the surface of a heating device. The $0.1 \mu \mathrm{M}$ probe concentration allowed for quick hybridization without saturation of the image while retaining the ability to see surface fluorescence above the background solution fluorescence.

\section{A.2 Methods: Assessing Surface Compatibility with SP-PCR through Real-time}

ABCB1 Gene Target PCR Assay from Spartan Bioscience. A PCR mastermix (5X Promega Colourless Buffer, $0.2 \mathrm{mM}$ dNTPs, $1 \mathrm{mM} \mathrm{MgCl} 2,2.5 \mu \mathrm{g} / \mathrm{ul}$ BSA, $0.5 \mathrm{X}$ SYBR, $0.5 \mu \mathrm{M}$ of Reverse Primer, $0.5 \mu \mathrm{M}$ of Forward Primer, 0.097 Units/ $\mu \mathrm{L}$ of Taq polymerase, $10 \mathrm{ng}$ of genomic DNA) was thermocycled for a 50 cycle reaction. Thermal cycling consisted of a 5 minute initial denaturation at $95^{\circ} \mathrm{C}$ followed by 50 cycles of $95^{\circ} \mathrm{C}$ denaturation for 10 seconds and $56.5^{\circ} \mathrm{C}$ extension/annealing for 30 seconds. A melt curve was then performed after 50 thermocycles by heating to $95^{\circ} \mathrm{C}$ for 1 minute 30 seconds, and then cooling to $55^{\circ} \mathrm{C}$ over 1 minute 30 seconds with imaging then performed at $1^{\circ} \mathrm{C}$ steps during heating back up to $95^{\circ} \mathrm{C}$.

Agarose Gel Analysis. After completing the real-time PCR and melt curve analysis, each of the samples was loaded on a $1.5 \%$ agarose gel and run at $80 \mathrm{~V}$ for 30 minutes. Imaging of gels was performed on a ProteinSimple Alphalmager HP system.

ABCB1 10 Cycle PCR Variant. The PCR mastermix of the ABCB1 gene target PCR assay was used without genomic DNA. The genomic DNA was replaced with synthetic DNA template at concentrations 
ranging from $0.5-50 \mathrm{nM}$. Thermal cycling was adjusted to $95^{\circ} \mathrm{C}$ denaturation for 2:00 (mm:ss) with 10 cycles of $\left(95^{\circ} \mathrm{C}-0: 05 ; 56.5^{\circ} \mathrm{C}-0: 30\right)$.

ABCB1 Asymmetric Variants. SYBR green mastermix (5X Promega Colourless Buffer, $0.2 \mathrm{mM}$ dNTPs, $1 \mathrm{mM} \mathrm{MgCl} 2,2.5 \mu \mathrm{g} / \mu \mathrm{L}$ BSA, 0.5 X SYBR, $0.0625 \mu \mathrm{M}$ of Reverse Primer, $0.5 \mu \mathrm{M}$ of Forward Primer, 0.97 Units/ $\mu \mathrm{L}$ of Taq polymerase, $5 \mathrm{nM}$ of Synthetic "Ultramer" DNA template) and Molecular Beacon Mastermix (5X Promega Colourless Buffer, $0.2 \mathrm{mM}$ dNTPs, $1 \mathrm{mM} \mathrm{MgCl}$, $0.1 \mu \mathrm{M}$ DNA template, 2.5 $\mu \mathrm{g} / \mu \mathrm{L}$ BSA, $0.5 \mu \mathrm{M}$ Molecular Beacon, $0.0625 \mu \mathrm{M}$ of Reverse Primer, $0.5 \mu \mathrm{M}$ of Forward Primer, 0.97 Units/ $\mu \mathrm{L}$ of Taq polymerase, $5 \mathrm{nM}$ of Synthetic "Ultramer" DNA template) were used with Thermal cycling of $95^{\circ} \mathrm{C}$ denaturation for 2:00 (mm:ss) with 10-20 cycles of (95C-0:05; 56.5C-0:30).

Ultramer Hybrid Tool (UHT) Hybridization Protocol. Two hybridization solutions were created to use the UHT probe displayed in Figure 5-1. The first consisted of $0.1 \mu \mathrm{M}$ of 5' fluorescently labelled probes prepared in $5 \times \mathrm{SSC} / 0.1 \%$ Tween-20. The second consisted of a PCR mastermix (5X Promega Colourless Buffer $0.2 \mathrm{mM}$ dNTPs, $1 \mathrm{mM} \mathrm{MgCl} 2,0.1 \mu \mathrm{M}$ DNA template) and $0.1 \mu \mathrm{M}$ UHT in aqueous solution. Fibres would be incubated in a fresh aliquot of the first solution for approximately 5- 10 minutes to achieve maximum hybridization. Hybridization in the second solution involved the incubation of fibres in the solution for approximately 10 minutes with the solution temperature at $55^{\circ} \mathrm{C}$. Removal of hybridization performed with either solution could occur by removing the fibre from the solution and then heating in a separate solution or alternatively could be performed by heating the hybridization solution itself beyond $70^{\circ} \mathrm{C}$. Either of these solutions could be interchangeably used with the Molecular Beacons $^{\mathrm{TM}}$ probes instead of the UHT at $0.1 \mu \mathrm{M}$ concentrations as well.

Real-time Solid Phase Taq Polymerase Assay. A modified version of the capillary based real-time viewing apparatus was created with a TEC heating and cooling device. This TEC device was placed under the glass capillary in to allow contact heating and maintenance of $55^{\circ} \mathrm{C}$ capillary temperature. A volume of $26 \mu \mathrm{L}$ of polymerase-free mastermix (5X Promega Colourless Buffer $0.2 \mathrm{mM}$ dNTPs, $1 \mathrm{mM} \mathrm{MgCl}, 0.1$

143 IPage Jason Koppert MASc Thesis 
$\mu \mathrm{M}$ DNA template, $2.5 \mu \mathrm{g} / \mu \mathrm{L}$ BSA, 0.5X SYBR) was used to fill the glass capillary. A DNA coated fibre was inserted into the capillary and incubated for 10 minutes to achieve maximum hybridization of the template DNA to the fibre surface. A high concentration polymerase mastermix solution $(7.46 \mu \mathrm{L}$ of $5 \mathrm{X}$ Promega Colourless Buffer $0.2 \mathrm{mM}$ dNTPs, $1 \mathrm{mM} \mathrm{MgCl}$, $0.1 \mu \mathrm{M}$ DNA template, $2.5 \mu \mathrm{g} / \mu \mathrm{L} \mathrm{BSA}, 0.5 \mathrm{X}$ SYBR, 17.57 Units of Taq polymerase) was then injected and mixed into the capillary through pipette mixing. Imaging was performed throughout the hybridization and enzyme injection to monitor real-time changes in fluorescence.

\section{A.3 Methods: Application of optical fibre hotwire devices in molecular assays}

\section{and SP-PCR}

TFBG Fibre Preparations. TFBG fibres were received in an uncoated, cleaved state and therefore required electroless deposition for mirror creation. Mirror creation allowed for the usage of device in "reflection mode" as discussed in

Figure 2-12. This deposition process is not detailed further due to TFBG fibres being tested for only a short period of time before switching to other devices. TFBG fibres were handled with extreme care during this process. The fibres were mounted on a syringe setup (Figure A-1). The fibres were then submerged for 20 to 30 mins in a freshly prepared Piranha Solution $\left(3: 1, \mathrm{H}_{2} \mathrm{SO}_{4}: \mathrm{H}_{2} \mathrm{O}_{2}\right)$. Fibres were then rinsed extensively with water and then the tips were submerged in $1 \%$ APTMS in methanol solution for 20 minutes. Care must be taken to avoid coating the grating region with APTMS. The fibres were then rinsed with methanol several times. Fibres were then placed into a solution of gold nanoparticles and left overnight (between 12 and 16 hours). After this overnight incubation, the fibre tips were then dipped into a 50/50 solution of $0.02 \%$ Chloroauric acid $\left(\mathrm{HAuCl}_{4}\right)$ and $171 \mathrm{mM}(\mathrm{NHOH} \bullet \mathrm{HCl})$ and incubated for 20 minutes. The incubation in the $50 / 50$ solution could be repeated if mirror formation had not produced satisfactory reflection when viewed on an Optical Spectrum Analyser. Reflection quality is 
indicated by the intensity of the Bragg Peak. The Bragg Peak should show reflection of $100 \%$ of source light at its wavelength and therefore should have no decrease in intensity (OdB peak height).

Nanoparticle Coating of the TFBG and Bulge Devices. APTMS functionalization of the TFBG and Bulge fibre device (See Figure 2-16 and Figure 6-1) allowed for incubation of the device in nanoparticle suspensions for coating of the device surfaces. After nanoparticle coated fibre devices were coated with a Sol gel coating to avoid interference of nanoparticle layers with subsequent DNA functionalization. Fibres were dipped into a sol-gel solution ( $9 \mathrm{~mL}$ ethanol $(95 \%), 50 \mu \mathrm{L} \mathrm{HCl}, 7 \mathrm{~mL}$ TEOS, $2.5 \mathrm{~mL}$ APTMS) and withdrawn from the solution at a rate of $0.5 \mathrm{~cm} / \mathrm{min}$ with a vertically oriented syringe pump. Fibres were then allowed to air- dry overnight.

Device Manufacturing. Gratings were created using UV exposure to doped optical fibres through a phase mask as per the work of Hill et al. (Hill, Malo, Bilodeau, Johnson, \& Albert, 1993). All devices created in the schematic of Figure 6-1 were created according to proprietary assembly methods and will not be divulged in this thesis.

DNA Functionalization of All Fibre Devices. The UV coating protocol detailed in Chapter 4 was used for all device spot-coating processes used in this chapter.

Mathematical Methods. The mathematical analysis of melting profile data was performed as per the following example.

Let say we had the vectors: I and T, both of length $\mathrm{n}$ :

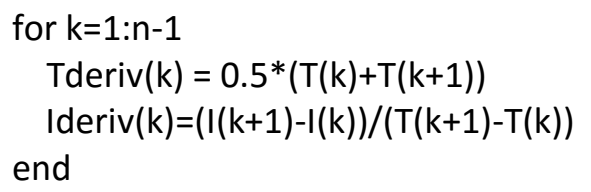

The data were boxcar smoothed (sliding average) 1-neighbor before and boxcar smoothed 1neighbor after the derivative. (In the sense that for every point, $I(k)$ becomes mean $(I(k-1: k+1)$, and Ideriv(k) becomes mean(Ideriv( $(\mathrm{k}-1: \mathrm{k}+1)) \ldots$.$) .$

145 IPage Jason Koppert MASc Thesis 
Hotwire Fibre SP-PCR. The mastermix developed in the previous chapter (5X Promega Colourless Buffer, $0.2 \mathrm{mM}$ dNTPs, $1 \mathrm{mM} \mathrm{MgCl} 2,2.5 \mu \mathrm{g} / \mu \mathrm{L}$ BSA, $0.5 \mathrm{X}$ SYBR, $0.0625 \mu \mathrm{M}$ of reverse primer, $0.5 \mu \mathrm{M}$ of forward primer, 0.97 Units/ $\mu \mathrm{L}$ of Hotstart Taq polymerase, $5 \mathrm{nM}$ of Synthetic “Ultramer" DNA template) was used for the SP-PCR assay. The mastermix was placed into the glass capillary tube. The thermocycling program was performed with the LabView ${ }^{\mathrm{TM}}$ interface. Thermal cycling parameters were $95^{\circ} \mathrm{C}$ for 2 minutes, $15 \times\left(95^{\circ} \mathrm{C}\right.$ for 5 seconds; $56^{\circ} \mathrm{C}$ for 1 minute 30 seconds). Only LAFDs were used for the optical fibre hotwire SP-PCR. The melting curve data was monitored after the SP-PCR thermocycling. After running of the melt curve with the post SP-PCR product, the fibre device was rinse with Tris-EDTA (TE)(10mM Tris-HCl/1mM EDTA) solution $\mathrm{pH} 8$ without adjusting the position of the LAFD. After replacing solutions in the glass capillary tube for rinsing, the fluorescent probe solution, specific for the primer region of the DNA surface coating, was introduced. This probe was then heated for melt monitoring after hybridization had been maximized. 